Portland State University

PDXScholar

Fall 12-16-2019

\title{
Flood Dynamics in the Portland Metropolitan Area, Past, Present, and Future
}

Lumas Terence Helaire

Portland State University

Follow this and additional works at: https://pdxscholar.library.pdx.edu/open_access_etds

Part of the Environmental Engineering Commons, and the Water Resource Management Commons Let us know how access to this document benefits you.

\section{Recommended Citation}

Helaire, Lumas Terence, "Flood Dynamics in the Portland Metropolitan Area, Past, Present, and Future" (2019). Dissertations and Theses. Paper 5354.

https://doi.org/10.15760/etd.7227

This Dissertation is brought to you for free and open access. It has been accepted for inclusion in Dissertations and Theses by an authorized administrator of PDXScholar. Please contact us if we can make this document more accessible: pdxscholar@pdx.edu. 
Flood Dynamics in Portland Metropolitan Area, Past, Present, and Future

by

\title{
Lumas Terence Helaire
}

A dissertation submitted in partial fulfillment of the requirements for the degree of

\author{
Doctor of Philosophy \\ in
}

Civil and Environmental Engineering

Dissertation Committee:

Stefan A. Talke, Chair

David A. Jay

Joseph Jurisa

Heejun Chang

Portland State University

2019 


\section{Abstract}

The Portland area has an extensive flood history since it was founded in 1845. In the late 19th century, the Portland area was prone to flooding from snowmelt freshets (3-6 months duration) and brief winter rain or rain-on-snow events. Since that time the magnitude of spring freshets has been curtailed by $45 \%$ due to climate change, flow diversions, and reservoir management. Along with changes in hydrology, the bathymetry of the Lower Columbia River has been altered by the dredging of the navigation channel, diking, and land reclamation. To understand how these changes in hydrology and bathymetry have affected tidal and flood wave propagation, I developed two hydrodynamic models, a modern model, and a model with bathymetry characteristic of the late 19th century. I then simulated a Columbia River spring freshet similar in duration to that of 1880. The results show that increased depth has increased the tidal range for low discharge conditions, and reduced the river slope for low and moderate river discharge. In a major spring freshet of $25 \times 10^{3} \mathrm{~m}^{3} \mathrm{~s}^{-1}$ magnitude, reduced floodplain access and confinement from higher modern levees results in similar peak water levels for the historical and modern bathymetry. The confinement in the modern system would result in a $30 \times 10^{3} \mathrm{~m}^{3} \mathrm{~s}^{-1}$ magnitude spring flood (similar to the 1948) having $0.5 \mathrm{~m}$ higher peak water levels than its historical counterpart. At $35 \times 10^{3} \mathrm{~m}^{3} \mathrm{~s}^{-1}$ discharge (similar to the 1894), modern levees would be likely be overtopped and the increased floodplain inundation would cause similar peak water levels in the modern and historical system.

Most large floods in Portland since 1948 have, however, been brief winter floods, primarily in the Willamette River. Therefore, using the modern model, I then simulated a 
recent rain-on-snow event, the February 1996 Willamette River flood. I then estimated future flood magnitude by incorporating sea level rise and increases in discharge due to climate change. The results show that $0.6 \mathrm{~m}$ of sea level rise increases peak water levels in Portland by $0.12 \mathrm{~m}$, and $1.5 \mathrm{~m}$ of sea level rise increases peak water levels by $0.39 \mathrm{~m}$. These increases in peak water level represent just $20-26 \%$ of the increased sea level at the coast. The mechanism limiting the increase in peak water levels in a sea level rise scenario is a reduction in frictional damping due to an increased depth. The reduction in damping results in a drop in the river slope in the Lower Columbia River. Scenarios incorporating a 10\% increase in runoff due to climate change produced a $0.78 \mathrm{~m}$ increase in peak water levels. Thus, model results suggest that projected changes in runoff due to climate change are likely to cause larger increases in peak water levels in Portland than the projected increases in sea level rise. In scenarios with both increased discharge and sea level rise, there are increases in peak water levels of $0.87 \mathrm{~m}$ and $1.08 \mathrm{~m}$ for $0.6 \mathrm{~m}$, and $1.5 \mathrm{~m}$ of sea level rise respectively. Coastal processes such as storm surge and the tidal phase are significant factors affecting flood magnitude, particularly in the estuary and the middle tidal river, but not in Portland. Finally, I found that some locations in the middle tidal river (Longview, Beaver) may be affected by both increases in flood magnitude, and coastal perturbations (tidal phase, storm surge magnitude).

In the last chapter, I analyzed how interactions at the three river junctions around Sauvie Island affect bed stress and water levels in the February 1996 flood. The Willamette River branches into a distributary, the Multnomah Channel (Junction A). The Willamette River flows into the Columbia River to form a confluence (Junction B), and the Multnomah 
Channel flows into the Columbia River at Junction C, downstream of the other two junctions. The results show that the Multnomah Channel plays a role in reducing flood risk by conveying Willamette River discharge downstream to the Columbia River at Junction C. The degree to which the Multnomah Channel can convey flow is limited by the inundation of the floodplains on the northern segment of Sauvie Island and overbank flow dispersing the flood wave. Backwater effects are also seen in Junction B due to Columbia River discharge and in the Columbia River downstream of Junction B due to inundation and overbank discharge. Constriction of the Columbia River channel downstream of Junction $\mathrm{C}$ raises the upstream water level gradient. The rating curve of water level versus discharge upstream of Junction $C$ is characterized by hysteresis, water levels are dependent on the discharge history, i.e., for a given discharge water levels on the rising limb are different from water levels on the falling limb. In locations upstream of the confluence of the Multnomah Channel and the Columbia River (Junction C), water levels are $0.8-1.3 \mathrm{~m}$ higher on the falling limb than the rising limb. In St Helens, at Junction C, the water levels are $\sim 0.1 \mathrm{~m}$ higher on the rising limb than the falling limb. In a sea level rise scenario, hysteresis is reduced by $16-25 \%$, due to increased baseline water levels reducing the bed stress. 


\section{Dedication}

I dedicate this dissertation to the most important and cherished people in my life:

Lumis, Madeline, Charlotte, Renauda, Armand, Morgan, Cameron, and Chloe. 


\section{Acknowledgements}

I would first like to thank advisor, Stefan Talke whose friendship, ideas, and encouragement has guided me through my graduate studies. I would like to thank my co-

advisor David Jay for guidance inside and outside the classroom. I really appreciate your strong professional ethics. I would also like to thank the other members of the Fluvial, Oceanic, Water-level Sciences (FLOWS) Research group specifically, Austin Hudson, and the late Drew Mahedy for the sharing ideas, friendships, and experiences.

I would like to thank Heejun Chang for being the GO representative of my dissertation committee and for allowing me to collaborate on the project that eventually became the fourth chapter of this dissertation. I appreciate your ideas and the perspective I was able to gain working with you and your research group.

I would like to thank Joe Jurisa for being a member of my dissertation and the ideas and guidance that you have given me during our time working together. 


\section{Table of Contents}

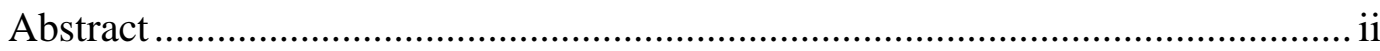

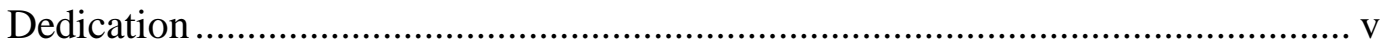

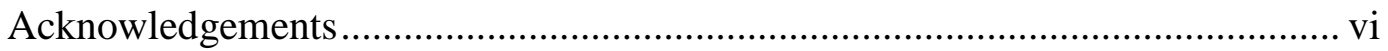

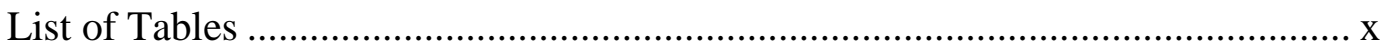

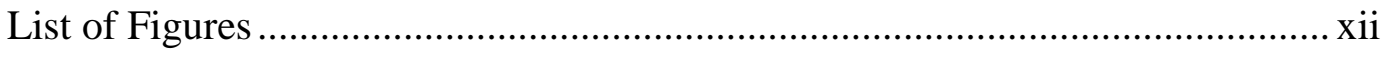

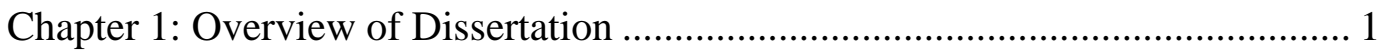

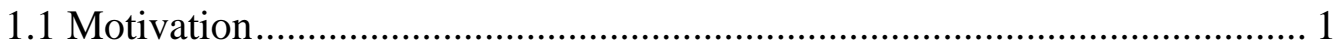

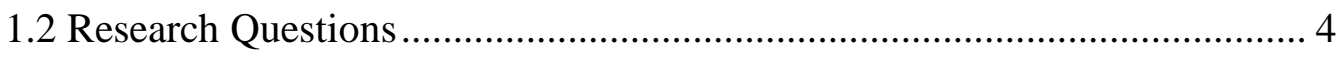

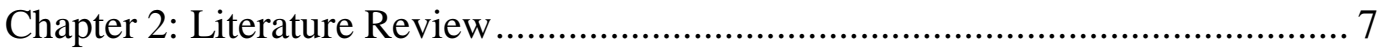

2.1 Site Characterization of the LCRE ................................................. 7

2.2 Changes in the LCRE and other estuaries.......................................... 12

2.3 Future Effects - Climate Change and Sea level Rise ............................ 13

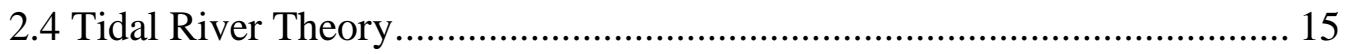

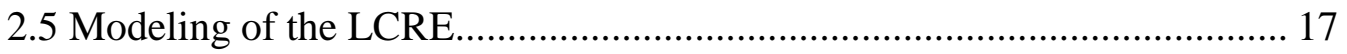

Chapter 3: Historical changes in Lower Columbia River and Estuary Floods: A

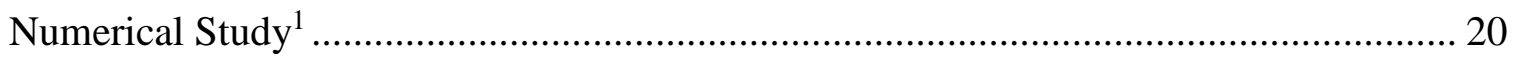

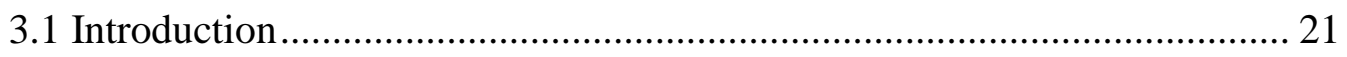




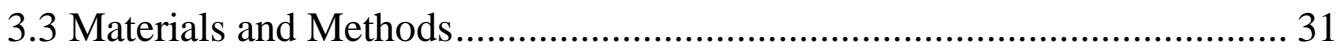

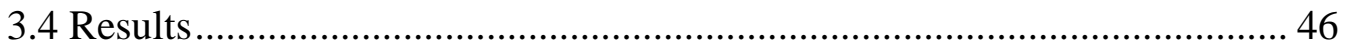

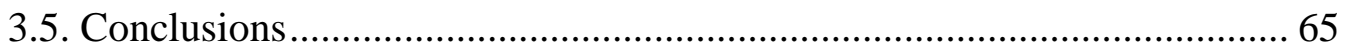

Chapter 4: A Modeling Study of the February 1996 Willamette River Flood ..... 67

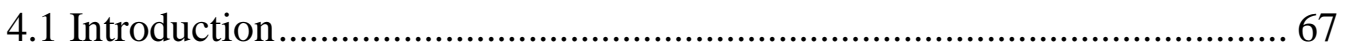

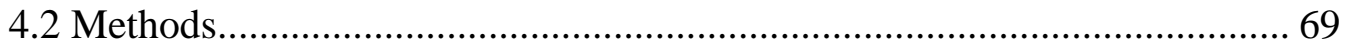

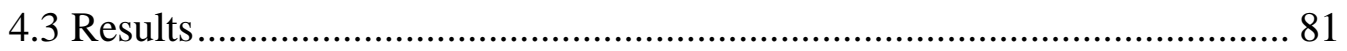

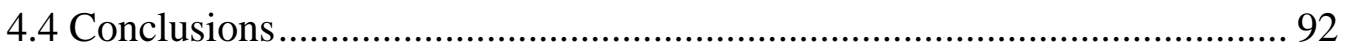

Chapter 5: Analysis of River Junction Dynamics............................................... 94

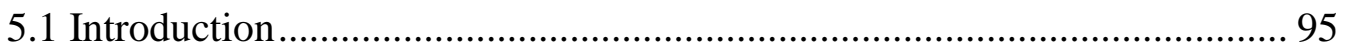

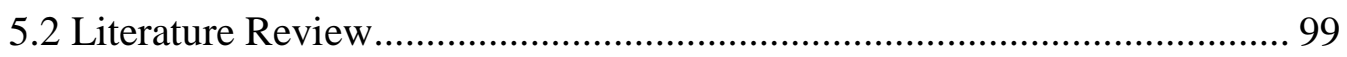

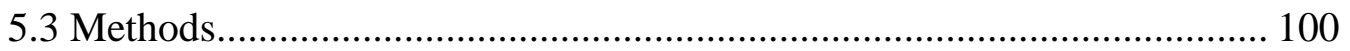

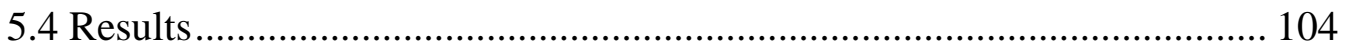

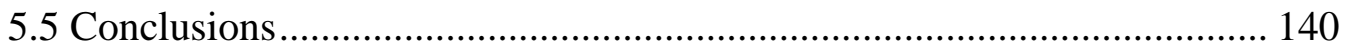

Chapter 6: Concluding Remarks and Future Direction....................................... 143

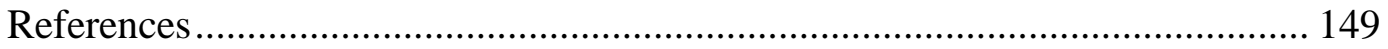

Appendix A: Supporting Information for Chapter 3 ……………………….... 163 
A. 1 - Model Grids 163

A.2 - Nonlinear Regression.... 164

A.3 - Modern Levees.

171

A.4 - Acceleration Terms - Spring Freshet.

A.5 - Sandy River/Willamette River Correlation 175 Appendix B: Supporting Information for Chapters 4 and 5 176

B.1 - Tidal Boundary Conditions 176

B.2 - Thin Dams 176

B.3 - Discharge Boundary Conditions

B.4 - Discharge Calibration. 190

B.5 - Area Extent of Flooding..... 191

B.6 - St Johns Bridge Water Level. 


\section{List of Tables}

Table 2.1: Acts of Congress authorizing expenditures for modification of the Columbia

River Channel and Mouth of the Columbia River.......................................................... 10

Table 3.1: Acts of Congress authorizing expenditures for modification of the Columbia

River Channel and Mouth of the Columbia River.......................................................... 29

Table 3.2: 19th century water level and discharge data.............................................. 32

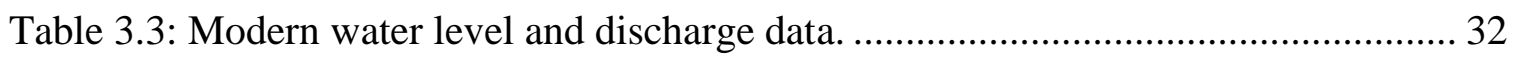

Table 3.4: Tidal constituents for historical model at the ocean boundary ....................... 40

Table 3.5: Tidal constituents for modern model at the ocean boundary ......................... 40

Table 3.6: Simulations run on the historical model ...................................................... 42

Table 3.7: Simulations run on the modern model........................................................... 43

Table 3.8: Modern coefficients and exponents for tidal datums at Morrison Bridge (1998-

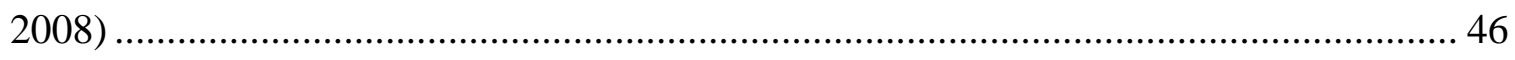

Table 3.9: Historical coefficients and exponents for historical daily water level at Morrison

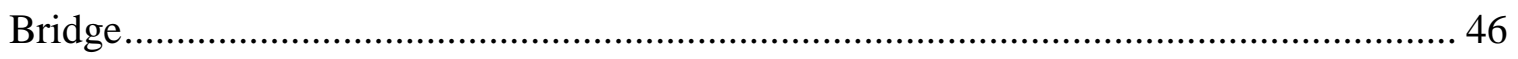

Table 3.10: RMSE errors [m] for the four largest tidal constituents in the spatial calibration

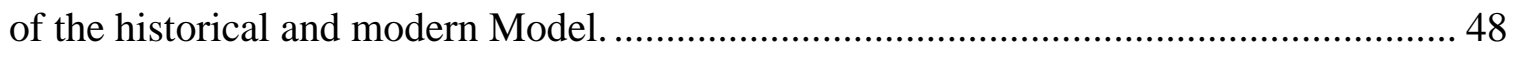

Table 4.1: Water level measurements used to verify February 1996 Flood simulations...............71

Table 4.2: Tidal constituents for modern model at the ocean boundary .......................... 75 
Table 4.3: Scenarios used to model, and to evaluate the sensitivity to sea level, rise, increases in discharge, magnitude of surge, and neap/spring tides............................. 78

Table 4.4: Model and measured water levels at seven gage stations, goodness of fit statistics 85

Table 4.5: Summary of change in peak water levels at MSB in climate and sea level rise

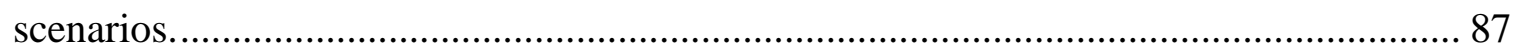




\section{List of Figures}

Figure 1.1: LCRE place names and system zonation (Jay et al., 2016): LCRE place names and system zonation (Jay et al., 2016) 3

Figure 2.1: LCRE channel depth 1878-1999 period relative to MLLW .10

Figure 3.1: The present-day shoreline of the LCRE and gauge stations used in the analysis (triangles). .26

Figure 3.2: LCRE channel depth in the historical (late 19th century) and modern period relative to NAVD88.

Figure 3.3: Model depth for historical model and modern. 39

Figure 3.4: Spatial calibration of a low flow event. 49

Figure 3.5: Comparison of Modern and Historical water level and discharge. 51

Figure 3.6: Comparison of historical and modern rating curve in Portland. 53

Figure 3.7: Inundation at the peak of the $25 \times 10^{3} \mathrm{~m}^{3} \mathrm{~s}^{-1}$ flood in the Portland/Vancouver metro area. (a) historical model and (b) modern model. 54

Figure 3.8: Peak total modeled water levels for $6 \mathrm{mo}$ simulated freshet in the historical and modern model. 56

Figure 3.9: Morrison Bridge water levels (green lines) modern model $25-30-35 \times 10^{3} \mathrm{~m}^{3} \mathrm{~s}^{-1}$ constant flow simulations (blue dots) river stage measurements 1879-1898. 57 
Figure 3.10: Peak water levels from the six-month normal distribution flood (a) historical

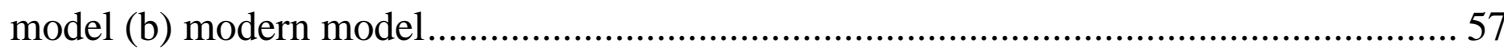

Figure 3.11: Tidally and depth averaged water level, channel velocity, water level gradient,

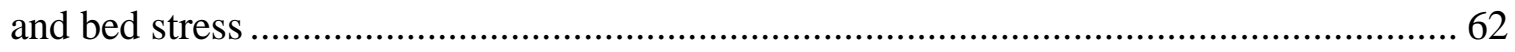

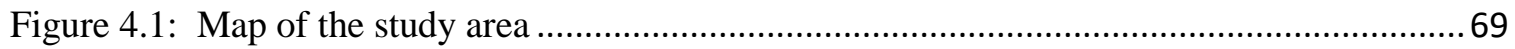

Figure 4.2: (a) location of the water level gages (b) Measured/predicted water levels at Toke Pt (c) South Beach (d) water level anomaly ................................................... 76

Figure 4.3: Measured water level on the Columbia River in Astoria, OR Jan - Feb 1996

Figure 4.4: Closeup of hydrograph of the peak of the flood for seven locations. 83

Figure 4.5: Comparison of model results and observations of peak water levels. The reference line is above NAVD88 datum. 84

Figure 4.6: Measured (black) and modeled water levels in Portland for the six different scenarios. 87

Figure 4.7: (left) Inundation under the baseline scenario A0 (right) the most severe scenario, B2 (1.5m SLR $+10 \%$ runoff increase $)$........ 88

Figure 4.8: Along channel changes in water level. Most severe (B2: $10 \%$ flow $+1.5 \mathrm{~m}$ SLR) (red), sea level rise, tides, storm surge, and runoff.

Figure 4.9: Difference in water level between simulations due to storm surge - Feb. 7 - 11, 1996 GMT 91 xiii 
Figure 4.10: Relative timing of coastal surge (black), and surface elevation in Portland (grey), Feb. 8-11, 1996 GMT

Figure 5.1: Map of model of observation points and cross-sections 96

Figure 5.2: Closeup of Junction C 97

Figure 5.3: closeup of Junction A and Junction B 98

Figure 5.4 river discharge at Junction A during the February 1996 flood 98

Figure 5.5: Effect of closing Multnomah Channel - hydrograph. Peak water level in Portland 105

Figure 5.6: Effect of closing Multnomah Channel - contour plot of the difference in water level. 106

Figure 5.7 Effect of Columbia R. discharge on flow partition and surface slope at Junction A. $(a, b, c)$ - variable Willamette R., $(d, e, f)$ variable Columbia R. 109

Figure 5.8 Ratio of Columbia R./Willamette R. discharge versus square root of surface slope ratio at Junction A for steady-state conditions. 110

Figure 5.9 Flow partition at Junction A during Feb 19 flood. 110

Figure 5.10 Terms of the Manning Equation at Junction A during flood. 112

Figure 5.11: Surface slope ratio at Junction A: steady-state (black) and the Feb 96 Flood (red). Steady -state based on Equation 5.7. 113

Figure 5.12: surface slope and hydraulic radius on Multnomah Channel rkm 10-16.... 114 xiv 
Figure 5.13: water level gradient through Reach 3 (Multnomah Channel) 118

Figure 5.14: Water level gradient through Reach 2 (Willamette R) and Reach 3 (Columbia R). 118

Figure 5.15: Contour plots of water levels at $18 \times 10^{3} \mathrm{~m}^{3} \mathrm{~s}^{-1}$ (baseline scenario) during the February 1996 flood (left) rising limb of the flood (right) falling limb. 119

Figure 5.16: Conceptual drawing of floodplain inundation on north Sauvie Island....... 120

Figure 5.17: Columbia River discharge downstream of Kelley Point (black) hydrograph at north Sauvie Island (grey). 121

Figure 5.18: Contour plot of the peak of the 1996 flood. Black lines are location of the monitoring cross-sections on the west bank of the Columbia River. 121

Figure 5.19: Floodplain discharge on the west bank of the Columbia River. See Figure 5.16 for the location of each monitoring cross-section. 122

Figure 5.20: Contour plot of the peak of the 1996 flood. Black lines are location of the monitoring cross-sections on the east bank of the Columbia River. 123

Figure 5.21: Model discharge cross-sections on the east bank (WA) of the Columbia River. See Figure 5.18 for the location of each monitoring cross-section 124

Figure 5.22: Discharge versus surface slope along Reach 3 (Multnomah Ch. - west path). The colored values represent days after February 4, 1996 GMT. 127

Figure 5.23: Discharge versus surface slope along and Reach 2. (Columbia R. - east path). The colored values represent days after February 4, 1996 GMT. 129 
Figure 5.24: Conceptual drawing of floodplain inundation on the risng limb and falling limb of a flood.

Figure 5.25: Conceptual drawing of the effect of floodplain storage on water level gradient.

Figure 5.26: Hysteresis at Kelley Point and Vancouver - baseline scenario. The colored values represent hours to peak discharge.

Figure 5.27: Hysteresis at St Helens - baseline scenario. The colored values represent hours to peak discharge. 131

Figure 5.28: Difference in water level between rising and falling limb along the Willamette River. $\mathrm{X}$-axis values are discharge from $6 \times 10^{3} \mathrm{~m}^{3} \mathrm{~s}^{-1}$ below peak to peak discharge.... 132 Figure 5.29: Hysteresis at St Johns Bridge and WR rkm 37 - baseline scenario 133

Figure 5.30: Difference in water level between rising and falling limb on the Willamette River at St Johns Bridge and WR rkm 37. 133

Figure 5.31: Peak bed stress in the Portland/Vancouver area Feb 6-16, 1996 for baseline scenario 135

Figure 5.32: Surface slope on the Multnomah Channel from rkm 10-16 for baseline scenario (light blue), and $1.5 \mathrm{~m}$ sea level scenario (blue)

Figure 5.33: Differences in water level on Willamette River between rising and falling limbs, 0m sea level rise (solid lines) and $1.5 \mathrm{~m}$ sea level rise (dashed lines). 138 
Figure 5.34: Peak bed stress in the Portland/Vancouver area Feb 6-16, 1996 for 1.5m sea level rise scenario.

Figure 5.35: Difference in peak bed stress $\times 100(0 \mathrm{~m}$ SLR $-1.5 \mathrm{~m}$ SLR) in the

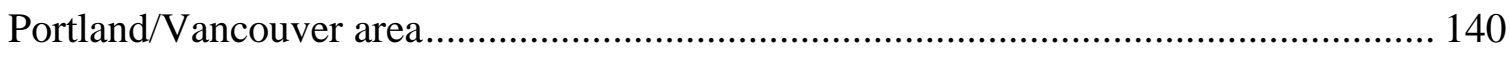




\section{Chapter 1: Overview of Dissertation}

How is long wave propagation (floods and tides) in a tidal river altered due to physical changes to bathymetry and boundary conditions? In this work, I study the effects of bathymetric alteration, sea level rise and altered river flow on flood risk in Portland and the Lower Columbia River. Specifically, two hydrodynamic models are developed and calibrated, a model based on late $19^{\text {th }}$ century bathymetry (the "Historical" model) and another based on modern bathymetry (the "Modern" Model). The models are used to investigate how bathymetry changes affect long wave propagation and water levels. The Historical and Modern models are calibrated to in-situ data in order compare and contrast spring freshets in both the Historical and Modern model. The Modern model is then used to simulate a rain-on-snow event and evaluate possible future changes in flood risks in Portland and along the entire Lower Columbia River (LCR), due to climate-induced changes in runoff and coastal sea level rise. The final section of this dissertation deals with the junction dynamics in the Portland/Vancouver area. In this chapter I examine the causes and implications of hysteresis in the rating curve.

\subsection{Motivation}

Estuaries, harbors, and tidal rivers all over the United States have been extensively modified for navigation, agriculture, flood protection and other uses (e.g. USACE COE, 1915). Similar infrastructure projects have been implemented world-wide, and include channel deepening (often doubling or tripling depth), loss of wetlands, streamlining of channels, narrowing of entrances, and construction of pile dikes and other flow- 
modification structures (Sherwood et al., 1990; Familkhalili \& Talke, 2016; Wang et al., 2018). These changes in bathymetry in many cases are combined with alterations to the river flow hydrograph due to changes in land use, reservoir management, and climate change (Cox et al., 2015; Jay et al., 2010; Keshtpoor et al., 2015; Manning et al., 2011; Passeri et al., 2015). Changes of this nature are seen in the Lower Columbia River and estuary (LCRE, see Figure 1.1). Marcoe \& Pilson, (2017) found that $68-70 \%$ of the total wetlands, and $55 \%$ of the total wetlands have been lost in the LCRE since the late 1800s. In this context, much of the historical (i.e. late $19^{\text {th }}$ century) wetland have been isolated from the river channel due to the installation of the dikes or levees. To aid navigation in the LCRE, the controlling depth of the river channel has been increased from $20 \mathrm{ft}(6.1 \mathrm{~m})$ in the late 19th century, to 43ft (13.1m) today (Hickson, 1961; Kassenbaum, 2011; Lockett, 1959). The construction of dams along the Columbia River (beginning in the late 1930s) altered the natural hydrologic cycle. Combined with climate changes and flow diversions (about 7\% of the mean flow), the magnitude of the May/June spring freshets (the primary source of historical floods) has been reduced by $45 \%$; similarly, the base flow during the July-October low flow periods has increased (Bottom et al., 2005; Jay and Naik, 2011; Naik and Jay, 2011). Over the next century, the Pacific Coast of Oregon and Washington is expected to experience a significant amount of sea level rise (Board and NRC, 2012). Additionally, changes in climate are expected to increase the intensity of extreme rainfall events (Najafi \& Moradkhani, 2015). 


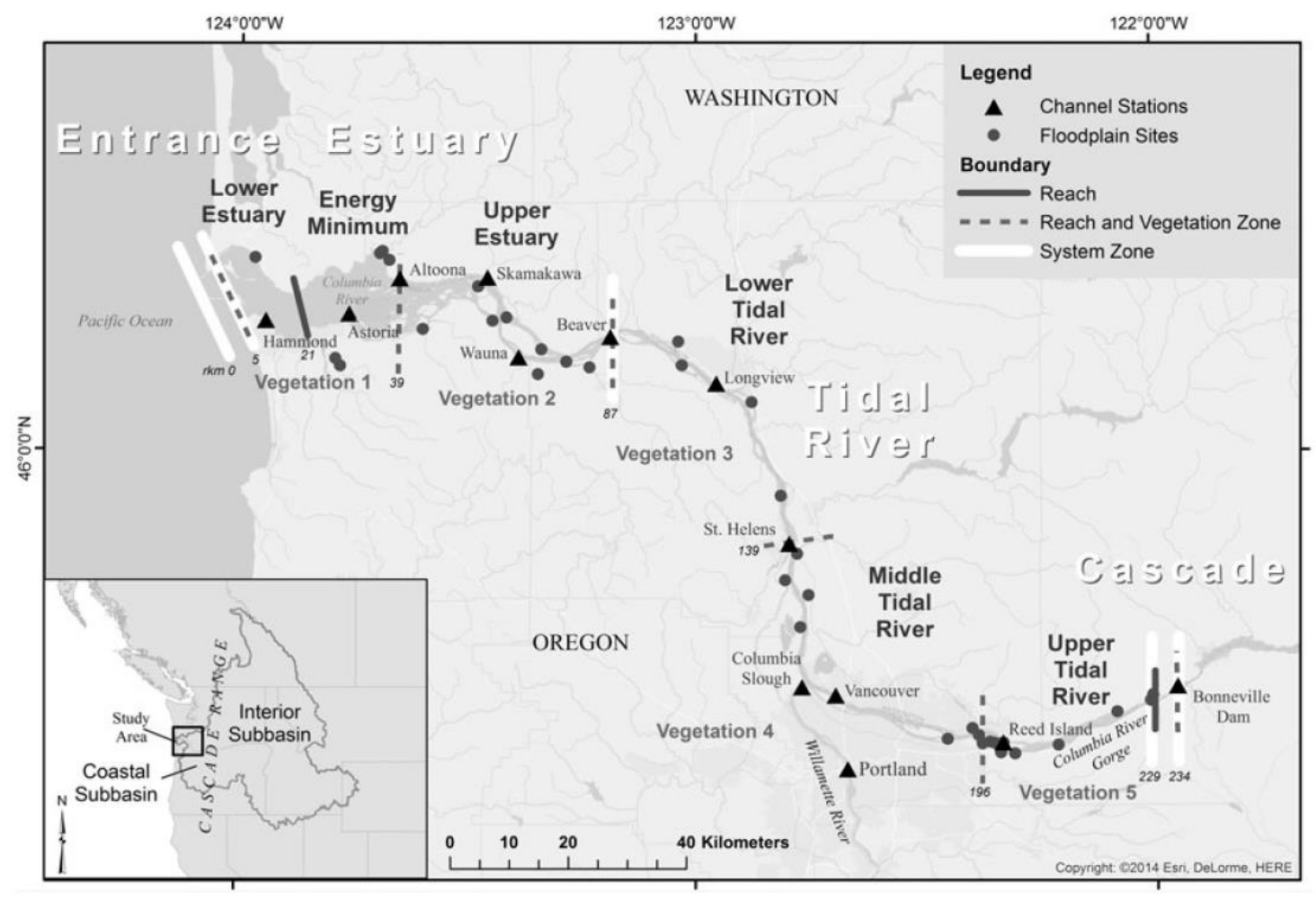

Figure 1.1: LCRE place names and system zonation (Jay et al., 2016): LCRE place names and system zonation (Jay et al., 2016)

In light of the previously mentioned changes in bathymetry and hydrology in the LCRE over past $\sim 150$ years, the first part of the thesis studies large spring snowmelt floods. In Chapter 3 I detail the development of a hydrodynamic model of the LCRE with bathymetry characteristic of the late $19^{\text {th }}$ century. By comparing historical tidal propagation under low discharge conditions. I then simulate a spring freshet similar in magnitude and duration to the 1880 spring freshet on historical and modern models. By modeling the flood, I can see if a large flood would have larger peak water levels in the modern bathymetry, and determine how flood propagation has been altered.

The second part of the thesis studies a rain-on-snow event in the Portland Metro area (the February 1996 flood) and investigates the possible future effect of climate change 
and sea level rise. The February 1996 flood is considered a 25-50-year event in terms of peak water level and discharge in the LCRE and is recent enough to have extensive discharge and water levels records. In accessing flood risk, I also consider how coastal processes such as storm surge and neap-spring fluctuations affect water levels. Projections of the climate induced changes in precipitation over the next century indicate that the intensity and possibly duration of precipitation events will increase, such that run-off during a typical flood event will accordingly increase. At the same time, sea level is projected to rise between $0.5-1.4 \mathrm{~m}$ on the west coast by the year 2100 , though the exact increase in the LCRE may be modified by geologic factors. To investigate the sensitivity of the Portland metro area to both increased run-off and sea level rise, I model multiple scenarios of sea level rise and runoff increases to determine the sensitivity of peak flood levels, inundation, and bed stress to altered boundary conditions.

The third part of the thesis continues with an analysis of a rain-on-snow event (the February 1996 flood), and examines the junction dynamics in the Portland/Vancouver area. This section continues with the February 1996 flood, and examines the flow dynamics in the Portland/Vancouver area between the Columbia River, Willamette River (WR) and the Multnomah Channel. I analyze controls on bed stress in the complex junction, and how bed stress is altered by sea level rise.

\subsection{Research Questions}

Based on the previous discussion, I investigate the following questions and test the following hypotheses: 
1. How have changes in channel bathymetry (channel deepening, isolation of the floodplain with levees and dikes) in the Lower Columbia River over the last 150 years altered the flood risk from a spring-freshet type floods?

Multiple factors can increase wave amplitude in a tidal channel. Increased depth reduces the effective wave damping and the isolation of the floodplain, which reduces flow over a highly frictional floodplain. Conversely, a deeper more efficient channel can reduce baseline water levels for any give flow, producing overall lower mean water levels.

2. How will sea level rise and climate-change induced changes to river flow alter the flood risks along the LCR-Willamette system?

Coastal processes that perturb the sea level, such as tides and storm surge are usually most prominent at the coast and then dissipate as they propagate upstream. Fluvial processes such as runoff from storms are strongest upstream but decrease in severity closer to the coast. Hence, there is a transition zone in which both fluvial and oceanic factors contribute to flood levels and bottom stress. As climate changes and sea level rises, will the transition region shift upstream or downstream, and will the magnitude be altered? Further, are there regions that are more (or less) vulnerable to climate change and sea level rise, due to the superposition of changing sea level, tides, storm surge, and river flood waves? 
3. How do the dynamics of the Columbia-Willamette River junction influence flood risk, bed stress and hysteresis in the Portland area?

Water levels in the Portland area are influenced by the interaction of three junctions:

the Multnomah Channel acting as a distributary of the Willamette River, the Willamette River flowing into the Columbia River to form a confluence, and the Multnomah Channel flowing into the Columbia River to form second confluence. Within the Portland area, channels and wetlands acts as sources and sinks for river discharge. A numerical modeling approach is used to parse how flow diversions and inundation affect flood risk, bed stress, and hysteresis in the Portland area. 


\section{Chapter 2: Literature Review}

This section provides a foundation for my research with a literature review divided into five sections. This review begins with a description of the bathymetry and hydrology of the LCRE. The following section is meant to give context to Chapter 3 of the dissertation by describing some of the anthropogenic alterations that have occurred in the LCRE and other estuaries and tidal rivers around the world. The following section of the literature review supports Chapter 4 of the dissertation with studies on some of the future effects of climate change, including sea level rise, changes in seasonal precipitation, and changes in the magnitude of an extreme flood event. The fourth section of the literature review contains an overview of the theory of longwave propagation in a tidal river and its' application in the LCRE. The final section deals with the history of efforts to model the LCRE.

\subsection{Site Characterization of the LCRE}

To begin to understand how bathymetry changes can potentially affect long wave propagation, it is critical to gain an understanding of the LCRE system, and the changes that have occurred over the past 150 years.

Jay et al. (2016) divided the Columbia River into five zones that are characterized by changes in the balance of tidal and fluvial energy. The Lower Estuary (rkm 5-39), primarily affected by tides and salinity intrusion, contains an Energy Minimum (EM) (rkm21-39). Within the EM, the sum of tidal and fluvial dissipation is minimized, and the tidal range is maximized. The Upper Estuary, (rkm 39-87), is characterized by tidal and 
fluvial inundation. The Lower Tidal River, with a landward boundary of rkm 139, has more inundation in the growing season than the estuary. The Middle Tidal River includes floodplain around the Willamette River mouth and has a greater depth and duration of inundation during the growing season than downstream, the Middle Tidal River has a landward boundary at rkm 196 (the entrance to the Columbia River Gorge). Finally, the Upper Tidal River (landward of Bonneville, OR at rkm 234) has very high inundation in the growing season and very low inundation during the rest of the year.

The LCRE is subject to natural changes in erosion and accretion, but the most significant changes are anthropogenic in nature (Sherwood et al., 1990). Since 1878, an ongoing effort has been made to maintain a navigation channel, through a series of modifications to the river mouth and channel. These modifications include the construction of jetties near the mouth of the river, dredging of the navigation channel, and the installation of pile dikes to encourage scouring and to direct the river along a desired path (training). The United States Congress has authorized the U.S. Army Corp of Engineers (USACE) to maintain the channel to depths that have increased since 1878 (Table 2.1) (Hickson and Rodolf, 1961; Lockett, 1959; Hickson, 1961; Kassenbaum, 2011). This controlling depth has increased from about $20 \mathrm{ft}(6 \mathrm{~m})$ in the late 19 th century, to $43 \mathrm{ft}(13 \mathrm{~m})$ relative to Mean Lower Low Water (MLLW) today (Figure 2.1). The channel dredging is deepest at the mouth of the river, where the six miles of the inbound side of the Mouth of Columbia River is maintained at $45 \mathrm{ft}$ depth, while the six miles of the outbound side is maintained at $48 \mathrm{ft}$ depth [http://www.nwp.usace.army.mil/Locations/OregonCoast/Mouth-of-the-Columbia/]. 
Table 2.1: Acts of Congress authorizing expenditures for modification of the Columbia River Channel and Mouth of the Columbia River.

\begin{tabular}{|c|c|c|}
\hline \multicolumn{3}{|c|}{ Mouth of the Columbia River } \\
\hline 1882 & Public Acts of the $47^{\text {th }}$ Congress & $30^{\prime}(9.1 \mathrm{~m})$ depth \\
\hline 1905 & River and Harbor Act & $40^{\prime}(12.2 \mathrm{~m})$ depth, $1 / 2$ mile $(0.8 \mathrm{~km})$ width \\
\hline 1954 & River and Harbor Act & $48^{\prime}(14.6 \mathrm{~m})$ deep, $1 / 2$ mile $(0.8 \mathrm{~km})$ width \\
\hline \multicolumn{3}{|c|}{ Columbia River Channel } \\
\hline 1878 & Act to Improve Rivers and Harbors & $20^{\prime}(6.1 \mathrm{~m})$ depth \\
\hline 1899 & Rivers and Harbors Appropriation & $25^{\prime}(7.6 \mathrm{~m})$ depth \\
\hline 1912 & River and Harbor Act & $30^{\prime}$ (9.1m) depth, 300' (91m) width \\
\hline 1930 & River and Harbor Act & $35^{\prime}(10.7 \mathrm{~m})$ depth, $500^{\prime}(152 \mathrm{~m})$ width \\
\hline 1962 & Rivers and Harbors Act & $40^{\prime}(12.2 \mathrm{~m})$ depth, $600^{\prime}(183 \mathrm{~m})$ width \\
\hline 1999 & Water Resources Development Act & $43^{\prime}(13.1 \mathrm{~m})$ depth \\
\hline
\end{tabular}

Depths relative to Mean Lower Low Water

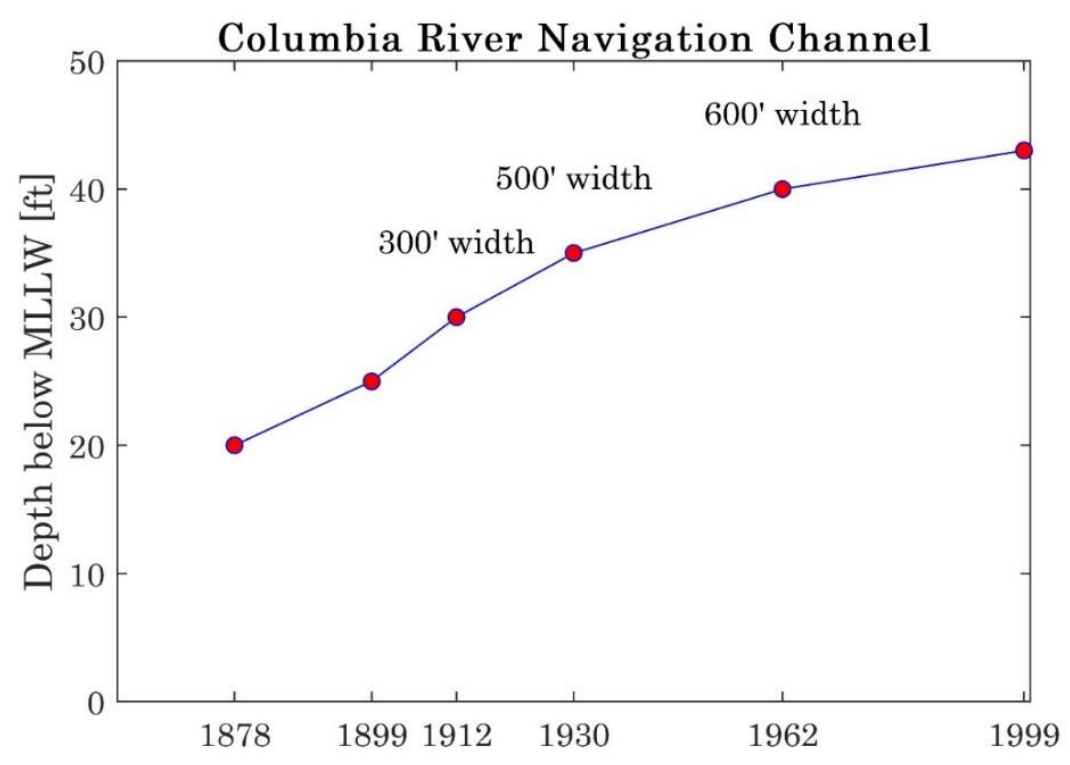

Figure 2.1: LCRE channel depth 1878-1999 period relative to MLLW.

Sherwood et al. (1990) provided an overview of some of the morphological changes to the LCRE and the effects of the changes. An analysis of USC\&GS (US Coast and Geodetic Surveys) surveys from the late 19th century to the mid-20th century, found that there are large changes in the morphology of the LCRE due mainly to navigational improvements (jetties, dredged channels, and pile dikes) and filling of wetland areas. The 
study found that there was a decrease in the tidal prism and net accumulation of sand in the estuary. It was also noted that river flow has been significantly altered by regulation and diversion for agriculture, and flow variations greater with timescales than one month have been greatly damped. A laterally averaged, multiple channel, 2-D flow model found that there is reduced mixing, increased stratification, and an altered neap-spring response.

Some more recent studies have further parsed out changes streamflow and land use since the late 19th century. Naik and Jay (2005) made estimates of virgin flow of the Columbia River at The Dalles from 1879-1999, finding that climate change has decreased the annual average flow volume by $>7 \%$, and irrigation depletion has reduced the flow by another $\sim 7 \%$. The changes in LCRE hydrology also extend to the disturbance process, such as the occurrence of bankfull exceedance flow, and low-frequency flow variations. Jay and Naik (2011) found that modern bankfull exceedance has increased from $~ 20,000$ $\mathrm{m}^{3} \mathrm{~s}^{-1}$ in the late 19 th century, to $\sim 24,000 \mathrm{~m}^{3} \mathrm{~s}^{-1}$ today. Flow regulation and water withdrawal have drastically reduced the occurrence of overbank flow compared with the late 19th century. The study also found that low-frequency disturbance processes $(0.5-2$ years) have been substantially suppressed, while high-frequency variations associated with power peaking have been augmented. Downstream, there has been an increase in salinity intrusion and a decrease in the size of the plume, both decreasing the habitat available for migrating juvenile salmonids that require low salinities.

Water levels in the LCRE have also evolved over the past century, as the tide range in the LCRE has increased. Jay (2009) noted a $77 \mathrm{~mm}^{\text {century }}{ }^{-1}$ increase in the $M_{2}$ constituent and a $35 \mathrm{~mm}$ century $^{-1}$ increase in the $K_{l}$ constituent at Astoria since 1925, and 
Jay et al (2011) noted an increase in tide range at Vancouver of $0.4 \mathrm{~m}$ during low flow conditions.

\subsection{Changes in the LCRE and other estuaries}

Development in the LCRE has significantly altered the amount of area that is tidally influenced. Marcoe and Pilson (2017) studied habitat change in the LCRE from 18702009. Marcoe and Pilson (2017) analyzed digitized and georeferenced USC\&GS maps from the late 19th century (Thomas, 1983; Graves et al., 1995; Burke, 2006) and compared them against modern satellite images, surveys, and aerial photographs. The authors found that there has been a loss of $68-70 \%$ of the vegetated tidal wetlands, along with a loss of $55 \%$ of the forested uplands. The major causes of these losses have been attributed to dikes and levees which isolate land from the river channel. A second significant factor is hydrological changes attributable to the Federal Columbia River Power System [FCRPS]. The increase in regulated flows has resulted in an overall reduction in the area wetted, and a decrease in the duration of inundation (see also Kukulka \& Jay, 2003a).

There are many examples of estuaries in the United State and around the world that have been artificially altered to facilitate navigation and development. Bowen (1972) proposed that embanking on the Thames River in England was the cause of the increase in tidal range. In the Cape Fear Estuary (NC), channel deepening has caused a doubling of the tide range and an amplification of storm surge waves (Familkhalili \& Talke, 2016). In Tampa Bay on the west coast of the state of Florida, the estuary with a natural depth of 3$4 \mathrm{~m}$ contains a 16m deep navigational channel. Zhu et al. (2018) found the deepening of the channel doubled the estuarine exchange flow, increase the salinity in the estuary, and 
altered the tidal current amplitude and the tidal range. The Pearl River system in Guandong province in south China is another example of a highly developed system. Cai et al. (2012) studied the effects of channel deepening in the Modaomen Estuary within the Pearl River system through the analysis of historical data and the application of a one-dimensional analytical model. The authors found that sand excavation and flow reduction between 1993 and 2011 have increased the tidal range by $0.1 \mathrm{~m}$ and decreased the travel time of the tidal wave by 30 minutes in the middle part of the estuary, and 80 minutes in the upper reaches. These examples clearly show that flow reduction and anthropogenic activities such as dredging and floodplain isolation can alter tidal propagation in estuaries. In this dissertation, I will show how bathymetric alteration has affected tide and flood wave propagation in the LCRE.

\subsection{Future Effects - Climate Change and Sea level Rise}

Along with the changing bathymetry in the LCRE, the nature of extreme events in the Pacific Northwest is also evolving. While increasing wintertime temperatures and a general reduction in the springtime snowpack (Mote et al. 2018) may reduce the size and duration of the springtime freshets (see Jay\& Naik, 2005 for discussion of spring and freshets in the LCRE), there remains a flood risk due to wintertime rain, and rain-on-snow events. Mote and Salathé (2010) downscaled global climate models to obtain a general estimate of expected changes in temperature and precipitation specific to the Pacific Northwest. The study concluded that in the next century, there will significant increases in annual temperature of up to $3.0^{\circ} \mathrm{C}$ by the $2080 \mathrm{~s}$. The author also concluded that overall changes in annual precipitation in the next century will be small $(+1 \%$ to $+2 \%)$, but there 
may be a shift to wetter autumn and winters and drier summers. Projections of run-off during the 100-yr flood event show that there may be an increase of 0-20\% in the Pacific Northwest (Najafi \& Moradkhani, 2015).

Oceanic water levels in the Pacific NW are nonstationary due in part to recurring oceanic processes such as the El Niño Southern Oscillation (ENSO), the Pacific Decadal Oscillation (PDO), and the Southern Oscillation Index (SOI). Merrifield and Thompson (2018) found that sea level variation between tide gauges San Diego, California and Fremantle, Australia were negatively correlated between 1980 and 2000. The authors found that during this period, low-passed-filtered sea level at San Diego exceeded global mean sea level (GMSL), while low-passed-filtered sea level at Fremantle were lower than GMSL. The variation in mean sea level between San Diego and Fremantle closely followed the inverse of the low-pass-filtered SOI.

The National Research Council conducts a comprehensive study of sea level rise on the west coast of the United (Board and National Research Council, 2012). The two most important factors contributing to sea level rise are changes in the density of seawater induced by temperature changes (thermosteric) and loss of land-based ice. Sea level rise due to thermosteric expansion is estimated to have contributed $1.6 \pm 0.5 \mathrm{~mm} \mathrm{yr}^{-1}$ at ocean depths above 3,000 m, accounting half of the observed rate of sea level (IPCC, 2007). Glacier and ice cap losses account have contributed to $0.77 \pm 0.22 \mathrm{~mm} \mathrm{yr}^{-1}$ from 1993 to 2003, and loss due to ice sheets have contributed $0.21 \pm 0.07 \mathrm{~mm} \mathrm{yr}^{-1}$ to sea level rise during that same period. 
In this dissertation, I utilize estimates of sea level rise projected by the National Research Council (Board and National Research Council, 2012). Applying the range used in that report, it is expected that sea level will increase by $0.5-1.4 \mathrm{~m}$ by the year 2100 .

\subsection{Tidal River Theory}

This section will cover the basic 1-D St. Venant equations (Cunge et al. 1980), and how they are applied to the interaction in between tides and river discharge in the LCRE

The St. Venant equations are derived from the Navier-Stokes equations and assume that the flow is sectionally integrated, there is constant density, and the hydrostatic assumption is applied. The hydrostatic assumption states the pressure is related to the water level is strictly related to the depth.

$$
\begin{gathered}
\underbrace{\frac{1}{\partial t}}_{\begin{array}{c}
\text { local } \\
\text { acceleration }
\end{array}}+\underbrace{\frac{u}{g} \frac{\partial u}{\partial x}}_{\begin{array}{c}
\text { convective } \\
\text { acceleration }
\end{array}}+\underbrace{\frac{\partial h}{\partial x}}_{\begin{array}{c}
\text { pressure } \\
\text { gradient }
\end{array}}=\underbrace{S_{0}}_{\text {bed slope }}-\underbrace{\frac{\tau_{0}}{p g R_{H}}}_{\text {friction }} \\
\underbrace{\frac{\partial Q}{\partial x}}_{\begin{array}{c}
\text { franport } \\
\text { tra }
\end{array}}+\underbrace{b \frac{\partial h}{\partial t}}_{\text {elevation }}=0 \\
\tau_{b} \cong \rho c_{D}|u| u=c_{D}\left|\frac{Q}{A}\right| \frac{Q}{A}
\end{gathered}
$$

In Equations 2.1 and 2.2, $u$ is the depth-averaged channel velocity, $g$ is the gravitational acceleration, $h$ is the water level, and $Q$ is the river discharge. On the right-hand side of Equation 2.1, $S_{0}$ is the bed slope, $\rho$ is the water density, $\tau_{0}$ is the bed shear stress, and $R_{H}$ is the hydraulic radius. Equation 2.3 is an approximation of the bottom friction term (Dronkers, 1964). In Equation 2.3, $C_{d}$ is a drag coefficient. The velocity is composed of a tidal and river component $\left(u=u_{T}+u_{R}\right)$. 


$$
\begin{gathered}
q=k+(-1)^{1 / 2} r \\
q=\left[(-1)^{1 / 2}-1\right] r
\end{gathered}
$$

The approximation of the bottom of the stress allows for useful analytical solutions. The bed stress controls the complex wave number (Equation 2.4) and, therefore tidal propagation (Jay et al. 2010). In Equation 2.4, $q$ is the complex wave number, $k$ is the wave number, and $r$ is the damping modulus.

Friedrichs and Aubrey (1994) applied a similar approach to the parameterizing the bed friction in the momentum equation to scale frictional tidal rivers. In the resulting solution, the pressure term balanced the friction term and the acceleration terms were negligible. In the case where tidal and fluvial energy are $\mathrm{f}$ the same magnitude, i.e., $u_{T} \approx$ $u_{R}$, the wave number and the damping modulus are approximately equal, and the complex wave is expressed solely in term of the damping of the damping modulus (Equation 2.5).

$$
\begin{gathered}
\frac{\zeta[x]}{\zeta_{T P}}=e^{-i q\left(x-x_{T P}\right)} \\
\log \left[\frac{|\zeta[x]|}{\left|\zeta_{T P}\right|}=+r\left(x-x_{T P}\right)\right. \\
\log \left[\frac{|\zeta[x]|}{\left|\zeta_{T P}\right|}\right]=a_{0}+a_{1} Q_{R}+a_{2}\left(\frac{T_{R, T P}^{2}}{Q_{R}^{n}}\right)
\end{gathered}
$$

Under the condition described previously, the tidal amplitude $(\zeta)$ ratio between a station of interest, in this case Tongue Point in Astoria (TP), and another station near is expressed by Equation 2.6. Taking the log of that ratio and applying the expression for complex modulus in terms of the damping modulus (Equation 2.5) yields Equation 2.7 (Jay et al., 2010). The bed stress is represented by the Dronkers (1064) approximation, and then 
expanded using a Chebyschev polynomial approach yielding Equation 2.8 (Kukulka and Jay, 2003a). In Equation 2.7, $Q_{R}$ is the river discharge, $T_{R, T P}$ is the tidal range at Tongue Point, $n$ is the tide-flow interaction component, and $a_{i}$ are the station model parameters (Kukulka and Jay, 2003a).

$$
W L=a_{0}+\underbrace{a_{1}\left(Q_{W R}\right)^{m 1}}_{\begin{array}{c}
\text { Willamette } \\
\text { River }
\end{array}}+\underbrace{a_{2}\left(Q_{T D}\right)^{m 2}}_{\begin{array}{c}
\text { Columbia } \\
\text { River }
\end{array}}+\underbrace{a_{3}\left(\frac{T_{R A}^{2}}{\left(Q_{T D}+Q_{W R}\right)^{m 3}}\right)}_{\text {Tides }},
$$

Equation 2.8 is used to describe tidal datums (Jay et al., 2010). in Chapter 3 I utilize this approach to approximate late $19^{\text {th }}$ century once-daily water level on the Willamette River in Portland (Jay at al. 2011).

\subsection{Modeling of the LCRE}

This study employs hydrodynamic modeling to analyze the propagation of tides and flood waves in a tidal river. This section details some previous efforts at modeling the Columbia River with numerical and analytical models.

Previous studies of the LCRE are helpful in understanding the present state of the system, but presently, there are no models that can help us understand the system prior to the large-scale anthropogenic and natural changes. In particular, previous modeling studies have not focused on changes to the tidal river, nor have they included realistic historic floodplains, both essential features in system evolution. Hamilton et al. (1990) used twodimensional vertical and horizontal grids in an early attempt to analyze historical changes, but these models, focusing only on the estuary, did not include a tidal river or modifications to it. MacCready et al. (2009) utilized the Regional Ocean Modeling System [ROMS], to 
examine circulation in the Columbia River estuary plume in the summer of 2004 . To understand the effects of changing morphology near the ocean entrance, Elias et al. (2012) used the Delft3D modeling system to develop a coupled hydrodynamic and wave model for the estuary mouth. The authors found that Similarly, the Center for Coastal Margin Observation \& Prediction (CMOP) has developed models for the purpose of monitoring and scientific research (Zhang et al., 2004; Zhang and Baptista, 2008; Kärnä et al., 2015; Kärnä and Baptista, 2016). The previous studies focused on the LCRE from the near-ocean to the estuary. In this study my model extends to the head of tides in the LCRE. I hope to show that the interaction between tides and river flow is significant even in the upper tidal river. The previous studies also focused on the present-day LCRE, this work will extend that knowledge with the development of a historical model.

The Columbia River has also been modeled with analytical formulations. In the work of Giese and Jay (1989) the authors used a one-dimensional harmonic transport model to study tidal energetics in the LCRE. The model provided a qualitative explanation for and a quantitative predictions of along-channel variations in tidal properties in terms of the momentum balance. The degree of the nonlinear interaction between the barotropic and the river in the LCRE is elucidated further in the work of Jay and Flinchem (1997). The authors showed that the in a tidal river such as the LCRE, tidal processes deviate markedly from the assumptions in traditional harmonic analysis. In the works of Kukulka and Jay (2003a, 2003b), the authors used nonstationary time series analysis methods and the St. Venant equation to model nonstationary tidal properties and reconstruct historical water levels in the LCRE. In the work of Jay et al. (2010) the authors applied regression models 
to determine the decadal evolution of datum levels on the Columbia River in Vancouver, WA.

In the above examples the complex interaction between tides and river discharge in the LCRE were modeled with one-dimensinal analytical solutions. In my dissertation I will utilize a two-dimensional hydrodynamic to explore this interaction in present-day LCRE (Chapter 3). With the development of a historical two-dimensional model of the LCRE I can determine how that interaction between tides and river discharge in the LCRE has evolved in response to alterations in bathymetry (Chapter 3). 


\section{Chapter 3: Historical changes in Lower Columbia River and Estuary Floods: A}

\section{Numerical Study ${ }^{1}$}

${ }^{1}$ Helaire, L., Talke, S. A., Jay, D. A., \& Mahedy, D. (2019). Historical Changes in Lower Columbia River and Estuary Floods: A Numerical Study. Journal of Geophysical Research: Oceans. doi: 10.1029/2019JC015055

Over the past 150 years, the Lower Columbia River Estuary (LCRE) controlling depth has approximately doubled, the majority of historical wetlands and floodplain have been reclaimed, numerous infrastructure projects have altered and confined flow pathways, and significant natural and anthropogenic changes to the discharge hydrograph have occurred. To investigate the effect of these changes on tides, river slope, and flood water levels, I construct and validate numerical models that simulate flow over late $19^{\text {th }}$ century and present-day bathymetry. The models are validated using archival (1853-1877) and modern tide measurements throughout the LCRE, and river stage measurements from the tidal river (1876-present). Historical floodplain roughness and levee heights are validated iteratively, by requiring simulations to match the observed roll-off in the river stage rating curve during floods. Measurements and model results show that environmental change has amplified tidal constituents, with peak change about $60 \mathrm{~km}$ from the coast. By contrast, increased depth has reduced river slope for low and moderate river discharge. For rarely observed extreme floods of $30 \times 10^{3} \mathrm{~m}^{3} \mathrm{~s}^{-1}$, simulated modern water levels exceed historical water levels in Portland (OR). These observations highlight competing hydrodynamic effects, which are investigated by scaling the St Venant equations for a simulated $25 \times 10^{3}$ $\mathrm{m}^{3} \mathrm{~s}^{-1}$ flood: while larger modern depth reduces frictional effects and decreases surface slope, reduced floodplain access confines modern flow into channels, increasing velocity, bed stress and water levels. However, the highly frictional historical floodplain conveyed 
little flow, limiting the effect of floodplain to storage effects; hence, most simulated historical floods exceed modern levels.

\subsection{Introduction}

Tidal rivers and estuaries all over the United States have been extensively modified for navigation, agriculture, flood protection, and other uses (USACE [United States Army Corp of Engineers], 1915). Similar infrastructure projects have been implemented worldwide, and include channel deepening (often doubling or tripling depth), loss of wetlands, streamlining of channels, narrowing of entrances, and construction of pile dikes and other flow-modification structures (Sherwood et al., 1990; Wang et al., \& Song, 2018). These physical changes are often combined with alterations in the river flow hydrograph, which can be caused by land-use changes, water resource management, and/or climate change (Cox et al., 2015; Keshtpoor et al., 2015; Passeri et al., 2015; Manning et al., 2011, Naik \& Jay, 2011). Altered bathymetry also has consequences for mean water levels and the dynamics of tide waves and other long waves. In the Cape Fear Estuary (NC), channel deepening caused a doubling of tide range and an amplification of storm surge waves (Familkhalili \& Talke, 2016). Similarly, Wang et al. (2018), studying the coastal areas of Shanghai, found that future changes in storm-flooding were more influenced by bathymetric changes than relative sea level rise. In the tidal Hudson River, channel deepening since 1930 reduced the effective drag, increasing the magnitude of tides and coastal storm surge observed in the tidal river (Ralston et al., 2019). However, flow management decreased flood magnitudes, and channel deepening also reduced the river slope. Hence, water level in Albany (NY) during the once-in10y event is now nearly $3 \mathrm{~m}$ 
lower than in the late $19^{\text {th }} /$ early $20^{\text {th }}$ century, more than compensating for the increased surge amplitude (Ralston et al., 2019).

In this chapter, I evaluate how tides and flood propagation within the Lower Columbia River Estuary (LCRE) have changed due to $\sim 150$ years of anthropogenic changes, including diking, land reclamation, and channel deepening. Approximately 68$70 \%$ of the vegetated tidal wetlands and $55 \%$ of the forested uplands have been lost in the LCRE since the late 1800's (Marcoe \& Pilson, 2017). Moreover, the mouth of the Columbia has been deepened and narrowed, and channels have been significantly dredged and streamlined for navigation purposes (Bottom et al., 2005). Jay et al. (2010) showed that as a result of changes, mean water levels (MWL) at Vancouver (rkm 170) dropped between 0.3-1.5 m since 1902, for river flow levels from $2.5-15 \times 10^{3} \mathrm{~m}^{3} \mathrm{~s}^{-1}$. These changes were attributed to decreased flow resistance caused by navigational channel dredging, and bed degradation related to dredging, gravel-mining, and a reduction in sand supply caused by the reservoir system (Templeton \& Jay, 2012) However, Jay et al. (2010) only considered low and moderate flow conditions at one location, and it remains unclear whether a large flood, such as often occurred in the past, would be higher or lower today than it was historically. Indeed, within a more riverine context, it is often argued that channel deepening and narrowing has increased flood risk (e.g., on the Mississippi River; Pinter et al., 2008; Munoz et al., 2018), in contrast with the Ralston et al. (2019) result on the Hudson River.

Since the magnitude of spring freshets on the Columbia River has been curtailed an average of $45 \%$ by reservoir management (e.g., Naik \& Jay, 2005), the best (and only) way 
to determine whether large historical floods would produce larger water levels today, were they to recur in the LCRE, is through numerical modeling. Several previous efforts have been made to develop predictive numerical models to capture the effects of long-term changes in the LCRE. Hamilton (1990) used a two-dimensional model in an early attempt to analyze historical changes to salinity intrusion and tides, but focused only on the lower $50 \mathrm{~km}$ of the estuary and did not attempt to calibrate their model to historical data. To understand the effects of changing morphology near the ocean entrance, Elias et al. (2012) used the Delft3D modeling system to develop a coupled hydrodynamic and wave model for the estuary mouth. They found that near the mouth of the river, sediment transport in the summer month is controlled by density stratification and is net landward. The Center for Coastal Margin Observation and Prediction [CMOP] has developed models for the purpose of monitoring and scientific research (Zhang et al., 2004; Zhang \& Baptista, 2008; Kärnä et al., 2015; Kärnä \& Baptista, 2016). These studies, focusing on the Columbia River estuary, provide insight into present-day mixing and transport processes, but are not meant to provide insights into long-term trends and system trajectory.

The recent recovery of archival tide data from the $19^{\text {th }}$ century (Talke \& Jay, 2013; Talke \& Jay, 2017), along with the digitization of historical bathymetry (Burke, 2010; see also Marcoe $\&$ Pilson, 2017), enables the modeling of late $19^{\text {th }}$ century conditions and interpreting system functioning during less anthropogenically altered periods. My approach, after developing models based on $19^{\text {th }}$ and early $21^{\text {st }}$ century bathymetry (hereafter named "historical" and "modern" models) is to first validate against data which reflects a range of tidal and fluvial forcing. Next, I simulate a historical flood the 1880 
spring freshet) in both models, and evaluate spatial changes to water levels and hydrodynamic processes during both mean and extreme conditions. Through statistical analysis, tidal analysis, and scaling of results, I examine how changing bathymetry and friction have affected the transmission of long waves (floods and tides), with implications for habitat inundation and flood risk.

\subsection{Background}

\subsubsection{Geography and Hydrology}

The Columbia River, with an average discharge of $\sim 7,500 \mathrm{~m}^{3} \mathrm{~s}^{-1}$, is the largest river on the Pacific Coast of North America and drains an area of $660,480 \mathrm{~km}^{2}$ (Figure 3.1; Naik \& Jay, 2005). The LCRE, with a length of $230 \mathrm{~km}$, is the tidal-river and estuarine section of the Columbia River, and stretches from the ocean to Bonneville Dam (Figure 3.1) (Naik \& Jay, 2005). The largest tributary, the Willamette River, enters the Columbia River at rkm 163, just downstream of Vancouver, WA. Together, the Willamette and the mainstem Columbia River provide $\sim 90 \%$ of the discharge that flows into the ocean (Orem, 1968). Discharge at The Dalles, Station 14105700, United States Geological Survey [USGS]), located $\sim 100 \mathrm{~km}$ upstream of Bonneville Dam, accounts for $75 \%$ of the flow that reaches the mouth of the river (Naik \& Jay, 2011). Several smaller tributaries discharge into the LCRE, including the Cowlitz River, Sandy River, and Lewis River. Based on an analysis of the Willamette River, these tributaries have the potential for significant discharge during winter rain or rain-on-snow events. However, these tributaries cannot discharge at a high rate long enough to influence a spring freshet. 
Natural and anthropogenic factors have altered river discharge since the 1800s, with the largest factor being the construction of dams along the Columbia River between the 1930s and early 1970s. Combined with a reduction in snow-pack due to climate change and the diversion of flow for agriculture, the magnitude of the May/June spring freshets (the primary source of historical floods) has been reduced by $45 \%$; by contrast, the base flow during the July-October low flow periods has increased (Bottom et al., 2005; Jay \& Naik, 2011; Naik \& Jay, 2011). Consequently, spring freshets between 1850 and 1970 were much larger than the freshets that have occurred since the completion of the reservoir system in the early 1970s.

Tidal statistics and tide range in the LCRE also appear to be changing over secular (century) time scales. Jay (2009) noted a $77 \mathrm{~mm}^{\text {century }}{ }^{-1}$ increase in the $M_{2}$ constituent and a $35 \mathrm{~mm}$ century ${ }^{-1}$ increase in the $K_{l}$ constituent at Astoria since 1925, and Jay et al. (2010) noted an increase in tide range at Vancouver of $0.4 \mathrm{~m}$ during low flow conditions. At present, the $M_{2}$ amplitude is $0.95 \mathrm{~m}$ at Tongue Point (rkm 25; Station 9439040, NOAA), and the $K_{1}$ amplitude is $0.4 \mathrm{~m}$ (Figure 3.1). The large $K_{1} / M_{2}$ ratio produces mixed semidiurnal tides, with a large diurnal inequality. In the Portland area, upstream discharge significantly influences tidal range. Under low flow conditions, Vancouver (see Figure 3.1; Station 9440083, National Oceanic and Atmospheric Administration [NOAA]) exhibits a tidal range as large as $1 \mathrm{~m}$. At high discharge $\left(>15 \times 10^{3} \mathrm{~m}^{3} \mathrm{~s}^{-1}\right)$, the tidal signal largely disappears. 


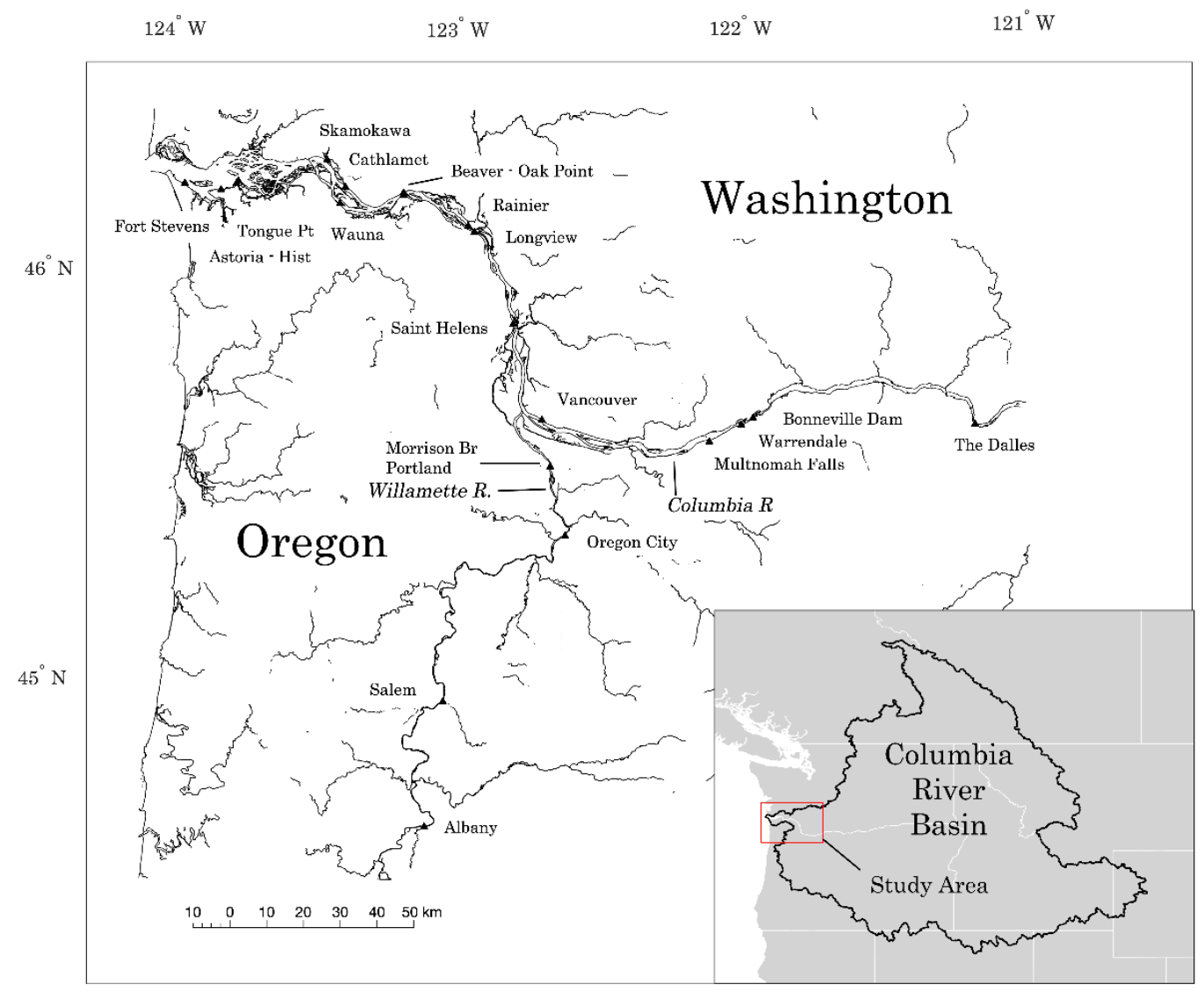

Figure 3.1: The present-day shoreline of the LCRE and gauge stations used in the analysis (triangles).

\subsubsection{Flood History and Changing Water Levels}

During the $19^{\text {th }}$ and early $20^{\text {th }}$ century, communities along the LCRE (Figure 3.1 ) were subject to multiple flooding events each decade, with the largest (the 1894 spring freshet) causing the city of Portland to be flooded for approximately three weeks. While a combination of reservoirs and levees have reduced flood frequency, river discharge still occasionally exceeds the modern bankfull flow of $\sim 24 \times 10^{3} \mathrm{~m}^{3} \mathrm{~s}^{-1}$ (Jay \& Naik, 2011). Since 1900 there have been five events exceeding this threshold: June 7- 9, 1913 (spring), May 29-June 20, 1948 (spring), June 3-8, 1956 (spring), December 24-26, 1964 (winter) and 
February 10-11, 1996 (winter) (Waananen et al., 1970; USACE, 1997; Jay \& Naik, 2011). Large spring flow peaks in $1956,1972,1974$ (with probably the largest $20^{\text {th }}$ century snowpack), 1997 and 2011 were successfully attenuated by reservoir management; however, none of these years combined a very large spring freshet with high spring rainfall, comparable to 1948. Despite the extensive Columbia Basin reservoir system, the combination of a heavy winter snowpack and unexpected spring rains remains a potential system failure mode that can result in dangerous floods, potentially as large or larger than 1948 (Mote \& Salathé, 2010; Salathé et al., 2014). This potential for property damage and loss of life underscores the need to understand the response of the system to changes in bathymetry.

\subsubsection{Navigation History}

Since 1878 , an ongoing effort has been made to maintain a suitable navigation channel, through a series of modifications to the river mouth and channel. These modifications include the construction of jetties near the mouth of the river, dredging of the navigation channel, and the installation of pile dikes to encourage scouring and to direct the river along a desired path (Lockett, 1959; Hickson, 1961; Dodge, 1976; Kassenbaum, 2011). The controlling depth of the shipping channel has increased from about $6 \mathrm{~m}$ in the late $19^{\text {th }}$ century, to $13 \mathrm{~m}$ relative to Mean Lower Low Water [MLLW] today (Table 3.1 and Figure 3.2). The channel is deeper at the mouth of the river, and the six miles $(9.7 \mathrm{~km})$ of the inboard side of the Mouth of Columbia River are maintained at 14.6m (48 foot) depth, while the six miles $(9.7 \mathrm{~km})$ on the outboard side are maintained at $16.8 \mathrm{~m}$ (55 foot) depth (USACE, n.d.). 
Table 3.1: Acts of Congress authorizing expenditures for modification of the Columbia River Channel and Mouth of the Columbia River.

\begin{tabular}{|c|c|c|}
\hline \multicolumn{3}{|c|}{ Mouth of the Columbia River } \\
\hline 1882 & Public Acts of the $47^{\text {th }}$ Congress & $30^{\prime}(9.1 \mathrm{~m})$ depth \\
\hline 1905 & River and Harbor Act & $40^{\prime}(12.2 \mathrm{~m})$ depth, $1 / 2$ mile $(0.8 \mathrm{~km})$ width \\
\hline 1954 & River and Harbor Act & $48^{\prime}(14.6 \mathrm{~m})$ deep, $1 / 2$ mile $(0.8 \mathrm{~km})$ width \\
\hline \multicolumn{3}{|c|}{ Columbia River Channel } \\
\hline 1878 & Act to Improve Rivers and Harbors & $20^{\prime}(6.1 \mathrm{~m})$ depth \\
\hline 1899 & Rivers and Harbors Appropriation & $25^{\prime}(7.6 \mathrm{~m})$ depth \\
\hline 1912 & River and Harbor Act & $30^{\prime}(9.1 \mathrm{~m})$ depth, 300' (91m) width \\
\hline 1930 & River and Harbor Act & $35^{\prime}(10.7 \mathrm{~m})$ depth, 500' $(152 \mathrm{~m})$ width \\
\hline 1962 & Rivers and Harbors Act & $40^{\prime}(12.2 \mathrm{~m})$ depth, 600' $(183 \mathrm{~m})$ width \\
\hline 1999 & Water Resources Development Act & $43^{\prime}(13.1 \mathrm{~m})$ depth \\
\hline
\end{tabular}

Depth relative to MLLW (Lockett, 1959; Hickson, 1961; Kassenbaum, 2011).

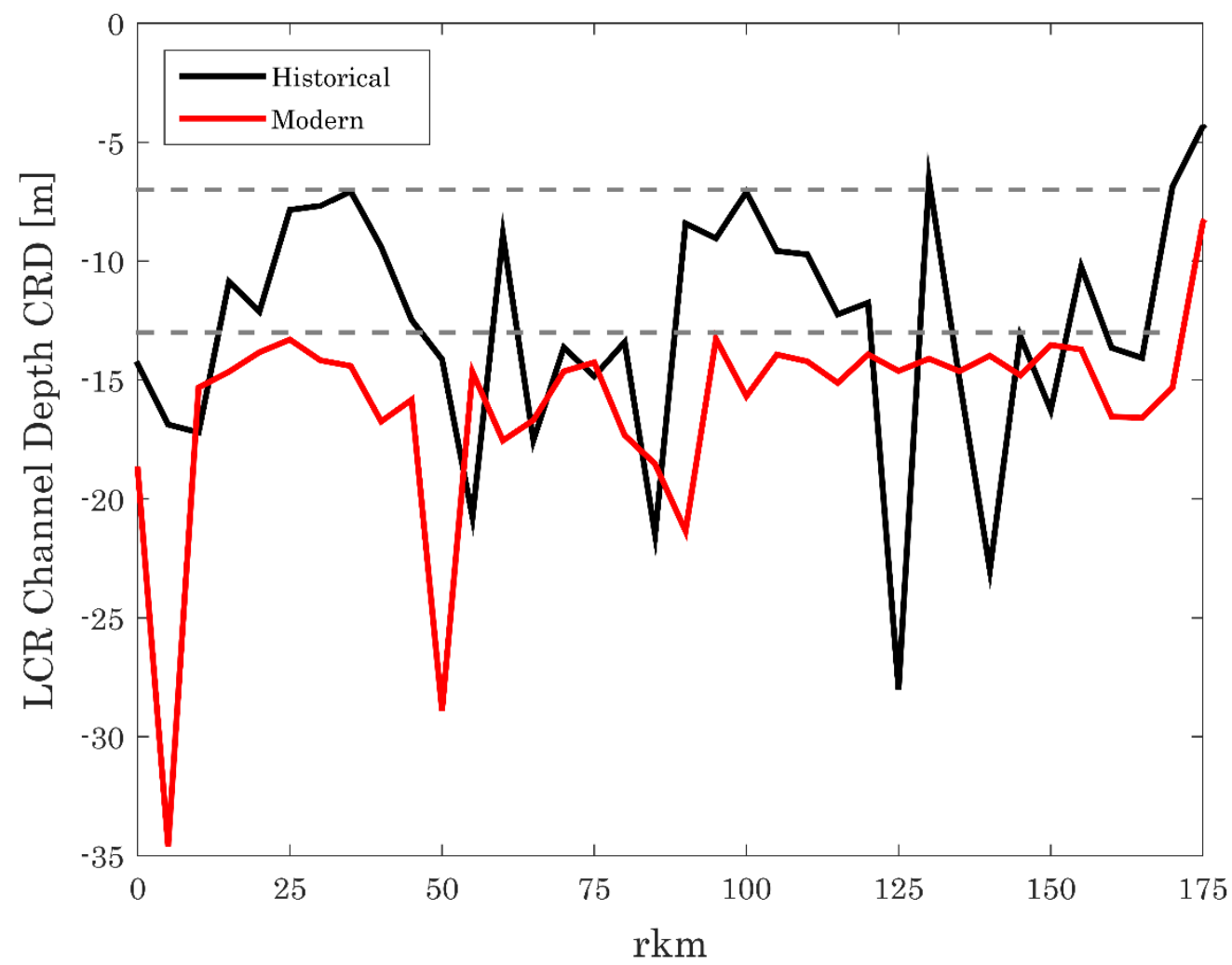

Figure 3.2: LCRE channel depth in the historical (late 19th century) and modern period relative to NAVD88.

The dotted gray lines indicate the approximate historical and modern controlling depth. 
Available maps created between 1792 and 1879 depict a river mouth with one, and sometimes two, channels that meandered over annual and decadal time scales and changed depth frequently. Uncertain bathymetry, combined with strong waves and large currents (rivers + tides), produced hazardous conditions that caused many shipwrecks (including two US Navy ships the USS Peacock and the USS Shark) and earned the region the name "Graveyard of the Pacific". The clear hazard, and the degradation of the available channel by the early 1880 s, motivated the US Congress to allocate money for improvement of the channel entrance (Public Acts of the $47^{\text {th }}$ Congress, 1882; Hickson \& Rodolf, 1951; Lockett, 1959; Kidby \& Oliver, 1965). The South Jetty, started in 1885 and completed in 1895 , extended 4.5 miles $(7.2 \mathrm{~km})$ into the ocean and was initially built to provide a 30 foot (9.1m) deep channel at the entrance. By 1896, only a 29 foot $(8.8 \mathrm{~m})$ deep channel was available at the bar and by 1898 , two channels had formed due to the continued accretion along the Clatsop Spit. To address such problems and accommodate increasing ship sizes, The Rivers and Harbors Appropriation Act of 1905 authorized a 40 foot (12.2m) deep, 1/2mile wide $(0.8 \mathrm{~km})$ channel at the mouth. This led to an extension of the South Jetty to 7 miles $(11.2 \mathrm{~km})$ in 1913 and the construction of the 3 mile $(4.8 \mathrm{~km})$ long North Jetty (completed in 1917). By 1931, due in part to the deterioration of the South Jetty, Clatsop Spit migrated north and west. Several projects were undertaken to alleviate this condition, including the rehabilitation of the South Jetty from 1931-36, rehabilitation of the North Jetty from 1938-39, construction of Jetty "A" normal to the North Jetty, and the installation of four pile dikes along the south shore of Sand Island in 1939 (Hickson \& Rodolf, 1951; 
Lockett, 1959). Further deepening of the entrance channel was authorized in 1954, and further deepening of the estuary and river was authorized in 1962 and 1999 (Table 3.1).

\subsection{Materials and Methods}

\subsubsection{Modern and Historic Data}

Extensive 19th century hydrological and tidal records are available for the LCRE (Talke \& Jay, 2013; Jay et al., 2010; Naik and Jay, 2005). The records serve to: a) characterize the tidal progression from the Pacific Ocean to Bonneville Dam, b) define the elevation vs. flow rating curve in the Portland area during the late 19th century, c) elucidate discharge patterns of the late $19^{\text {th }}$ century, and d) provide boundary conditions for the historic model. By comparing $19^{\text {th }}$ century data with modern data, I can analyze changes to boundary conditions and secular changes in water levels and tides. Table 3.2 details the historical records used in this chapter, and Table 3.3 details the modern data.

A long series of tide records at Astoria from 1853-1876 has been recovered (Talke \& Jay, 2017), as well as tide logs from 13 stations in the LCRE, an estuary survey in 1868, and a river survey in 1877 during low flow conditions (Table 3.2). Water levels were extensively quality assured to eliminate data with measurement and timing errors (Helaire; 2016), and short series were discarded. After quality assurance, only 6 short term records (Table 3.2) were of sufficient quality to perform a tidal harmonic analysis using robust least-squares fitting (Pawlowicz et al., 2002; Leffler \& Jay, 2009). The constituent amplitudes and phases obtained from harmonic analysis were later used to calibrate and validate the model. The same approach was used with modern data (Table 3.3). 
Table 3.2: 19th century water level and discharge data.

\begin{tabular}{|c|c|c|c|c|}
\hline Station & River & Rkm & Type & Dates \\
\hline${ }^{1}$ Fort Stevens, OR & $\mathrm{CR}$ & 2.6 & high/low tide & Jul $15-$ Sep 15,1868 \\
\hline${ }^{1}$ Astoria, OR & $\mathrm{CR}$ & 24 & hourly water level & $1870-1876$ \\
\hline${ }^{1}$ Cathlamet, WA & $\mathrm{CR}$ & 60 & high/low tide & Sep 12 - Oct 15,1877 \\
\hline${ }^{1}$ Oak Point, WA & $\mathrm{CR}$ & 87 & high/low tide & Sep 12 - Oct 15,1877 \\
\hline${ }^{1}$ Rainier, OR & $\mathrm{CR}$ & 108 & high low tide & Sep 12 - Oct 15,1877 \\
\hline${ }^{1}$ Vancouver, WA & $\mathrm{CR}$ & 168 & high/low tide & Sep 12 - Oct 15,1877 \\
\hline${ }^{1}$ Warrendale, OR & $\mathrm{CR}$ & 228 & $30-60 \mathrm{~min}, 18-20 \mathrm{hrs} / \mathrm{day}$ & Sep 13 - Oct 10,1877 \\
\hline${ }^{2}$ Morrison $\mathrm{Br}$. & WR & 12.8 & daily water level & Jan 1876 - Jun 1878 \\
\hline${ }^{3,4}$ Morrison $\mathrm{Br}$ & WR & 12.8 & daily water level & $1879-1898$ \\
\hline${ }^{2}$ Albany, OR & WR & 190 & daily water level & Jun $1877-$ Jun 1878 \\
\hline${ }^{5}$ Albany, OR & WR & 190 & daily discharge & 1878-1888 (gaps); 1892-date \\
\hline${ }^{6}$ The Dalles, OR & CR & 305 & daily discharge & 1878 - present \\
\hline
\end{tabular}

CR - Columbia River, WR - Willamette River, MSB-Morrison Bridge, Portland. 1. digitized tide logs (USC\&GS, 1877) 2. discharge estimate (USACE, 1915) 3. daily water level at EV2 database (https://www.ncdc.noaa.gov/EdadsV2) 4. USWB (1879-1898) 5. USWB (1878-1888) 6. Henshaw and Dean (1915)

Table 3.3: Modern water level and discharge data.

\begin{tabular}{|c|c|c|c|c|c|c|}
\hline Station & River & rkm & Type & Dates & Source & Station ID \\
\hline${ }^{1}$ Hammond, OR & $\mathrm{CR}$ & 14.5 & 10 min water level & Sep. 1-30, 2005 & NOAA & 9439011 \\
\hline${ }^{1}$ Astoria & $\mathrm{CR}$ & 28 & 10 min water level & Sep. 1-30, 2005 & NOAA & 9439040 \\
\hline${ }^{1}$ Skamokawa & $\mathrm{CR}$ & 54.2 & 10 min water level & Sep. 1-30, 2005 & NOAA & 9440569 \\
\hline${ }^{1}$ Longview & $\mathrm{CR}$ & 106.7 & 10 min water level & Sep. 1-30, 2005 & NOAA & 9440422 \\
\hline${ }^{1}$ Saint Helens & $\mathrm{CR}$ & 138.6 & 10 min water level & Sep. $1-30,2005$ & NOAA & 9439201 \\
\hline${ }^{1}$ Vancouver, WA & CR & 171.1 & 10 min water level & Sep. 1-30, 2005 & NOAA & 9440083 \\
\hline${ }^{2}$ Morrison $\mathrm{Br}$. & WR & 12.8 & 10 min water level & Sep. 1-30, 2005 & USGS & 14211720 \\
\hline${ }^{2}$ Morrison $\mathrm{Br}$. & WR & 12.8 & hourly discharge & Sep 1-30, 2005 & USGS & 14211720 \\
\hline${ }^{3}$ Bonneville & $\mathrm{CR}$ & 234 & hourly discharge & Sep 1-30, 2005 & USACE & \\
\hline
\end{tabular}

CR - Columbia River, WR - Willamette River 1. NOAA - https://tidesandcurrents.noaa.gov/map/index.html 2. USGS - https://waterdata.usgs.gov/nwis/ 3. http://www.fpc.org/river/flowspill/FlowSpill.asp

Daily water level readings from the Willamette River at Portland (OR) have been measured nearly continuously since at least 1876, first at Stark Street and later at the nearby Morrison Bridge [MSB]. Multiple copies of $19^{\text {th }}$ and early $20^{\text {th }}$ century records exist, including at the City of Portland archives (1880-1914), the National Weather Service office 
in Portland (1876, 1879-1898), the U.S. Signal Service and US Weather Bureau [USWB] archives at the National Centers for Environmental Information (1879-1972) (https://www.ncdc.noaa.gov/EdadsV2), and a series of reports compiled by the United States Weather Bureau (USWB, 1893-1946). Graphical records of stage height from 1876 to 1878 were found and digitized from the Annual Report of the US Army Corps, 1879. For analysis of modern water levels, mean, minimum and maximum daily water levels are available from 1972, and hourly (or better) readings are available 1986-present from USGS and NOAA, though there are gaps.

Daily discharge records for the Columbia River at The Dalles for 1878 to the present are available from USGS (http://waterdata.usgs.gov/usa/nwis/uv?14105700). Fragmentary discharge estimates were made for the Willamette River at Albany, OR between 1878 and 1888 (39\% percent complete) and continuously from 1892 onward (USGS Station \# 1417100). Water level in Portland is dependent on Columbia and Willamette River discharge, as well the tidal amplitude. To provide a more complete Willamette River flow record, an estimate of the Willamette River discharge in the $19^{\text {th }}$ century was determined through an iterative model using inputs of river discharge, water level, and downstream tidal range.

\subsubsection{Bathymetry}

In my model I used river channel and floodplain bathymetry from a merged dataset of multibeam surveys and LiDAR derived elevations (USACE, 2010). Continental shelf depths were obtained from The National Geophysical Data Center [NGDC] Digital Elevation Model [DEM] (NGDC, 2003). 
The majority of the bathymetry and topography data used to produce my historical DEM were extracted from hydrographic surveys made by the US Coast and Geodetic Survey [USC\&GC] (present-day National Geodetic Survey) between 1868 and 1901. The digitized and georeferenced surveys were tied horizontally to the North American Datum of 1983 [NAD83], and vertically to North American Vertical Datum of 1988 [NAVD88] (Burke, 2010). These surveys typically measured the topography below MLLW. To obtain intertidal flats and floodplain bathymetry, I integrated modern Lidar measurements (USACE, 2010) into the historical DEM, after removing modern landscape features such as roads and dikes. Because vertical land motion due to tectonics is small in the tidal river (Burgette et al., 2009), the bathymetry of extant wetlands is likely well estimated. Subsidence due to oxidation of soil in diked regions causes an unknown error in floodplain bathymetry (in practice, this is compensated for by using a larger friction coefficient - see Results and Supplement). Outside of the immediate river mouth, continental shelf bathymetry was defined using modern surveys; similarly, bathymetry upstream of rkm 219 and upstream of Portland (OR) is obtained from modern measurements. My analysis of Portland water levels (see Results) suggests that before 1900, significant overbank flow occurred for river discharges of greater than $\sim 20 \times 10^{3} \mathrm{~m}^{3} \mathrm{~s}^{-1}$. I estimated the spatially variable levee height implied by a $20 \times 10^{3} \mathrm{~m}^{3} \mathrm{~s}^{-1}$ discharge by analyzing the water surface profile from Bonneville ( $\mathrm{rkm} 230$ ) to the ocean compiled by the US Army Corps for historical floods from as early as 1876 (USACE, 1963). The USACE flood profile contains an estimate of flood stage along the river channel from Bonneville to the estuary. The resulting DEM was checked and modified using georeferenced $19^{\text {th }}$ century LCRE 
topography sheets (Burke, 2010), which provide information about the placement of historical wetlands, channels, forests, and other ecotypes. Where available, additional navigation maps, particularly of the Willamette River, were recovered and digitized (Thorn, 1888; McIndoe \& Thomson, 1911). The resulting DEM represents 19th century conditions as well as possible with available data (see Helaire, 2016).

\subsubsection{Model and Computational Grid}

Simulations were run on the Delft3D platform (Roelvink and Van Banning, 1995), and were based on a modified version of the grid used in Elias et al. (2012) that had been expanded to include floodplains and extends the domain to the head of tides. Since I am primarily interested in the tidal river landward of salinity intrusion, I used a barotropic (depth averaged) approach. Nonetheless, to define tidal propagation through the estuary, I extended the grid 30-35 km into the open ocean (Figure 3.3). The tidal amplitude and phase of the oceanic tides of the eight largest harmonic constituents (Tables $3.4 \& 3.5$ ) are defined at the extreme southwest and northwest points on the ocean boundary and are obtained from the Oregon State University Tidal Prediction Software (OTPS) tide model using the Pacific Northwest regional sub-model (Egbert and Erofeeva, 2002). Neumann boundaries are applied on the north and south edge of the coastal boundary (

The model segment representing the estuary and fluvial domain extends upstream from the mouth of the Columbia River to Bonneville, OR (CR rkm 234), and includes the Willamette River from the confluence with the Columbia River to a discharge boundary at the head of tides at Oregon City, OR (WR rkm 41). The model grid extends from the river channel far enough to model $20 \mathrm{~m}$ of inundation relative to NAVD88, sufficient to model a 
historical event such as the flood in June 1894. The model has a grid resolution varying from $2 \mathrm{~km}$ in the ocean to $50 \mathrm{~m}$ in some of the smaller channels. To make use of multiple cores on my workstation and decrease computation time, I decomposed both the historical and modern model into different subdomains, using well-validated functionality (Roelvink \& Van Banning, 1995, Hydraulics, 2006) that has been previously applied to the Columbia River Estuary (i.e., Elias et al., 2012). I used five subdomains in the modern model with 242,382 total grid cells, and six subdomains in the historical model with 334,629 total grid cells. The larger number of cells in the historical model was needed to accurately model overland flow, and necessitated the additional subdomain. Since I have data within each subdomain (Table 3.2 and 3.3), I was able to validate through calibration of low-discharge events that any small errors that might occur at the connection points between domains did not materially affect results and could be neglected.

The grids are divided into sub-domains representing different reaches of the coupled ocean-river system. The modern model has an ocean subdomain, which is $58 \mathrm{~km}$ from north-to-south and extends 30-35 km from the coast. The next subdomain represents the entrance to the Columbia River and the estuary up to Columbia River rkm 50. The lower reaches of the tidal river are represented by a subdomain from rkm 50-136 on the Columbia River. Further upstream is a subdomain representing the Portland/Vancouver area, including the Columbia River from rkm 136-176 and the tidally influenced segment of the Willamette River, from the confluence with the Columbia River to the extent of tidal influence at Oregon City ( $\mathrm{rkm} 41)$. The final subdomain represents the Columbia River 
upstream of the dredged shipping channel (USACE, n.d.), and stretches upstream from rkm 176 to Bonneville, OR (rkm 234).

The historical model has an ocean subdomain that is $50 \mathrm{~km}$ from north-to-south and extends roughly $30 \mathrm{~km}$ into the ocean. The ocean subdomain includes the mouth of the river channel and the most seaward $14 \mathrm{~km}$ of the Columbia River. Upstream of the ocean subdomain is a subdomain representing the estuary, which includes the Columbia River from rkm 14-52. The lower reaches of the tidal river are represented by a subdomain from rkm 52-140. The Portland/Vancouver area is represented by two subdomains. One subdomain includes the Columbia River from rkm 140-176 and the Willamette River from the confluence with the Columbia River, downstream to Willamette River rkm 7. The other subdomains represent the Willamette River from rkm 7 to the end of tidal influence at Oregon City (WR rkm 41). The final subdomain models the upper reaches of the tidal Columbia River from 172 to Bonneville (CR rkm 234).

The historical and modern models have similar run parameters. The water in the domain representing the coastal ocean is set to $15^{\circ} \mathrm{C}, 31$ parts per thousand (ppt) salinity, and $1000 \mathrm{kgm}^{-3}$ density and represents the average salinity on the Oregon coasts in the months of June and July. The river discharge from the Willamette River and Columbia River is set to $20^{\circ} \mathrm{C}, 0$ ppt salinity, and $1000 \mathrm{kgm}^{-3}$ density, representative of average values in the month of June. Turbulent energy is assumed to be transported laterally, with the background horizontal eddy viscosity and eddy diffusivity set to $10 \mathrm{~m}^{2} \mathrm{~s}^{-1}$ and $1 \mathrm{~m}^{2} \mathrm{~s}^{-1}$ respectively. A time of step of 0.5-1.0 minute was used depending on the model run. Both the modern and historical models use a single vertical layer. Since the river is energetic 
and I am interested in flood conditions, the assumption of well mixed conditions is reasonable. A depth variable Chézy coefficient is applied (see Appendix A). 


\section{Historical Grid}
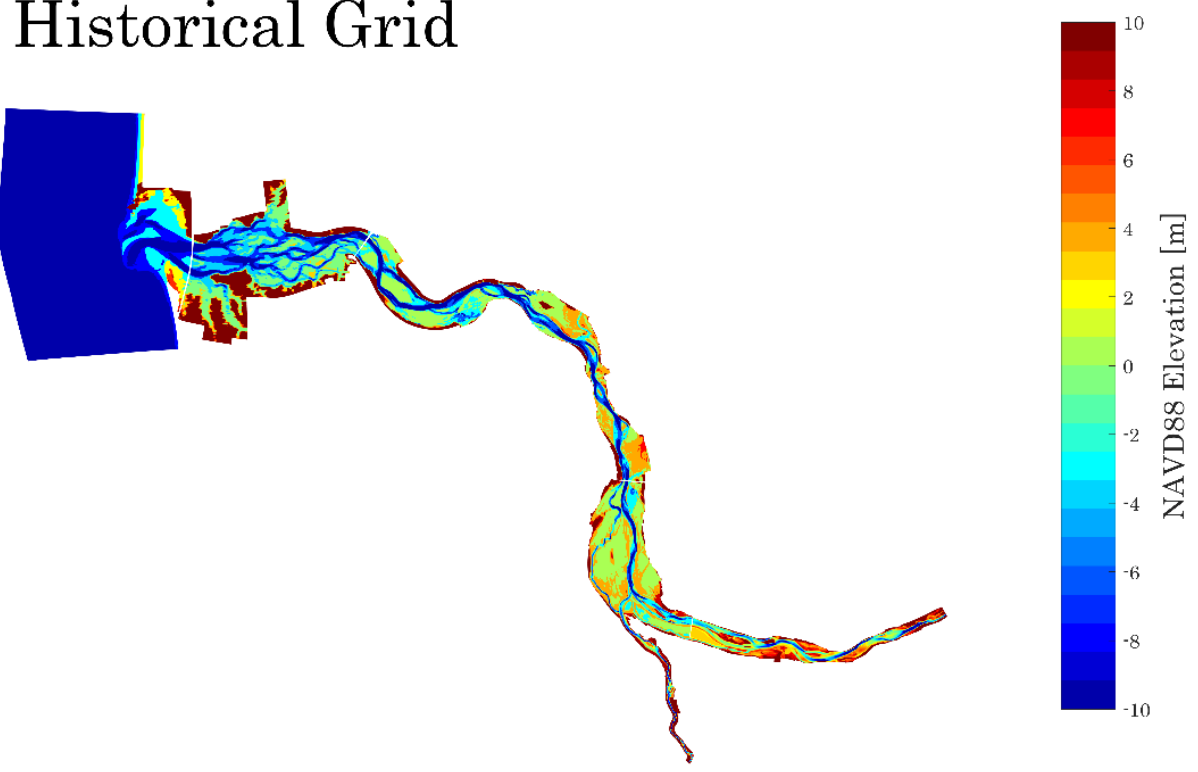

\section{Modern Grid}
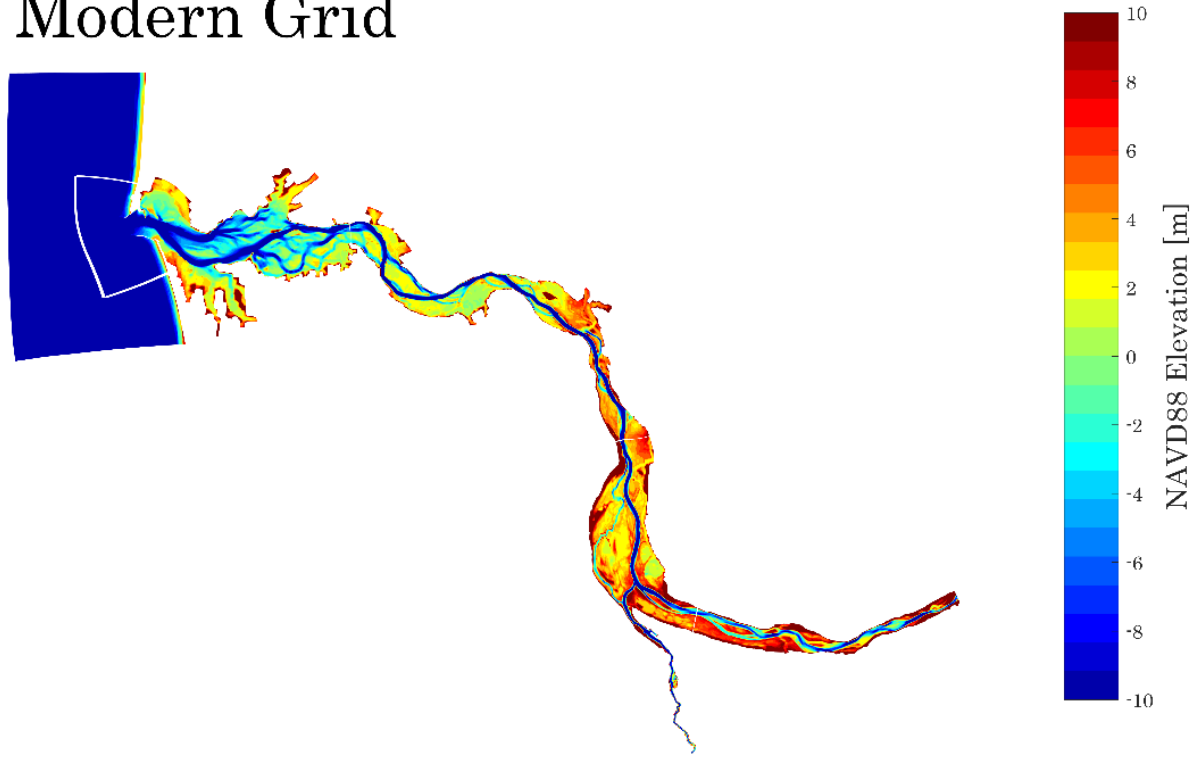

Figure 3.3: Model depth for historical model and modern. 
Table 3.4: Tidal constituents for historical model at the ocean boundary

\begin{tabular}{ccc|ccc}
\hline \multicolumn{3}{c|}{ Southwest } & \multicolumn{3}{c}{ Northwest } \\
Constituent & Amplitude $(\mathrm{m})$ & Phase $\left({ }^{\circ}\right)$ & Constituent & Amplitude $(\mathrm{m})$ & Phase $\left({ }^{\circ}\right)$ \\
\hline M2 & 0.890 & 232.57 & M2 & 0.896 & 232.89 \\
\hline S2 & 0.248 & 259.63 & S2 & 0.252 & 260.48 \\
N2 & 0.187 & 206.50 & N2 & 0.190 & 207.44 \\
K2 & 0.066 & 249.86 & K2 & 0.067 & 251.34 \\
K1 & 0.426 & 240.20 & K1 & 0.426 & 239.74 \\
O1 & 0.265 & 224.60 & O1 & 0.263 & 224.58 \\
P1 & 0.131 & 235.96 & P1 & 0.131 & 236.05 \\
\hline Q1 & 0.047 & 213.58 & Q1 & 0.047 & 214.40 \\
\hline
\end{tabular}

Table 3.5: Tidal constituents for modern model at the ocean boundary

\begin{tabular}{ccc|ccc}
\hline & Southwest & & \multicolumn{3}{c}{ Northwest } \\
\hline Constituent & Amplitude $(\mathrm{m})$ & Phase $\left(^{\circ}\right)$ & Constituent & Amplitude (m) & Phase $\left({ }^{\circ}\right)$ \\
\hline M2 & 0.883 & 231.4 & M2 & 0.889 & 232.2 \\
S2 & 0.247 & 258.8 & S2 & 0.253 & 260.2 \\
N2 & 0.187 & 206.0 & N2 & 0.190 & 207.3 \\
\hline K2 & 0.066 & 249.6 & K2 & 0.067 & 251.3 \\
K1 & 0.424 & 239.6 & K1 & 0.428 & 239.5 \\
O1 & 0.264 & 224.2 & O1 & 0.264 & 224.3 \\
\hline P1 & 0.131 & 235.4 & P1 & 0.131 & 236.0 \\
Q1 & 0.047 & 213.6 & Q1 & 0.047 & 214.4 \\
\hline
\end{tabular}

\subsubsection{Calibration}

The historical and modern models were calibrated to reproduce tidal constituents along the channel during low-flow conditions and to reproduce mean water level, tide range, mean high water, and mean low water in Portland during a variety of flow conditions (Tables $3.6 \&$ 3.7). Small-scale and sub-grid scale roughness elements such as vegetation in the floodplain, debris such as log-jams, or small-scale morphodynamical features are known to affect frictional drag (e.g., Arcement Jr. \& Schneider, 1989). To account for increased floodplain drag, I used a depth dependent roughness parameterization in which the Chézy friction coefficient varies depending on whether it is above or below Mean 
Lower Low Water. A similar approach has been used before to model tidal amplification and asymmetry (e.g., Nicolle \& Karpytchev, 2007). During calibration (section 4.1), I first considered low-river discharge conditions and calibrated the historical model to match September-October 1877 tides and the modern model to reproduce August-September 2005 tides. Next, I altered floodplain friction until the rating curve for water level vs. flow matches measurements to within $10 \%$ (section 4.2). My simplified approach effectively assigns one roughness value to vegetation in each domain, and provides insight into how resistant to flow the historical floodplain was.

In both the historical and modern models, the river channels have lower roughness - as indicated by a higher Chézy coefficient $\left(\mathrm{m}^{1 / 2} \mathrm{~s}^{-1}\right)$ - than the floodplains, and the upstream river channels have higher roughness (lower Chézy coefficients) than the estuary. In the modern model, channel roughness ranges from 55-96, compared to $25-50$ for the historical model. Within the estuary in the modern model, a low roughness (large Chézy) of 96 was used, to account for the reduction in friction caused by salinity (see Giese \& Jay, 1989). In the historical estuary, a Chézy roughness of 50 was used. The larger roughness in the historical channel likely has some basis in fact. Compared to the modern channel, sand waves and other features were not regularly dredged. Moreover, the annual reports of the US Army Corps regularly described shifting sand-bars at the mouths of tributary rivers such as the Willamette and Cowlitz, as well as at the estuary mouth, features that may not be fully represented in the historical bathymetry. Finally, the shallower depth likely meant that salinity intrusion was less, which causes the effective friction to increase (Giese \& Jay, 1989). I note that the roughness may also compensate somewhat for any 
inaccuracies in the historical bathymetry and datum; for example, since the bathymetry is a composite of different surveys between 1868 and 1901, it is possible that conditions changed over time. These observations reinforce the need to use historical data to validate the model.

\subsubsection{Simulations}

Many numerical simulations were run to quantify the landward progression of the tide, upstream water levels, and the interaction between tides and river discharge (Tables 3.6 and 3.7). Constant discharge simulations were used to estimate the equilibrium response of water levels to stationary forcing. In addition, the response of both the modern and historical models to a large spring freshet was simulated by applying a Gaussian hydrograph (standard deviation $(\sigma)=30$ days) with a duration of 179 days (Mar. $4-$ Aug. $30,2005)$, a baseline amplitude of $2.5 \times 10^{3} \mathrm{~m}^{3} \mathrm{~s}^{-1}$, and a peak amplitude of $25 \times 10^{3} \mathrm{~m}^{3} \mathrm{~s}^{-1}$. This peak discharge, though typically not observed in the modern system, was exceeded five times between 1858 and 1894 and is approximately representative of the 1880 spring freshet.

Table 3.6: Simulations run on the historical model

\begin{tabular}{lccc}
\hline Run Type & Columbia River discharge & Willamette River discharge & Duration \\
\hline tidal decay & The Dalles estimated & Portland estimated & Aug $31-$ Oct 18,1877 \\
\hline water level & $2,500 \mathrm{~m}^{3} \mathrm{~s}^{-1}$ constant & $250 \mathrm{~m}^{3} \mathrm{~s}^{-1}$ constant & Apr $11-$ Nov 11,1876 \\
\hline Water level & $5,000 \mathrm{~m}^{3} \mathrm{~s}^{-1}$ constant & $250 \mathrm{~m}^{3} \mathrm{~s}^{-1}$ constant & Apr $11-$ Nov 11,1876 \\
\hline water level & $10,000 \mathrm{~m}^{3} \mathrm{~s}^{-1}$ constant & $250 \mathrm{~m}^{3} \mathrm{~s}^{-1}$ constant & Apr $11-$ Nov 11,1876 \\
\hline water level & $15,000 \mathrm{~m}^{3} \mathrm{~s}^{-1}$ constant & $250 \mathrm{~m}^{3} \mathrm{~s}^{-1}$ constant & Apr $11-$ Nov 11,1876 \\
\hline water level & $20,000 \mathrm{~m}^{3} \mathrm{~s}^{-1}$ constant & $250 \mathrm{~m}^{3} \mathrm{~s}^{-1}$ constant & Apr $11-$ Nov 11,1876 \\
- water level & $25,000 \mathrm{~m}^{3} \mathrm{~s}^{-1}$ constant & $250 \mathrm{~m}^{3} \mathrm{~s}^{-1}$ constant & Apr $11-$ Nov 11,1876 \\
\hline water level & $30,000 \mathrm{~m}^{3} \mathrm{~s}^{-1}$ constant & $250 \mathrm{~m}^{3} \mathrm{~s}^{-1}$ constant & Apr $11-$ Nov 11,1876 \\
- flood pulse & Gaussian $25,000 \mathrm{~m}^{3} \mathrm{~s}^{-1}$ max & $250 \mathrm{~m}^{3} \mathrm{~s}^{-1}$ constant & Feb $17-$ Oct 19,2005 \\
\hline
\end{tabular}


Table 3.7: Simulations run on the modern model

\begin{tabular}{llcc}
\hline Run Type & Columbia River discharge & Willamette River discharge & Duration \\
\hline tidal decay & Bonneville measured & Portland measured & Aug 31-Oct 18, 1877 \\
\hline water level & $2,500 \mathrm{~m}^{3} \mathrm{~s}^{-1}$ constant & $250 \mathrm{~m}^{3} \mathrm{~s}^{-1}$ constant & Apr 11 - Aug 1, 2005 \\
\hline water level & $5,000 \mathrm{~m}^{3} \mathrm{~s}^{-1}$ constant & $250 \mathrm{~m}^{3} \mathrm{~s}^{-1}$ constant & Apr 11 - Aug 1, 2005 \\
\hline water level & $7,500 \mathrm{~m}^{3} \mathrm{~s}^{-1}$ constant & $250 \mathrm{~m}^{3} \mathrm{~s}^{-1}$ constant & Apr 11 - Aug 1, 2005 \\
\hline water level & $10,000 \mathrm{~m}^{3} \mathrm{~s}^{-1}$ constant & $250 \mathrm{~m}^{3} \mathrm{~s}^{-1}$ constant & Apr 11 - Aug 1, 2005 \\
\hline- water level & $12,500 \mathrm{~m}^{3} \mathrm{~s}^{-1}$ constant & $250 \mathrm{~m}^{3} \mathrm{~s}^{-1}$ constant & Apr 11-Aug 1, 2005 \\
\hline water level & $15,000 \mathrm{~m}^{3} \mathrm{~s}^{-1}$ constant & $250 \mathrm{~m}^{3} \mathrm{~s}^{-1}$ constant & Apr 11 - Aug 1, 2005 \\
\hline water level & $25,000 \mathrm{~m}^{3} \mathrm{~s}^{-1}$ constant & $250 \mathrm{~m}^{3} \mathrm{~s}^{-1}$ constant & Apr 11 - Aug 1, 2005 \\
\hline flood pulse & Gaussian $25,000 \mathrm{~m}^{3} \mathrm{~s}^{-1}$ max & $250 \mathrm{~m}^{3} \mathrm{~s}^{-1}$ constant & Feb 17 - Oct 19, 2005 \\
\hline
\end{tabular}

\subsubsection{Interpretation}

The tidally-averaged momentum and mass balance in open channel flow is approximated using the St. Venant equations (Cunge et al., 1980), under the assumption that flow is sectionally integrated, density is constant, and that the vertical pressure distribution is hydrostatic:

$$
\begin{aligned}
\frac{1}{g} \frac{\partial u}{\partial t}+\frac{u}{g} \frac{\partial u}{\partial x}+\frac{\partial h}{\partial x} & =S_{O}-\frac{\tau_{0}}{\rho g R}, \\
\frac{\partial Q}{\partial t}+b \frac{\partial h}{\partial t} & =0
\end{aligned}
$$

On the left-hand side of Equation 3.1, $g$ is gravitational acceleration, $u$ is along channel velocity, $t$ is the time scale, $x$ is the along-channel direction, and $h$ is the elevation above mean surface elevation. The left-hand side of Equation 3.1 is balanced by the difference between the surface slope, $S_{o}$, and the friction slope, $S_{f}$, which is a function of the water density, $\rho$, the bed stress, $\tau_{0}$, and the hydraulic radius, $R$. The hydraulic radius, $R$, is approximately equal to the depth in a wide and relatively shallow river such as the Columbia River. In Equation 3.2, $Q$ is the along channel discharge, and $b$ is the channel 
width. As key parameters such as bed friction and depth change, the relative magnitude of each term in the equation changes, leading to measureable differences in the slope, phase speed, and dispersion of a flood wave. To help interpret and understand how altered bathymetry and bed friction have changed river slope and flood waves, I therefore use model results to estimate terms in Equation 3.1 (see Results).

Variations in $d h / d x$ (Equation 3.1) over time must be balanced by changes to the friction slope, $S_{f}$. The friction slope can depend on many factors, but in the simplest case, friction relates directly to the velocity and Chézy roughness, such that a decrease in roughness (higher Chézy coefficient) causes a decrease in the friction slope.

$$
\tau=\frac{\rho u^{2}}{C}
$$

In Equation 3.3, $\tau$ is the bed stress, $C$ is the Chézy friction coefficient, $\rho$, is the water density, and $u$ is the channel velocity.

Jay et al. (2016) developed a modified rating curve to predict how water levels in the LCRE respond both to river discharge and to the time-varying frictional interaction of river flow and oceanic tides. Applied to the water level series in Portland, I must include terms to account for water level variations caused by flow from the Willamette River $\left(Q_{W R}\right)$ and the Columbia River. Hence, the Jay et al. (2016) equation for water level (WL) becomes:

$$
W L=a_{0}+\underbrace{a_{1}\left(Q_{W R}\right)^{m 1}}_{\begin{array}{c}
\text { Willamette } \\
\text { River }
\end{array}}+\underbrace{a_{2}\left(Q_{T D}\right)^{m 2}}_{\begin{array}{c}
\text { Columbia } \\
\text { River }
\end{array}}+\underbrace{a_{3}\left(\frac{T_{R A}^{2}}{\left(Q_{T D}+Q_{W R}\right)^{m 3}}\right)}_{\text {Tides }}
$$


Where the subscript $W R$ denotes the Willamette River, the subscript $T D$ refers to flow measurements at The Dalles, and $T_{R A}$ is the greater diurnal tide range at Astoria (OR), obtained from tide prediction software (Pawlowicz et al., 2002). The final term models the interaction between ocean tides and river discharge. The constant $a_{i}$ are coefficients, and $m_{i}$ are exponents, and are found by a non-linear regression technique that minimizes the error between water level observations and predictions.

While Equation (3.4) is sufficient to statistically model modern water levels, an additional term is needed in historical data to account for the roll-off in the rating curve that occurs once overbank flow is initiated. I model overbank flow with an additional power law term, such that

$$
W L=a_{0}+\underbrace{a_{1}\left(Q_{W R}\right)^{m 1}}_{\begin{array}{c}
\text { Willamette } \\
\text { River }
\end{array}}+\underbrace{a_{2}\left(Q_{T D}\right)^{m 2}}_{\begin{array}{c}
\text { Colimbia } \\
\text { River }
\end{array}}+\underbrace{a_{3}\left(\frac{T_{R A}^{2}}{\left(Q_{T D}+Q_{W R}\right)^{m 3}}\right)}_{\text {Tides }}+\underbrace{a_{4} \max \left(\frac{Q_{W R}+Q_{T D}}{Q_{C R T}} \mid 1\right)^{m 2}}_{\text {overbank flow term }}
$$

For flows below a critical discharge $\left(Q_{\text {Crit }}\right)$ of $20 \times 10^{3} \mathrm{~m}^{3} \mathrm{~s}^{-1}$, the "overbank flow term" reduces to the constant $a_{4}$; above the critical discharge, the term exerts an influence on the water level curve, and models the kink in the observed rating curve caused by historical overtopping (see Results). The coefficients and exponents for the modern period (Equation 3.4) are given in Table 3.8, and those for the historical period (Equation 3.5) are given in Table 3.9.

The most obvious difference in the coefficients between modern and historical periods is that $a_{0}$ was substantially larger historically (Tables 3.8 and 3.9). However, this is a byproduct of the inclusion of the overbank term. Below $20 \times 10^{3} \mathrm{~m}^{3} \mathrm{~s}^{-1}$ discharge in the historical model, the overbank term simply reduces to the coefficient $a_{4}$. Under these 
conditions, the constant term is -0.12 and is smaller than modern MWL. The second difference, is that the modern flow exponents for the Columbia River and Willamette River, $m_{1}$ and $m_{2}$, are larger than the historical flow exponents.

Table 3.8: Modern coefficients and exponents for tidal datums at Morrison Bridge (1998-2008)

\begin{tabular}{llll|ll}
\hline Coefficient & LLW & MWL & HHW & Exponents & \\
\hline a0 & -1.06288 & -0.652115 & 0.132244 & $\mathrm{~m} 1$ & 0.95 \\
\hline a1 & 0.655633 & 0.59757 & 0.493093 & $\mathrm{~m} 2$ & 1.2 \\
\hline a2 & 0.21758 & 0.197587 & 0.174479 & $\mathrm{~m} 3$ & 0.7 \\
\hline a3 & 0.09608262 & 0.138429 & 0.2016 & & \\
\hline
\end{tabular}

Table 3.9: Historical coefficients and exponents for historical daily water level at Morrison Bridge

\begin{tabular}{cccc}
\hline & Coefficients & \multicolumn{2}{c}{ Exponents } \\
\hline $\mathrm{a} 0$ & 2.53 & $\mathrm{~m} 1$ & 0.45 \\
$\mathrm{a} 1$ & 0.48 & $\mathrm{~m} 2$ & 0.78 \\
\hline $\mathrm{a} 2$ & 0.83 & $\mathrm{~m} 3$ & 1.38 \\
$\mathrm{a} 3$ & 0.33 & & \\
$\mathrm{a} 4$ & -2.65 & & \\
\hline
\end{tabular}

\subsection{Results}

\subsubsection{Tides}

Analysis of tide records and model results suggests that semidiurnal and diurnal constituents were smaller historically than they are today over most of the LCRE. In the historical model, the semidiurnal $M_{2}$ amplitude peaked at $0.95 \mathrm{~m}$ at $\mathrm{rkm} 25$ and dropped steadily up to rkm 165, where a more precipitous drop in amplitude occurred (Figure 3.4). In the modern model, $M_{2}$ amplitude also peaks near rkm 25, with an amplitude $(1.03 \mathrm{~m})$ that is $8.4 \%$ higher than in the historical model. $M_{2}$ amplitude then remains nearly constant for 25 kilometers upstream to Wauna, and decreases steadily thereafter. The largest difference 
in $M_{2}$ between historical and modern simulations occurs at rkm 61 (Figure 3.4). Both models show a precipitous decrease in tide magnitudes near the confluence with the Willamette River, but at slightly different locations (rkm 165 historically, and rkm 170 in the modern model). Reasons include: a) an abrupt change in channel depth immediately downstream of Vancouver, with a location that is slightly different in the modern model due to the Port of Vancouver/Portland, b) an increase in roughness further landward, due to a lack of dredging (modern system) and c) the junction with the Willamette River and the historical bar that formed there.

Similar to the $M_{2}$ tide, the $S_{2}$ tide is amplified at the entrance, likely due to bathymetric convergence. Also similar to the $M_{2}$ tide, the $S_{2}$ tide is also damped more heavily in the historical model than the modern model (Figure 3.4). The $S_{2}$ tide has a peak amplitude of $0.255 \mathrm{~m}$ at around rkm 25 in the historical model, similar to $M_{2}$. In the modern model, the peak amplitude is larger $(0.346 \mathrm{~m})$ and peaks further upstream (rkm 35). Like $M_{2}$, the $S_{2}$ amplitude steadily decreases upstream of the amplitude peak until there is a large drop in amplitude near Vancouver (historical - rkm 165, modern - rkm 170). The $K_{l}$ tide is also damped more in the historical model than the modern model. In the historical model the $K_{l}$ peak amplitude is $0.31 \mathrm{~m}$, compared to $0.41 \mathrm{~m}$ in the modern model. The $O_{l}$ tide, conversely, has similar behavior in the historical and modern model. The $O_{l}$ tide has an amplitude of $0.27 \mathrm{~m}$ at the entrance of the channel in both the historical and modern models.

For low flow conditions, the root mean square error (RMSE) between measured and modeled $M_{2}$ tides was $0.055 \mathrm{~m}$ and $0.057 \mathrm{~m}$ across all gauge stations for the historical and modern model, respectively (Tables $2 \& 3$ ). The difference between modeled and 
measured constituents was slightly larger in the historic model than the modern model (Table 3.10), likely reflecting the different time period of harmonic analysis of $19^{\text {th }}$ century data, but also possibly occurring due to the greater probability of timing and transcription errors in historic field data (see e.g. Zaron \& Jay, 2014). I note that the available late $19^{\text {th }}$ and early $20^{\text {th }}$ century bathymetric and water level measurements are not synoptic. They were collected over a 40-year period, during which time large modifications were made to the channel and floodplain. Thus, the modeled topography and bathymetry represent a system that never actually existed in the form modeled, but which is typical for the time period and which represents historical processes.

Table 3.10: RMSE errors [m] for the four largest tidal constituents in the spatial calibration of the historical and modern Model.

\begin{tabular}{ccc}
\hline & Historical & Modern \\
\hline M2 & 0.055 & 0.057 \\
\hline S2 & 0.041 & 0.024 \\
K1 & 0.041 & 0.020 \\
\hline O1 & 0.016 & 0.007 \\
\hline
\end{tabular}



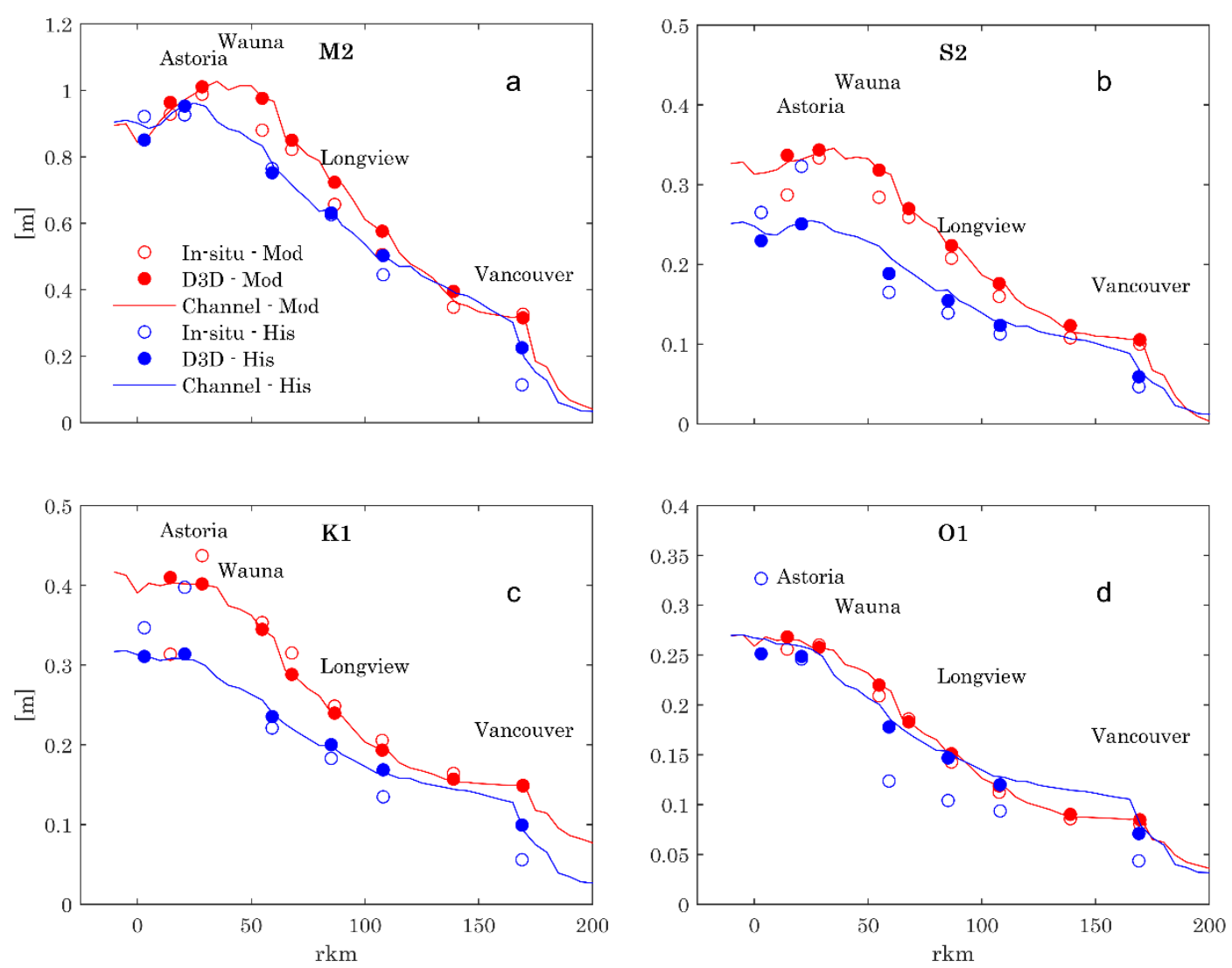

Figure 3.4: Spatial calibration of a low flow event.

Open dots represent in-situ measurements, filled dots represent model outputs (D3D - Delft3D) for stations. Solid line presents model output in river channel. (a) M2 (b) S2 (c) K1 (d) O1

\subsubsection{Changes in Mean Water Level and Discharge}

Mean water levels in the Portland/Vancouver area have changed substantially over the last 150 years, particularly between April and September (Figure 3.5). For example, water levels in June from 1879 to 1898 averaged more than 3m higher than during 1989 to 2008 (Figure 3.5c). A large part of the change is attributed to the changing hydrograph at The Dalles (Figure 3.5a), which produces a smaller backwater effect in Portland during the 
seasonal spring freshet than before the onset of flow regulation ca. 1970. Conversely, increased Columbia River discharge during winter months has slightly increased median water levels. Nonetheless, a portion of the reduced spring levels - as I show below - is likely attributable to a reduced river slope, such that the same river discharge results in a lower mean water level today than in the past (as also suggested in Jay et al., 2010). The Willamette River hydrograph has also changed over time and influences the seasonality of mainstem Columbia River and Willamette River water levels to a lesser degree (Figure $3.5 b$ ), with a decrease in early spring flows (February to April) and an increase in summertime and early autumn flows (August to October). The Willamette changes likely influence the seasonality of average water-levels in Portland; the regression coefficients in Table 3.9 suggest a change of $0.05-0.18 \mathrm{~m}$ during spring for the mean water level hydrograph. Since mean Willamette flows are an order of magnitude less than the Columbia River, effects of changed Willamette flow on mean water level are restricted to the tidal Willamette between Kelly Point and Oregon City (Figure 3.5b; see also map on Figure 3.1). 

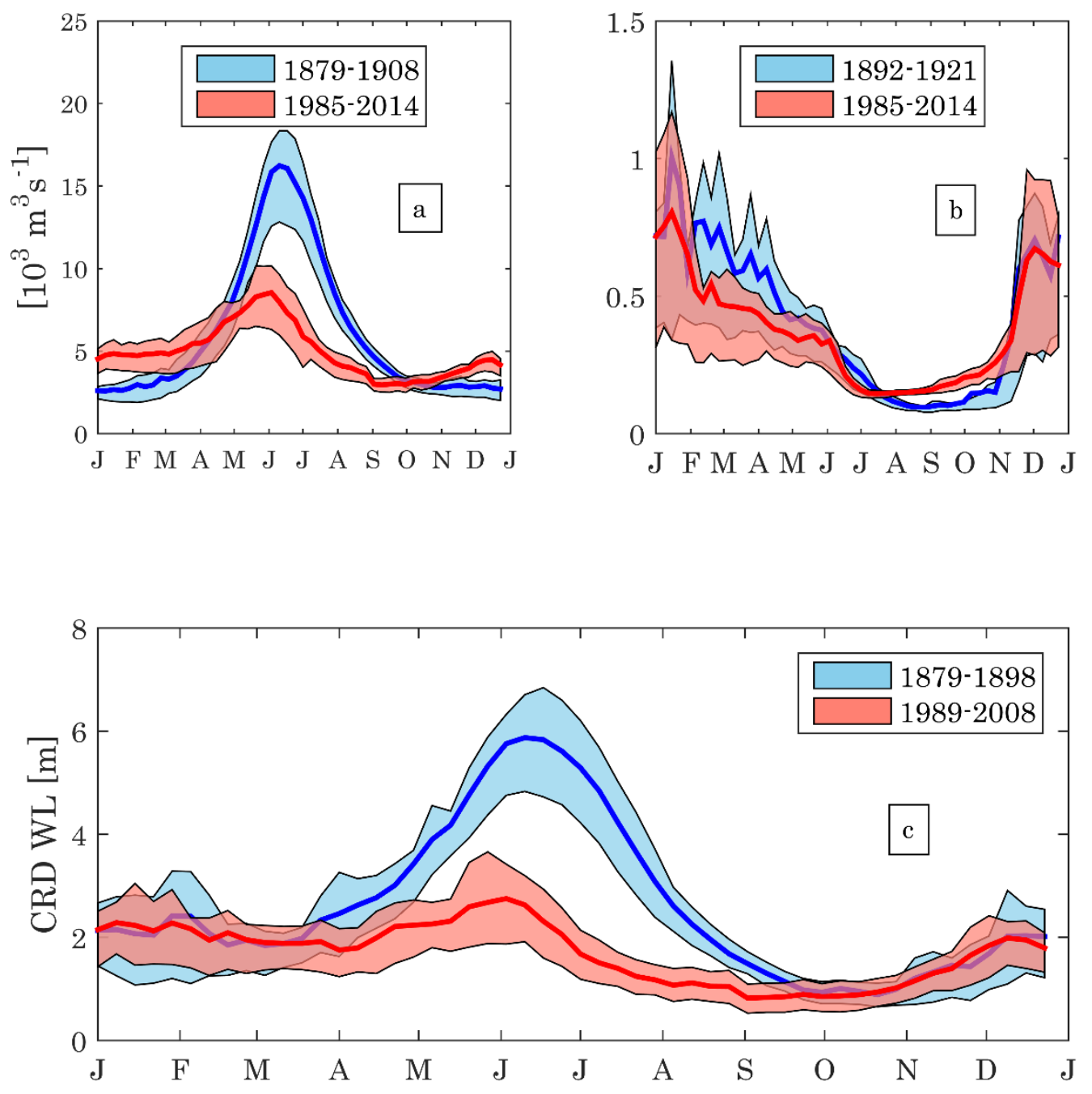

Figure 3.5: Comparison of Modern and Historical water level and discharge.

solid lines are mean, fill area is $25-75 \%$ quantile (a) Columbia River weekly mean discharge at The Dalles (b) Willamette River weekly mean discharge at Albany (c) Willamette River mean weekly water level at Morrison Bridge in Portland.

A rating curve for the modern and historical period is shown in Figure 3.6. The historical rating curve and nonlinear regression is for daily water level from 1879-1898 and is restricted to Willamette River discharge below $500 \mathrm{~m}^{3} \mathrm{~s}^{-1}$, or total discharge above $20 \times 10^{3} \mathrm{~m}^{3} \mathrm{~s}^{-1}$ total discharge. A comparison of the modern and historical stage vs. flow 
rating curves (Figure 3.6) during periods of low Willamette River flow demonstrates how system dynamics have changed over the past century. Most obviously, historical peak flows are much larger than modern peak flows, resulting in a larger range of flowconditions and overall larger backwater magnitudes. Moreover, the modern curve lies below the historical curve for all flows from $5-15 \times 10^{3} \mathrm{~m}^{3} \mathrm{~s}^{-1}$; therefore, the same river flow produces a lower river stage today ( 0.5 to $1 \mathrm{~m}$ lower) than historically, depending on discharge (see also Jay et al., 2010 for a similar result in Vancouver, WA). Also, the modern curve is slightly concave up, whereas the historical curve is concave down. The shape of the historical curve reflects the effect of overbank flow; as water levels exceeded the natural levee height, water spread laterally and the rate of change in water depth per unit increase in discharge $(d h / d Q)$ decreased. If the modern rating curve is assumed to be correct at high flows, it would intersect and exceed the historical rating curve around $20 \times 10^{3} \mathrm{~m}^{3} \mathrm{~s}^{-1}$. If this were the case, modern flood control measures and navigation improvements would actually lead to larger water levels during floods, as has been suggested for the Mississippi River (e.g., Munoz et al., 2018). Not enough data are available to statistically evaluate the modern system response above $15 \times 10^{3} \mathrm{~m}^{3} \mathrm{~s}^{-1}$, thus, it is unclear, without modeling, whether such an extrapolation to larger flows is valid. Hence, I next use modeling results to evaluate whether a 'cross-over' will occur or whether the modern system water levels are always below historical norms. 


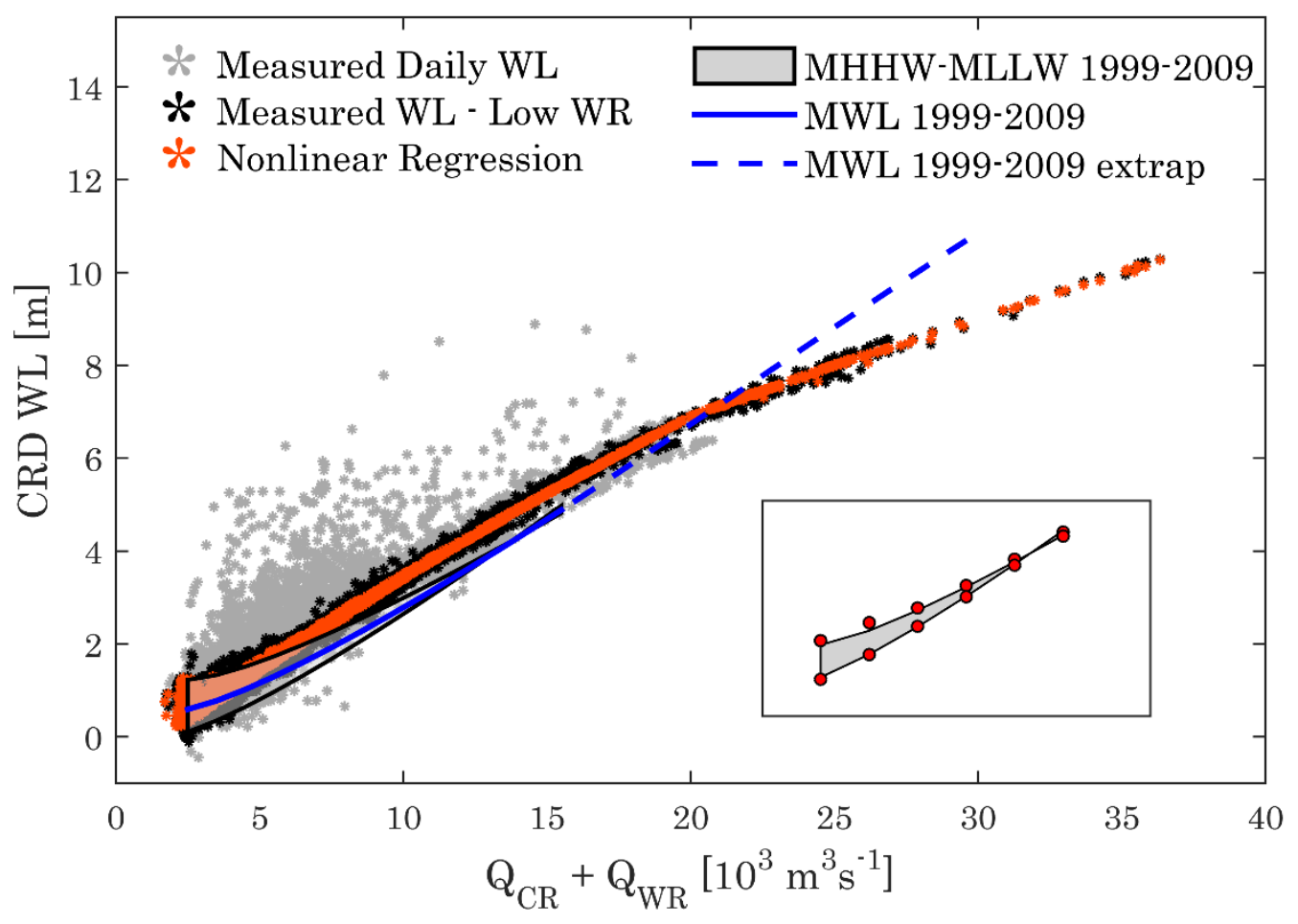

Figure 3.6: Comparison of historical and modern rating curve in Portland.

Rating curve of water level at Stark Street/Morrison Bridge 1879-98, The inset reproduces the LLW and HHW bounds for the modern period that are shown at the left around the mean MWL curve (blue), to highlight the concave-up shape.

\subsubsection{Modeled Flood Properties}

Simulations confirm the qualitative expectation that inundation patterns due to a $25 \times 10^{3} \mathrm{~m}^{3} \mathrm{~s}^{-1}$ flood occurring over a six-month period are different under modern and historical conditions (Figure 3.7), as might also be predicted by the rating curves (Figure 3.6). Interestingly however, results suggest that historical peak flood levels are similar to (and slightly larger than) modern flood levels in the Portland/Vancouver metro area, despite a greater areal extent of flooding in the historical model (Figure 3.7). Consequently, the cross-over predicted by extrapolating the rating curve in Figure 3.6 is not found in model results. However, the $0.5-1 \mathrm{~m}$ difference observed at low flows, and 
caused by a decrease in the modern slope during those conditions, has been largely erased. Thus, while levees included in the modern model prevent inundation of areas such as Sauvie Island (Figure 3.7), the resulting confinement of flow to the main channel (and decrease in off-channel storage) evidently increases water levels faster (larger $d h / d Q$ ) at elevated flows.

Historical Inundation

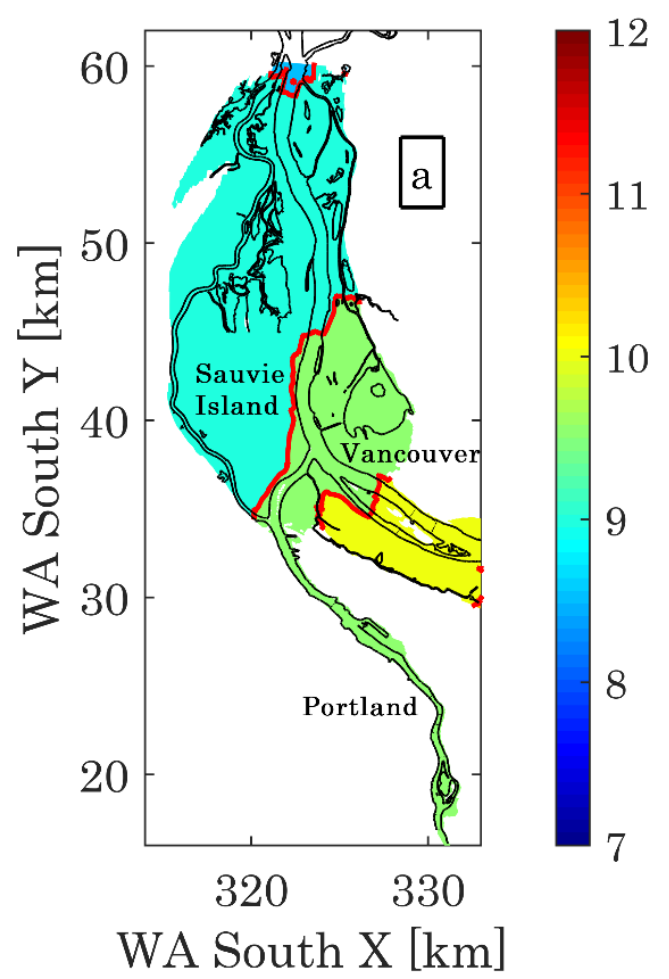

Modern Inundation

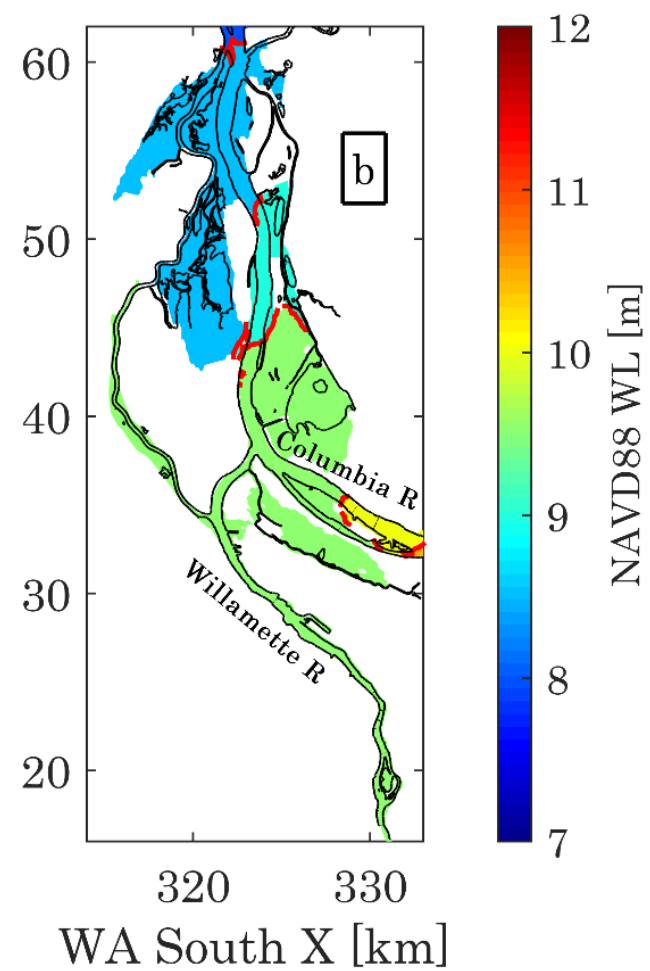

Figure 3.7: Inundation at the peak of the $25 \times 10^{3} \mathrm{~m}^{3} \mathrm{~s}^{-1}$ flood in the Portland/Vancouver metro area. (a) historical model and (b) modern model.

Contour maps overlaid with the modern coastline.

The difference in peak water level in the historical and modern models is spatially variable (Figure 3.8). Near the head of tides at Bonneville Dam, simulations suggest that historical water levels exceeded modern levels by as much as $2.6 \mathrm{~m}$. Closer to the 
Portland/Vancouver metro area, water levels in the historical model still exceed the modern model, but only by $0.1 \mathrm{~m}$. Within this geometrically constrained reach, a cross-over does occur at a much larger flow rate than is expected from extrapolation of the modern statistical model (Figure 3.6). At $30 \times 10^{3} \mathrm{~m}^{3} \mathrm{~s}^{-1}$, simulations show that the modern water levels in Portland would be $9.81 \pm 0.04 \mathrm{~m}$ elevation relative to CRD, which is approximately $0.5 \mathrm{~m}$ higher than the expected historical river stage at this discharge (Figure 3.9). Though this flow level has been exceeded only once in peak flow records extending back to the 1850s (USGS station 14105700), this observation does point out a vulnerability in the modern flood control system. Curiously, at $35 \times 10^{3} \mathrm{~m}^{3} \mathrm{~s}^{-1}$ discharge, equivalent to the June 1894 flood, simulations indicate that the modern water levels relax towards water levels and are about the same as historical water levels in Portland, approximately $10 \pm 0.04 \mathrm{~m}$ relative to CRD (Figure 3.9; see also Figure 3.6). Modern levee heights were built to withstand a flood close to 1894 levels; hence, once that level is reached, overbank flooding commences and the rating curve for modern flow changes. 

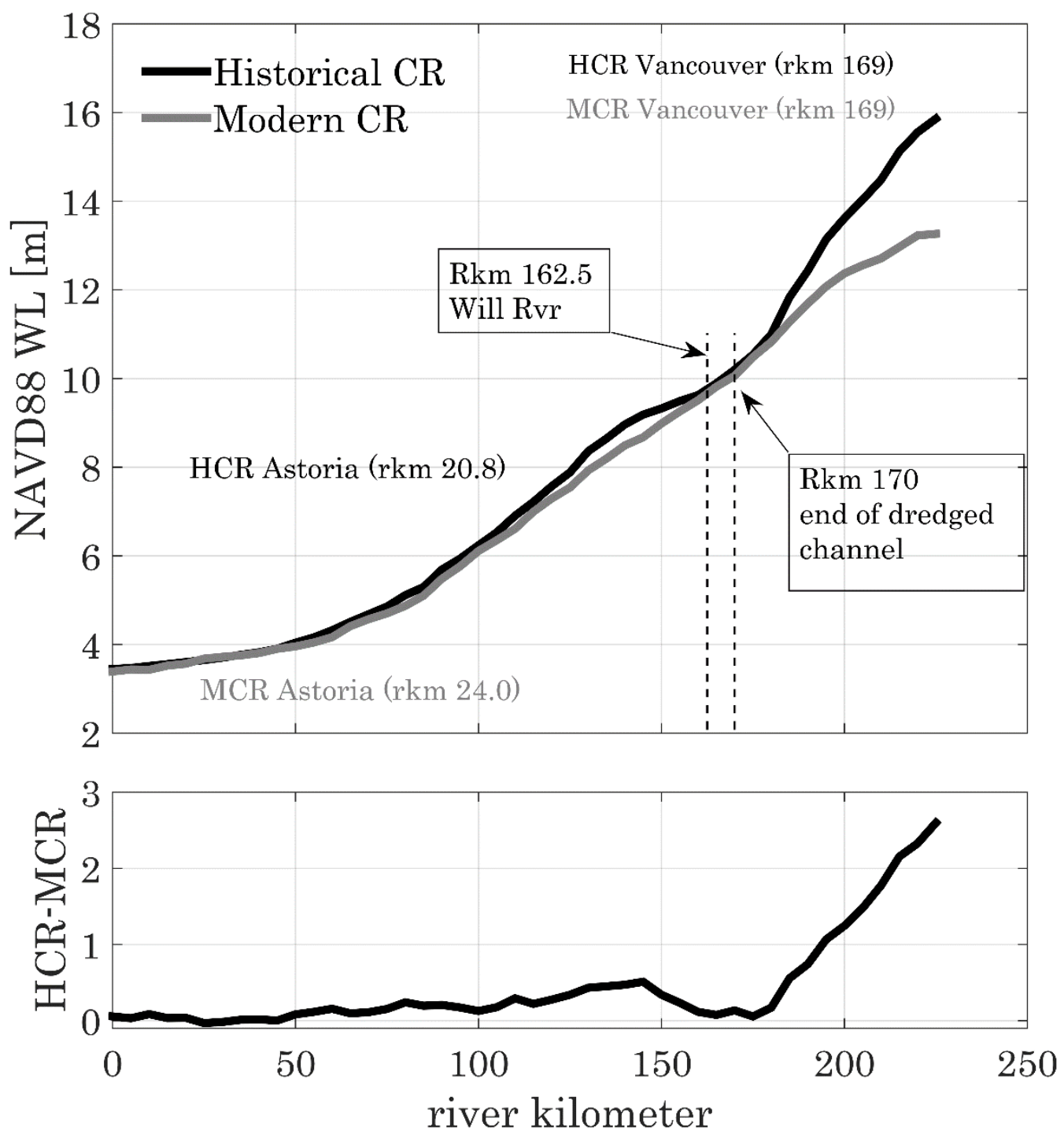

Figure 3.8: Peak total modeled water levels for 6 mo simulated freshet in the historical and modern model. 


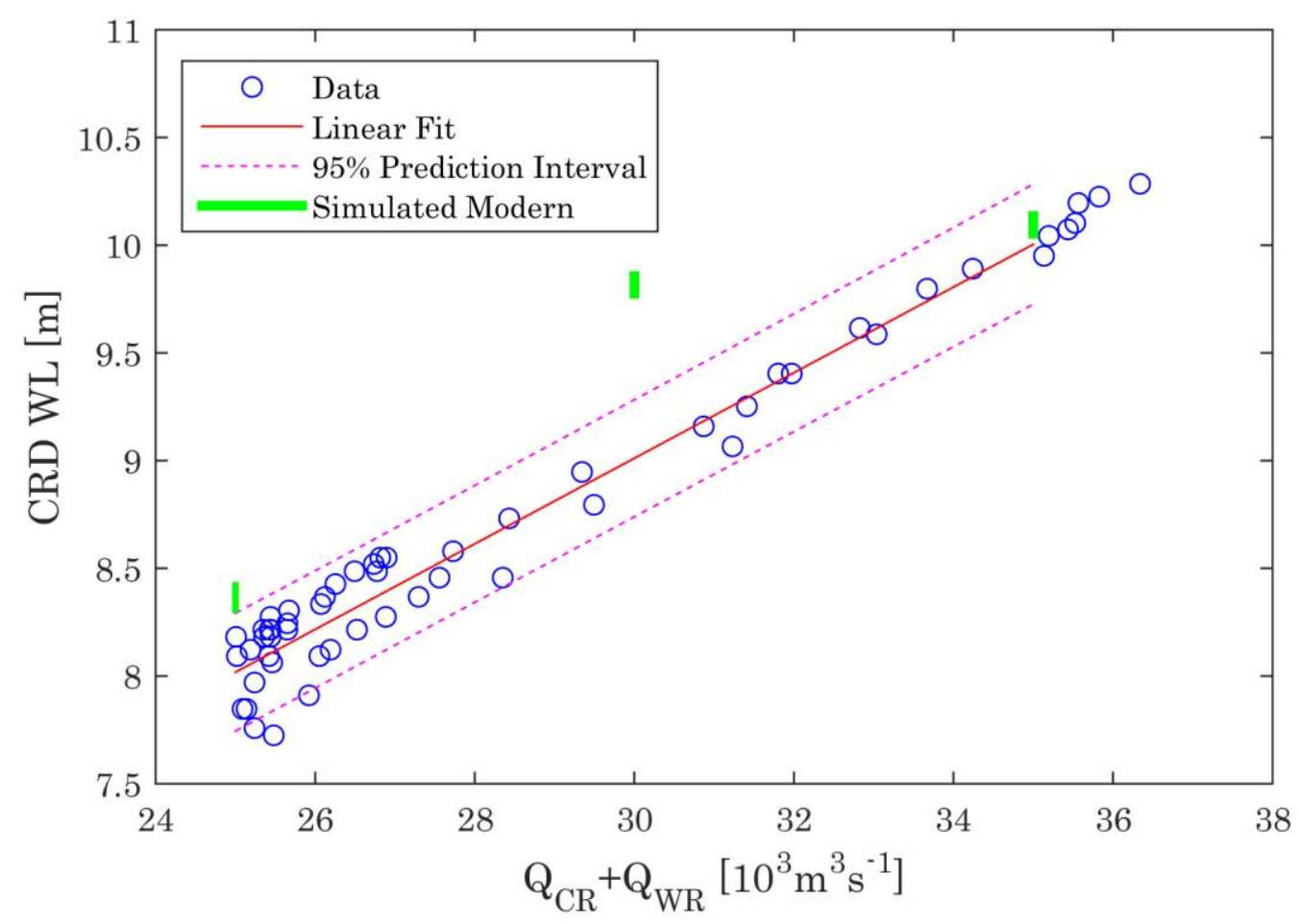

Figure 3.9: Morrison Bridge water levels (green lines) modern model $25-30-35 \times 10^{3} \mathrm{~m}^{3} \mathrm{~s}^{-1}$ constant flow simulations (blue dots) river stage measurements 1879-1898.

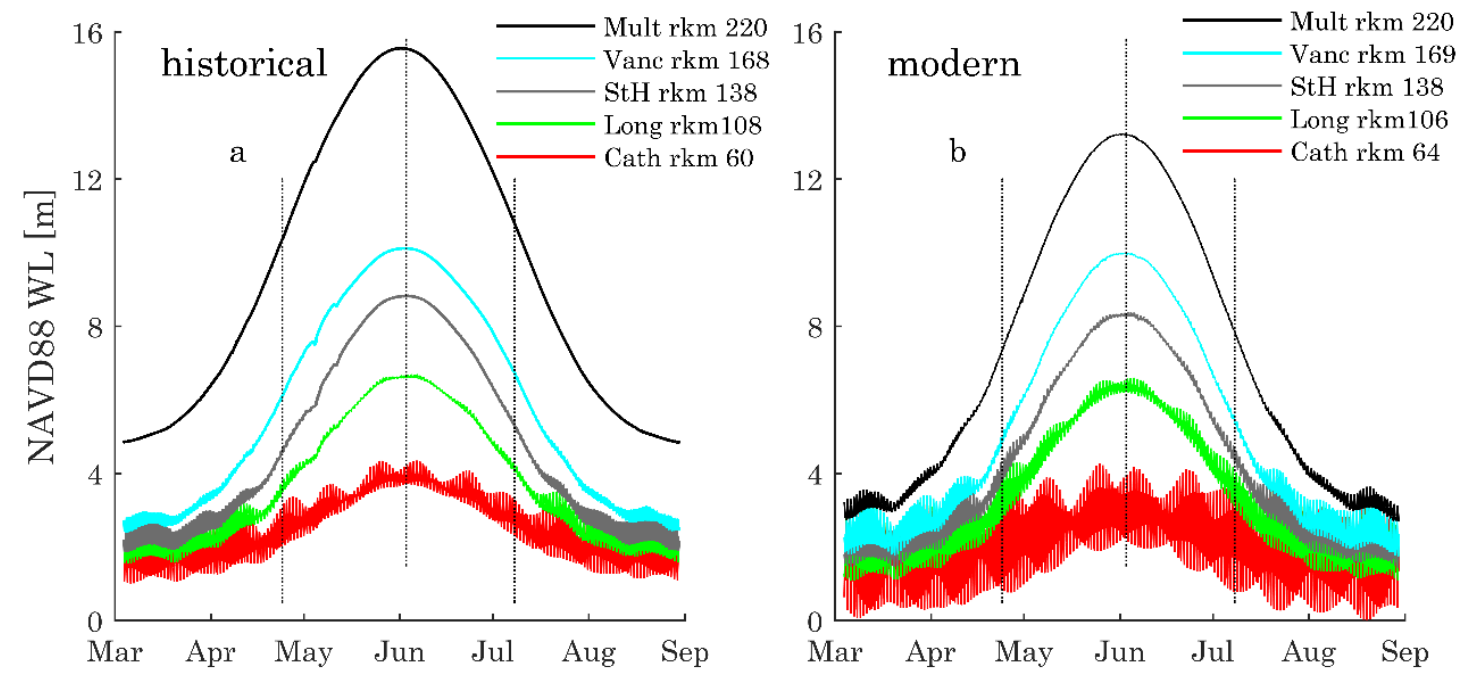

Figure 3.10: Peak water levels from the six-month normal distribution flood (a) historical model (b) modern model

(Mult. - Multnomah Falls, Vanc $=$ Vancouver, $\mathrm{StH}=$ St Helens, Long $=$ Longview, Cath $=$ Cathlamet $)$. 
Model results also suggest that tides were damped more under historical flood conditions than modern conditions (Figure 3.10). Hence, at the peak flow of a $25 \times 10^{3} \mathrm{~m}^{3} \mathrm{~s}^{-}$ ${ }^{1}$, tide range decreased to below $1 \%$ of values at the mouth at rkm 130 ; in the modern model, the tides intruded to rkm 160 before dipping below the $1 \%$ threshold. Despite the difference in tidal damping in the historical and modern models, the total water levels downstream of Longview during the $25 \times 10^{3} \mathrm{~m}^{3} \mathrm{~s}^{-1}$ freshet are similar (Figure 3.8). The contributions to peak water levels due to tides and discharge have been altered in the modern case, with a larger tidal range compensated by lower baseline water levels. At Longview (rkm 108) there is only a $0.09 \mathrm{~m}$ difference between historical and modern peak water levels for the $25 \times 10^{3} \mathrm{~m}^{3} \mathrm{~s}^{-1}$ flood $(6.69 \mathrm{~m}$ historically vs. $6.60 \mathrm{~m}$ today; see Figure 3.10). At the peak of the flood, the modern tidal range is $0.24 \mathrm{~m}$, compared to $0.05 \mathrm{~m}$ in the historical case. The drop in the baseline water level over the past 150 years at this flow rate is compensated by an increase in tidal range, which diminishes some of the flood control benefits of a deep channel. Farther downstream, in Cathlamet (rkm 60), peak water levels are much larger in the modern model, due to the increase in tide amplitudes since the $19^{\text {th }}$ century; differences in mean water level are relatively small, due the diminishing effect of river flow on water levels (Figure 3.10). The increased water levels around Cathlamet are driven by increases in the $M_{2}$ constituent, which are maximal around rkm 60 (Figure 3.4). In the estuary and lower tidal river, therefore, the spatial pattern of changed tide amplitudes is therefore quite significant in terms of flood risk, particularly since model results in other estuaries suggest that locations of large tide change are also regions of large changes to storm surge amplitudes (Familkhalili \& Talke, 2016). 


\subsubsection{Channel Dynamics}

To interpret water level trends, I note that diverse and sometimes conflicting changes have occurred over time. First, the channel and floodplain in the modern model are less rough than in the historical model (see Supplement). Initial evidence of the difference in roughness is seen in the calibration of the tidal phase progression, where the historical model required a lower Chézy roughness value in the channel and floodplain than the modern model. Further, an examination of the topographical survey sheets (Burke, 2010) shows more vegetated floodplain than is the case today. This interpretation is supported by the findings of Marcoe and Pilson (2017), who found that the since the late $19^{\text {th }}$ century $55 \%$ of the forested wetland and $68-70 \%$ of all wetlands have been lost. The larger historical bed roughness in both the channel and the floodplain produces a steeper surface slope and higher water levels at each point, for flows at and below $25 \times 10^{3} \mathrm{~m}^{3} \mathrm{~s}^{-1}$. Effectively, a larger pressure gradient was required to drive the same flow historically, compared to today (third term in Equation 3.1). Additionally, the effect of friction is smaller in the deeper modern channel (Figure 3.2), because depth-averaged frictional effects are inversely proportional to depth (section 3.3.6 and Equation 3.1).

Reduction in roughness and friction effects causes tidal ranges to increase, while at the same time reducing mean water levels. As a result, LLW has dropped, but only minor changes to HHW have occurred; this effect is particularly evident during low and moderate flows (see also Jay et al., 2010; Ralston et al., 2019). The largest increases to HHW occur where a maximum in $M_{2}$ change occurs; while a function of river flow, this occurs around rkm 60 (Figure 3.4). At high flows, modern levees constrain flow, limiting inundation but 
potentially increasing elevation in the main channel compared to historical conditions, since water cannot spread out laterally. Hence, several countervailing factors exist that can either decrease or increase modern water levels, compared to historical conditions. In locations in which overbank flow was once prominent (e.g., Figure 3.7), modern flow confinement tends to increase water levels during floods; where changes to lateral inundation are less extreme (such as upstream of Vancouver), frictional changes may be more important. Such opposing factors have led to different amounts of water level change in different reaches, as suggested by Figure 3.8.

Considering the issue from a kinematic point of view by considering the relationship between elevation and flow through a cross-section; $h=Q /(u b)$, where $h$ is the water surface elevation relative to the bed, $Q$ is river discharge, $b$ is width, and $u$ is mean channel velocity. Taking the derivative with respect to flow, I find that the rate of change in water level with an incremental change of flow $\left(\frac{d h}{d Q}\right)$ is:

$$
\frac{d h}{d Q}=\frac{1}{u b}-\frac{Q}{u^{2} b}\left(\frac{d u}{d Q}\right)-\frac{Q}{u b^{2}}\left(\frac{d b}{d Q}\right)
$$

where the first term on the right hand side is a constant for a given flow rate $(u)$ and geometry, and $\frac{d u}{d Q}$ and $\frac{d b}{d Q}$ are the rates of change of velocity and width, respectively, with an incremental change in flow. Since $\frac{d b}{d Q}$ has decreased (for high flows at and below $25 \times 10^{3}$ $\left.\mathrm{m}^{3} \mathrm{~s}^{-1}\right)$ in the modern model due to channelization and levee construction, the lhs term $\frac{d h}{d Q}$ must necessarily increase (i.e., the slope in the rating curve must increase), unless changes in sectionally averaged velocity (first and second terms on rhs) outweigh changes in width 
(third term on rhs). The flow velocity is governed by the momentum equation, and further analysis is required to assess which terms dominate.

Thus, I estimate terms in the St. Venant equations in finite difference form with model outputs. Spatial derivatives are estimated using a $\Delta x$ of $5 \mathrm{~km}$, and a $\Delta t$ of 10 minutes. The Columbia River Datum [CRD] (Hickson, 1912) is used to approximate the average historical bed slope $\left(S_{0}\right)$. The slope of the water level between two adjacent observation points, minus the estimated bed slope, approximates the water level gradient with respect to the bed slope $(\Delta h / \Delta x)$.

$$
\frac{1}{g} \frac{\Delta u}{\Delta t}+\frac{u}{g} \frac{\Delta u}{\Delta x}+\frac{\Delta h}{\Delta x}=S_{O}-S_{f}
$$

An analysis of the output from the simulations show that the first acceleration term $\left(\frac{1}{g} \frac{\Delta u}{\Delta t}\right)$ in Equation 3.7 is always negligible (see Supplement). The second acceleration term $\left(\frac{u}{g} \frac{\Delta u}{\Delta x}\right)$ is only significant near Beaver (rkm 87, see Figure 3.1) during the peak of the flood (see Supplement), and the momentum balance is usually between the pressure gradient $(\Delta h / \Delta x)$ and the difference of the bed slope and the friction slope $\left(S_{0}-S_{f}\right)$. If the acceleration terms are negligible compared to the other remaining terms (as here), the St. Venant equation reduces to the diffusive wave approximation.

$$
\frac{\Delta h}{\Delta x}=S_{O}-S_{f}
$$

Figure 3.11 shows tidally averaged ( 24.84 hours, $24 \mathrm{~h} 50 \mathrm{~m})$ water levels ( $1^{\text {st }}$ row), depth-averaged channel velocity ( $2^{\text {nd }}$ row), water level gradient ( $\left.\Delta h / \Delta x\right)$ (third row), and 
bed stress (fourth row) during rising water levels (1), peak water levels (2) and falling water levels (3).
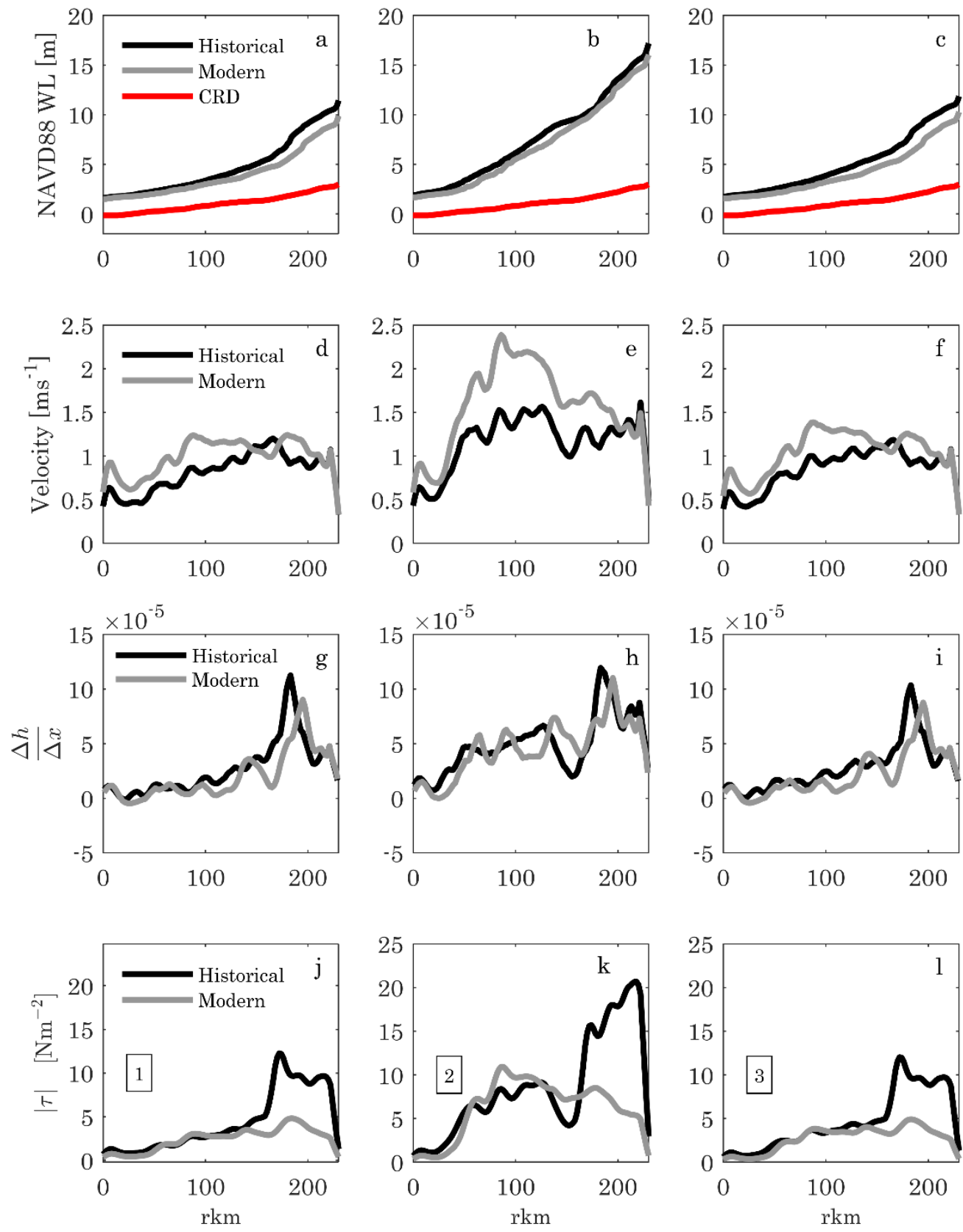

Figure 3.11: Tidally and depth averaged water level, channel velocity, water level gradient, and bed stress

Tidally and depth averaged water level (row 1), channel velocity (row 2), water level gradient (row 3), and bed stress (row 4), in the historical and modern model during three phases of the flood 1- rising limb, 2 peak, 3 - falling limb 
Results suggest that modern flows within the shipping channel have higher velocities than historical flows (Figure 3.11, second row, d-f). During all three phases of the flood, the velocity peaks at $\mathrm{rkm} 88$, near Beaver ( $\mathrm{rkm} 85)$. This is a relatively narrow section of the river and much of the historical floodplain in this area is now isolated by levees (see Supplement). Since the cross-section discharge is the same in both models, the lower channel velocity in the historical model means that the cross-sectional area must be larger. This is accomplished by floodplain inundation, which conveys some flow. This flow is relatively small, due to the high friction in the historical floodplain (modern currents would be larger, due to their larger Chézy coefficient).

Though the total water level drop between Portland and the ocean is similar in both models for the $25 \times 10^{3} \mathrm{~m}^{3} \mathrm{~s}^{-1}$ case, the spatial variability in the slope is different. In the historical model, during the peak of the flood $\Delta h / \Delta x$ decreases downstream of the Willamette confluence, likely due to the inundation of Sauvie Island (Figure 3.7). In the modern model, the isolation of the floodplain by levees affects water level gradients. For example, three small peaks in water level gradient occur near rkm 65, rkm 91, and rkm 139. The small peak at rkm 65 is likely caused by the isolation of the floodplain between Skamokawa and Wauna (see Figure 3.1 for placename locations). The second smaller peak at $\mathrm{rkm} 91$ is likely related to the isolation of the large floodplain near Beaver, (see Figure 3.1 and Supplement). The third smaller peak is likely related to channel convergence upstream of St. Helens (rkm 139) and isolation of the floodplain on the east bank of the Columbia River upstream of rkm 139 (see Figure 3.3 and Supplement). To summarize, the differences in water level gradients between the modern and historical models are 
related to changes in friction, channel depth, and floodplain inundation, mostly driven by the presence of flood control levees present in the modern model.

Higher velocity in the modern model (Figure 3.11, second row, d-f) during flood conditions works to increase bed stress, compared to the historical condition; by contrast, smaller roughness in the modern model tends to decrease bed stress (see Equation 3.3). My results suggest that during a $25 \times 10^{3} \mathrm{~m}^{3} \mathrm{~s}^{-1}$ flood, increased velocity and decreased roughness nearly compensate each other, producing similar water levels and surface gradients in both models. Hence, results show that during the rising and falling limbs of the flood modern and historical bed stress are nearly identical downstream of rkm 140 (Figure 3.11, bottom row, first and third panel, $\mathrm{j} \& \mathrm{l}$ ). During the peak flood, modern bed stress is slightly larger. Since the surface slope scales with $\tau / g h$ (Hoitink \& Jay, 2016), the larger modern depth compensates for the larger bed stress, producing the previously mentioned similarities in average slope.

Spatial variability in bed stress also occurs between the modern and historical models, reflecting flow confinement. In the modern model, during the peak of the flood there is a large peak in bed stress at rkm 86 near Beaver (Figure 3.1), exceeding the historical bed stress (Figure 3.11 bottom row, middle panel, k). This peak in bed stress corresponds to the peak in depth averaged channel velocity (Figure 3.11, second row, middle panel, e). Conversely, there is a large dip in historical bed stress at rkm 154 upstream of St Helens, OR (Figure 3.1), where the Columbia River flows past Sauvie Island (Figure 3.11, bottom row, middle panel, k). At this location, during the peak of the flood, there are also dips in the water level gradient and depth-averaged channel velocity (Figure 
3.11, second and third rows, middle panels, e \& h). It appears that the inundation of Sauvie Island in the historical model diffused the flood wave and lowered the channel velocity and bed stress.

\subsection{Conclusions}

Numerical simulations of hydrodynamics on $19^{\text {th }}$ century and modern bathymetry, and analysis of water levels records, are used to investigate the evolution of tidal and flood processes in the LCRE. Channel deepening and reduced hydraulic roughness have caused mean water levels to drop during low flow conditions, particularly upstream in the Portland/Vancouver metro area (0.5-1m less, depending on river flow; Figure 3.6). Hence, though peak annual water levels in Portland have dropped primarily due to decreased river flow (Figure 3.5), navigation improvements and diking play a significant role. At the same time that mean water levels have dropped, tide amplitudes have increased, with the largest increase in $M_{2}$ during low flow conditions observed upstream of Astoria, at rkm 61 (Figure 3.4). These results are explainable as the effect of increased depth and reduced roughness, which decreases the damping of long waves (see e.g., Friedrichs \& Aubrey, 1994). These same factors reduce the surface slope during low flow (e.g., Jay et al., 2010; Ralston et al., 2019).

The reduced mean water levels observed during low and moderate flow largely vanish during a high flow event, at least in the Portland/Vancouver area ( $\sim 0.1 \mathrm{~m}$ difference $)$. This occurs due to the increased channel velocity during modern, confined conditions, which acts to increase bed stress and surface slope. By contrast, historical flows overtopped the natural levees during large floods, reducing the channel velocity and 
providing large storage areas, both of which act to reduce the difference between historical and modern water levels, particularly in regions in which large floodplains exist (such as near Portland/Vancouver). At a larger discharge of $30 \times 10^{3} \mathrm{~m}^{3} \mathrm{~s}^{-1}$, modern water levels would be $\sim 0.5 \mathrm{~m}$ higher than historically in Portland/Vancouver, due to flow confinement. Once significant overbank flooding occurs in the modern model (around $35 \times 10^{3} \mathrm{~m}^{3} \mathrm{~s}^{-1}$ ), historical and modern water levels are again similar. While such flow levels have not occurred since 1894, the combination of sea level rise and predictions of increased precipitation and run-off due to climate change (Najafi \& Moradkhani, 2015) suggest that careful reassessment of system vulnerabilities is warranted. 


\section{Chapter 4: A Modeling Study of the February 1996 Willamette River Flood}

Over the course of the next century, it is expected climate-induced changes in runoff will result in a decrease of spring snowmelt floods, while the winter storm intensity may increase (Mote \& Salathé, 2010; Najafi \& Moradkhani, 2015). These changes underscore the need to understand winter rain and rain-on-rain snow events, and how they may be altered due to climate change and sea level rise. In order to understand the how climate change may alter extreme events, I modeled the February 1996 flood on the Willamette River. The February 1996 flood was a rain-on-snow event, with antecedent snowfall followed by warm, intense precipitation, causing more than $\$ 35$ million damage in 2015 dollars (SHELDUS, 2017). In this chapter modeled ocean tides and the discharge records from the Willamette and Columbia Rivers and the seven largest downstream tributaries. The modeled peak water levels are within $0.05 \mathrm{~m}$ of observed values within the Portland area. Flood magnitude in Portland is most sensitive to increases in discharge due to climate change, a $10 \%$ increase in discharge produced a $0.78 \mathrm{~m}$ increase in peak water level. Conversely, flood magnitudes in Portland are significantly less sensitive to coastal perturbations. Only $20-26 \%$ of the increase in sea level rise is reflected in higher peak water levels in Portland. Peak water levels in Portland are similarly insensitive to other coastal processes such as storm surge and spring-neap tidal phase.

\subsection{Introduction}

Coastal Rivers, including the lower Willamette River, have experienced several significant winter-time floods since the advent of modern flood control in the mid-20th century, notably the Christmas-day flood in 1964 (\$11.6M, 20 lives lost) and a 1996 flood 
that caused more than $\$ 35$ Million damage in 2015 dollars (SHELDUS, 2017). Both floods were rain-on-snow events, with antecedent snowfall followed by warm, intense precipitation. Such rain-on-snow events have historically caused the largest winter-time floods on the Willamette, including events in Dec. 1861 and Feb. 1890 in which peak discharge in Salem (OR) was roughly 100\% and 80\% larger than the 1996 event (USGS station 14191000). Because these extreme floods were unregulated and occurred under a 19th-century climate, these magnitudes are not directly comparable to modern flows. Nonetheless, these events suggest that large flows are relatively common and that a 1996 magnitude event may plausibly occur again in the next 50-100 years.

In the coastal basins surrounding the lower Columbia River Estuary and the Portland (OR) metropolitan area (Figure 4.1), winter precipitation intensity is projected to increase throughout the 21 st century, according to downscaled climate change scenarios (Chang et al., 2010; Halmstad et al., 2013; Najafi \& Moradkhani, 2015; Salathé et al. 2014; Shields \& Kiehl, 2016). As a result, run-off during the 100-year flood event during wintertime is expected to increase by $0-20 \%$ throughout the Willamette River (WR) watershed and other nearby coastal watersheds, depending on location (Najafi \& Moradkhani, 2015). Additionally, global sea level is projected to rise due to melting glaciers and warming ocean waters, with regional variability caused by oceanographic circulation, vertical land motion (both glacial isostatic adjustment and plate tectonics), and gravitational effects (Board and National Research Council, 2012; IPCC 2013; Kopp et al., 2014, 2017). Trends in sea level will likely increase flood risk in Portland, where the river water level is affected by upstream flow, backwater discharge from the Columbia River 
(CR), and tides. Because both ocean tides, storm surge, sea level, and river discharge impact Portland water levels, a numerical modeling approach was chosen that includes both an ocean boundary and river discharge from multiple tributaries.

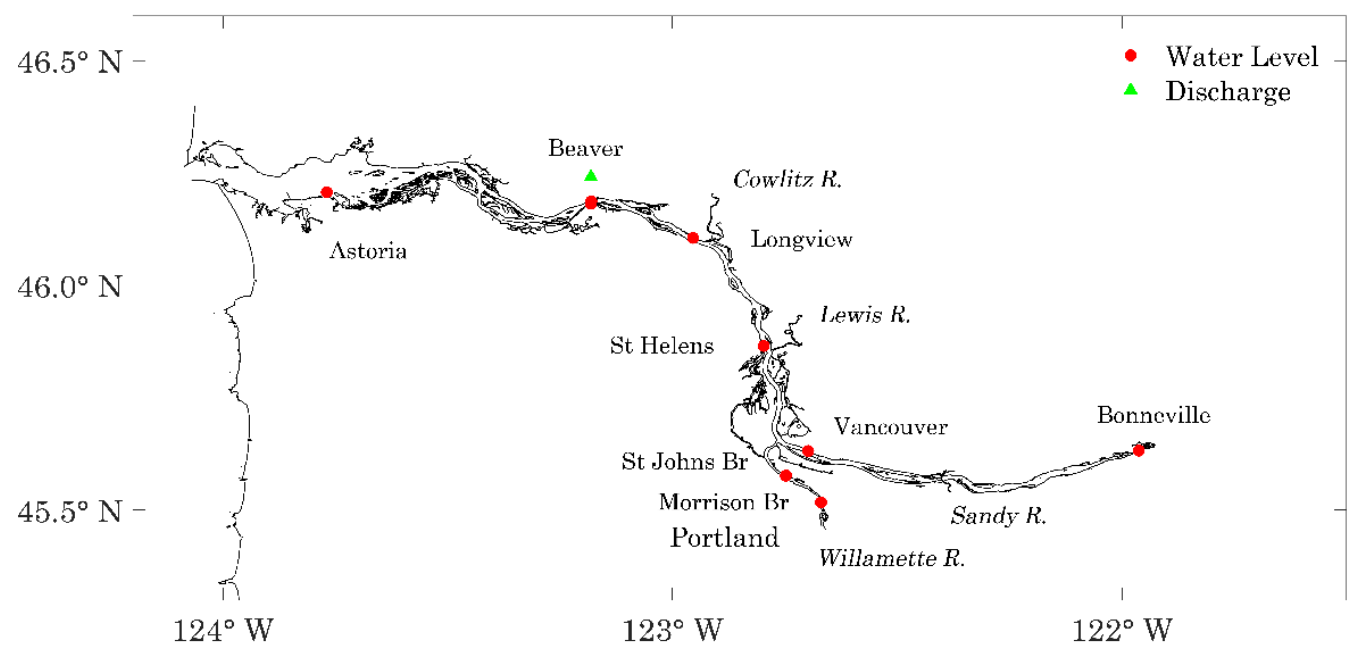

Figure 4.1: Map of the study area

\subsection{Methods}

\subsubsection{Present and Future Flood Risks}

In the 19th and early 20th century, the Portland Metro area (Figure 4.1) was subject to multiple flooding events each decade, with the largest (in 1894) causing the downtown area to be flooded for approximately 3 weeks. These floods typically occurred in May and June due to backwater discharge from the Columbia River during the snow-melt driven spring-freshet (Naik \& Jay, 2011), though occasional winter-time floods stemming from the Willamette River (e.g., Dec. 1861 and Feb 1890) also occurred. While a combination 
of flood-control reservoirs and levees on both the Willamette and Columbia Rivers (and their tributaries) have reduced flood frequency, river discharge still occasionally exceeds the modern bankfull discharge of $24 \times 10^{3} \mathrm{~m}^{3} \mathrm{~s}^{-1}$ (Jay and Naik, 2011). Since 1900, there have been five events exceeding this threshold: in 1913 (spring), 1948 (spring), 1956 (spring), 1965 (winter) and 1996 (winter) (Jay \& Naik, 2011; USACE, 1997; Waananen et al., 1970;). Although the possibility remains that could a very large spring freshet that could cause flooding in the Portland area (see Helaire et al. 2019), this chapter is focused on winter rain or rain-on-snow events.

In the assessing flood risks along the LCRE, some estimate of the effect of sea level rise must be included. Future sea level rise in coastal areas will invariably worsen the flood risks, particularly in coastal areas. Increases in local sea levels are projected to increase the likelihood of the extreme flood events (e.g. 10-year and 100-year flood events) for coastal locations throughout the world (Kopp et al., 2014; Tebaldi et al., 2012). Additionally, sea level rise has also driven large increases in nuisance level flooding at U.S. tide gauges over the last half-century (Street and Park, 2014). Because of the dependence of upriver water levels of coastal sea level and tides (Jay et al., 2010), the magnitude of given flood event, will be larger in the future than now. This chapter helps to quantify some of the effects of sea level rise.

\subsubsection{Water Level Data}

Table 4.1 summarizes the data I used for verifying simulations of the 1996 flood. Unfortunately, many of the tide gauges along the river lost power and only a subset of data is available (USACE, 1997). To increase data coverage, I applied a never-before-used data 
set collected for the City of Portland Bureau of Environmental Services at the St John's Bridge (Willamette River rkm 9.6) and provided by Dr. Scott Wells of Portland State University (unpublished data, 1996). This measurement is corrected for atmospheric pressure fluctuations (see Appendix), and the datum was approximated through comparison with the USGS gauge (station 14211720) $11 \mathrm{~km}$ upstream during low water conditions, which may introduce some error. Based on non-physical fluctuations in the Morrison Bridge data set, there is an estimated error of up to $0.1 \mathrm{~m}$ error in water level measurements (see Figures $4.3 \& 4.4$ ). Such errors may occur during a flood due to water level variations (e.g., standing waves, Bernoulli effects, etc.) around the structures upon which sensors are fastened (Salaheldin et al., 2004), in addition to the usual sources of error like datum uncertainty (Parker et al., 2007; see also Hudson et al., 2017).

Table 4.1: Water level measurements used to verify February 1996 Flood simulations.

\begin{tabular}{|c|c|c|c|c|c|}
\hline River & Site & Source & \multicolumn{2}{|c|}{ Location } & Description \\
\hline Willamette River & Morrison Bridge & USGS 14211720 & \multicolumn{2}{|c|}{ RM12.8 } & Hourly WL \\
\hline Willamette River & St Johns Bridge & City of Portland* & $\mathrm{RM}$ & 6.5 & $30 \mathrm{~m} \mathrm{WL}$ \\
\hline Columbia River & Vancouver, WA & USGS 14144700 & & & Hourly WL \\
\hline Columbia River & St Helens, OR & NWS SHNO3 & & & Peak flood WL \\
\hline Columbia River & Longview, WA & USGS 14207500 & & & Hourly WL \\
\hline Columbia River & Beaver Army Terminal & USGS 14246900 & $\mathrm{RM}$ & 53.8 & $\begin{array}{l}\text { Daily Ave discharge } \\
\text { Hourly WL }\end{array}$ \\
\hline Columbia River & Astoria - Tongue Pt & NOAA 9439040 & & & $6 \mathrm{~m} \mathrm{WL}$ \\
\hline
\end{tabular}

$\mathrm{WR}=$ Lower Willamette River; CR = Lower Columbia River; RM 0 is at the Pacific Ocean and Kelly Point for the Columbia and Willamette Rivers, respectively. 


\subsubsection{Numerical Model}

The Delft 3D model, a well-validated hydrodynamic model that solves for mass balance and the shallow water equations (Roelvink and Van Banning, 1995), to the LCRE. This model, build on the Delft3D platform, builds off the model described in Chapter 3 and simulates the effects of tides and river flow from the continental shelf to near the head of tides (see Appendix). Compared the model in Chapter 3, I increased resolution from $\sim 200 \mathrm{~m}$ to $\sim 50 \mathrm{~m}$ within the Portland Metro area, increased the total number of discharge boundaries to eight, and slightly adjusted bed friction to enable a better calibration with 1996 conditions. These changes allowed us to simulate the February 1996 flood (section 2.3), which I used as the baseline example of a significant flood event (section 2.2). Bathymetry in both the channels and floodplain were derived from US Army Corps of Engineers datasets (USACE, 2010). Bridge piers, pile dikes and other flow obstructions in the Portland Metro Area were modeled using Delft 3D functionality since they influence flood heights (see Appendix). The entire model domain (see Appendix) was broken into seven model sub-domains to enable the enhanced resolution in the Portland region and decrease computational run-time. Large floods typically inhibit salinity intrusion, and stratification is unlikely during turbulent flood conditions. Therefore, I used a depth=averaged, barotropic modeling approach. Depending on the reach, the Chézy friction coefficient $\left[\mathrm{m}^{1 / 2} \mathrm{~s}^{-1}\right]$ varied between 30 (Columbia River gorge) and 65 (see Appendix A and Helaire, 2016). 


\subsubsection{River Discharge}

A significant challenge in modeling discharge from the 1996 flood event is that many gauges failed or were compromised (USACE, 1997), such that some discharge records are available as daily averages, or only contain an estimate of the peak flow. Further, many small tributaries in the Gorge region and elsewhere are ungauged but taken as a whole, add significantly to the total discharge. Moreover, some river gauges are located far upstream from their entrance into the Columbia River. Finally, since the flood heights and discharge magnitudes are far outside the typical range of calibration, some increased uncertainty in estimates may be expected. Following standard practice (Sauer \& Turnipseed, 2010), it is assumed that water level elevations are known to within about $0.05 \mathrm{~m}$, and discharge to within about $10 \%$ of the values during the flood.

A watershed model of the 1996 event was unavailable, so I approximated hydrographs using available information (more detail in Appendix B3 - Discharge Boundaries). Daily averaged discharge over a 28-day period at the Morrison Bridge was interpolated to hourly values from daily estimates, by assuming that the daily average occurred at noon every day, and the discharge varied linearly from day-to-day. The time of peak was inferred from water level data (available hourly). The shape of the hydrograph for rivers with only a peak flow estimate (e.g., Kalama River and Washougal River) was obtained through comparison with nearby rivers, or from hydrographs from smaller, more recent events. The hydrograph of ungauged regions was estimated by scaling flows to nearby, gauged watersheds by using the ratio of their watershed areas. Finally, floodwaters are routed from their gauge location to the model boundary using approximations for the 
wave speed and checked through comparison with other known flood pulses. While necessarily approximate, the synthetic hydrographs of smaller tributaries are necessary to obtain reasonable water levels. The error obtained by ignoring important tributaries and by not routing flows would be greater than including approximations, and the good comparison with measured water levels (see section 3.1) validates this ad-hoc approach. The Chapter 4 Appendix B3 details the type of the data, the sources, assumptions, and methods used to create the discharge boundaries in the model.

\subsubsection{Ocean Boundary}

The Willamette River is a tidal river to the Willamette Falls at Oregon City, OR; therefore, the model must include tidal forcing to simulate daily water level fluctuations in the Portland Metro area. Moreover, tidal forcing increases frictional damping with-in the tidal river, leading to a larger river slope and higher water levels in Portland than in their absence (e.g., Kulkulka \& Jay, 2003). I applied the tidal amplitudes and phases of the nine largest constituents at the ocean boundaries (Table 4.2), using values obtained from the OSU Tidal Prediction Software (OTPS) model (Egbert \& Erofeeva, 2002), a barotropic model that simulates tides over the entire Pacific Ocean. These nine largest constituents represent $\sim 98 \%$ of the tidal energy at the Oregon coast. The Pacific Ocean is assumed to have a mean sea level [MSL] of +1.15 m relative to NAVD88, a salinity of $31.5 \%$, a density of $1022 \mathrm{~kg} \mathrm{~m}^{-3}$. The mean sea level elevation on the coastal boundary was derived from the NOAA VDatum program (https://vdatum.noaa.gov/) and is approximately the average of the MSL datum obtained from tide gauges at South Beach (OR) and Willapa Bay over the 1983-2001 epoch. 
Table 4.2: Tidal constituents for modern model at the ocean boundary

\begin{tabular}{ccc|ccc}
\hline \multicolumn{3}{c}{ Southwest } & \multicolumn{3}{c}{ Northwest } \\
\hline Constituent & Amplitude $(\mathrm{m})$ & Phase $\left(^{\circ}\right)$ & Constituent & Amplitude $(\mathrm{m})$ & Phase $\left(^{\circ}\right)$ \\
\hline M2 & 0.946 & 231.7 & $\mathrm{M} 2$ & 0.941 & 233.3 \\
S2 & 0.254 & 258.1 & $\mathrm{~S} 2$ & 0.251 & 256.5 \\
N2 & 0.194 & 205.3 & $\mathrm{~N} 2$ & 0.193 & 204.0 \\
K2 & 0.052 & 242.6 & $\mathrm{~K} 2$ & 0.052 & 240.9 \\
\hline K1 & 0.375 & 234.4 & $\mathrm{~K} 1$ & 0.374 & 233.8 \\
\hline O1 & 0.215 & 227.5 & O1 & 0.215 & 226.6 \\
P1 & 0.131 & 235.8 & P1 & 0.131 & 235.0 \\
\hline Q1 & 0.038 & 221.1 & Q1 & 0.038 & 220.4 \\
\hline
\end{tabular}

To correctly model the flood, water levels on the ocean boundary should include tides and nontidal perturbations to the ocean water level. Water level measurements at NOAA gauges at Toke Pt, WA in Willapa Bay (9440910) and South Beach in Newport, OR (94335380) show a 0.5m water level anomaly around February 8, 1996, GMT (Figure 4.2). The magnitude of the surge was small compared to other storm surges in recent history. For example, from 1979 - 2018 there were ten storm surges from 1.3-1.6m in magnitude. The gauges are located on the Pacific coast and are fed by smaller systems than the Columbia River. South Beach and Toke Point's proximity to the Pacific Ocean minimized the effect of river slope, and mean tide level should be close to the mean tidal range of the Pacific Ocean. To obtain an ocean boundary for the Delft3D model, I first ran the OPTS program over the simulation dates to obtain a water level time series with only tidal forcing. I then filtered the measured water level Toke Pt. and South Beach with a $24 \mathrm{~h} 50 \mathrm{~min}$ boxcar filter forward and backward to extract the nontidal components. I took the average of the nontidal water levels at these two locations and used it as an approximation of the coastal storm surge. Finally, I added the surge water levels to the tidal water levels obtained from OTPS to obtain water levels on the ocean boundary for the Delft3D model. 

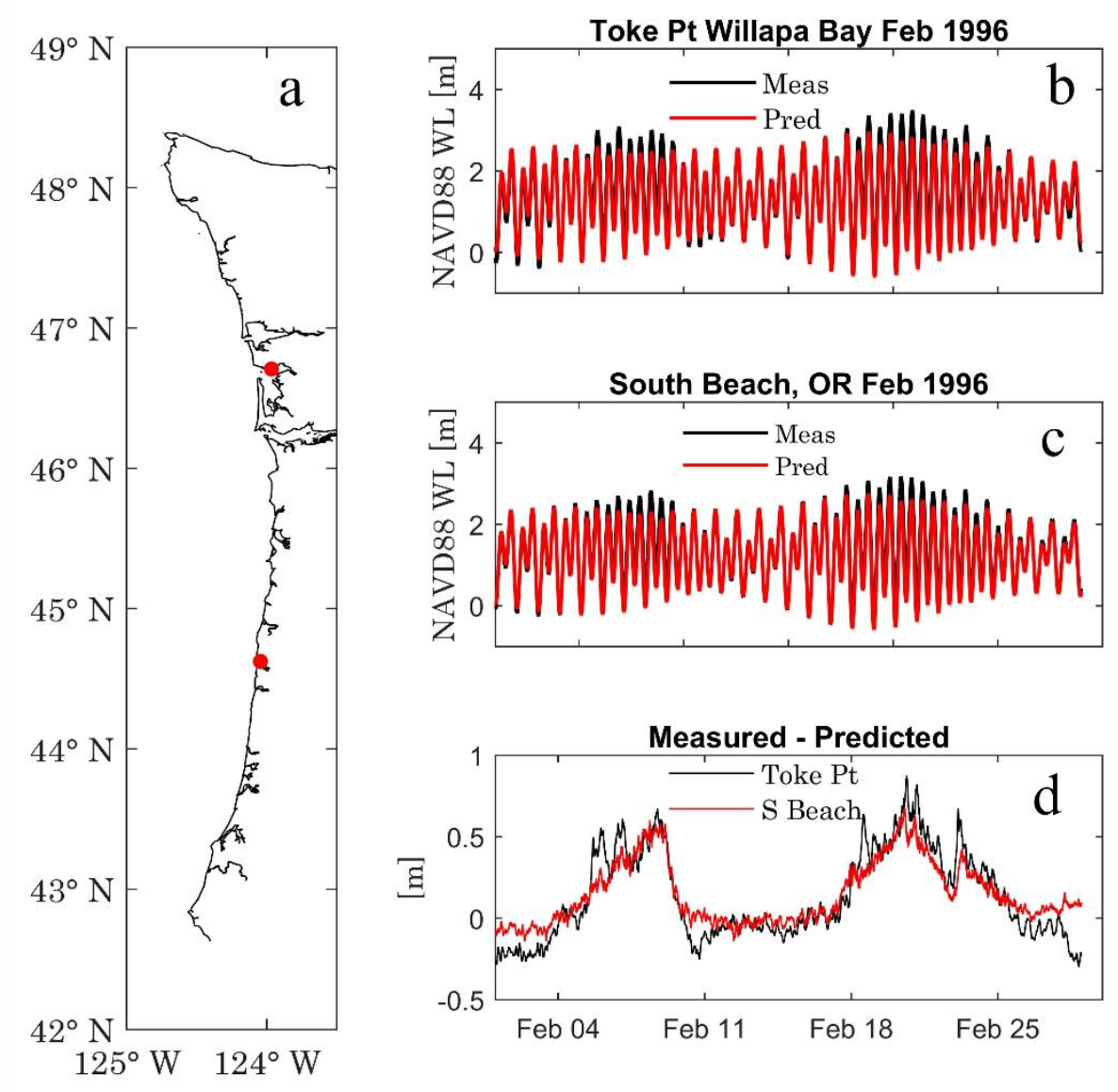

Figure 4.2: (a) location of the water level gages (b) Measured/predicted water levels at Toke Pt (c) South Beach (d) water level anomaly

\subsubsection{Scenario Definition}

The first set of simulations was a $2 \times 3$ matrix, with two climate scenarios, and three different values of sea level rise (Table 4.3). An initial simulation using measured and estimated discharge, and contemporary coastal forcing, was used to ensure that the model accurately produced peak water levels that occurred during the February 1996 event (A0 Table 4.3). The A0 simulation will henceforth be referred to as the "baseline" scenario. I evaluated the effect of climate change with the present climate (A), and a future climate 
(B). Three levels of sea level rise were used, (1) no change in sea level, (2) a $0.6 \mathrm{~m}$ increase in sea level at the coast, and (3), a 1.5m increase in sea level at the coast.

The individual factors affecting flood risk in the LCRE are spatially variable, i.e. sea level and storm surge are significant at the coast, while discharge affects mainly the tidal river. To quantify the spatial variability of the contributing factors, I ran a series of comparisons (Table 4.3). I used simulation A0 NS (0m SLR, 0\% discharge increase, no surge) as an example of the lowest magnitude flood. It is based on the baseline A0 scenario, but with no storm surge (Table 4.3). This simulation was used as a benchmark to determine how each factor increases flood risk

The modeled 10\% increase in run-off (Table 4.3) is consistent with the consensus estimate of generally wetter winters in the Willamette Basin and the Pacific Northwest. Because I cannot deterministically simulate a future event, I, therefore, choose to model the consequences of increased flow by making the (middle-of-the-road) estimate of a $10 \%$ increase in run-off, using the 1996 flood event as a template. While no two floods are alike, I note that the 1964 rain-on-snow event (see e.g. Waananen et al., 1970), was quite similar to the 1996 event, both in terms of peak water level and the shape of the hydrograph. Therefore, the 1996 event is a good example of the type of flood event that might be expected to occur every 25-50 years (e.g., Jay and Naik, 2011), even in the absence of climate change. 
Table 4.3: Scenarios used to model, and to evaluate the sensitivity to sea level, rise, increases in discharge, magnitude of surge, and neap/spring tides.

\begin{tabular}{|c|c|c|c|c|c|}
\hline & Scenario & SLR (m) & Flow Incr. (\%) & surge (yes/no) & Neap/Spring \\
\hline & A0 & 0 & 0 & yes & neap \\
\hline \multirow{5}{*}{ 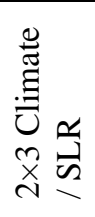 } & A1 & 0.6 & 0 & yes & neap \\
\hline & A2 & 1.5 & 0 & yes & neap \\
\hline & B0 & 0 & 10 & yes & neap \\
\hline & B1 & 0.6 & 10 & yes & neap \\
\hline & B2 & 1.5 & 10 & yes & neap \\
\hline \multirow{5}{*}{ 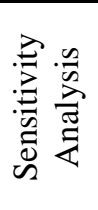 } & A0 NS & 0 & 0 & no & neap \\
\hline & A0 NS Spring & 0 & 0 & no & spring \\
\hline & A1 NS & 0.6 & 0 & no & neap \\
\hline & B0 NS & 0 & 10 & no & neap \\
\hline & B2 Neap & 1.5 & 10 & yes & spring \\
\hline
\end{tabular}

A $10 \%$ increase in precipitation run-off in the Willamette basin would likely produce a larger than $10 \%$ increase in the river flow discharge at Oregon City if it is assumed that reservoir storage and flow management remains unchanged. In 1996, flow management reduced peak flows by $3,000 \mathrm{~m}^{3} \mathrm{~s}^{-1}$ to $\sim 12,000 \mathrm{~m}^{3} \mathrm{~s}^{-1}$, from an unregulated amount of $\sim 15,000 \mathrm{~m}^{3} \mathrm{~s}^{-1}$ (USACE, 1997). Since a $10 \%$ increase in run-off should be applied to the unregulated flow, I estimate that peak unregulated flow increases to roughly $\sim 16,500 \mathrm{~m}^{3} \mathrm{~s}^{-1}$ in scenario B (Table 4.3). Applying 3,000 $\mathrm{m}^{3} \mathrm{~s}^{-1}$ of storage to this amount, I estimate that the peak flow at Oregon City is $\sim 13,500 \mathrm{~m}^{3} \mathrm{~s}^{-1}$ in scenario B, or rather a $12.5 \%$ increase in flow from scenario A.

The sea level rise scenarios in Table 4.3 are based on consensus estimates of between 0.6-1.5m of sea level rise on the US Pacific coast by the year 2100 (OSB \& NRC, 2012). Within this estimate, the effects of spatially variable vertical land motion are neglected, which is highly variable near the coast but is a lesser factor with-in the tidal river and in Portland (Burgette et al., 2009). Similarly, it is beyond the scope of this dissertation 
to consider erosion, deposition, and the other adjustments to system bathymetry that may occur due to sea level rise and anthropogenic management of the system. Hence, the sea level rise scenarios represent the changes that would happen if oceanic sea level rise occurs quickly relative to the time scales of morphodynamic adjustment and vertical land motion within the system.

The contribution of the Columbia River to increased wintertime flooding poses a challenge, due to its large basin that extends over portions of seven states and Canada. Analysis of the 1996 flood shows that tributaries such as the Hood River and Deschutes, as well as upstream tributaries such as the Snake River, affect flows at Bonneville Dam during the peak of the Willamette hydrograph, and therefore affect flood heights. In the absence of a full hydrological model that accounts for upstream reservoir management, I make some simplifying assumptions about the possible climate-induced changes in runoff in an extreme flood (i.e., 50-year or 100-year flood). In scenario B, I assume that there is no increase in the Columbia River discharge upstream of The Dalles. Downstream of The Dalles I apply a $10 \%$ proportional increase in run-off and river discharge to other coastal tributaries (e.g., Cowlitz), though it is noted that storage effects could apply to the Lewis River basin as well. Beyond these factors, important hydroshed characteristics such as antecedent soil moisture, snow cover, and air temperature likely affect the characteristics of a future rain-on-snow event but are beyond the scope of this effort.

I am interested in understanding the degree to which tidal range at the coast affects peak water levels in Portland. The February 1996 storm occurred during the neap tidal cycle or the period of the lower tidal range during the 14-day cycle. Figure 4.3 shows the 
hydrographs water levels at Tongue Point in Astoria (Columbia River rkm 29) from Jan 14 - Feb. 14, 1996. The green rectangle roughly represents the period of peak water levels in the Portland area (Feb. 9-11, 1996), while the rectangle represents the spring tide. Meanwhile, the elevated flood levels on Feb. 8-9 1996 are the signature of a storm surge. To estimate the effect of tides on peak flood levels, I simulated the flood occurring two weeks earlier. The river hydrographs and the coastal surge are offset by two weeks. These changes will force the discharge peak to occur at roughly the same time as spring tide, or larger tidal range at the coast. The baseline simulation, simulation with normal timing of the hydrograph are labeled "neap", while simulations with the discharge hydrograph or coastal surge offset are called "spring" (Table 4.3).

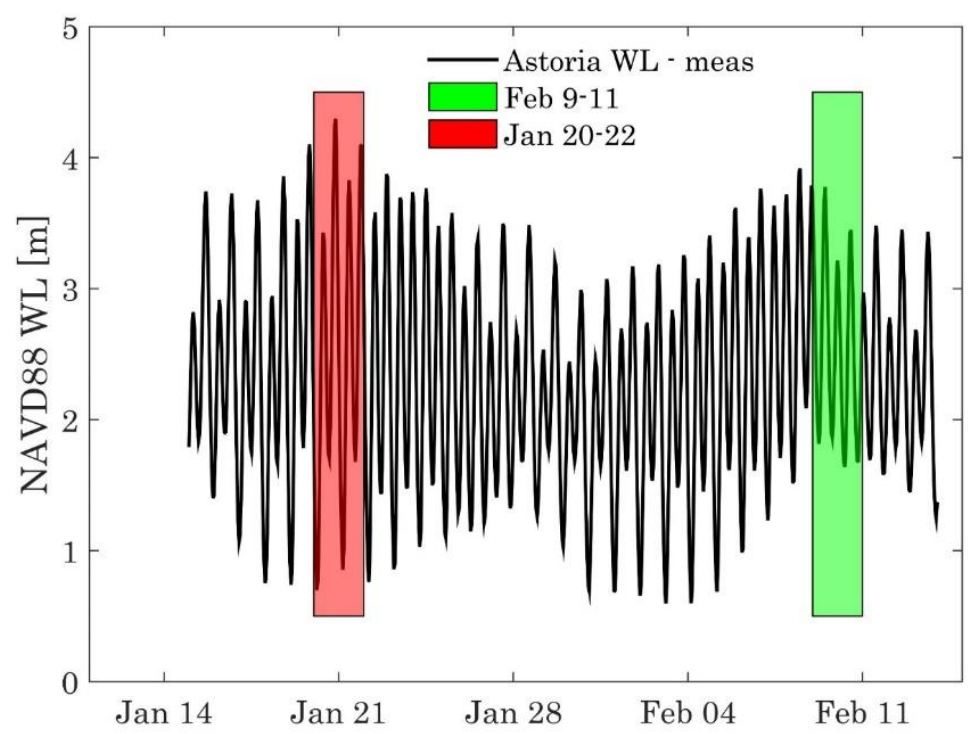

Figure 4.3: Measured water level on the Columbia River in Astoria, OR Jan - Feb 1996

This approach of offsetting the hydrographs back 14 days is only a first-order approximation of how the neap-spring cycle affects flood water levels. Time constraints 
limited the number of simulations that are run. Ideally, I would like to run multiple simulations over the entire 14-day neap-spring to capture full interaction between tides and river hydrographs. Additionally, I am only dealing with a single neap spring cycle, and not looking considering annual or interannual changes in coastal tide range.

\subsubsection{Model Calibration}

In calibrating the model, I optimize water levels in the Portland Metro area to agree with locally measured water levels. The model performance is verified by comparing modeled 1996 water levels against the measured water level at seven locations along Lower Columbia River (Figures 4.1 and 4.2, Table 4.1). The model Chézy bed roughness is manually adjusted until the error between modeled and measured discharge is minimized. The model is optimized for the Portland area, with the error in peak water level reduced to $5 \mathrm{~cm}$. I also assess modeled discharge at Beaver ( $\mathrm{Rm} 86)$ against daily average discharge estimated by the USGS (station 14246900). The modeled daily average discharge is targeted to be within $10 \%$ of the measured values.

\subsection{Results}

This section begins with an overview of the model calibration and shows how accurate the simulation is hindcasting flood progression and peak water levels. I next examine the interaction between sea level rise and climate-induced changes in discharge. The $2 \times 3$ matrix of plausible climate and sea level rise scenarios is explored in terms of flood risk in the Portland area. Finally, I look to do a sensitivity analysis where I analyzed 
individual components of flood risk, i.e. storm surge, sea level rise, climate, and neap/spring effect.

\subsubsection{Water Levels - Baseline Scenario}

The calibration shows that the Delft 3D model captured both the baseline water levels in the Portland area on the rising limb, peak, and falling limb of the flood event (Figure 4.4). At the Morrison Bridge, in downtown Portland, the simulated water level agreed with the measured water level within $0.04 \mathrm{~m}(0.4 \%)$ (Figure 4.4 and Table 4.4). In the Portland area, at St John Bridge (9km downstream of MSB) are within $0.01 \mathrm{~m}(0.1 \%)$. In nearby Vancouver on the Columbia River (rkm 170), peak water levels were within $0.06 \mathrm{~m}(0.61 \%)$

Further downstream on the Columbia at St Helens (rkm 138), and Longview (rkm 107), the model underestimated peak water levels by $\sim 0.28 \mathrm{~m}(3.38 \%)$, and $0.43 \mathrm{~m}(6.65 \%)$, respectively. At Beaver Army Terminal in the Columbia River (rkm 86), the model matched observed peak water levels. Finally, at Tongue Point in Astoria (rkm 29), the modeled output was within $0.10 \mathrm{~m}(2.91 \%)$ of measured peak water levels. The deviation for measured versus observed peak water levels is shown in Figure 4.5. The timing of peak water levels changes by location. Downstream of Longview the peak water level is a function of tides and storm surge, in addition to the rising arm of the flood hydrograph. Upstream of Longview, the timing of the peak water occurs near peak discharge. 

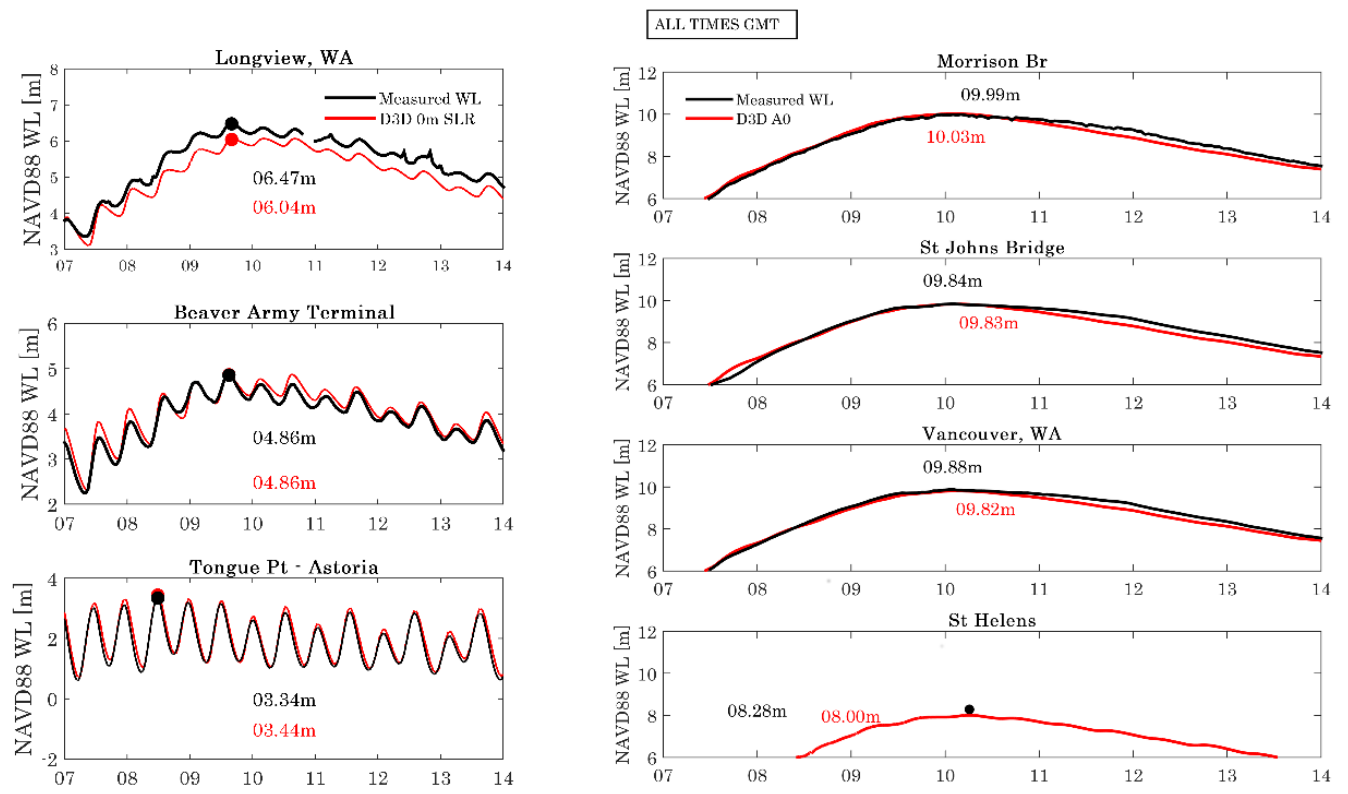

Figure 4.4: Closeup of hydrograph of the peak of the flood for seven locations. 
X Columbia R. $\times$ Willamette R.

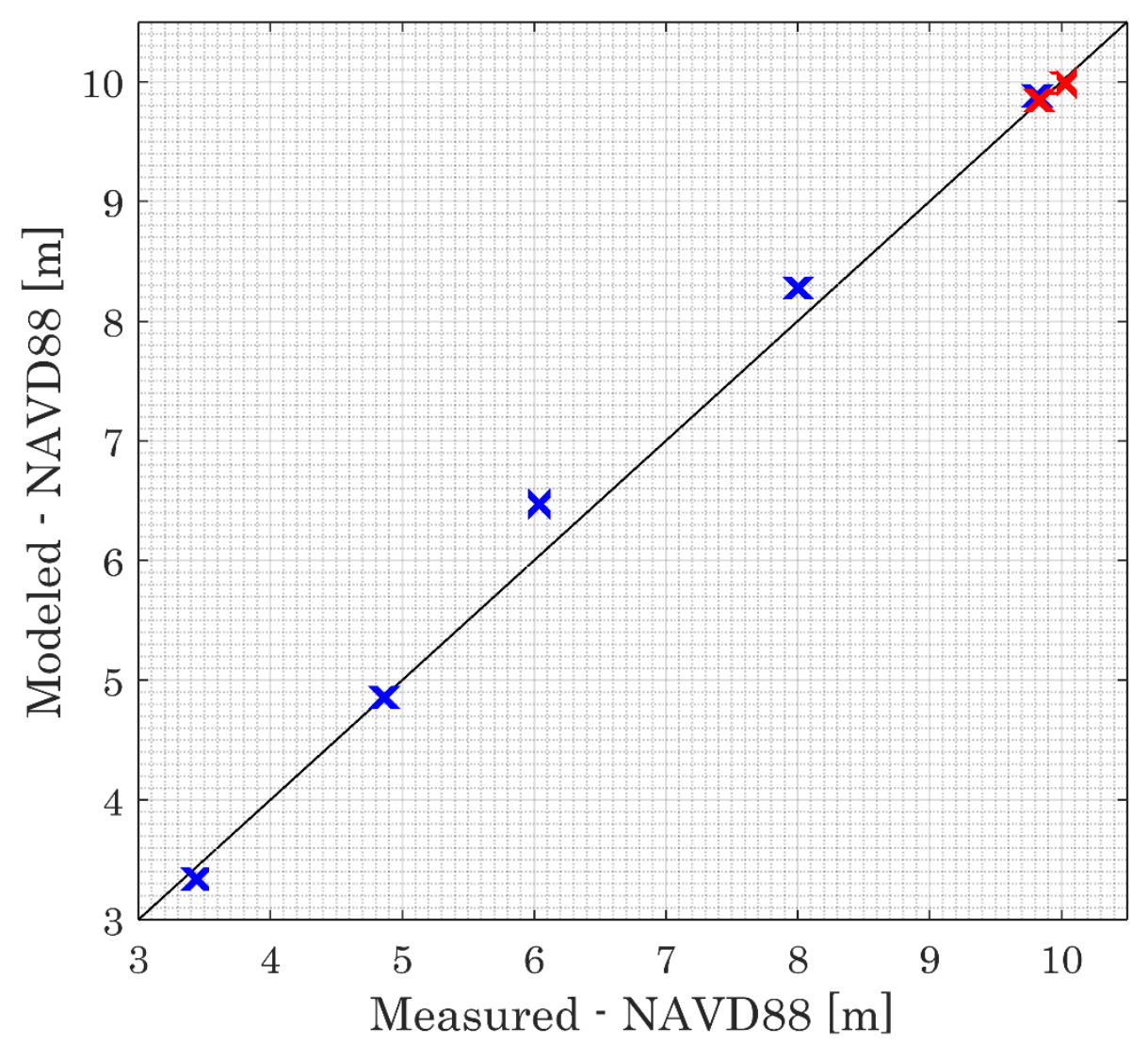

Figure 4.5: Comparison of model results and observations of peak water levels. The reference line is above NAVD88 datum. 
Table 4.4: Model and measured water levels at seven gage stations, goodness of fit statistics

\begin{tabular}{llcccc}
\hline \multicolumn{1}{c}{ River } & \multicolumn{1}{c}{ Site } & $\begin{array}{c}\text { Meas. } \\
(\mathbf{m})\end{array}$ & $\begin{array}{c}\text { Model } \\
(\mathbf{m})\end{array}$ & $\begin{array}{c}\text { Model - Meas. } \\
(\mathbf{m})\end{array}$ & $\begin{array}{c}\text { Model -Meas. } \\
(\boldsymbol{\%})\end{array}$ \\
\hline Willamette River & Morrison Bridge & 9.99 & 10.03 & 0.04 & $0.40 \%$ \\
\hline Willamette River & St Johns Br (RR) & 9.84 & 9.83 & 0.01 & $0.10 \%$ \\
\hline Columbia River & Vancouver, WA & 9.88 & 9.82 & -0.06 & $-0.61 \%$ \\
\hline Columbia River & St Helens, OR & 8.28 & 8.00 & -0.28 & $-3.38 \%$ \\
\hline Columbia River & Longview, WA & 6.47 & 6.04 & -0.43 & $-6.65 \%$ \\
\hline Columbia River & Beaver Army Terminal & 4.86 & 4.86 & 0.00 & $0.00 \%$ \\
\hline Columbia River & Astoria - Tongue Pt & 3.44 & 3.34 & -0.10 & $-2.91 \%$ \\
\hline rmse & $\mathbf{0 . 1 9 9 5 m}$ & & & & \\
\hline Chi- squared & $\mathbf{0 . 0 4 1 6 m}$ & & & &
\end{tabular}

Although the precise reasons for the differences between measured and modeled results are unknown, there are some possible explanations. The results suggest that flows from the Columbia River boundary might be underestimated, while flows from downstream tributaries such as the Lewis and Cowlitz River might be overestimated. It is quite probable that some errors exist in published river discharge estimates since discharge estimates are most likely based on calibrations to much lower flows than the observed flood peak. There may also be small errors in the measurement of the river stage. It is also possible that bed roughness is under-predicted on the Columbia River upstream of Vancouver during the flood, though the bed friction was increased (decreased Chézy) to account for larger roughness variation upstream of the end of the shipping channel in Vancouver. Finally, I note that there might be some ambiguity in the published water levels. Since gauges are often attached to bridge piers, the location of the gauge may influence the measured height, since water piles up on the upstream side, but swiftly decreases and is lower on the downstream side, of a typical bridge pier. The presence of 
spikiness in the MSB data set (see Figure 4.4), which is not observed at the St Johns RR bridge, suggests that there may be some uncertainty in water level measurements. USGS reports that acceptable error for the datum of the gage is $0.01 \mathrm{ft}(0.003 \mathrm{~m})$. USGS requires stage measurement to be within $0.01 \mathrm{ft}(.003 \mathrm{~m})$ or 0.2 percent of the effective stage, whichever is higher. Peak water levels range from $4 \mathrm{~m}$ above the datum at Tongue Point (NOAA 9439040) to nearly 10m above the datum at Morrison Bridge, making the expected error (datum + stage measurement) in the range of $0.01-0.02 \mathrm{~m}$ (Sauer \& Turnipseed, 2010).

\subsubsection{Interaction between Sea Level Rise and Climate-Induced Changes in}

\section{Discharge}

In the parameter space of this study, climate-induced changes in discharge appear to a more significant factor than sea level rise for future flood risk in the Portland area (Figure 4.6 and Table 4.5). At $0 \mathrm{~m}$ sea level rise, a 10\% increase in discharge produced a $0.78 \mathrm{~m}$ increase in peak water level $(\mathrm{A} 0-10.03 \mathrm{~m}, \mathrm{~B} 010.81 \mathrm{~m})$. Comparing both $0.6 \mathrm{~m}$ sea level rise scenarios, a $10 \%$ increase in discharge caused an additional $0.75 \mathrm{~m}$ rise in water level (A1 - 10.15m, B1 - 10.90m). Similarly, at $1.5 \mathrm{~m}$ sea level rise, a $10 \%$ increase in discharge produced an increase in peak water level of $0.69 \mathrm{~m}(\mathrm{~A} 2-10.42 \mathrm{~m}, \mathrm{~B} 2-11.11 \mathrm{~m})$. The results of the study also show that increase in peak water levels due only to sea level rise, are $20-26 \%$ of the sea level increases at the coast. At $1.5 \mathrm{~m}$ sea level rise, peak water levels in Portland only rise by $0.39 \mathrm{~m}(\mathrm{~A} 0-10.03 \mathrm{~m}, \mathrm{~A} 2-10.42 \mathrm{~m})$. The increases due in peak water levels due to climate change remain fairly consistent over all three sea level rise scenarios. 
The difference in water levels between the baseline A0 simulation, and the most severe case B2 (1.5m SLR/10\% flow increase) are best visualized by a comparison of the inundation profiles. Under the A0 scenario (0m SLR, 0\% discharge increase) scenario the 10m (relative to NAVD88) inundation contour extended to Morrison Bridge in Portland (Figure 4.7). By contrast, under the B2 scenario (1.5m SLR, 10\% discharge increase), the $10 \mathrm{~m}$ contours extended nearly to St Helens, OR. There was also increased inundation in North Portland and in the Vancouver area (Figure 4.7).

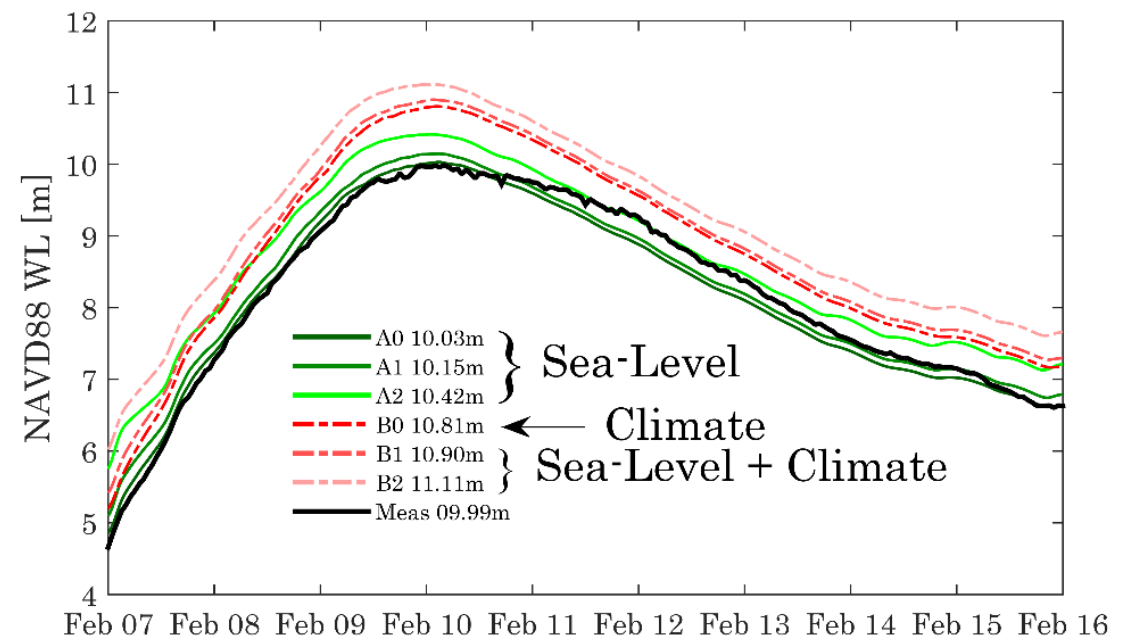

Figure 4.6: Measured (black) and modeled water levels in Portland for the six different scenarios.

Table 4.5: Summary of change in peak water levels at MSB in climate and sea level rise scenarios.

\section{Sea Level Rise Scenario}

\begin{tabular}{|l|c|c|c|c|}
\hline & & $\mathbf{0 m}$ & $\mathbf{0 . 6 m}$ & $\mathbf{1 . 5 m}$ \\
\hline Runoff Increase & $\mathbf{0 \%}$ & & 0.12 & 0.39 \\
\cline { 2 - 5 } & $\mathbf{1 0 \%}$ & 0.78 & 0.87 & 1.08 \\
\hline
\end{tabular}



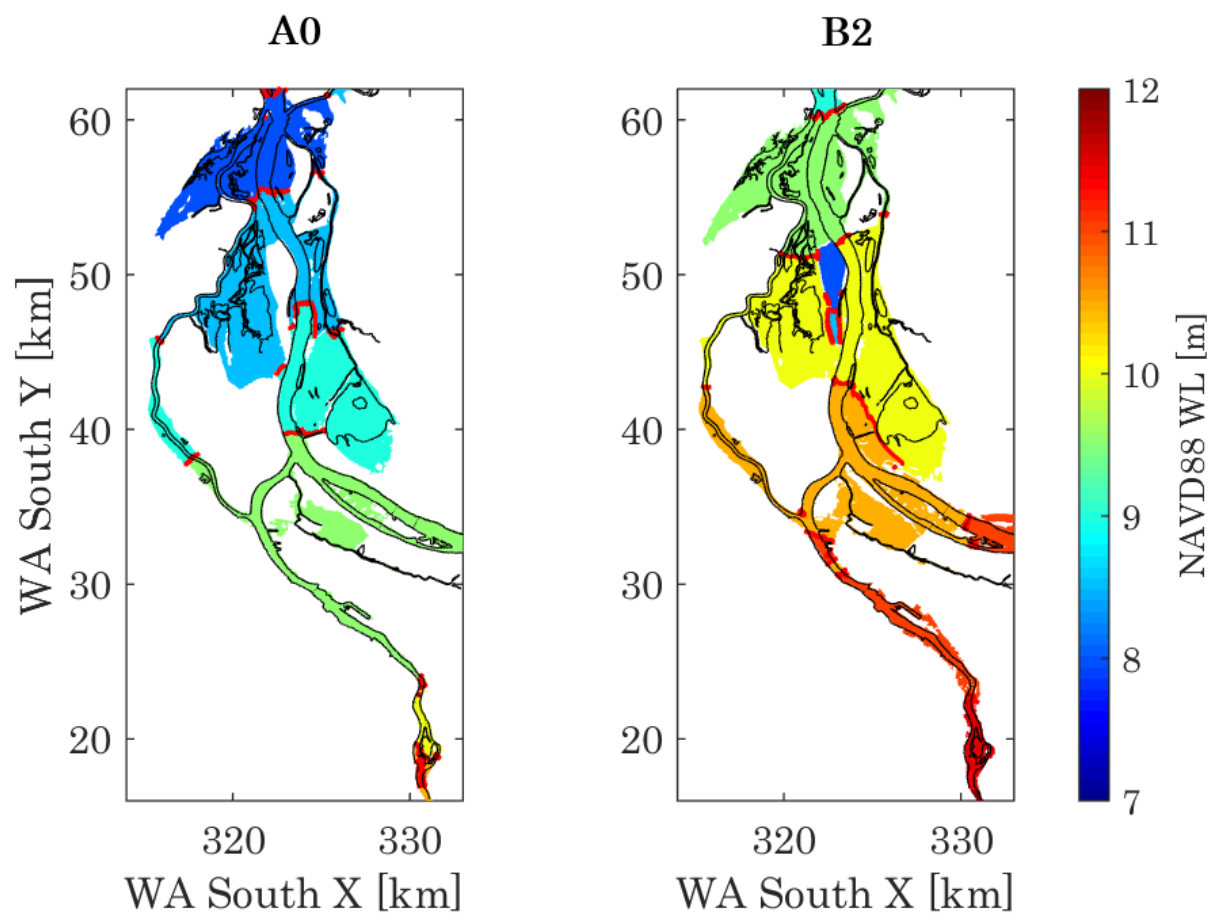

Figure 4.7: (left) Inundation under the baseline scenario A0 (right) the most severe scenario, B2 (1.5m SLR $+10 \%$ runoff increase).

\subsubsection{Sensitivity Analysis}

The effect the different process (climate change, sea level rise, storm surge, etc.), were assessed by comparing single factors in a series of model simulations (see Table 4.3 - Sensitivity Analysis). For example, the change in peak water level due to a storm surge is determined by calculating the difference in peak water level between simulations $\mathrm{A} 0$ and A0 NS (see Table 4.3). Similarly, the changes in peak water level due to $0.6 \mathrm{~m}$ of sea level rise is determined by calculating the difference in peak water levels between simulations A1 NS and A0 NS. The results of all the comparisons are shown in Figure 4.8. The effect of sea level rise (Figure 4.8 - A1 NS - A0 NS) is that $0.6 \mathrm{~m} \mathrm{SLR} \mathrm{caused} \sim 0.6 \mathrm{~m}$ increase in peak water level from the coast ( $\mathrm{rkm} 0)$ to rkm 50, with lower increase landward of rkm 
50. This scenario produces a $0.16 \mathrm{~m}$ increase in peak water levels at Portland $(180 \mathrm{~km}$ upstream). The effect of increased discharge (Figure 4.8 - B0 NS) is that the increases in peak water levels are highest upstream $(0.75 \mathrm{~m}$ at $\mathrm{rkm} 180)$, with the effects diminishing seaward. At the coast ( $\mathrm{rkm} 0)$, there is less than $0.1 \mathrm{~m}$ increase in peak water levels. The effect of spring tides at the coast is somewhat similar to the progression of the $M_{2}$ tide in the spatial calibration in Chapter 3 (Figure 4.8 - A0 NS Spring). There is a 028m increase at the coast, and the increase in peak water level is maximized at roughly rkm $50(0.5 \mathrm{~m})$, and then steadily decreases downstream $(0.06 \mathrm{~m}$ at rkm 180$)$.

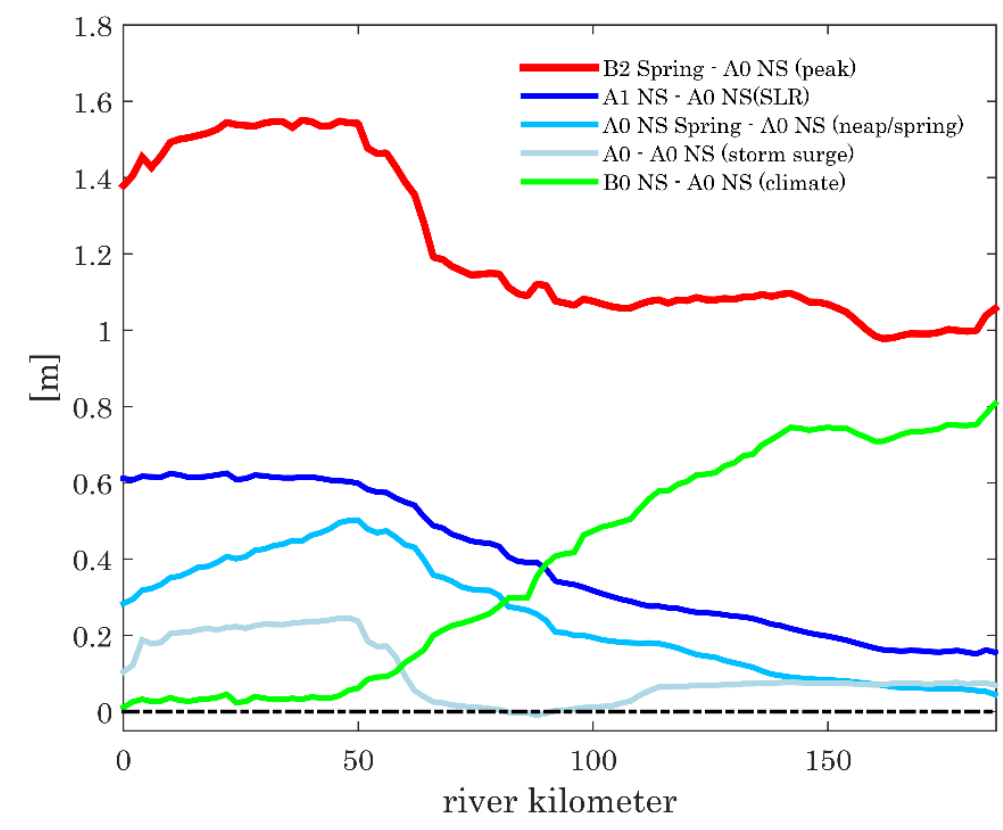

Figure 4.8: Along channel changes in water level. Most severe (B2: $10 \%$ flow + $1.5 \mathrm{~m} \mathrm{SLR)} \mathrm{(red),} \mathrm{sea} \mathrm{level}$ rise, tides, storm surge, and runoff.

The presence of storm surge alters flood wave and tidal wave progression along the estuary/river continuum and affects both the magnitude and timing of peak water levels (Figure $4.8 \mathrm{~A} 0$ ). The storm surge causes a rise in peak water levels from the coast to rkm 
80 , no change in peak water levels from rkm 80-100, and then a marginal increase in peak water levels downstream of rkm 100. Although surge is prescribed on the coastal boundary, the effect of the surge propagates far upstream. Figure 4.9 is a contour plot of the effect of the storm surge from Feb. 7-11, 1996 from to coast to the upper reaches of the Willamette River. The plot was constructed by taking the differences in surface elevation between A0 (baseline), and A0 NS (no storm surge) simulations (see Table 4.3) in the channel from the coast to Portland. The results show that a $0.25 \mathrm{~m}$ anomaly reaches up to Beaver (Columbia River - rkm 86), representing approximately 50\% of the storm surge magnitude. Figure 4.10 shows the hydrographs of the coastal storm surge, and the Portland water level on the same time scale. The relative difference in timing of the storm and the flood wave is seen in the timing peak water levels in the calibration of the baseline scenario. On the Columbia River at Longview (rkm 107), Beaver (rkm 86) and Astoria (rkm 29), peak water levels occurred before Feb 10, 1996; conversely, at gage stations upstream of Longview, the flood peaks some time from Feb. 10-11, 1996 (Figure 4.4). In locations downstream of Longview (Beaver, Astoria), the storm surge influenced the timing of peak water levels, while upstream of Longview (Portland), the timing of the flood peak coincides with the peak of the discharge hydrograph. 


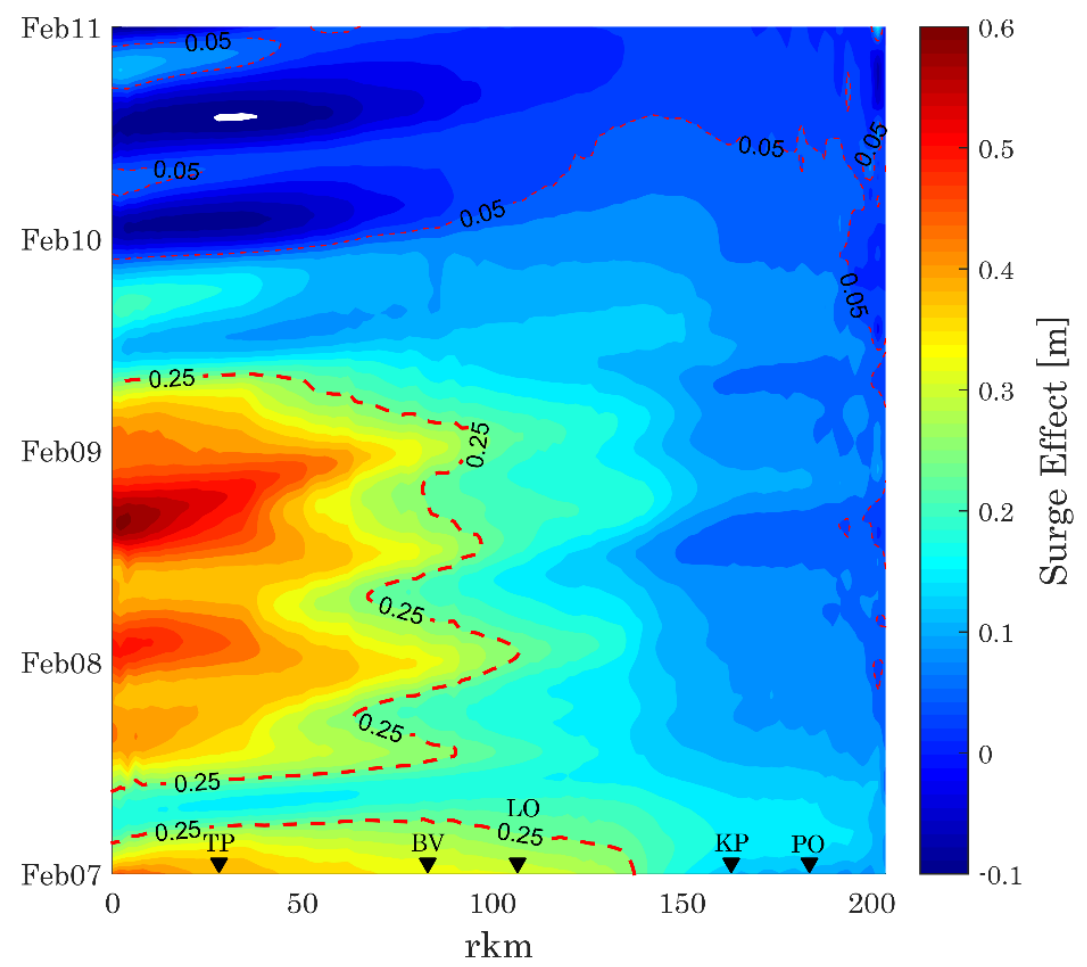

Figure 4.9: Difference in water level between simulations due to storm surge - Feb. 7 - 11, 1996 GMT.

The red dashed contour lines represent $0.05 \mathrm{~m}$ and $0.25 \mathrm{~m}, 10 \%$ and $50 \%$ of the surge magnitude.

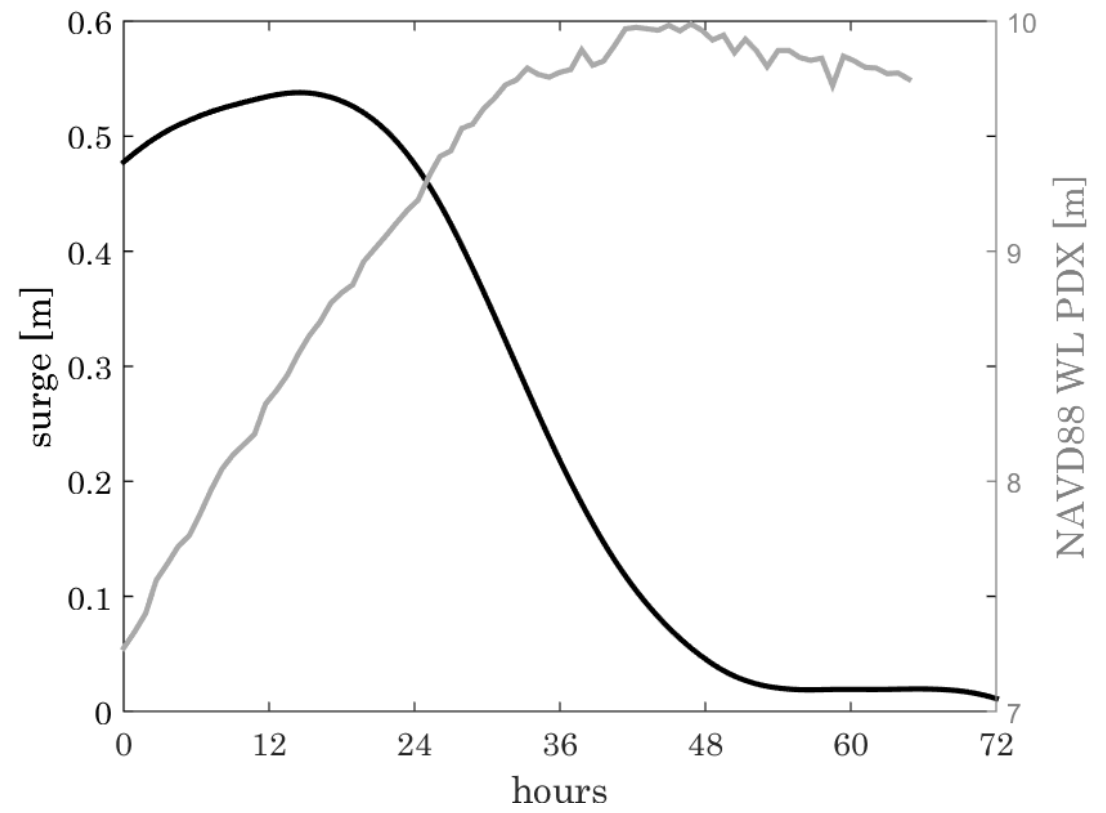


Figure 4.10: Relative timing of coastal surge (black), and surface elevation in Portland (grey), Feb. 8-11, 1996 GMT.

The final comparison is that of the most extreme flood scenario B2 Spring, $(1.5 \mathrm{~m}$ SLR, $10 \%$ discharge increase, flood coinciding). Figure 4.8 shows that the largest increase in peak water levels occurs between the coast and rkm 50. The results also show $>1 \mathrm{~m}$ increases in peak water levels throughout the river channel.

\subsection{Conclusions}

The chapter simulates a winter rain-on-snow flood, with a recurrence interval of 25-50 years. Based on projections of increased winter precipitation, this flood serves an exemplar of future extreme events. The magnitude of the effect of climate-induced changes in discharge and future sea level rise was quantified by increases in peak water level. After calibrating the baseline scenario, I found that future changes in discharge due to climate change for a 100-year flood event will have a greater impact in the Portland than projected increases in sea level. In Portland a $10 \%$ increase in discharge in the February 1996 flood produced $0.78 \mathrm{~m}$ higher water levels in Portland, while $0.6 \mathrm{~m}$ of sea level rise produced $0.12 \mathrm{~m}$ higher water peak water levels, and $1.5 \mathrm{~m}$ of sea level rise produced $0.39 \mathrm{~m}$ higher water levels.

The results of the study showed that while the February 1996 flood event may have been a 25-50-year event for river discharge, it was probably not a significant event in terms of tides or storm surge. Therefore, future changes due to coastal forcing may be larger during a significant coastal event. The interaction between river discharge and coastal ocean will be even more significant in the next 100 years due to the looming prospect of 
significant sea level rise in the Pacific Northwest. Finally, winter precipitation intensity is projected to increase throughout the 21 st century, meaning that rain or rain-or-snow events will still be a significant factor in extreme events. The next chapter deals with the junction dynamics in the Portland area. This chapter will deal examine how the complex flow dynamics in the between the Willamette River, Columbia River, and Multnomah Channel affect hysteresis and bed stress. 


\section{Chapter 5: Analysis of River Junction Dynamics}

In this chapter, I investigate how the large network of channels downstream of Portland interacted and affected water levels and bed stress during the February 1996 Flood described in Chapter 4. The Lower Columbia River in the Portland is a system with three junctions (Figures 5.1 to 5.3). First, the Willamette River flows downstream from the head of tides at Oregon City and reaches Multnomah Channel, a distributary channel that siphons off a varying degree of flow (Figures 5.1 and 5.3), forming Junction A. Second, the Willamette River joins the Columbia River at Kelley Point (Figure 5.3), forming a confluence (Junction B). Finally, downstream of Kelley Point, the Columbia River, and Multnomah Channel met (Figure 5.2), forming another confluence near St Helens (Junction C). Willamette and Columbia River inflows are most important boundary conditions for an analysis of the junction dynamics during the 1996 Flood. Accordingly Figure 5.4 shows the discharge hydrographs of the Columbia River (upstream of Kelley Point at rkm 165) and Willamette River (upstream of the confluence with Multnomah Channel at St Johns Bridge).

Calibrated numerical simulations of the February 1996 event show that wetlands on the northern segment of Sauvie Island become inundated on the rising limb of the flood, creating a backwater effect on the falling limb of the flood. The backwater flooding causes a hysteresis, where for a given discharge water level in Portland is $>1 \mathrm{~m}$ higher on the falling limb of the flood than the rising limb. The reservoir of water on the northern segment of Sauvie Island lowers the surface slope along the Multnomah Channel, so that the flow partition from the Willamette River (Junction A), is biased more toward flow through the 
Willamette River. Simulations incorporating sea level rise show that there is a general reduction in the amount of hysteresis. The reduction in the hysteresis effect is due to lower initial bed stress cause by the higher initial water levels.

\subsection{Introduction}

River junctions are significant because discharge from multiple sources converges in a single location. Backwater effects, and abrupt changes in channel geometry may create strong changes in flow velocity and bed stress. Of particular interest along the Lower Willamette River, is the presence of contaminated sediment at various Superfund sites (https://portlandoregon.gov/bes/56848). Along with environmental concerns due to legacy pollution, there are also concerns about the maintenance of the river channel. Thus, there is a need to understand erosion and deposition patterns, particularly in large flood events that move a disproportional volume of sediment compared to normal flow conditions (Templeton \& Jay, 2012). This chapter extends an analysis of the February 1996 flood from Chapter 4 to cover junction dynamics in the system comprised of the Willamette River, Columbia River, and Multnomah Channel.

This chapter seeks to answer Question \#3 from Chapter 1 - How do the dynamics of the Columbia River/Willamette River/Multnomah Channel junction influence flood risk, bed stress and hysteresis in the Portland area? I begin with a basic description of flow in an open channel, extend that theory to describe bed stress in a channel and flow partition at the junction, and then I apply this theory to the Willamette River/Multnomah Channel junction (Junction A). The chapter then details the bed stress and surface slope response to changes in inundation. I map water level and surface slope changes during the rising 
and falling limbs of the flood, to show how inundation, particularly in north Sauvie Island affects upstream water levels in the Portland area. The chapter concludes with an analysis of the effects of sea level rise on hysteresis.

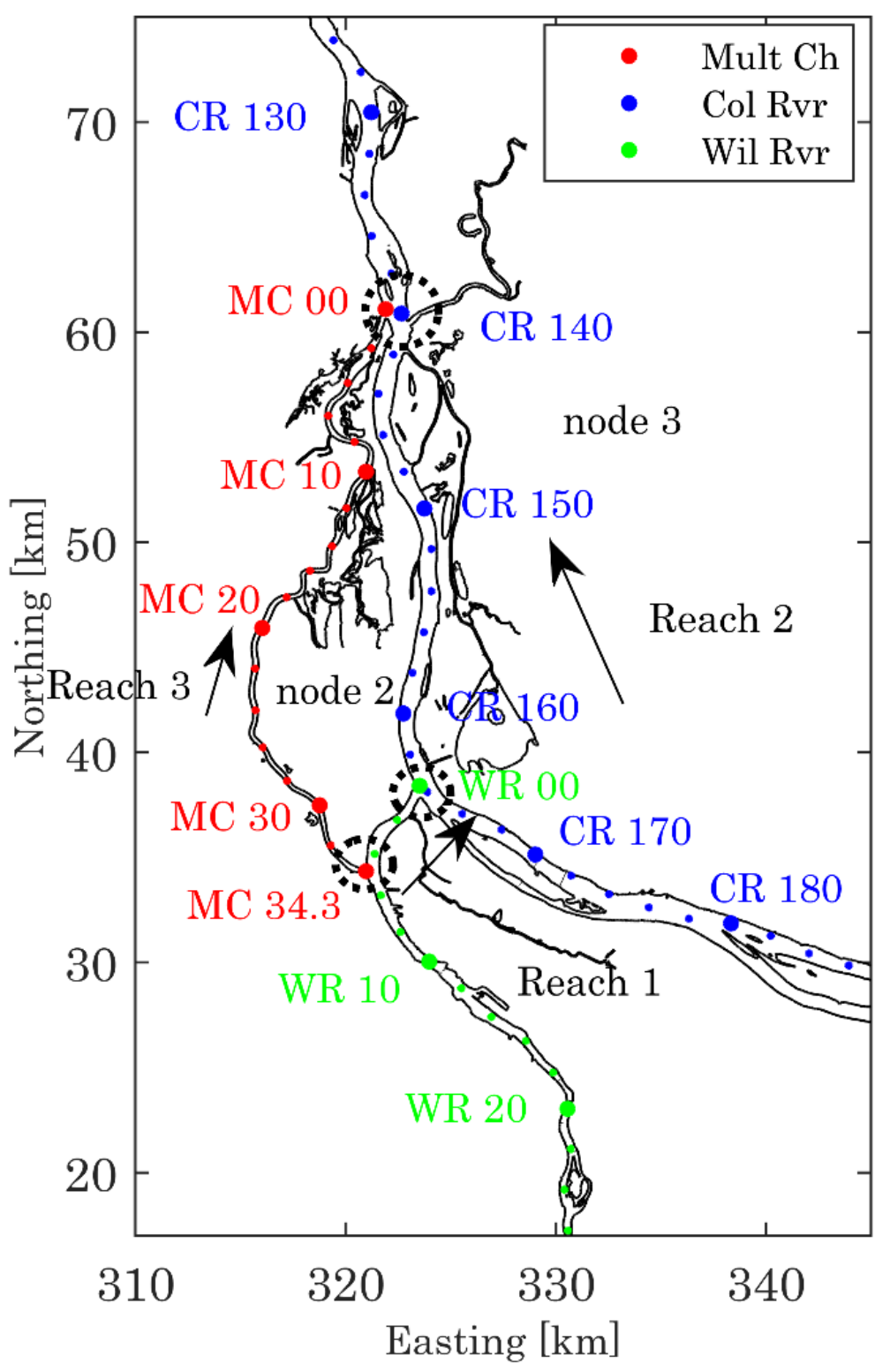

Figure 5.1: Map of model of observation points and cross-sections 


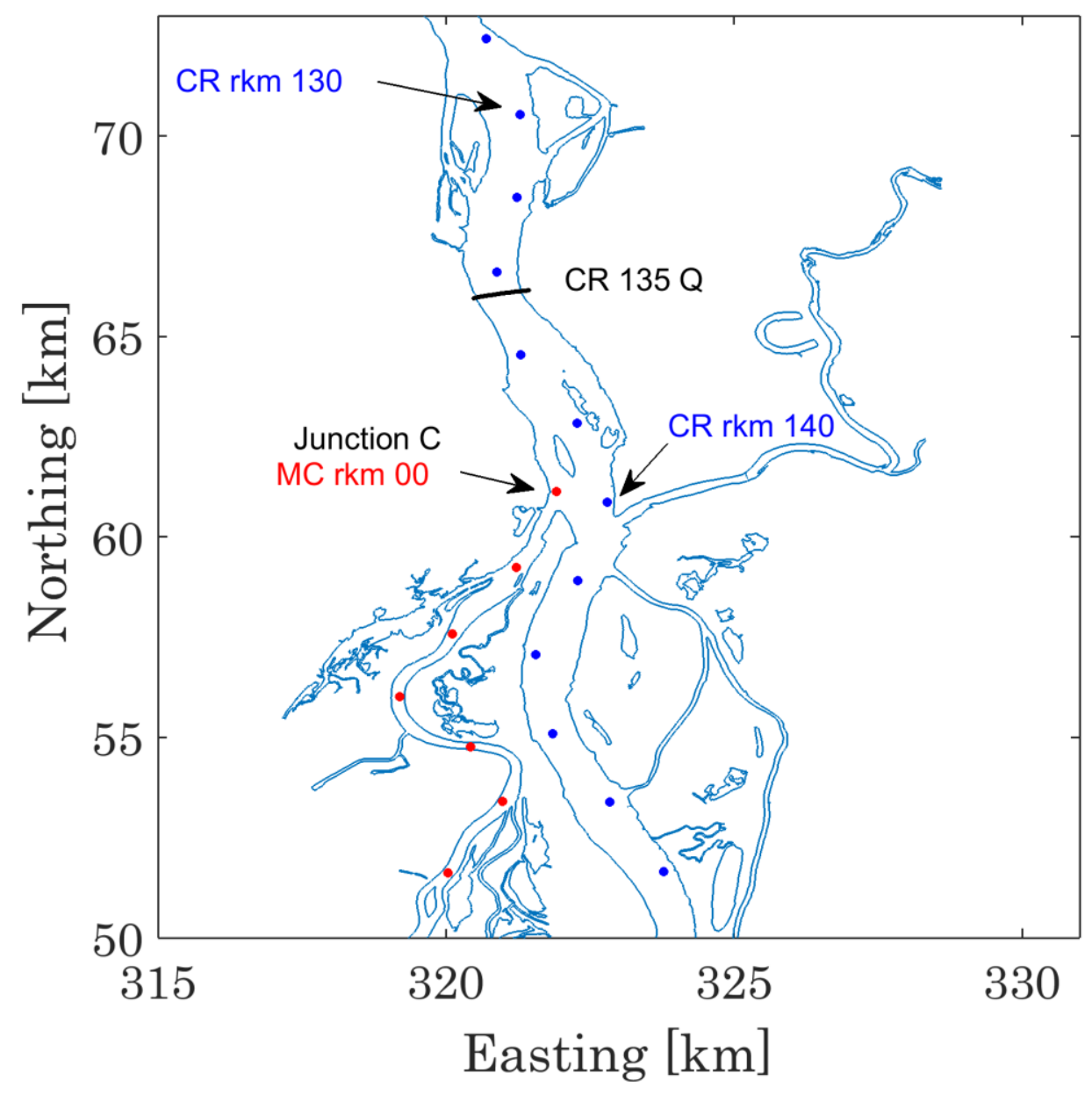

Figure 5.2: Closeup of Junction C 


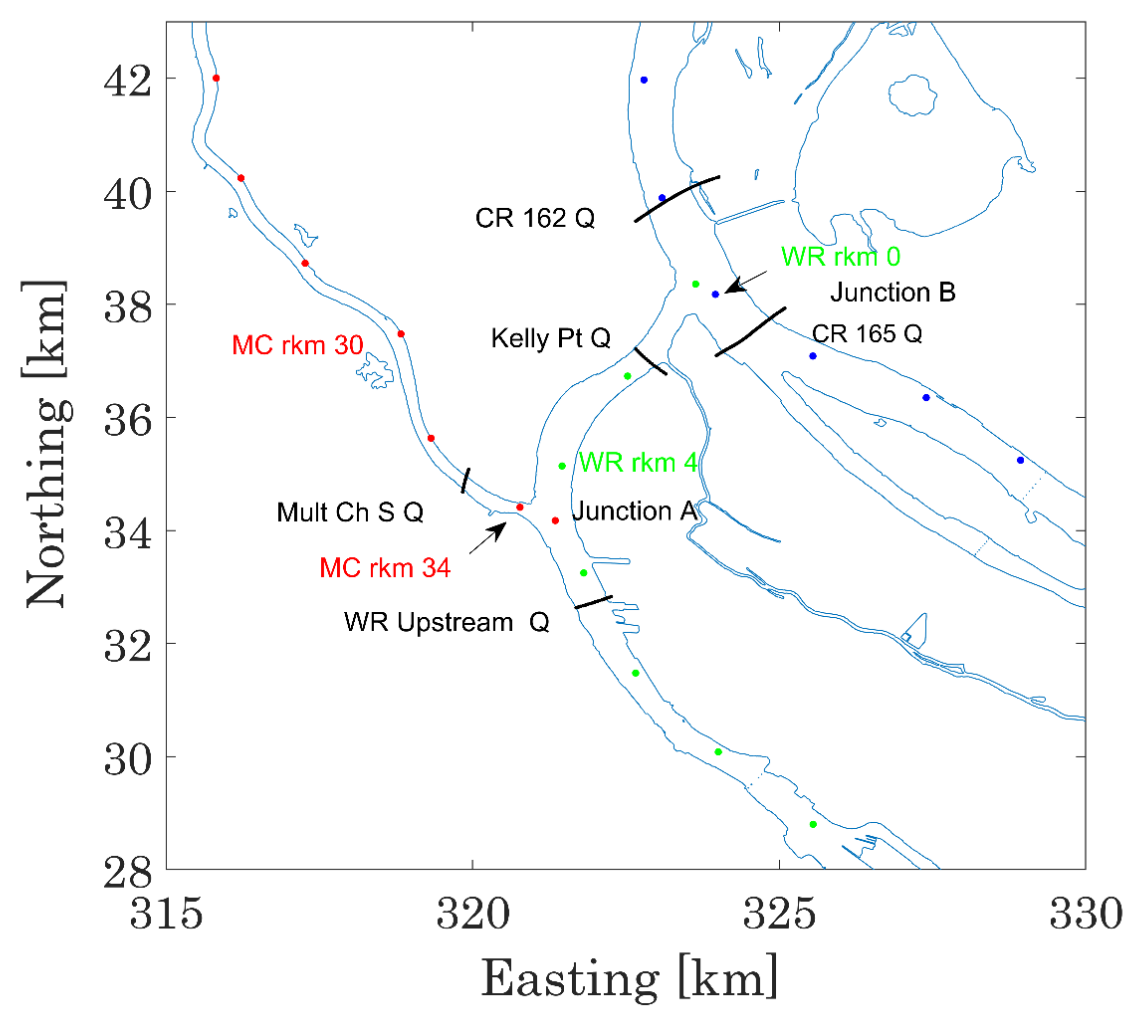

Figure 5.3: closeup of Junction A and Junction B.

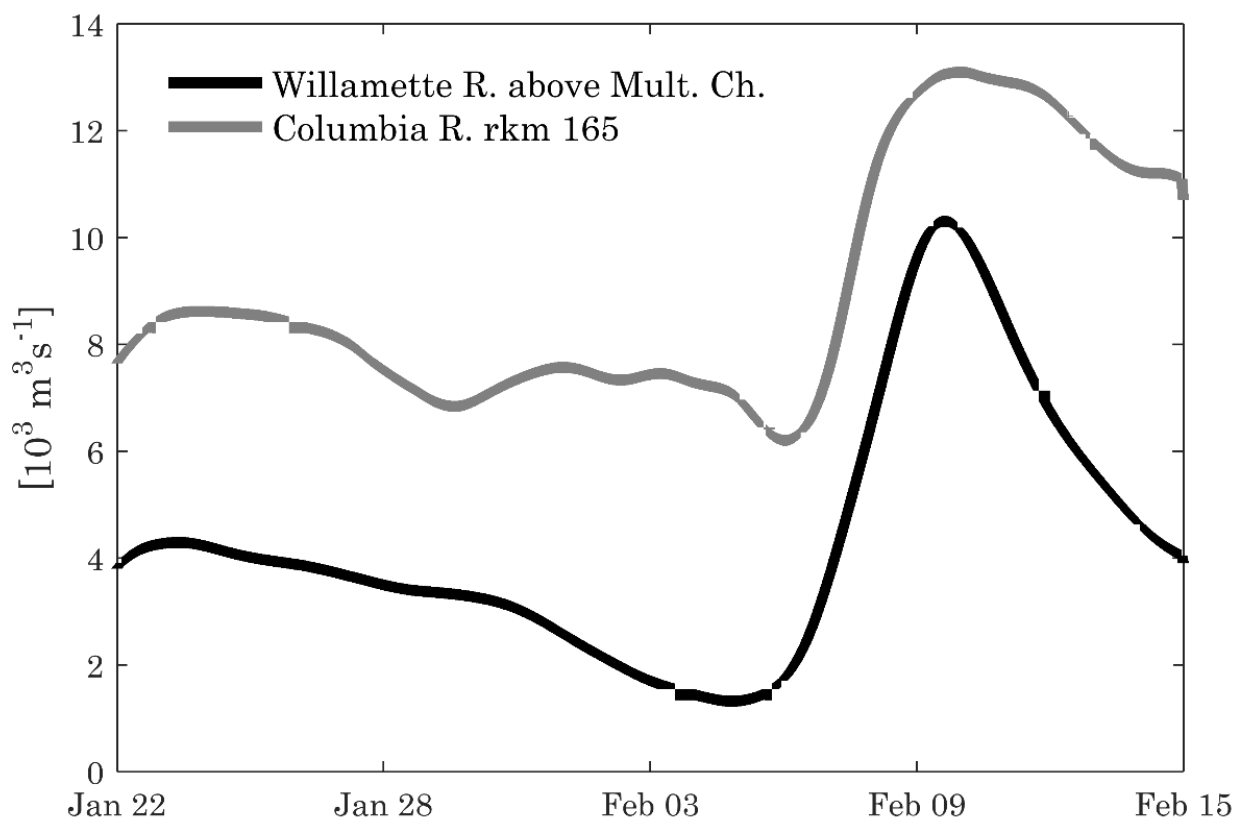

Figure 5.4 river discharge at Junction A during the February 1996 flood 


\subsection{Literature Review}

The dynamics of the three-node junction in the LCRE have some similarities to river deltas where flow may alternatively diverge and converge around islands. Warner et al. (2003) studied residual circulation patterns in a channel network tidally driven from opposing entrances. In a study of the Central Bay within the San Francisco Bay the authors found that a sill on the west entrance of created a subtidal water level gradient driving water and sediment eastward. Buschman et al. (2010) used numerical models of idealized deltas to study flow division within the delta apex junction of the Berau system, along the east coast of Kalimantan, Indonesia. The authors found that in deltas with channels of uneven length, tidal energy causes the river discharge to preferentially steer towards the shorter channel due to a subtidal water level gradient. Finally, in the work of Sassi et al. (2011), the authors used depth-averaged finite element models to study the division of river discharge over distributary channels in the Mahakam Delta in Indonesia. The authors found that at a delta, the steepening of the tidally-averaged water level in the shorter channel enhanced the gradient in the longer and shallower channel. The enhanced subtidal water level gradient favored the allocation of river discharge to the longer and shallower northern channel.

The stage-discharge relationship as measured by rating curves plays an essential role in the hydrological cycle of a river system. When the rating curve is a single-valued function, it is possible to obtain discharge measurements solely from stage data. Factors such as backwater discharge, unsteady river flow, and floodplain storage often cause rating curves to exhibit hysteresis. With hysteresis, the rating curve for the falling and rising limb 
are different (Chow, 1959). The Jones method is commonly used to analyze rating curves exhibiting hysteresis (Jones, 1964; Boyer, 1964). The Jones method and similar variations help to deal with hysteresis associated with unsteady river flow (Petersen-Øverleir, 2006). More recently, hysteresis has been modeled using artificial neural networks (Tawfik et al., 1997; Jain \& Chalisgaonkar, 2000; Deka \& Chandramouli, 2003).

In this study, my simulated flood generates overbank flow. Hysteresis in the areastage relationship can occur during floods with significant overbank flow. This phenomenon is typical in less developed, seasonally-inundated floodplains. For example, Rudorff et al., (2014) found that there is a counterclockwise area-stage hysteresis, i.e., lower water levels on rising flows, in the Várzea do Lago Grande de Curuai (Curuai

floodplain), along the Amazon River near Óbidos, Pará, Brazil. The Poyang region of China has a similar area-stage or area-volume hysteresis (Zhang et al. 2015, Huang et al. 2017, Zhang \& Werner, 2017). The authors found that in a river-floodplain system subject to overbank flow, there are high water levels and relatively low inundation during the rising limb of the flood. Conversely, during the falling limb of the flood, there is more extensive inundation for a given stage.

\subsection{Methods}

This section details the methodology for the analyzing junction dynamics in the Lower Columbia River. Chapter 4 and Appendix B describe the model setup. Model outputs are used to analyze patterns in water level, surface slope, bed stress, inundation, and cross-sectional discharge. 
In order to analyze water level and discharge I used a simplified relationship. The Gauckler-Manning or Manning equation is an empirical equation first presented in 1889 [Manning, 1891]. Under the assumption of uniform flow in a channel (Limerinos, 1970), the flow velocity in SI units is given by:

$$
\begin{aligned}
& \qquad \frac{Q}{A}=V=\frac{1}{n} R_{h}^{2 / 3} S^{1 / 2} \\
& Q=\text { cross-sectional discharge through the river channel }\left[\mathrm{L}^{3} \mathrm{~T}^{-1}\right] \\
& V=\text { depth averaged channel velocity }\left[\mathrm{LT}^{-1}\right] \\
& A=\text { cross-sectional area of the channel }\left[\mathrm{L}^{2}\right] \\
& n=\text { Gauckler-Manning coefficient }(0.025)\left[\mathrm{T} \mathrm{L}^{-1 / 3}\right] \\
& R_{h}=\text { hydraulic radius, area/wetted perimeter }[\mathrm{L}] \\
& S=\text { friction slope }[-]
\end{aligned}
$$

With the assumption of a logarithmic velocity profile the bed stress is given by:

$$
\begin{aligned}
& \qquad \tau_{B}=\rho c_{d} V^{2} \\
& \tau_{b}=\text { bed stress }\left[\mathrm{ML}^{-1} \mathrm{~T}^{-2}\right] \\
& \rho=\text { fluid density }\left[\mathrm{ML}^{-3}\right] \\
& c_{d}=\operatorname{drag} \text { coefficient }(0.0025)[-] \\
& V=\text { velocity at } 1 \mathrm{~m} \text { above the bed }
\end{aligned}
$$


The velocity in Equation 5.2 can be replaced with the velocity in the Manning Equation (Equation 5.1), yielding

$$
\tau_{B}=\rho c_{d} \frac{1}{n^{2}} R_{h}^{4 / 3} S
$$

Equation 5.3 is a formulation for the bed stress based on the Manning Equation. The analysis is simplified by using a constant density $(\rho)$, and there is no suspended sediment in the model. Using this formulation, it can be shown how changes in bed stress are related to changes in bed roughness $\left(c_{d}\right)$, channel configuration $\left(R_{h}\right)$, or friction slope $(S)$. The friction slope defined in this way is not a true friction slope; it is more akin to a surface slope; also, Equation 5.3 does not account for the bed slope. The term surface slope will be used going forward.

The bed stress formulation used in Equation 5.3 is useful in describing the interplay between the hydraulic radius, water level gradient, and bed stress, but it is not an exact formulation. In the Delft3D formulation (Equation 5.4), bed stress is estimated directly from the depth-averaged velocity, $U$, and the two-dimensional Chézy coefficient, $C_{2 D} ; C_{2 D}$ $=65$ here:

$$
\overrightarrow{\tau_{b}}=\frac{\rho_{0} g|\vec{U}| \vec{U}}{C_{2 D}^{2}}
$$

Usually, bed stress is estimated using a velocity $1 \mathrm{~m}$ from the bed, and a constant drag coefficient as in Equation 5.2 (e.g., Fong et al., 2009). This approach results in lower values of bed stress, unless $c_{D}$ and $C_{2 D}$ are adjusted so that Equations 5.2 and 5.4 yield similar results. As an example, I compared the depth-averaged velocity and the velocity 
$1 \mathrm{~m}$ from the bed at Morrison Bridge (WR rkm 20). Assuming fine sand, a roughness length scale on the order of $10^{-5} \mathrm{~m}$, and velocity at the surface of $1 \mathrm{~ms}^{-1}$. At flow depth of $20 \mathrm{~m}$ (measured from the bed), the depth-averaged velocity is $15 \%$ higher than the velocity at $1 \mathrm{~m}$ depth.

The Manning Equation is used to determine whether changes in hydraulic radius, $R h$, or changes in surface slope, $\mathrm{S}$, drive the changes in flow partition. Starting from Junction A, Willamette River discharge can either flow downstream to junction B (east path to Kelley Point) or flow to Junction C (west path to St Helens, see Figure 5.1); the west path $(34 \mathrm{~km})$ is longer than the east path $(29 \mathrm{~km})$. The discharge through Reach 1 and Reach 3 are approximated using the Manning Equation. To simplify calculations, I assumed rectangular cross-sections and a constant Gauckler-Manning coefficient, $n=0.025$. For the discharge through Reach 1, the Willamette River is assumed to have a constant depth of $12 \mathrm{~m}$ below NAVD88 and a constant width of 400m. For the discharge through Reach 3, the Multnomah Channel is assumed to have a constant depth of $9 \mathrm{~m}$ below NAVD88 datum and a constant width of 170m. From Equation 5.1:

$$
\begin{gathered}
Q_{R 1}=\frac{1}{n} A_{R 1} R_{R 1}^{\frac{2}{3}} S_{R 1}^{\frac{1}{2}}(t) \\
Q_{R 3}=\frac{1}{n} A_{R 3} R_{R 3}^{\frac{2}{3}} S_{R 3}^{\frac{1}{2}}(t) \\
\text { Ratio }=\frac{Q_{R 1}}{Q_{R 3}}=\frac{A_{R 1} R_{R 1}^{\frac{2}{3}} S_{R 1}^{\frac{1}{2}}}{A_{R 3} R_{R 3}^{\frac{2}{3}} S_{R 3}^{\frac{1}{2}}}(t)
\end{gathered}
$$


Equations 5.4 and 5.5 are approximations for the discharge through Reach 1 and Reach 3 respectively, while Equation 5.6 gives the flow partition, or how the discharge is divided at the Junction A. In all three cases discharge is time-dependent.

To estimate the modeled discharge through Reaches 1 and 3, I use the mean of tidally averaged water levels at four model observation points between junction $\mathrm{A}$ and junction B (Figure 5.1), and four points between Junction A and Multnomah Channel rkm 30 (Figure 5.1). The surface slopes $(S)$ are determined from linear regression fits of the tidally averaged water levels at the observation points in the two channels. The discharge ratio derived from the Manning Equation (Equation $5.4 \& 5.5$ ), is compared to the modeled discharge through the cross-sections (Figure 5.1). This application of the Manning Equation is used to determine whether changes in surface slope or changes in water level control the flow partition through junction A.

\subsection{Results}

\subsubsection{Flow Partition}

The Multnomah Channel serves an important purpose: by increasing the crosssectional carrying capacity of Willamette River discharge, it serves to reduce water levels in Portland. This is shown by artificially closing Multnomah channel at Junction C, and comparing water levels in Portland during the 1996 flood with the baseline simulation (not closed; see Figure 5.5). The peak of the February 1996 flood event is increased by $0.35 \mathrm{~m}$ by closing the Multnomah Channel (Figure 5.5). Figure 5.6 is a contour plot of the difference in water level with Multnomah Channel closed, versus the Multnomah Channel completely open. Along the Willamette River, closing the Multnomah Channel results in 
a $0.17-0.33 \mathrm{~m}$ increase in peak water level. On the Columbia River downstream of rkm 150 , there is at a $0-0.17 \mathrm{~m}$ increase in water levels. Conversely, along the Multnomah Channel, there is a decrease in peak water levels of $0.33 \mathrm{~m}$ on the northern segment near junction $\mathrm{C}$, and a decrease in peak water levels in excess of $1.00 \mathrm{~m}$ on the southern end of the channel, near the junction A. The results show that although Multnomah Channel is comparatively small, with $\sim 30 \%$ of the cross-sectional area of the Willamette River, it still plays a significant role in the flow dynamics of the region.

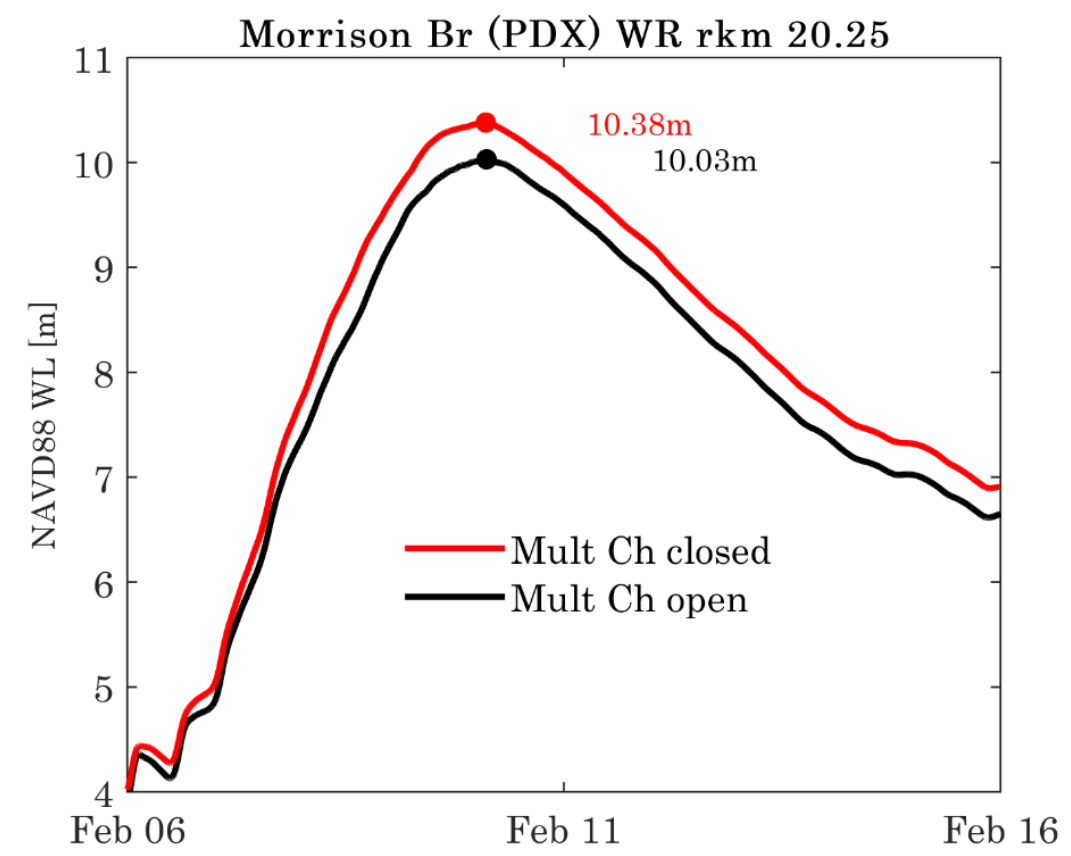

Figure 5.5: Effect of closing Multnomah Channel - hydrograph. Peak water level in Portland 


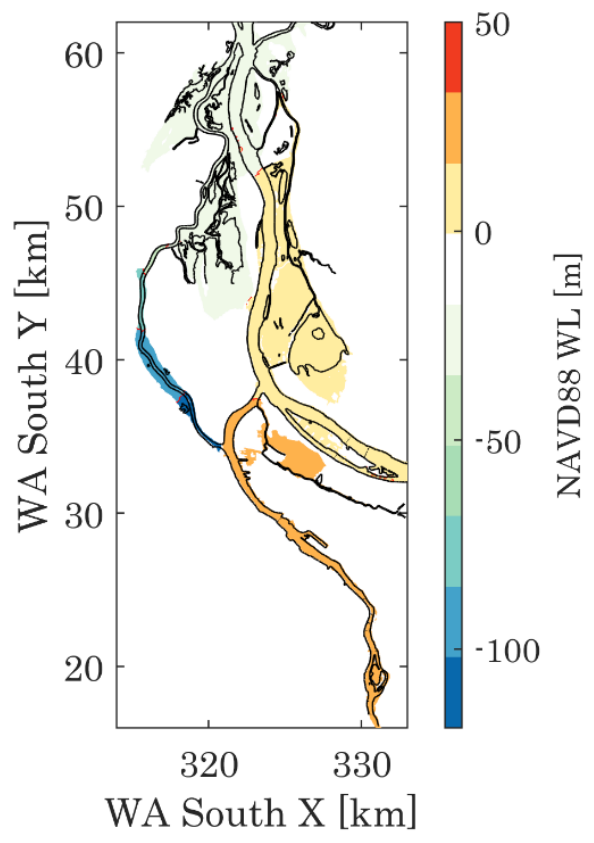

Figure 5.6: Effect of closing Multnomah Channel - contour plot of the difference in water level.

The February 1996 flood produced high Willamette River downstream discharge and significant discharge from the Columbia River (Figure 5.2). I used two flow artificial simulations with flows covering the range of flows seen in 1996 to evaluate how the Columbia River to Willamette River discharge ratio affects the flow partition at Junction A. In both simulations use tidal conditions from 1996, i.e. the tidal amplitude and phases from the eight largest tidal constituents. These simulations are artificial in the sense that the input flows are stepwise constant, rather than continuously varying. This approach allows evaluation of "equilibrium", steady flow conditions, independent of transient effects. The tidal forcing is, however, as observed during the 1996 flood period.

In the first simulation, the Willamette River discharge (at Oregon City, at WR 41) increases in two steps from $2,500 \mathrm{~m}^{3} \mathrm{~s}^{-1}$ to $7,500 \mathrm{~m}^{3} \mathrm{~s}^{-1}$ in $2,500 \mathrm{~m}^{3} \mathrm{~s}^{-1}$ increments, while the 
Columbia River discharge (Bonneville CR 234) remains at 2,500 $\mathrm{m}^{3} \mathrm{~s}^{-1}$ (Figure 5.7a). Figures 5.7a and 5.7d show the discharge time series of modeled discharge at St Johns Bridge (WR rkm 9.7) and Columbia River rkm 165 (upstream of Kelley Point). These locations are downstream of discharge boundaries and tidally influenced. With increasing Willamette River discharge, more Willamette River discharge flows towards the Junction B (Kelley Point), less discharge goes through the Multnomah Channel towards Junction C (St Helens), $\mathrm{Q}_{\mathrm{WR}} / \mathrm{Q}_{\mathrm{MC}}$ increases (Figure 5.7b), and the square root of the surface slope ratio $\left(\mathrm{S}_{\mathrm{R} 1} / \mathrm{S}_{\mathrm{R} 3}\right)^{1 / 2}$ increases (Figure 5.7c). In the second experiment, the Columbia River discharge increases in two steps from 2,500 $\mathrm{m}^{3} \mathrm{~s}^{-1}$ to $7,500 \mathrm{~m}^{3} \mathrm{~s}^{-1}$ in $2,500 \mathrm{~m}^{3} \mathrm{~s}^{-1}$ increments, while the Willamette River discharge remains constant at 2,500 $\mathrm{m}^{3} \mathrm{~s}^{-1}$ (Figure 5.7d). As the ratio of Columbia River discharge increases, more Willamette River discharge flows through the Multnomah Channel towards Junction C (St Helens), QwR/QMC decreases (Figure 5.7e), and the surface slope ratio $\left(\mathrm{S}_{\mathrm{R} 1} / \mathrm{S}_{\mathrm{R} 3}\right)^{1 / 2}$ decreases (Figure 5.7f).

Combining the results of the two experiments, I can estimate how the ratio of Willamette River discharge to Columbia River discharge affects the surface slope ratio. Figure 5.6 is a plot of the discharge ratio (Columbia R./Willamette R.) versus the square root of the surface slope ratio (Reach $1 /$ Reach 3 ). The results show predictably that high Columbia River discharge tends to drive flow towards the Multnomah Channel at Junction A, i.e. $\left(S_{R 1} / S_{R 3}\right)^{1 / 2}$ increases. I have also fitted the relationship between the discharge ratio and the surface slope ratio with a $3^{\text {rd }}$ order polynomial.

$$
\left(\frac{S_{R 1}}{S_{R 3}}\right)^{\frac{1}{2}}(x)=0.0754 x^{3}+0.0963 x^{2}-0.7008 x+2.0326
$$


In Equation 5.7, $x$ is the discharge ratio (Columbia R/Willamette $\mathrm{R}$ ) and $S^{1 / 2}$ is the square root of the surface slope ratio (Reach 1/Reach 3). This equation is based on the constant flow simulations (Figure 5.7), and it defines an approximation of the steady-state relationship between discharge ratio and surface slope ratio at Junction A.

The results show that when the ratio of Columbia River discharge to Willamette River discharge reaches 1.5 , the square root of the surface slope ratio (Reach 1/Reach 3 ) drops below 1.0, and more Willamette River flows down the Multnomah Channel (Reach 3). Although the surface slope is larger in Multnomah Channel, the hydraulic radius (less depth) and the channel width are smaller; consequentially, the Willamette River has higher discharge in the simulations in this study. During the February 96 Flood, there were no flow reversals along the Willamette River, i.e., discharge continually flowed towards the Columbia River. During large freshets such as the Columbia River freshet simulated in Chapter 3 of this dissertation, the ratio of Columbia R./Willamette R. discharge may increase to 10 or higher. At the peak of such a large freshet, the Multnomah Channel can carry more discharge than the Willamette River. 

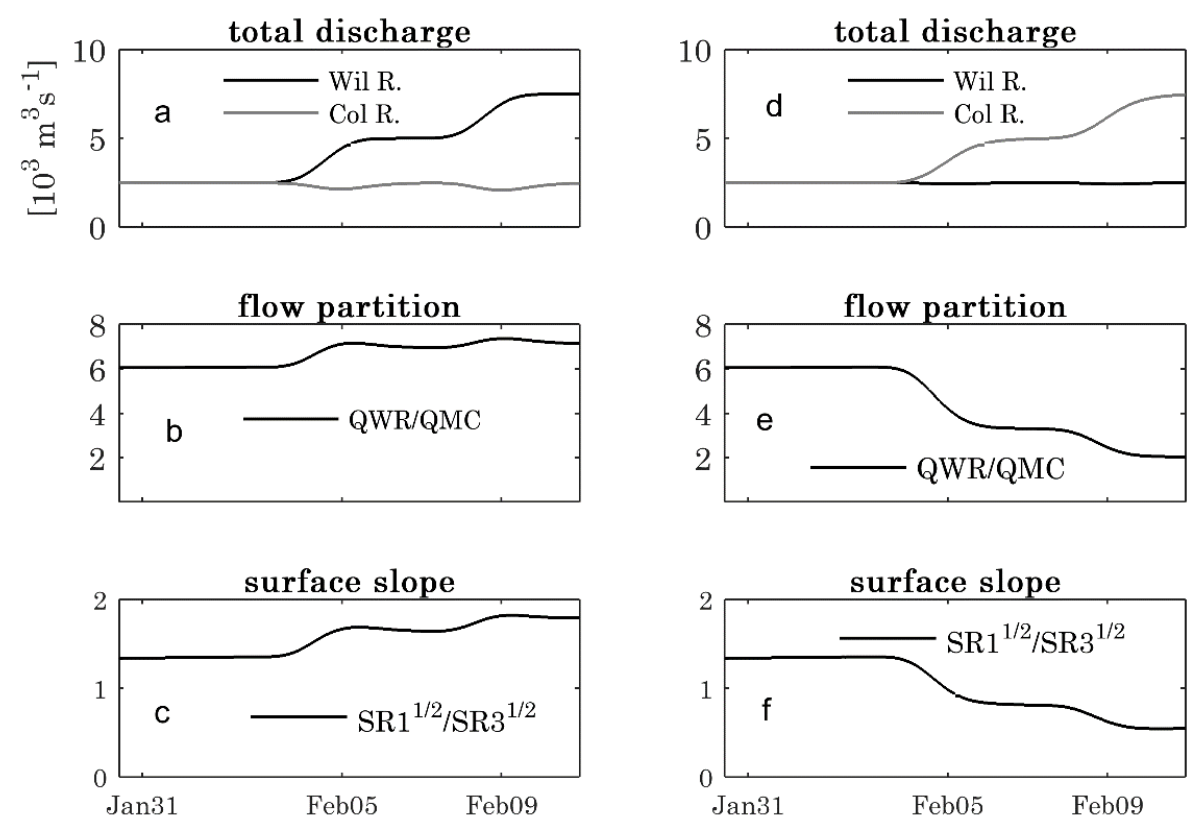

Figure 5.7 Effect of Columbia R. discharge on flow partition and surface slope at Junction A. (a,b,c) variable Willamette R., (d,e,f) variable Columbia R.

The tides are those of Jan-Feb 1996, but that the flows are hypothetical, stepped as described in the text.

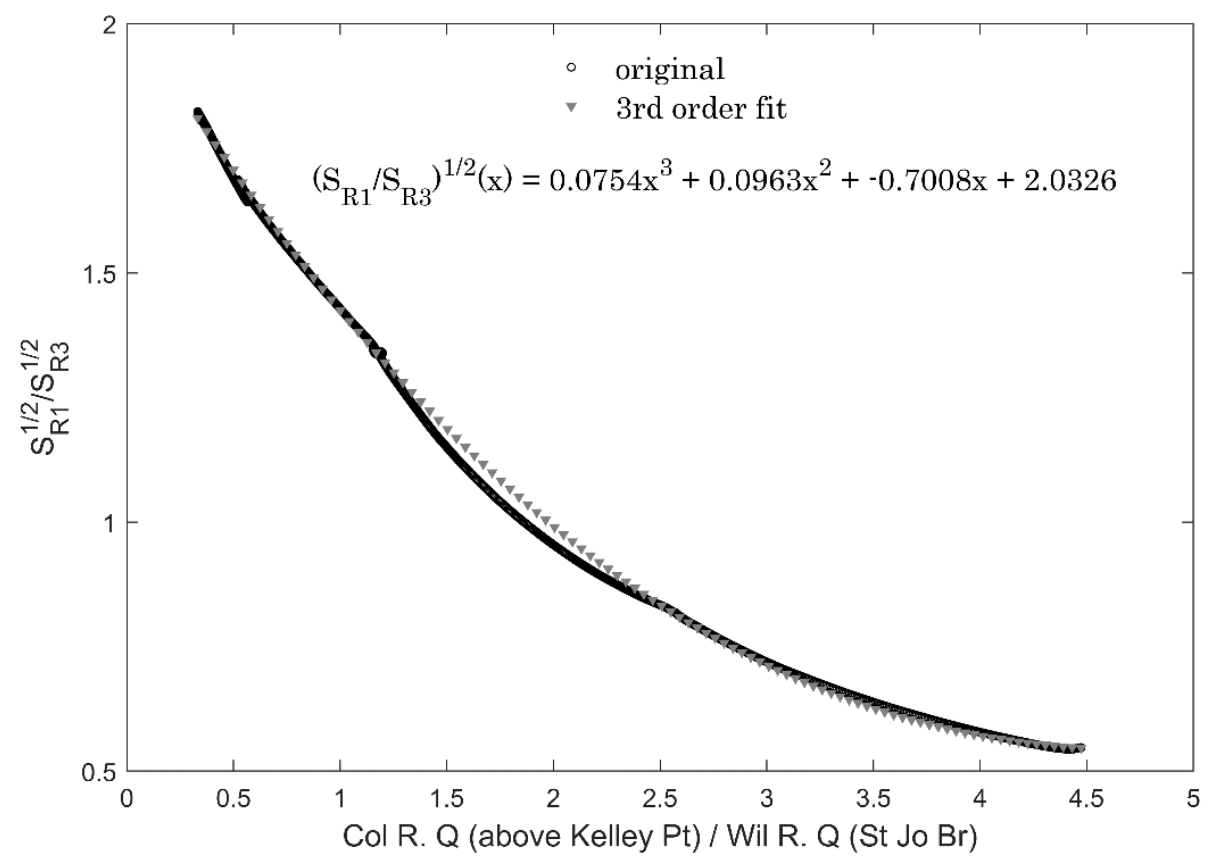


Figure 5.8 Ratio of Columbia R./Willamette R. discharge versus square root of surface slope ratio at Junction A for steady-state conditions.

I apply the same analysis used to determine flow partition at steady-state conditions to the February 1996 flood. The results show that the empirical flow partition (Equation 5.6) produces a similar result to the modeled cross-sectional discharge through Reach 1 and Reach 3 (Figure 5.9). The results show that the flow partition varies from nearly 1, i.e., the Willamette River and the Multnomah Channel have nearly the same carry-capacity, to nearly 2.8, i.e., the Willamette River carrying 2.8 times the discharge of the Multnomah Channel in Reach 1. To determine which terms on the right-hand side of Equation 5.6 are important, I analyzed them individually (Figure 5.10). The area ratio between Reach 1 and Reach 3 (Figure 5.10 top), varies from 2.75 to 2.9 (5.5\%), while the hydraulic radius term (Figure 5.10 middle) varies from $1.18-1.20(1.7 \%)$. By contrast, the surface slope term (Figure 5.10 bottom) varies from $0.3-0.8(167 \%)$. Clearly, variations in the flow partition are driven mainly by changes in the surface slope ratio $\left(\mathrm{S}_{\mathrm{R} 1} / \mathrm{S}_{\mathrm{R} 3}\right)^{1 / 2}$ of Equation 5.6.

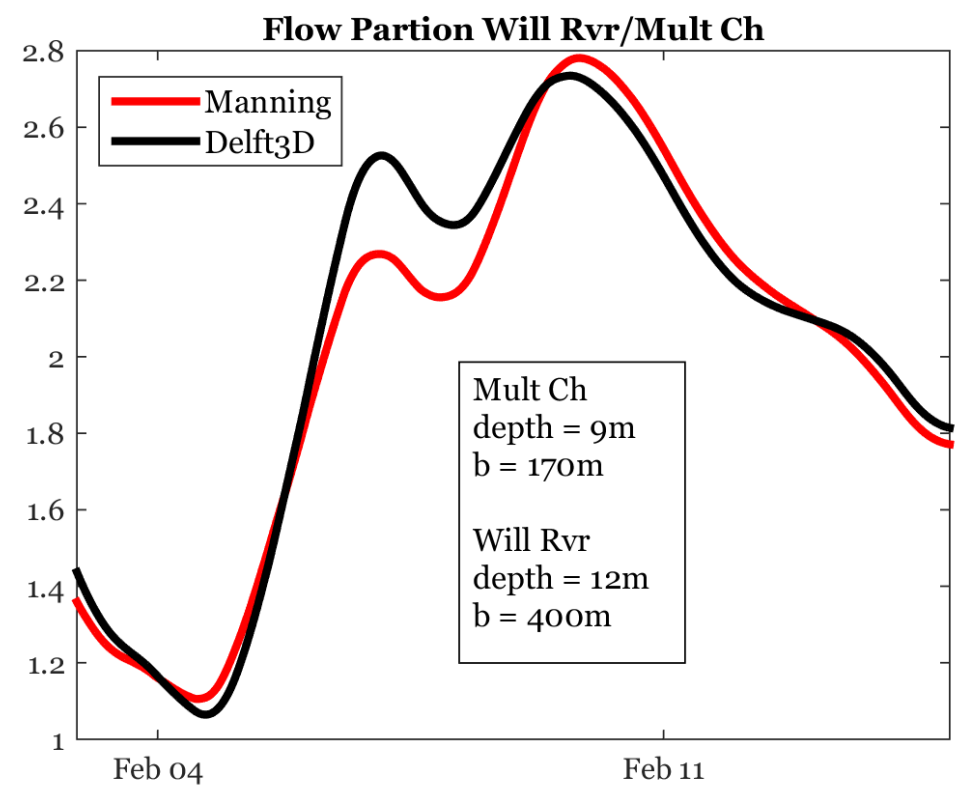

Figure 5.9 Flow partition at Junction A during Feb 19 flood. 
Figure 5.11 shows the comparison between the surface slope ratio during the flood (black) and the steady-state surface slope ratio based on Equation 5.7. The results show that the surface slope ratio at Junction A is much lower than the steady-state relationship from Equation 5.7. This means that much more discharge goes through Multnomah Channel than would be expected. Differences between the "equilibrium" (steady) and transient responses are likely due to the time needed to fill and empty wetlands, a relatively slow process compared to barotropic adjustments in surface slope. 

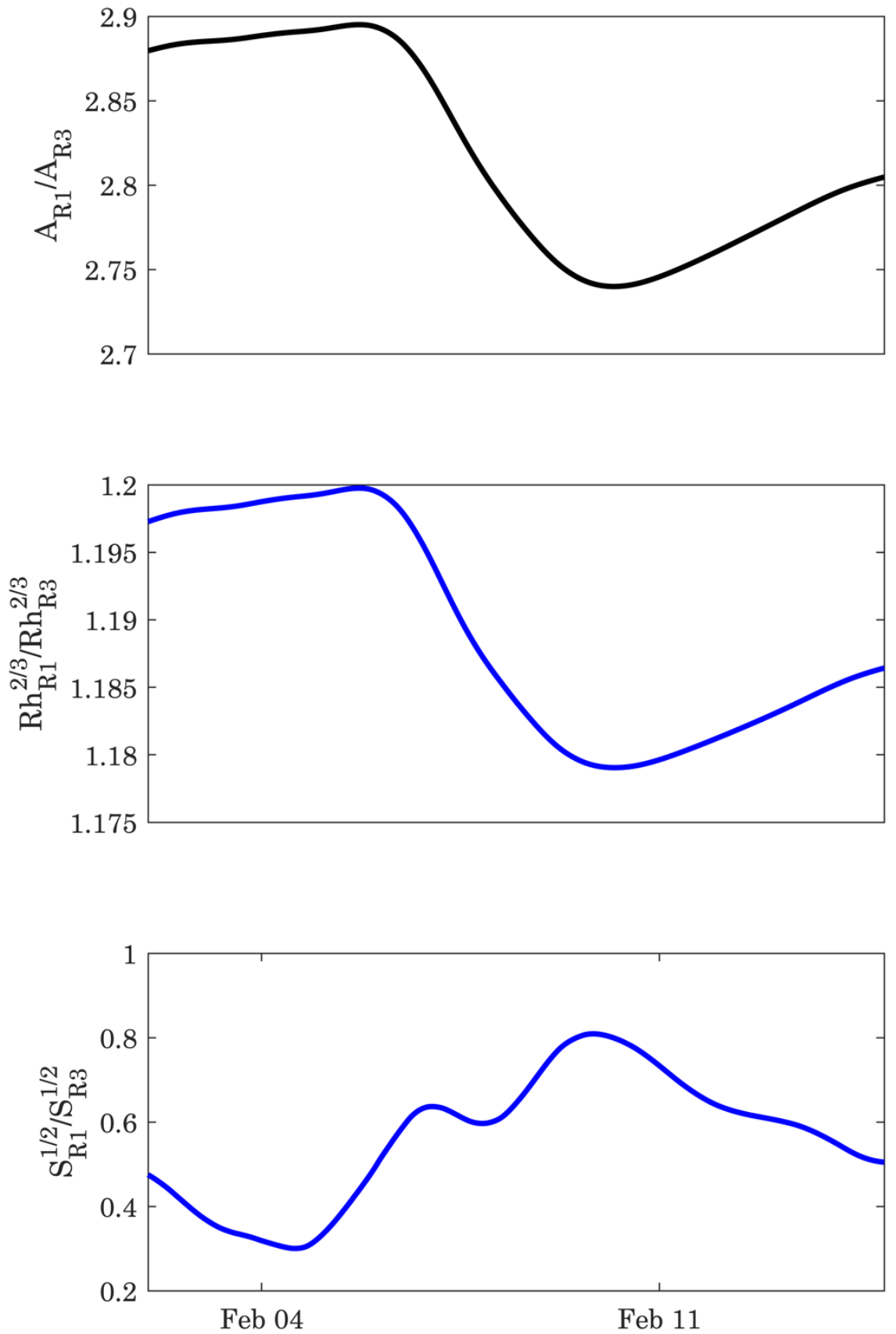

Figure 5.10 Terms of the Manning Equation at Junction A during flood 


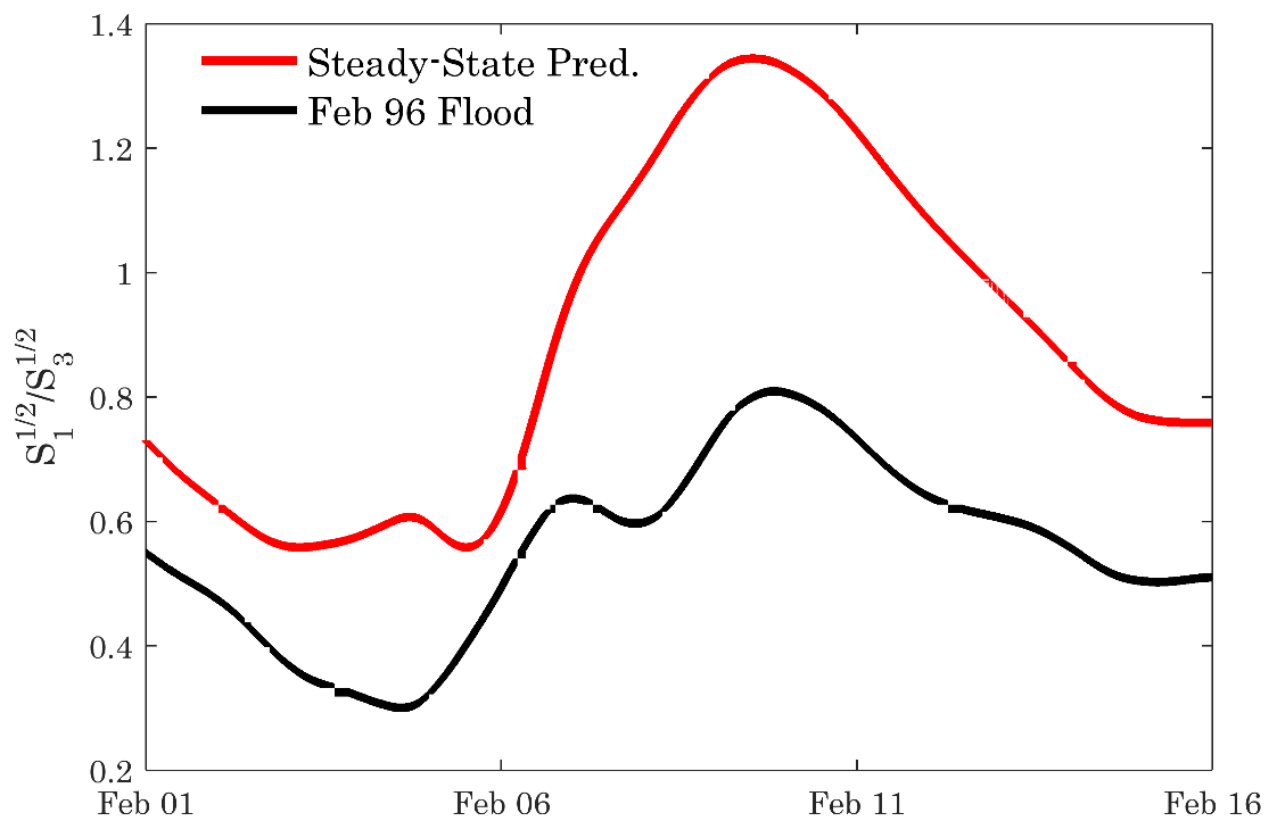

Figure 5.11: Surface slope ratio at Junction A: steady-state (black ) and the Feb 96 Flood (red). Steady -state based on Equation 5.7.

The changes in the terms of the Manning Equation along the Multnomah Channel give insights to changes in flow partition at Junction A. Figure 5.12 shows the surface slope from rkm 10-16 on the Multnomah Channel, with total discharge (Columbia River rkm $162+$ Multnomah Channel rkm 32) plotted as red dots on the top panel, and the hydraulic radius raised to the $4 / 3$ power at Multnomah Channel rkm 10. The results show that in the middle segment of Multnomah Channel, the surface slope is highest at $16 \times 10^{3}$ $\mathrm{m}^{3} \mathrm{~s}^{-1}$ discharge and lowest at peak discharge. Also, the surface slope between a discharge of $16 \times 10^{3} \mathrm{~m}^{3} \mathrm{~s}^{-1}$ and peak discharge is higher on the rising limb than the falling limb. I look to changes in water levels along Multnomah Channel to explain the difference in surface slope on the rise and falling limbs. The results show that the surface slope and flow 
partition at Junction A is initially controlled by the ratio of Columbia River to Willamette River when the flow remains within the river banks.
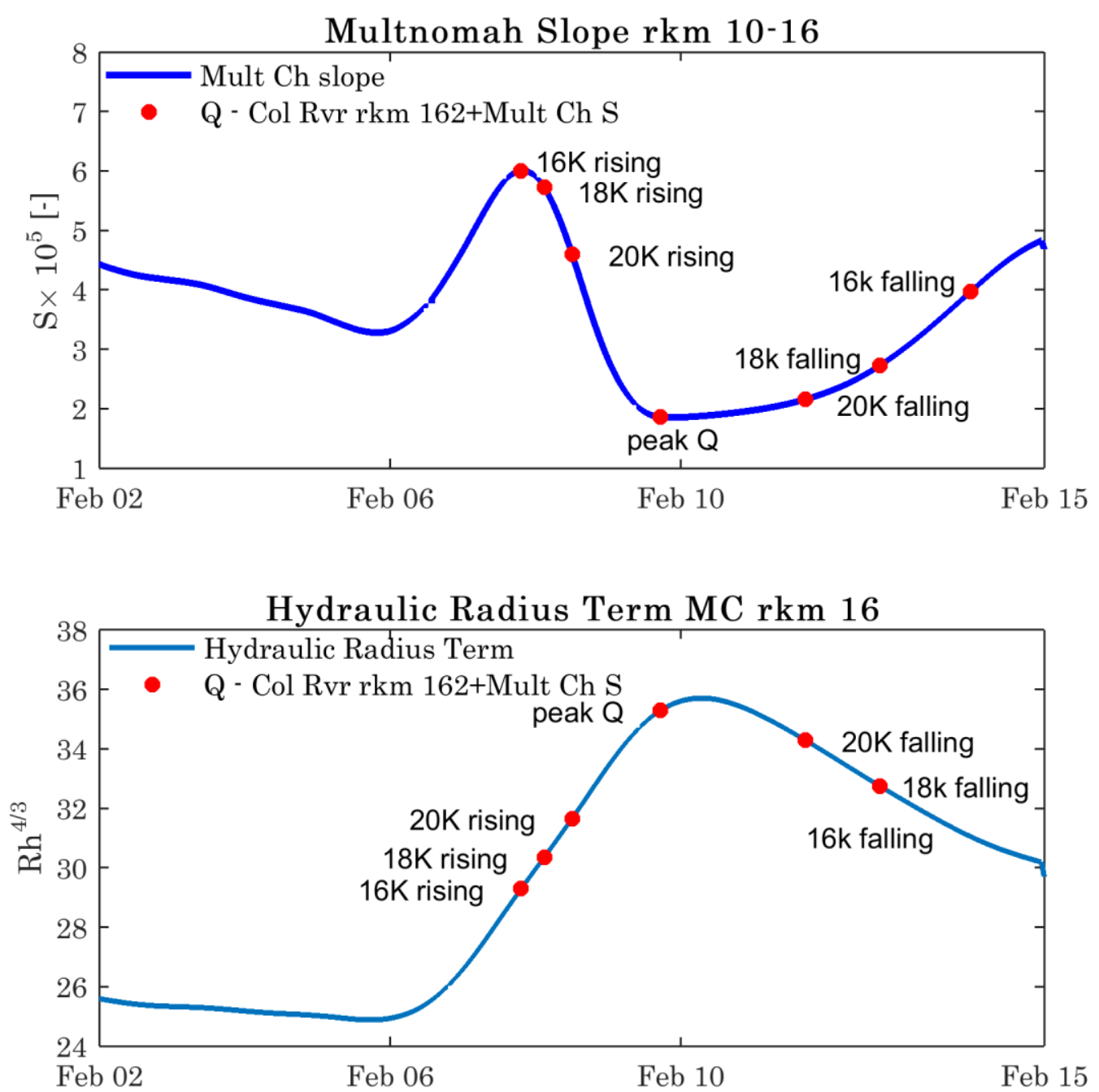

Figure 5.12: surface slope and hydraulic radius on Multnomah Channel rkm 10-16.

The shapes of the water level gradient along the flow paths (Willamette River/Multnomah Channel) on the rising and falling limbs of a flood are indicative of processes, such as inundation, that affect hysteresis. Figure 5.13 is a plot of the water level gradient through the west path around Sauvie Island (Junction A - Junction C) during the 
rising and falling limbs of the flood for a flow of $18 \times 10^{3} \mathrm{~m}^{3} \mathrm{~s}^{-1}$. I am using the Columbia River discharge at rkm 162 as a reference, and I am plotting the elevation drop relative to the elevation at the confluence of Multnomah Channel and the Willamette River (Junction A). The shape of the water level curves particularly from Multnomah Channel rkm 10 20 are markedly different. On the rising limb in this segment, the curve is concave up, while on the falling limb, the curve is concave down. There are also distinct differences in the surface slope near the Willamette River. Using the segment of the river from Multnomah Channel rkm 0-10, the rising limb has a surface slope of $5 \times 10^{-5} \mathrm{~m} / \mathrm{m}$, while the surface slope in that same segment drops to $3.47 \times 10^{-5} \mathrm{~m} / \mathrm{m}$ on the falling limb.

Interestingly, the shape of the water level gradient along the east path around Sauvie Island changes less between rising and falling limbs of the floods. Figure 5.14 shows the water level difference around the east path measured relative to the elevation at Junction A. The decrease in water level along Willamette River and Columbia River is measured with respect to elevation at the junction of the Willamette River and Multnomah Channel (node 1). The plot is based on Columbia River discharge at rkm 162. It is immediately obvious that the Willamette River between rkm 0-4.85 (Junction A - Junction B), has a very low surface slope on both the rising and falling limbs. In this stretch of the river, the surface slope drops from $2.12 \times 10^{-5} \mathrm{~m} / \mathrm{m}$ on the rising limb, to $1.58 \times 10^{-5} \mathrm{~m} / \mathrm{m}$ on the falling limb, significantly less than the surface slope on the south end of Multnomah Channel. The Columbia River downstream of Kelley Point has a higher surface slope and smaller variation in the surface slope between the rising and falling limbs. Along the Columbia River (Junction B - Junction C), the surface slope drops from $6.47 \times 10^{-5} \mathrm{~mm}^{-1}$ on the rising 
limb, to $5.59 \times 10^{-5} \mathrm{~mm}^{-1}$ on the falling limb. In summary, flow alters the surface slope along both paths, but the slope of the west path changes to a much lesser degree than that of the east path.

Multnomah Channel serves as a release point and a bypass for Willamette River discharge, but the constriction in the Columbia River upstream of Junction C may act to back up flow and raise water levels. Using the combined discharge of the Columbia River at rkm 162 and the downstream discharge Multnomah Channel rkm 32 (see Figures 5.1, 5.2 and 5.3 for model discharge cross-sections) as a reference, I plotted the differences in inundation between the rising and falling limbs of the flood at $18 \times 10^{3} \mathrm{~m}^{3} \mathrm{~s}^{-1}$ discharge. The water level at all locations is significantly higher on the falling limb than the rising limb (Figure 5.15). The inundation plots show that the wetlands on the northern segment of Sauvie Island are partially inundated with up to 6m (NAVD88) of water on the rising limb of the flood (Figure 5.15 left). On the falling limb of the flood, there is more extensive inundation and water levels within the same area rise to $8 \mathrm{~m}$. I also measure the inundation with an observation point in north Sauvie Island; Figure 5.17 is a plot of the water level on the Sauvie Island floodplain (grey), and the Columbia River discharge at rkm 162 (downstream of Kelley Point). On February 8, 1996, the water level in north Sauvie Island begins to rise. The water level peaks on February 10, 1996, and then slowly begins to fall.

The differences in water level before and after peak discharge suggest that the wetlands around Sauvie Island are serving as a reservoir, accumulating upstream discharge from the Columbia River and the Multnomah Channel, and lowering water levels. Figure 5.16 is a conceptual drawing of the entry paths for floodplain inundation in north Sauvie 
Island. Figure 5.18 is a contour plot of water level at the peak of the February 1996 flood. The plot also shows the locations of the Delft3D monitoring cross-sections on the west bank of the Columbia River along north Sauvie Island. The text in Figure 5.18, e.g. w fldpl01a, indicate the names of the individual cross-sections. During this flood event, there is a maximum discharge rate of nearly $2.4 \times 10^{3} \mathrm{~m}^{3} \mathrm{~s}^{-1}$ on to the Sauvie Island floodplain (Figure 5.19). Figure 5.20 is contour plot of water level at the peak of the February 1996. The plot shows the locations of Delft3D monitoring cross-sections on the east bank of the Columbia River between Kelley Point and St Helens. During this flood event, there is a maximum discharge rate of nearly $1.8 \times 10^{3} \mathrm{~m}^{3} \mathrm{~s}^{-1}$ on to the floodplains on the east bank of the Columbia River (Figure 5.21) at the time of peak flood flow. The combined floodplain discharge of $4.2 \times 10^{3} \mathrm{~m}^{3} \mathrm{~s}^{-1}$ (east bank plus west bank) is approximately $21 \%$ of the peak discharge of the Columbia River at rkm 162. 


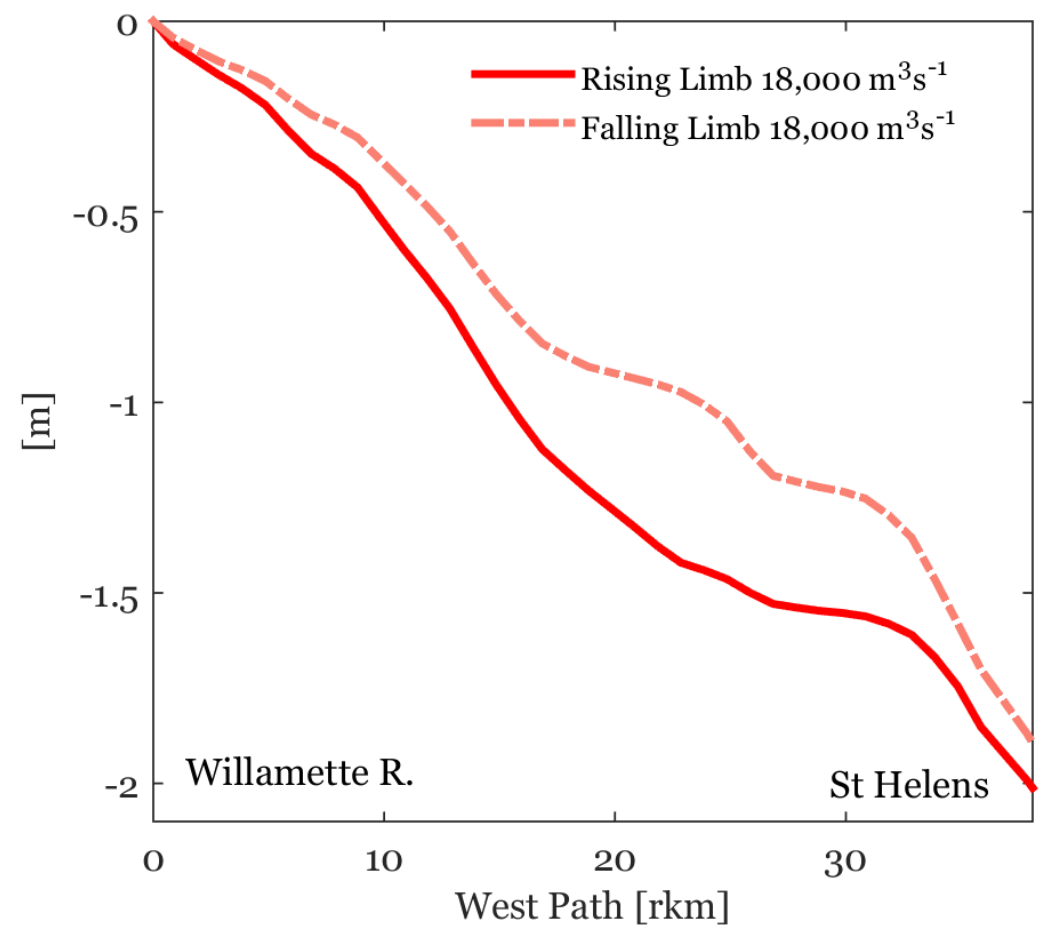

Figure 5.13: water level gradient through Reach 3 (Multnomah Channel)

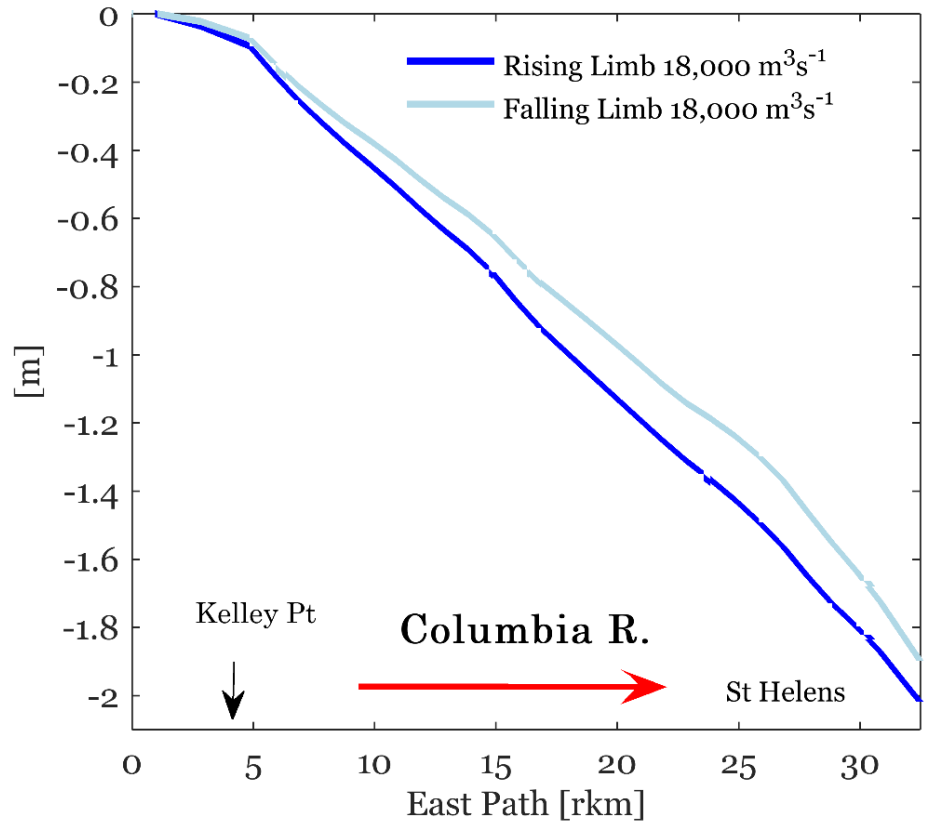

Figure 5.14: Water level gradient through Reach 2 (Willamette R) and Reach 3 (Columbia R) 

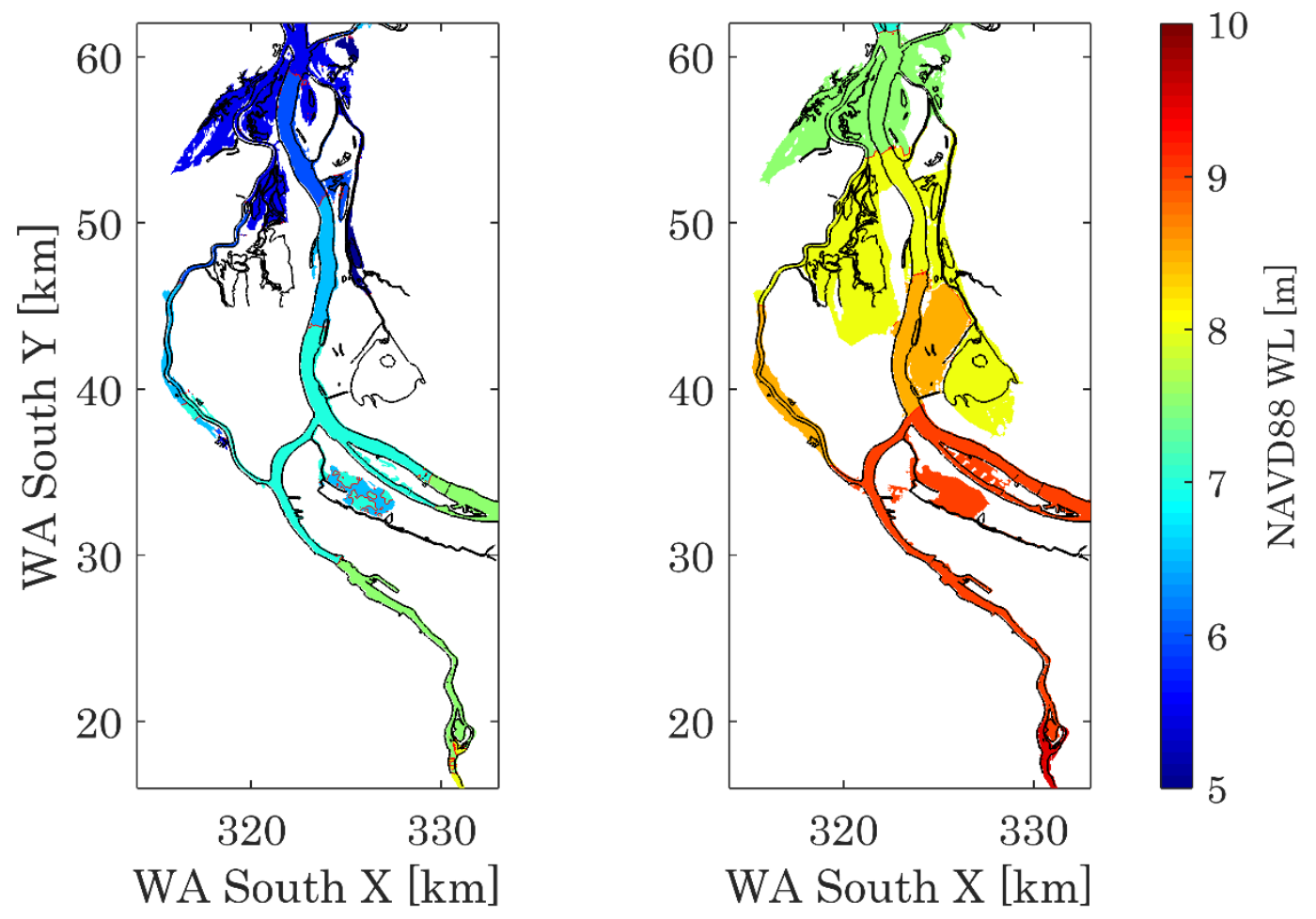

Figure 5.15: Contour plots of water levels at $18 \times 10^{3} \mathrm{~m}^{3} \mathrm{~s}^{-1}$ (baseline scenario) during the February 1996 flood (left) rising limb of the flood (right) falling limb 


\section{$\Longrightarrow$ Floodplain Discharge}

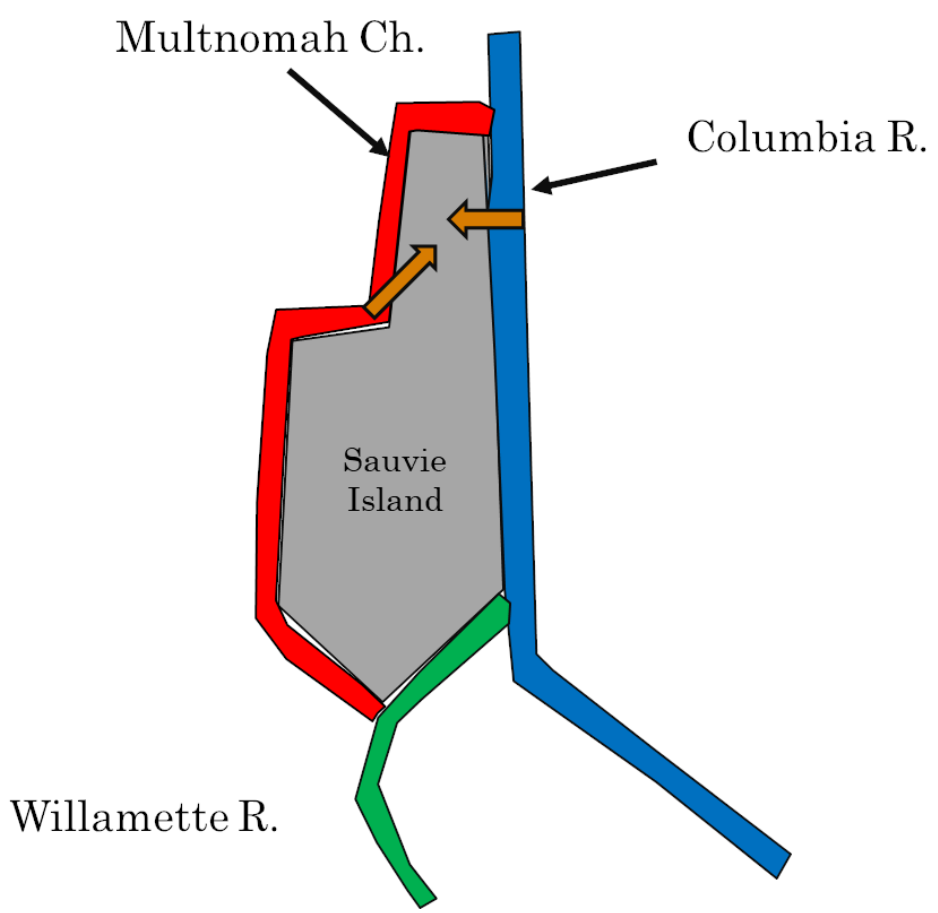

Figure 5.16: Conceptual drawing of floodplain inundation on north Sauvie Island

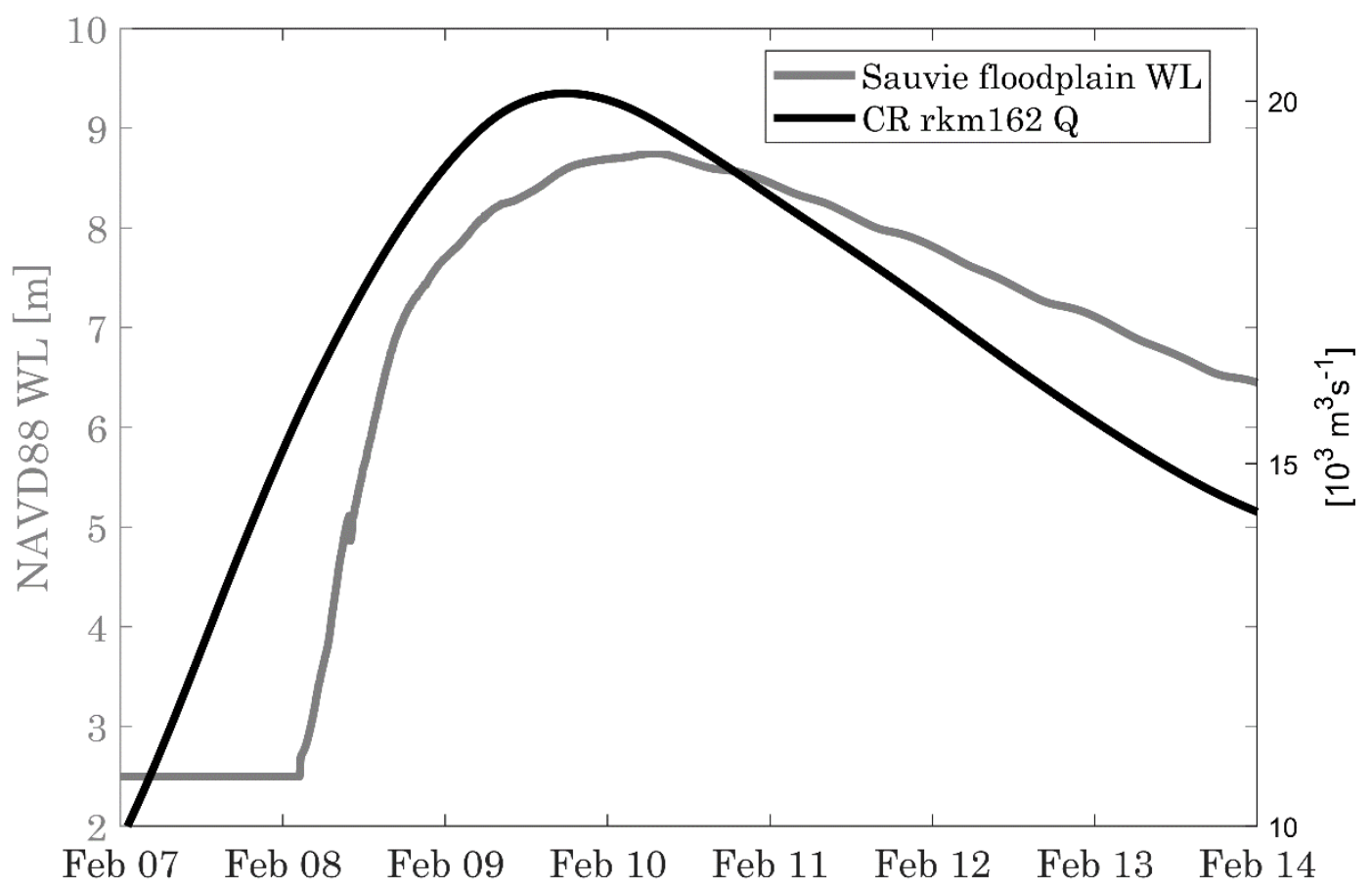


Figure 5.17: Columbia River discharge downstream of Kelley Point (black) hydrograph at north Sauvie Island (grey)

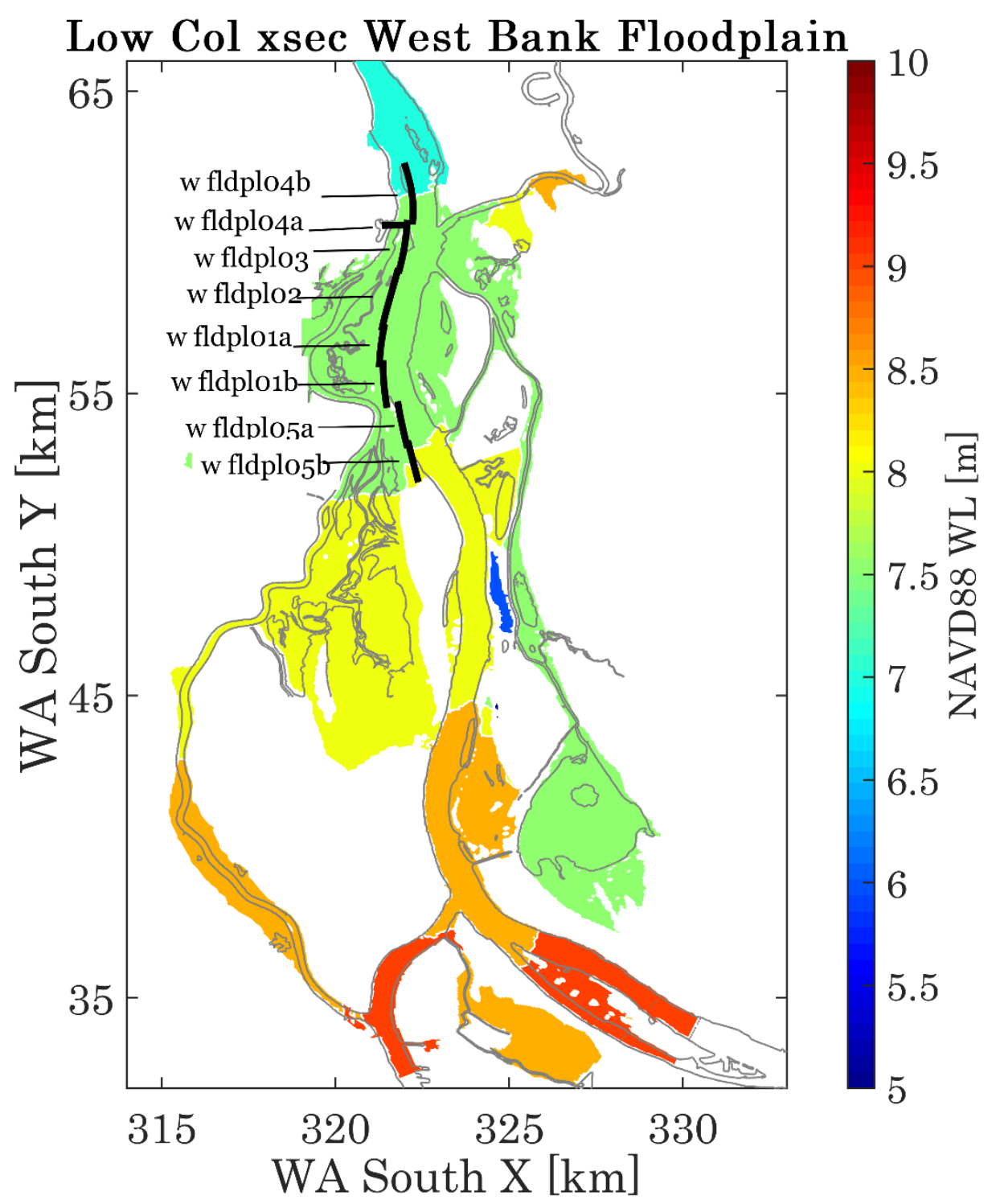

Figure 5.18: Contour plot of the peak of the 1996 flood. Black lines are location of the monitoring crosssections on the west bank of the Columbia River. 


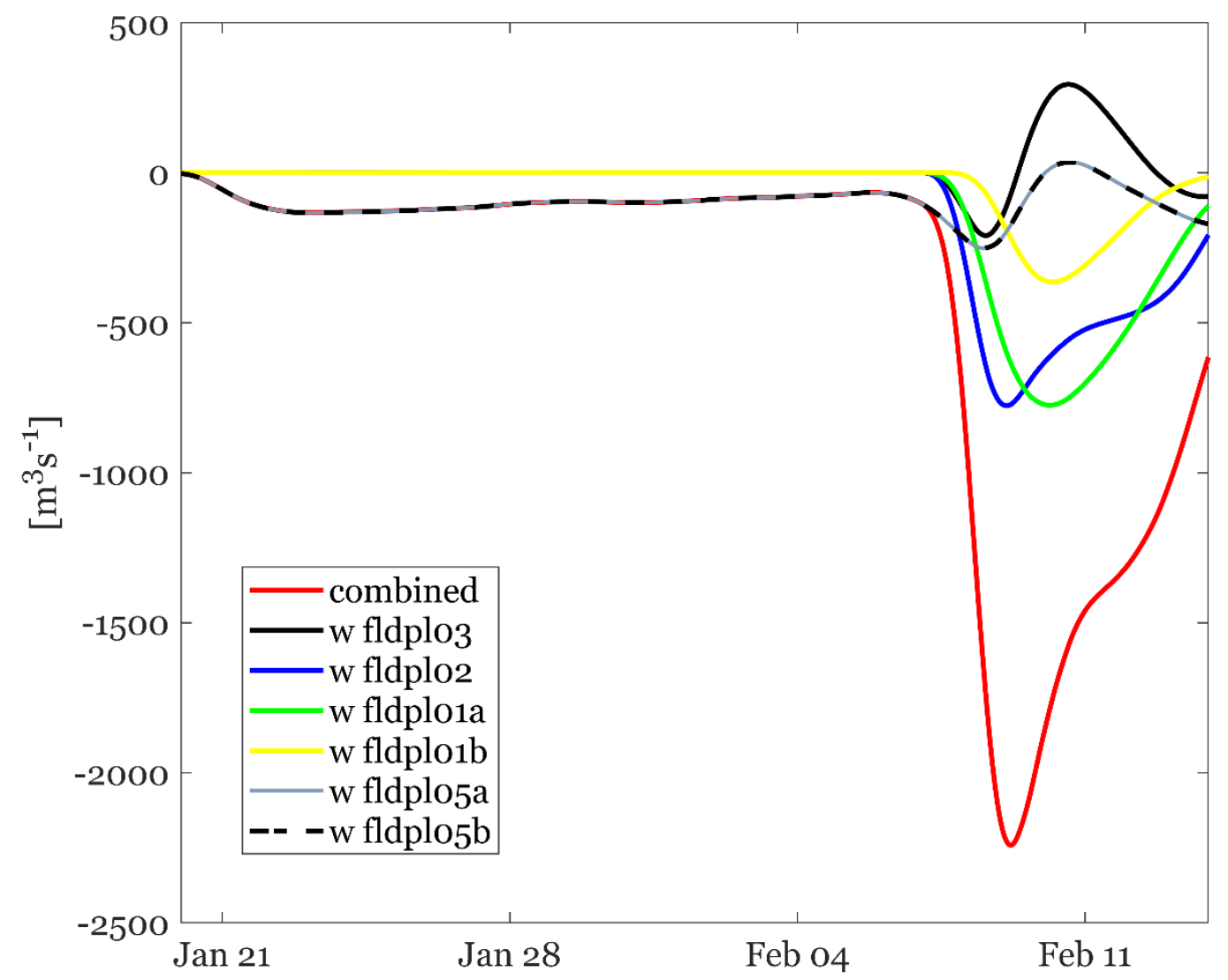

Figure 5.19: Floodplain discharge on the west bank of the Columbia River. See Figure 5.16 for the location of each monitoring cross-section. 


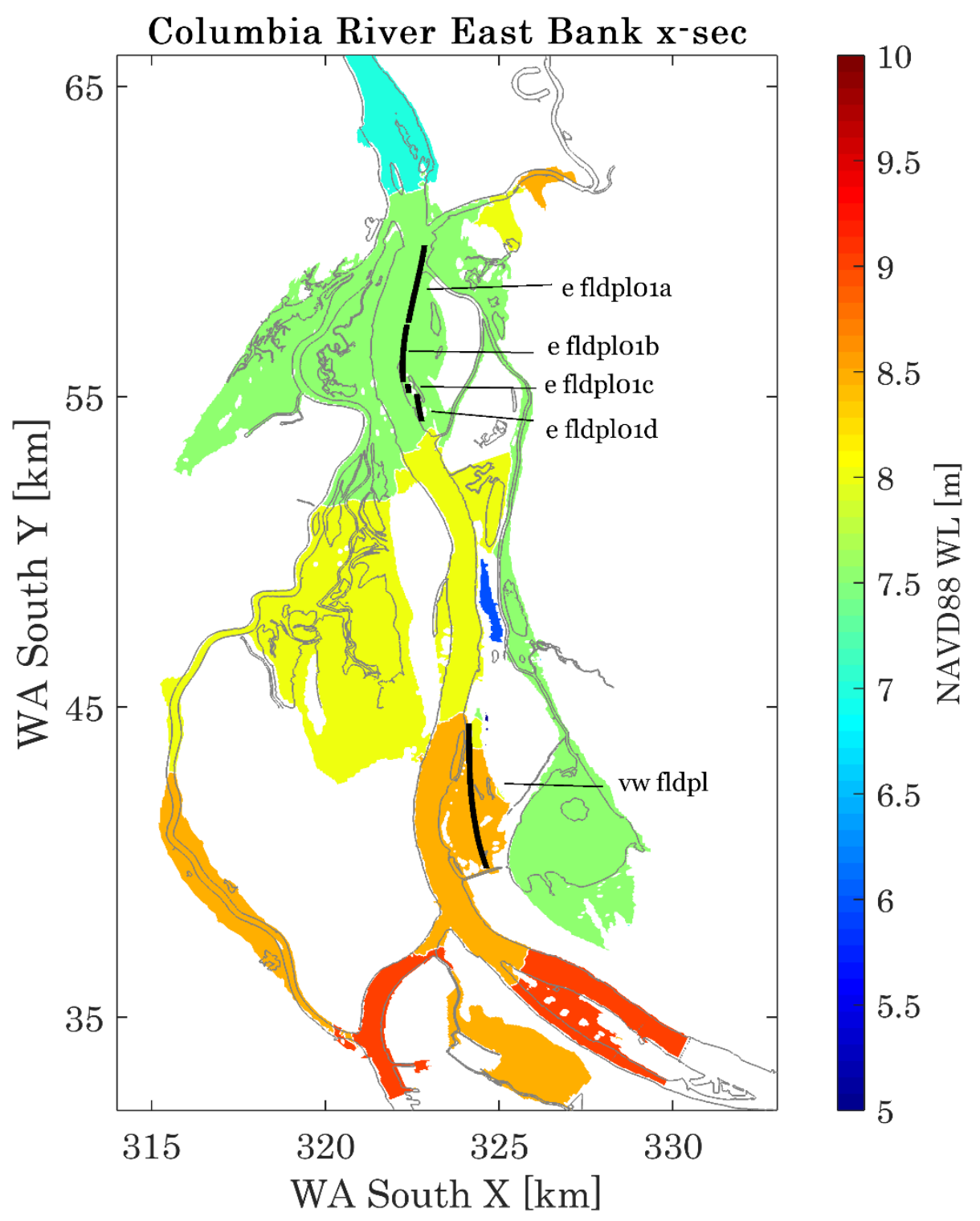

Figure 5.20: Contour plot of the peak of the 1996 flood. Black lines are location of the monitoring crosssections on the east bank of the Columbia River. 


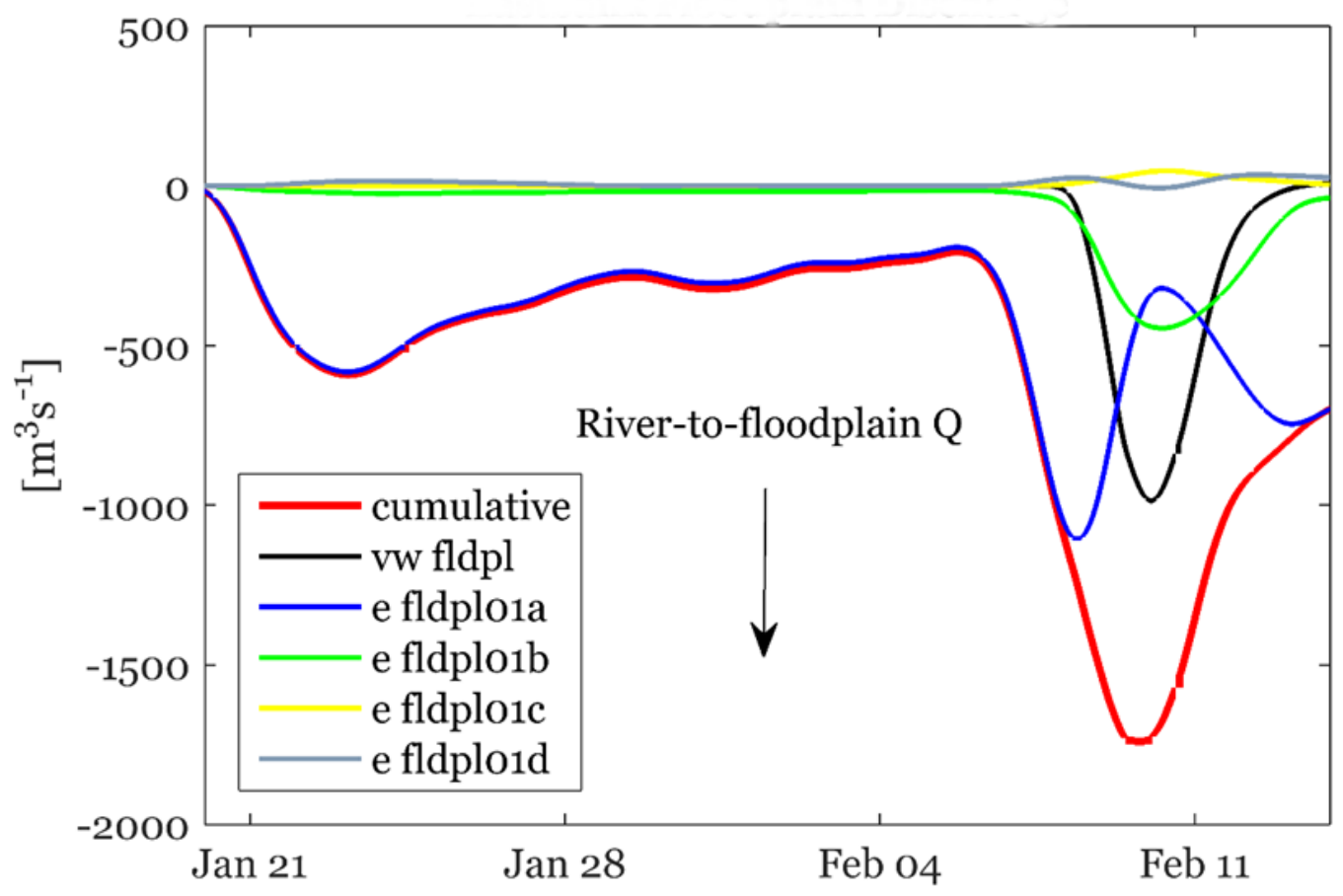

Figure 5.21: Model discharge cross-sections on the east bank (WA) of the Columbia River. See Figure 5.18 for the location of each monitoring cross-section.

The effects of floodplain inundation are shown by evaluating spatial changes of discharge versus surface slope for the three reaches studied here. Through Reach 3, distinct patterns in the surface slope emerge in the upstream region, which is upstream of the inundated wetlands, the middle segment, which has a significant amount of inundation, and the downstream segment, which is mostly downstream of the inundated wetlands. There is no correlation between discharge and surface slope near Junction A and the middle segment of Multnomah Channel. In the upstream Multnomah Channel (rkm 30-34), the surface slope peaks one day before the discharge (Figure 5.18, top), and the surface slope on the falling limb is lower for a given discharge than on the rising limb. While the upstream 
segment of Multnomah Channel remains below the bankfull level, the middle segment has a small degree of inundation on the rising limb, and much more extensive inundation on the falling limb (Figure 5.13). In the middle segment of Multnomah Channel, the surface slope peaks over two days before the discharge. The surface slope reaches a minimum value when the discharge peaks, and then slowly rises on the falling limb. I propose that the decrease in surface slope on the rising limb is due to overbank discharge, while the rise in surface slope after the discharge peak is likely due to the wetlands draining. Meanwhile, in the downstream section of Reach 3 from Multnomah Channel to the confluence with the Columbia River, the surface slope peaks at the same time as the river discharge (Figure 5.18 - bottom). The surface slope is not appreciably affected by the upstream inundation.

The most significant changes in surface slope through Reach 1 and Reach 2 occur in locations with floodplain inundation. Through Reach 1, (the Willamette River between the confluence with the Multnomah Channel and the Kelley Point), there is a small amount of flow into the Columbia Slough $\left(350 \mathrm{~m}^{3} \mathrm{~s}^{-1}\right.$ peak discharge). The surface slope is likely not affected by the small amount of flow diverted through the Columbia Slough (Figure 5.13). In Reach 2, the discharge versus surface slope relationship follows a similar pattern to Reach 3. In the upstream region of the Reach 3 near Junction B (Columbia River rkm 154-162), the surface slope peaks roughly one day before the discharge peak, and for a given discharge, the surface slope is lower on the falling limb than the rising limb (Figure 5.19 , top). In the middle segment of the Reach 3 (Columbia River rkm 144-150), the surface slope peaks roughly 1.5 days before the discharge peak (Figure 5.19, middle). The surface slope reaches a minimum at the discharge peak and then remains nearly constant 
as the discharge drops. Further downstream in Reach 3 (Columbia River rkm 136-142), the surface slope peaks at the same as the discharge, and for a given discharge the surface slope is the same on the rising and falling limbs (Figure 5.19, bottom). 

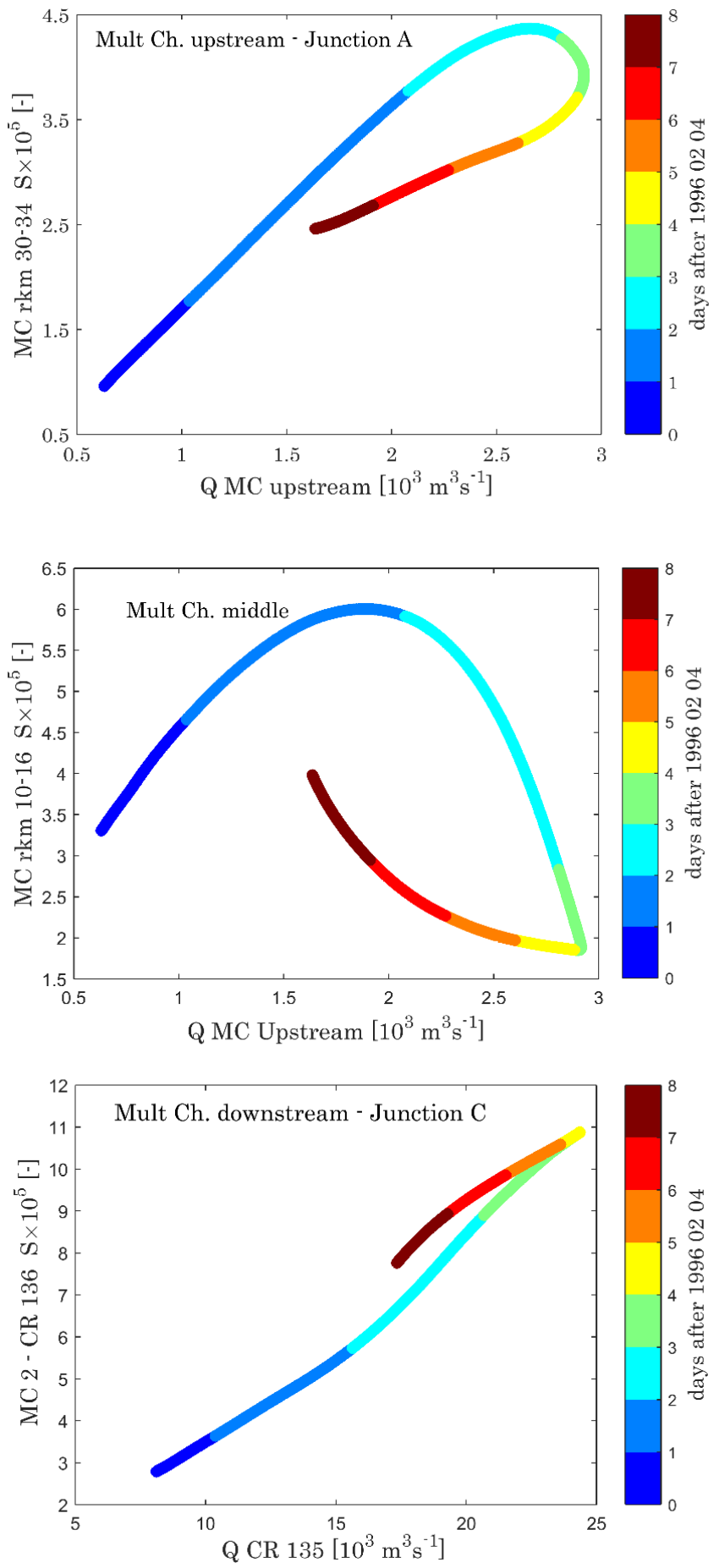

Figure 5.22: Discharge versus surface slope along Reach 3 (Multnomah Ch. - west path). The colored values represent days after February 4, 1996 GMT. 

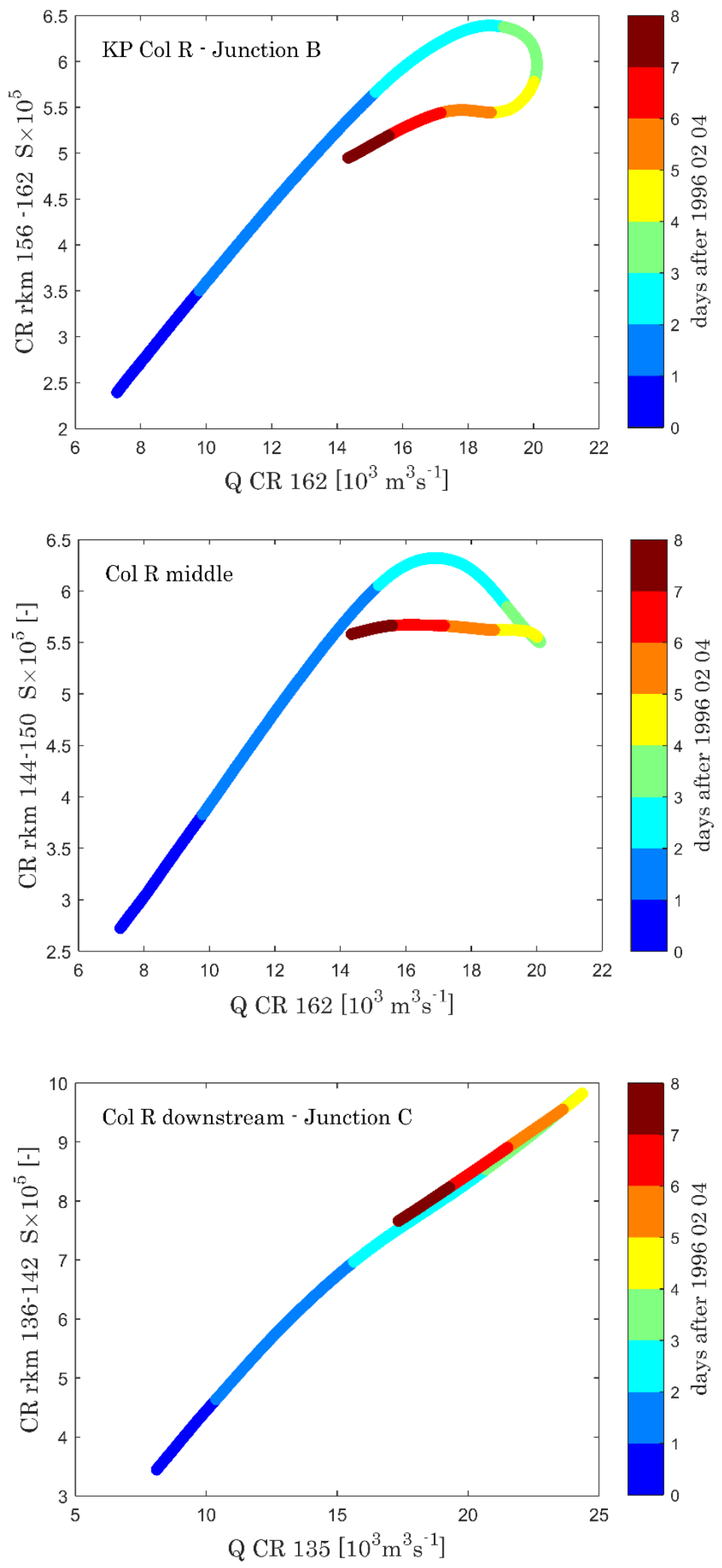
Figure 5.23: Discharge versus surface slope along and Reach 2. (Columbia R. - east path). The colored values represent days after February 4, 1996 GMT.

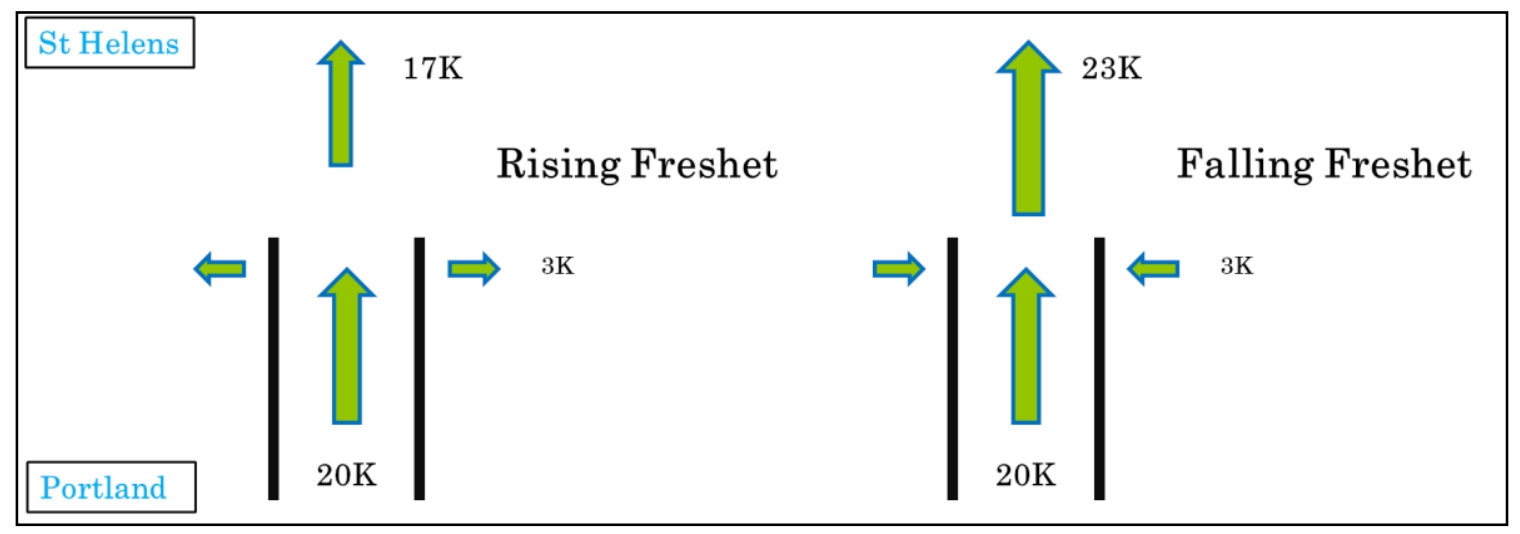

Figure 5.24: Conceptual drawing of floodplain inundation on the risng limb and falling limb of a flood.

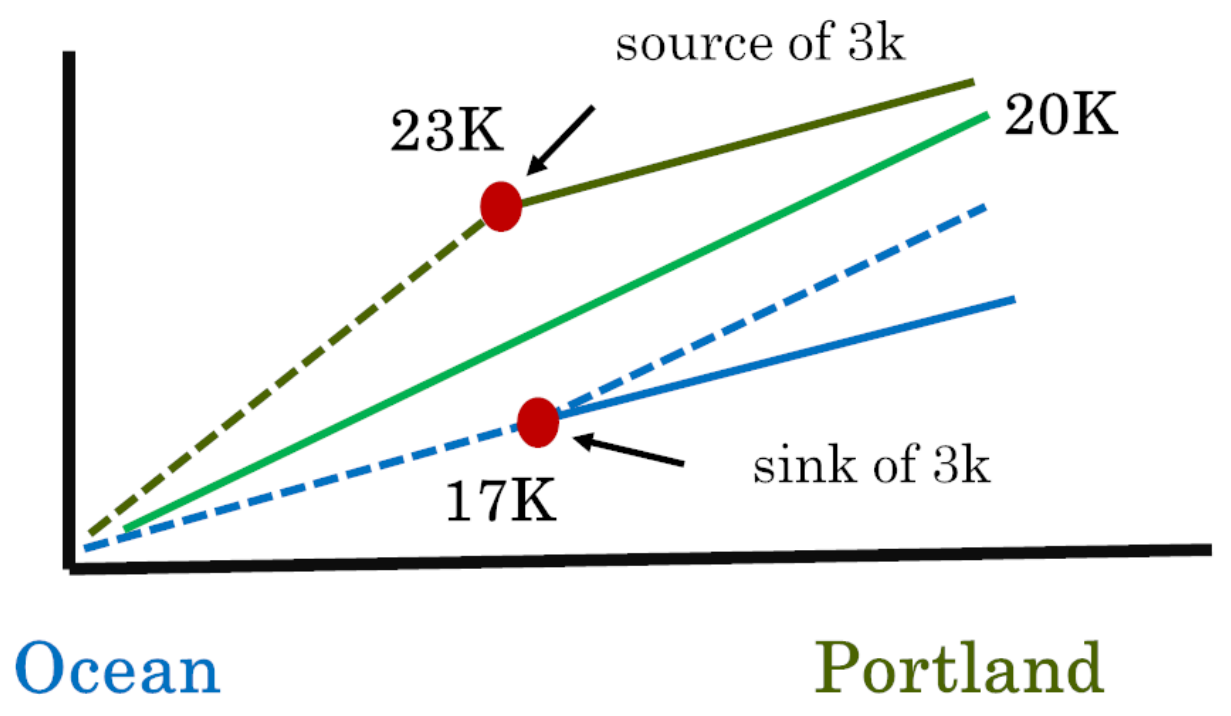

Figure 5.25: Conceptual drawing of the effect of floodplain storage on water level gradient.

I have shown that there is significant floodplain inundation during the February 1996 flood (Figure 5.18 - 5.21). During the rising limb of the flood, the floodplains initially act as a sink, accumulating upstream discharge from the Columbia River and the Multnomah Channel. On the falling limb of the flood, the same wetlands now act as a 
source, with the accumulated floodplain discharge draining back into the river channel (Figure 5.24). Floodplain discharge affects surface slope when the wetlands are acting as a sink. In the conceptual model in Figure 5.25, floodplain downstream of Portland are accumulating discharge. From the perspective of an observer in Portland, there is a higher water level gradient than would be expected from the measured discharge (blue lines in Figure 5.25). When the wetlands are acting as a source, the stored water from the wetlands drain back into the river channel and raise the water level in the channel. From the perspective of an observer in Portland, there is a lower water level gradient than would be expected for the measured discharge (dark green lines in Figure 5.25).

\subsubsection{Hysteresis of the Rating Curve}

In the previous section, I showed that inundation and overbank flow on the northern segment of Sauvie Island causes a drop in upstream surface slope leading to hysteresis in the rating curve of discharge versus water level. With hysteresis, the water levels are dependent on the discharge and the discharge history. The hysteresis in locations upstream of St Helens (Junction C), is seen in more detail in plots of rating curves at Kelley Point and Vancouver Columbia River rkm 162 (Figure 5.26). This effect is not seen on the Columbia River immediately downstream of the confluence of the Columbia River and Multnomah Channel (Junction C). At St Helens (CR rkm 135), the peak discharge and peak water levels occur at roughly the same time, and there are slightly higher water levels on the rising limb, compared to the falling limb (Figure 5.27).

To quantify the level of hysteresis, I examine differences in water level for a given discharge range on the rising and falling limbs of a flood. Figure 5.28 shows the water 
level difference between the rising and falling limbs at Kelley Point (WR rkm 0) and the Columbia River (CR rkm 170). The results show that the water level difference is up to $0.8 \mathrm{~m}$ at both Kelley Point and Vancouver.
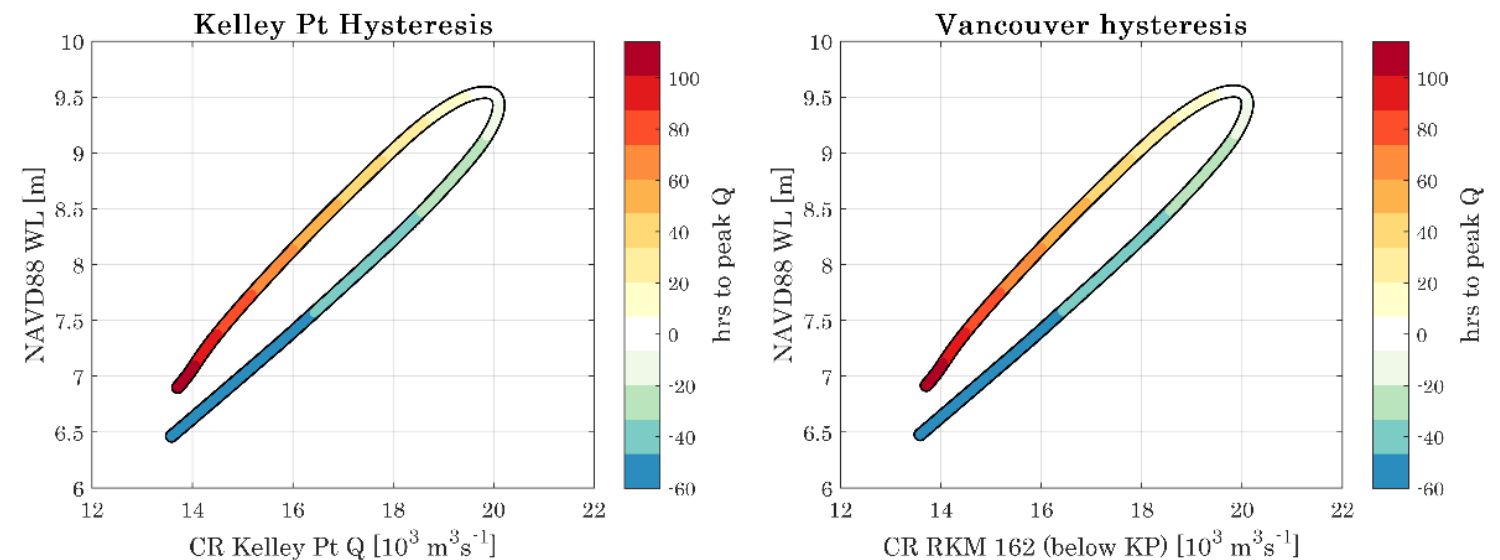

Figure 5.26: Hysteresis at Kelley Point and Vancouver - baseline scenario. The colored values represent hours to peak discharge.

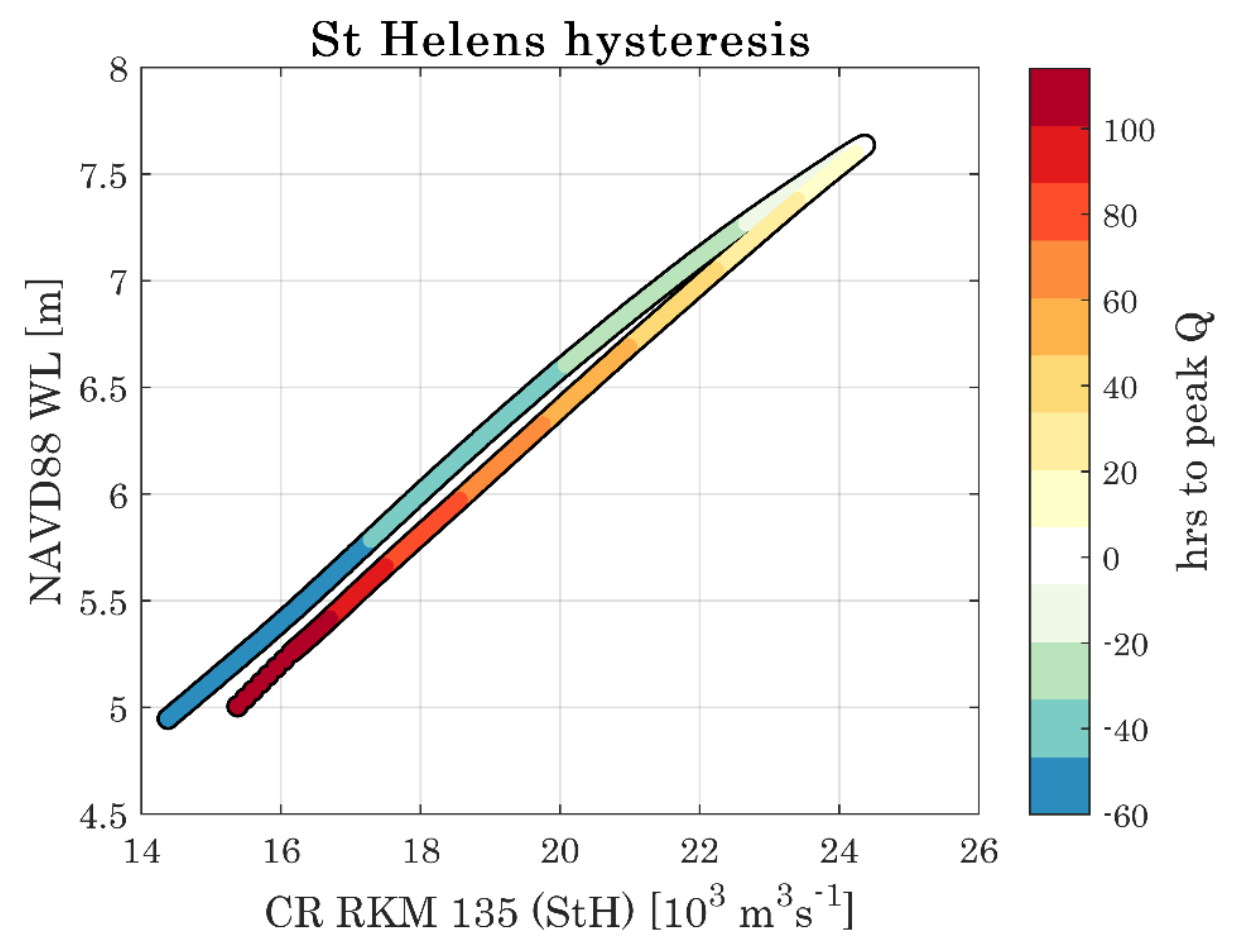

Figure 5.27: Hysteresis at St Helens - baseline scenario. The colored values represent hours to peak discharge. 


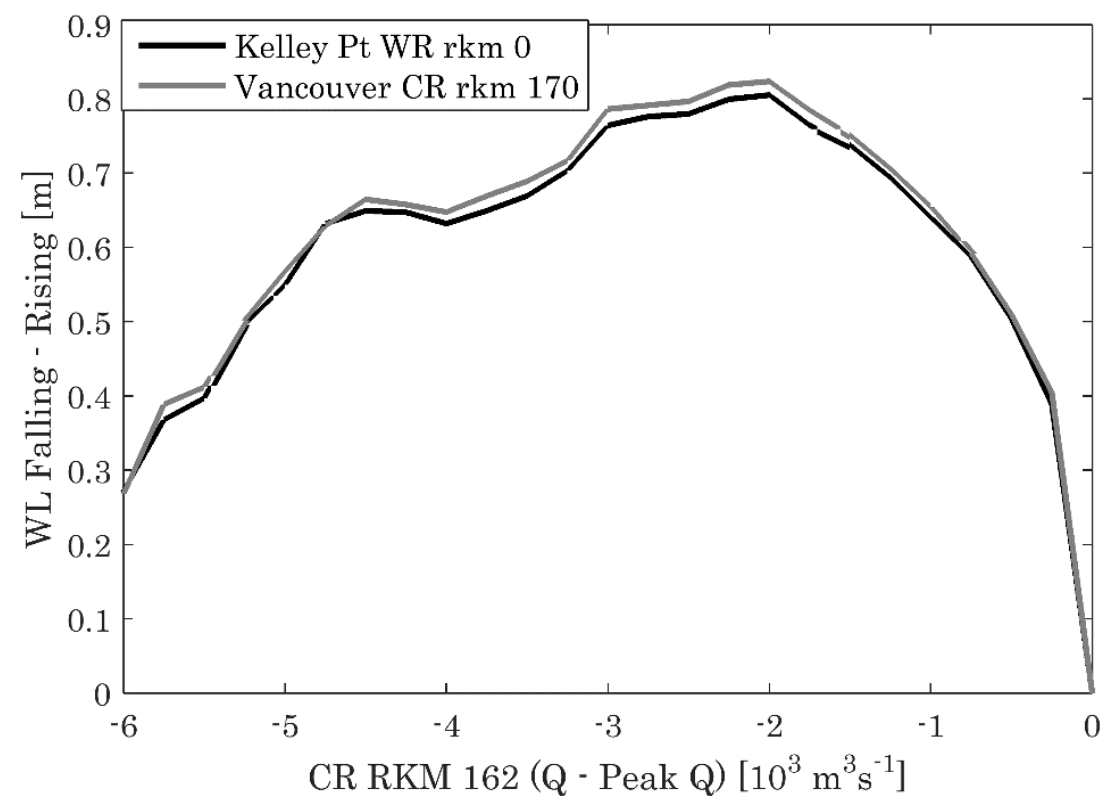

Figure 5.28: Difference in water level between rising and falling limb along the Willamette River. X-axis values are discharge from $6 \times 10^{3} \mathrm{~m}^{3} \mathrm{~s}^{-1}$ below peak to peak discharge.

Along the Willamette River, hysteresis is most prominent downstream, closest to Junction A, and diminishes in the upstream direction towards Oregon City. In Figure 5.29, the rating curve at St Johns Bridge shows that there is an over 1m difference in water level between the rising and falling limbs at $6-9 \times 10^{3} \mathrm{~m}^{3} \mathrm{~s}^{-1}$ discharge. Further upstream on the Willamette River at rkm 37 , the hysteresis is diminished and is only $0.76 \mathrm{~m}$ at $8 \times 10^{3} \mathrm{~m}^{3} \mathrm{~s}^{-1}$ discharge. Figure 5.30 shows the water level difference between the rising limb and falling limb at St John Bridge (WR rkm 9.7) and in the upstream Willamette River (WR rkm 37). The plot shows that from $4,000 \mathrm{~m}^{3} \mathrm{~s}^{-1}$ below the peak discharge to peak discharge, there is up to 1.6m of difference between the rising and falling limb at St Johns Bridge (WR 9.7). The difference between the falling limb and the rising drops to $1.1 \mathrm{~m}$ further upstream (WR rkm 37). 

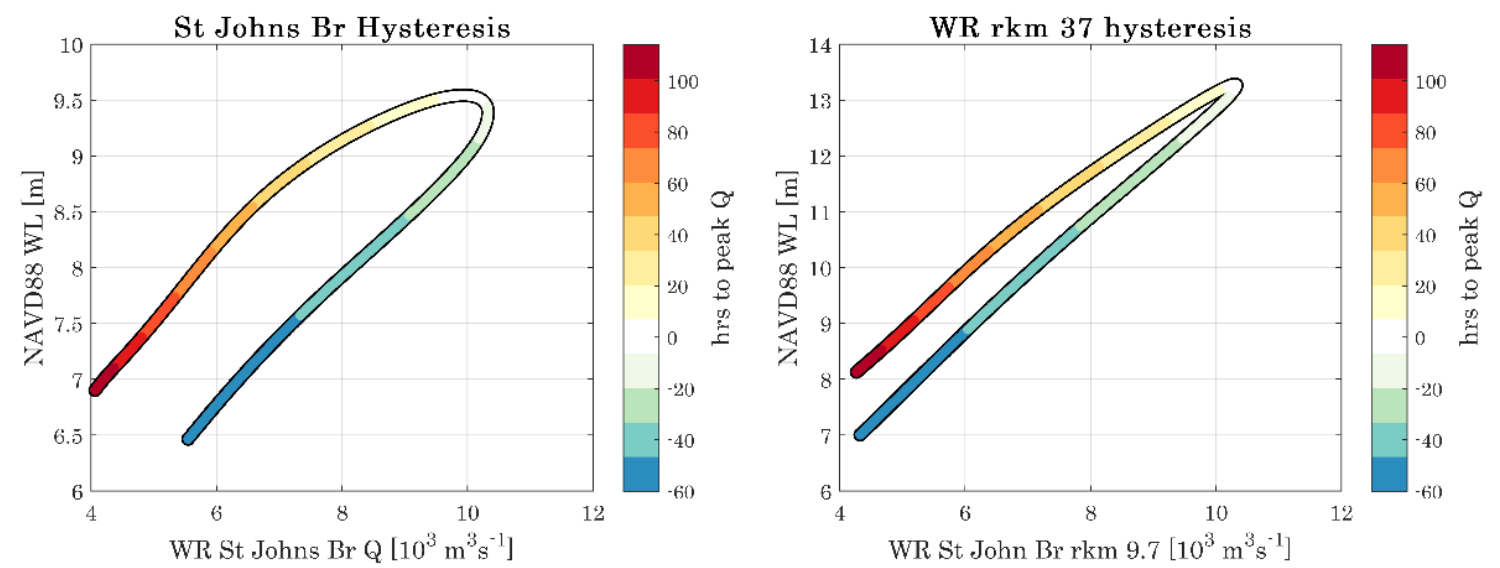

Figure 5.29: Hysteresis at St Johns Bridge and WR rkm 37 - baseline scenario

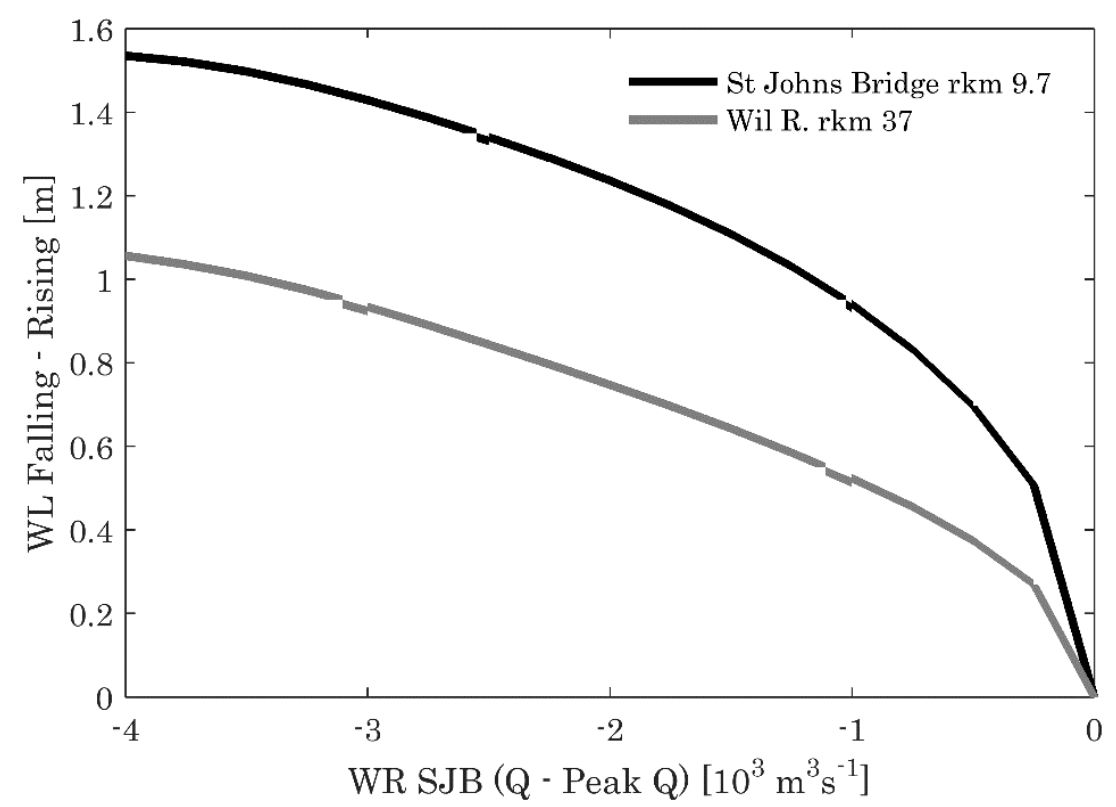

Figure 5.30: Difference in water level between rising and falling limb on the Willamette River at St Johns Bridge and WR rkm 37.

\subsubsection{Bed Stress}

Bed stress is an extremely important parameter with respect to sediment erosion, deposition, and transport, particularly in Portland Harbor, the site of a major Superfund site. Erosion of sediment is dependent on the critical shear stress, i.e., the minimum value 
of bed stress needed to move sediment. Studies conducted by the United States Environmental Protection Agency (USEPA) show that the highest critical shear stress in the Willamette River Superfund site is $>1 \mathrm{~Pa}$ (USEPA, 2016).

The bed stress is closely related to the surface slope (Equation 5.3), meaning changes in surface slope discussed in the previous segment will also affect bed stress. It is also closely related to surface slope. Figure 5.31 is a contour plot of the modeled peak bed stress from February 6-16, 1996. Peak bed stress in the Willamette River between Multnomah Channel and Kelley Point (Reach 1) is low compared to most of the mainstem Columbia River (Figure 5.31). In Reach 1, the peak bed stress is, for the most part, less than $1 \mathrm{~Pa}$. In comparison, peak bed stress exceeds $6 \mathrm{~Pa}$ in large segments of the river channel of the mainstem Columbia River between Kelley Point and St Helens (Reach 2). Along the Multnomah Channel, there is moderately high bed stress near Junction A ( 4 $\mathrm{Pa})$, and a high bed stress $(>6 \mathrm{~Pa})$ in the middle segment of Multnomah channel and near Junction C. The critical bed stress near the Portland Superfund is spatially variable, but is less than $1 \mathrm{~Pa}$ within the area with contaminated sediment. The high bed stress has in flood similar to the February 1996 event could move contaminated sediment downstream, and it could also cover contaminated sediment. 


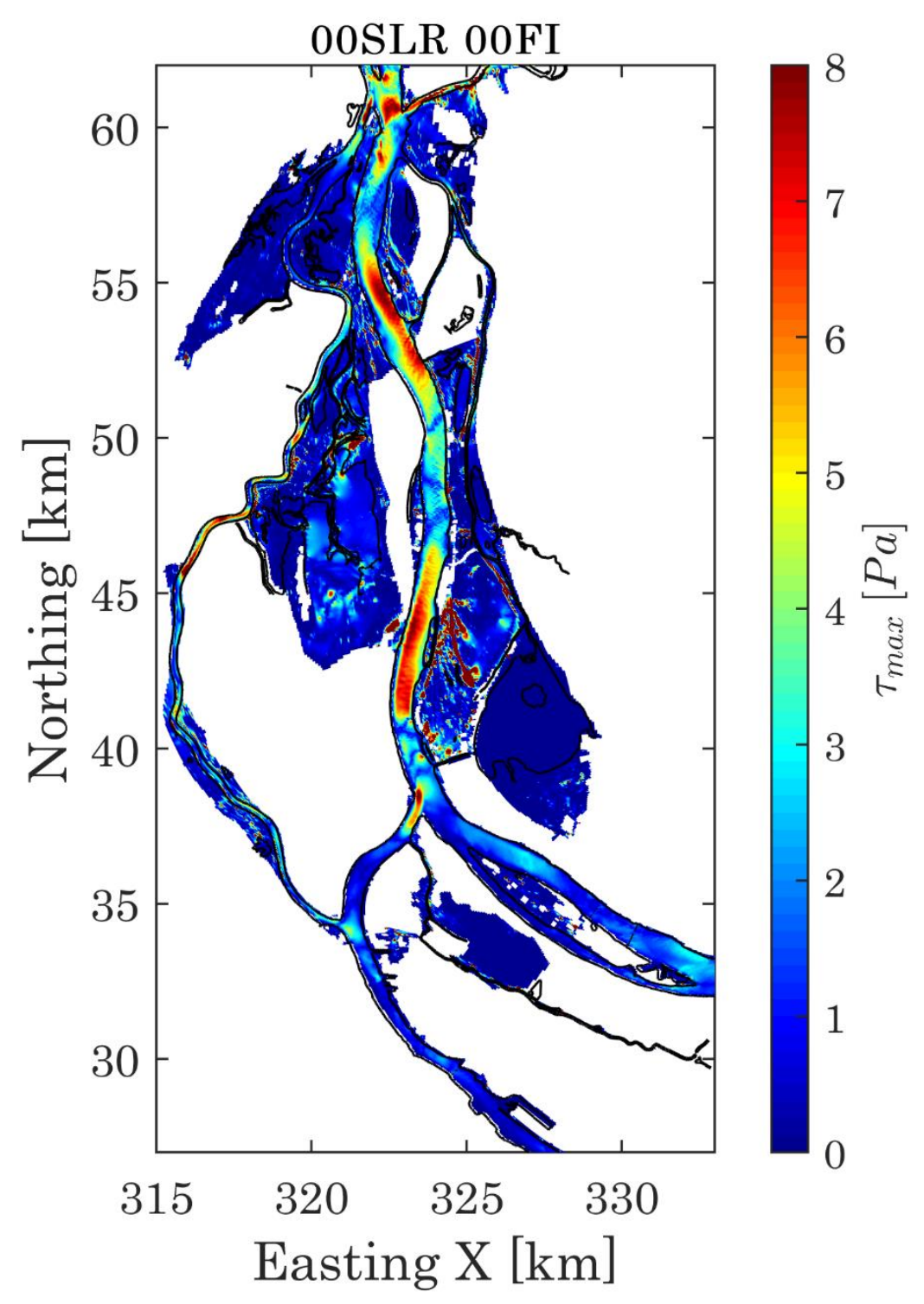

Figure 5.31: Peak bed stress in the Portland/Vancouver area Feb 6-16, 1996 for baseline scenario

\subsubsection{Sea level Effects on Hysteresis}

I showed previously in Chapter 3 that changes in channel depth due to dredging caused a reduction in surface slope and lower baseline water levels at Vancouver and Portland for river discharge below $15 \times 10^{3} \mathrm{~m}^{3} \mathrm{~s}^{-1}$ (see Figure 3.6 and section 3.4.2) in the 
Modern Model under normal sea level conditions. We hypothesize that the effect of incremental sea level rise may be similar to dredging, in the sense that the increased channel depth should reduce the surface slope by reducing friction. It has been shown through scaling analysis that increases in channel depth reduce frictional damping in strongly convergent tidal rivers (Friedrichs \& Aubrey, 1994). The reduction in friction in a sea level rise scenario is seen in the results from Chapter 4 , where a drop in the friction slope mitigates some of the effects of sea level rise (see chapter 4 section 3.3).

How will the increase in depth alter the surface slope, and ultimately the bed stress in a flood scenario? This is a significant issue when considering a sea level rise scenario, as the change in surface slope alters the magnitude and timing of flood peaks. To estimate changes in bed stress, I start with a scaling of the bed stress in a river channel. As noted in Equation 5.3, the changes in bed stress are dependent on how much the depth increases compared to the expected decrease in surface slope:

$$
\tau_{B}=\rho c_{d} \frac{1}{n^{2}} \boldsymbol{R}_{h}^{4 / 3} \boldsymbol{S}
$$

Using Multnomah Channel as a location to evaluate the effects of sea level rise, the results indicate that the reduction in surface slope is the control parameter for changes in bed stress in a sea level rise scenario. The peak surface slope $(\mathrm{S})$ is roughly cut in half, and the change in surface slope as a function of discharge $(d S / d Q)$ is reduced (Figure 5.32). 


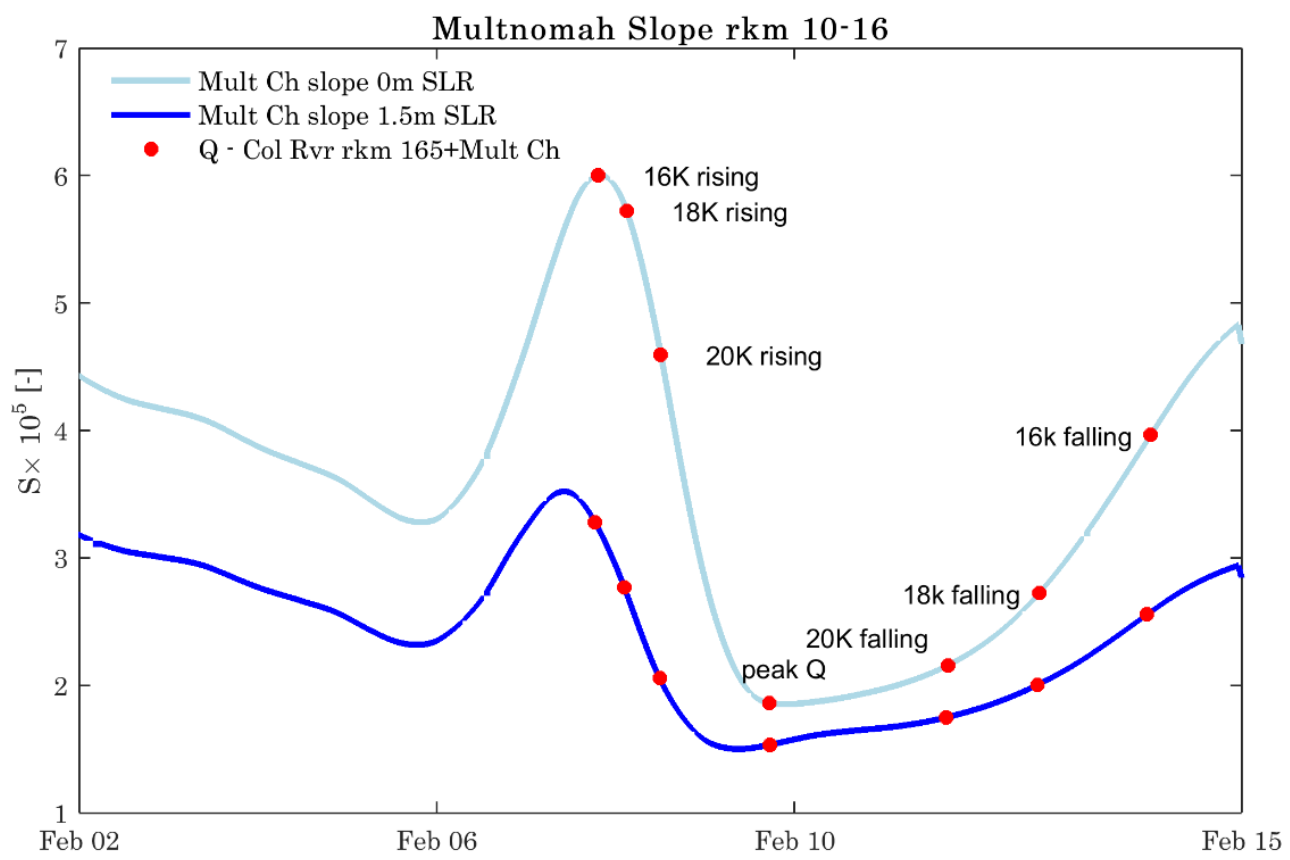

Figure 5.32: Surface slope on the Multnomah Channel from rkm 10-16 for baseline scenario (light blue), and $1.5 \mathrm{~m}$ sea level scenario (blue)

Model results confirm that sea level rise reduces the amount of hysteresis. In the scenario with $1.5 \mathrm{~m}$ SLR, at all locations, except St Helens, there is an appreciable drop in the amount of hysteresis; i.e., the difference in water level between the rising and falling limbs. Figure 5.33 shows the change in the amount of hysteresis along the Willamette River at St Johns Bridge and upstream at Willamette River rkm 37. 


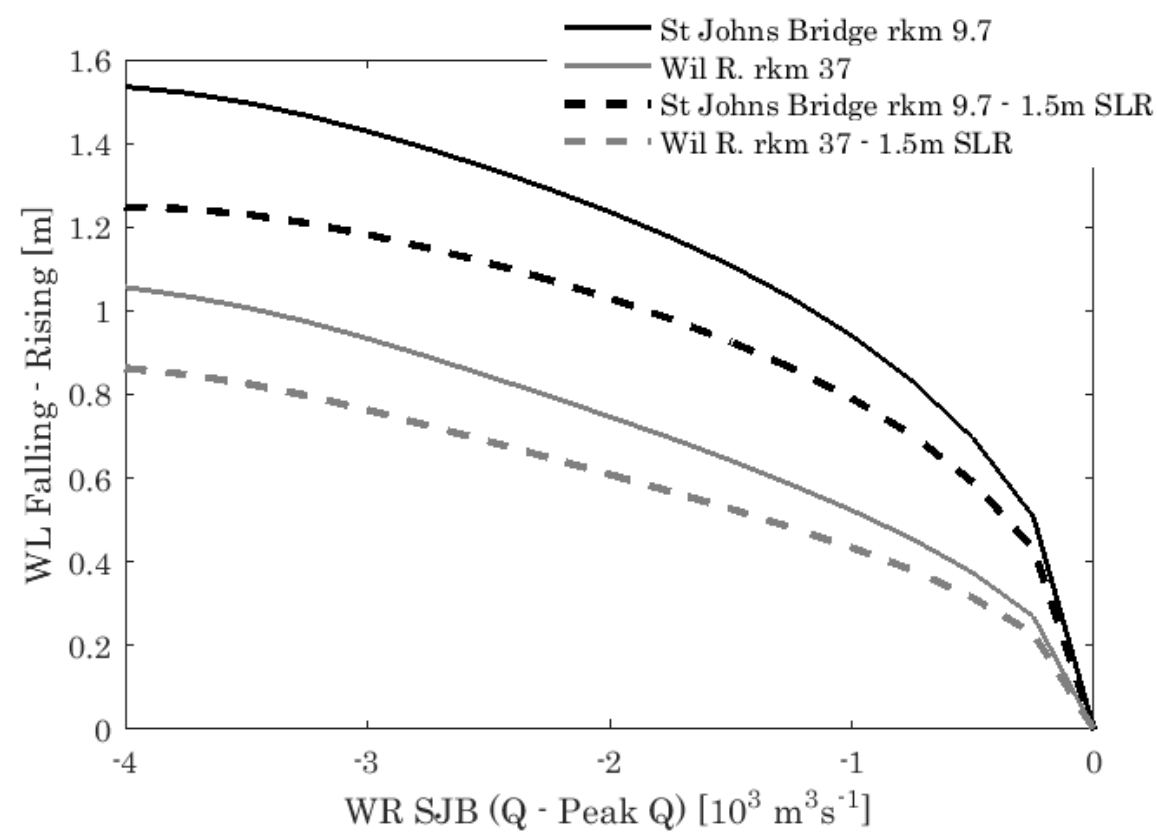

Figure 5.33: Differences in water level on Willamette River between rising and falling limbs, $0 \mathrm{~m}$ sea level rise (solid lines) and $1.5 \mathrm{~m}$ sea level rise (dashed lines).

Sea level rise does not change the spatial pattern of peak bed stress in the flood simulation but instead alters the magnitude of peak stress. Figure 5.34 is a contour plot of the peak bed stress for the $1.5 \mathrm{~m}$ sea level rise scenario. The majority of Reach 1 in the Willamette River between Junction A and Junction B still exhibits peak bed stress lower than $1 \mathrm{~Pa}$. The highest bed stress remains in the mainstem Columbia River between Junction B and Junction C, and is $>6 \mathrm{~Pa}$. Junction A has slightly lower bed stress ( 4 Pa) than the other junctions. Figure 5.35 is a contour plot of the difference in peak bed stress between the baseline scenario (Figure 5.31) and the 1.5m sea level rise scenario (Figure 5.34). The highest change in peak bed stress occurs in the river channels, the Columbia River between Kelley Point and Saint Helens, and the Willamette River ( 1 Pa). There is also a large decrease in peak bed stress $(\sim 1 \mathrm{~Pa})$ in the north Sauvie Island wetlands. The 
large decrease in peak stress may alter sand transport. A reduction in bed stress would decrease bed transport, and the sediment that is moved may not travel as far.

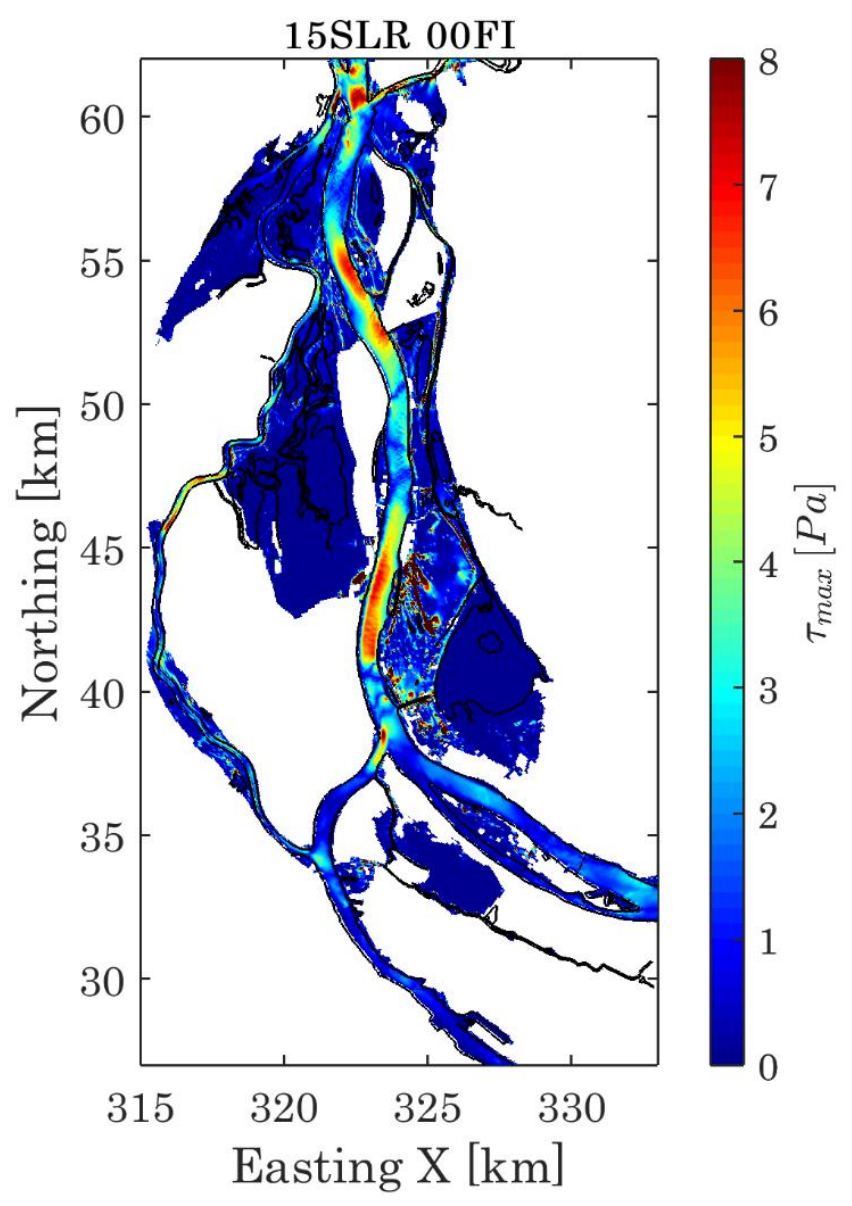

Figure 5.34: Peak bed stress in the Portland/Vancouver area Feb 6-16, 1996 for 1.5m sea level rise scenario 


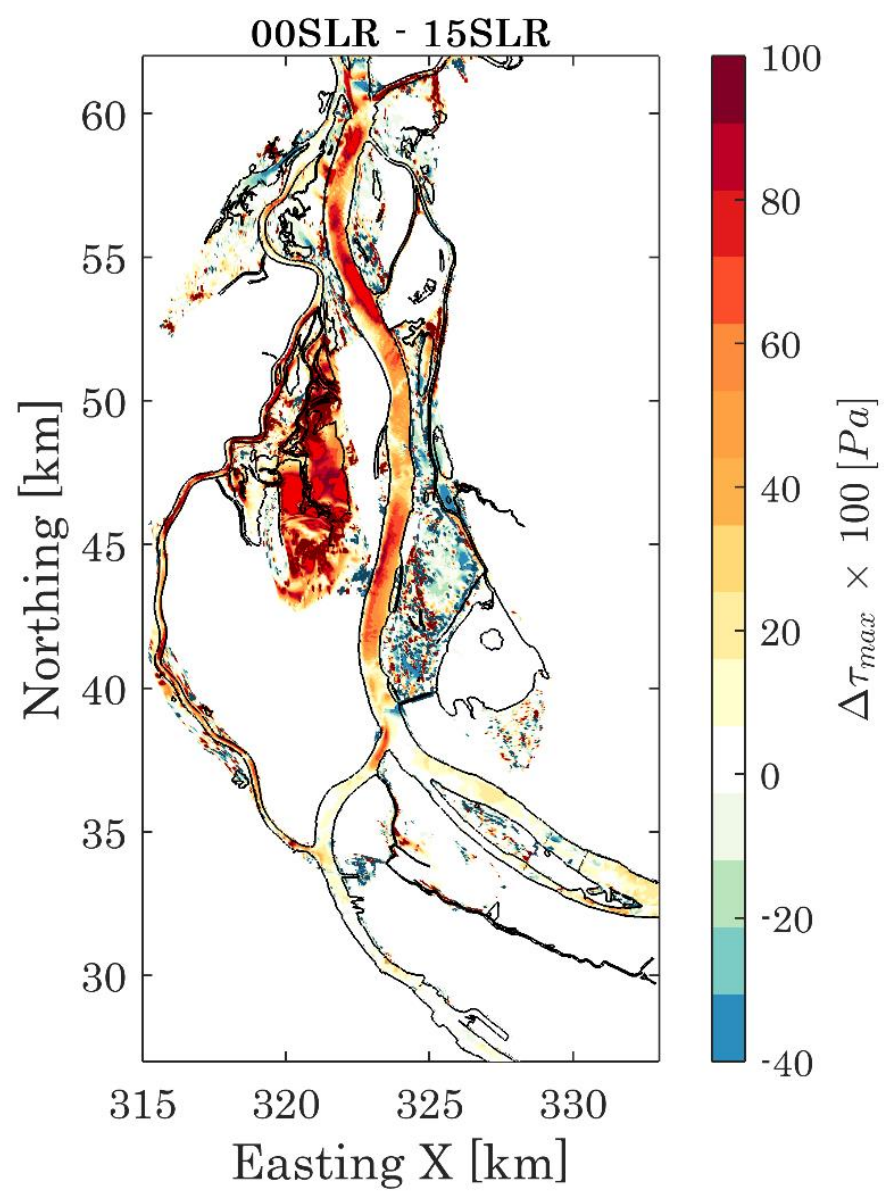

Figure 5.35: Difference in peak bed stress $\times 100(0 \mathrm{~m} \mathrm{SLR}-1.5 \mathrm{~m}$ SLR $)$ in the Portland/Vancouver area

\subsection{Conclusions}

This chapter continues from Chapter 4 the analysis of the February 1996 Willamette River flood, with an examination of flow dynamics in the three river junctions around Sauvie Island. This work is motivated by the need to understand how extreme flows interact with complex bathymetry, and how this will change as sea levels rise. It is 
particularly useful for understanding the feedbacks between discharge, inundation, and water levels.

I analyze the confluence of channels surrounding Sauvie Island in terms of a system with three junctions to better understand the patterns of bed stress and hysteresis in the Portland area. The main mechanisms driving hysteresis are the following:

- Discharge

- Willamette River discharge contributed to overall flood discharge creating overbank flow

- Columbia River discharge contributed to overall flood discharge creating overbank flow

- Hydrodynamic Response

- Columbia River discharge upstream of Kelley Point causes a reduction in surface slope at Junction B (Kelley Point) due backwater from the Columbia River

- Overbank flow from the Columbia River and Multnomah Channel causes a reduction in surface slope in downstream Multnomah Channel (Reach 3)

- Constriction of the Columbia River channel downstream of Junction C raises upstream water levels

- Wetlands in North Sauvie Island acting as a discharge sink on the rising limb, and as a source on the falling limb 
In terms of consequences, hysteresis in the rating curve causes a large difference in water level on the rising and falling limbs of a flood and significantly affects bed stress. In areas with significant overbank discharge, such as the Multnomah Channel, there is generally low peak bed stress compared to segments of the channel without overbank discharge. In the Willamette River, peak bed stress is highest at the junction with the Multnomah Channel (near rkm 5) and the confluence with the Columbia River (MC rkm 0). In a sea level rise scenario, these areas experience the largest drop in peak bed stress. With the assumption that bathymetry is unchanged, sea level rise results in a deeper channel creating a reduction in frictional damping.

This chapter provides an initial analysis of hysteresis dynamics in Portland/ Vancouver Harbor, which consists of a complex set of three junctions with connecting channels. The results show the degree to which the Multnomah Channel conveys flood discharge and how backwater discharge affects flow through the channel. The results of this study and the Chapter 3 results on the modern model also show how channel constriction, in this case, downstream of Junction C (St Helens), raises upstream water level gradients. The model results in Chapters 4 and 5 likely underestimate the effects of flow constriction in this segment of the Columbia River, because the calibration of the baseline scenario underestimated peak water levels in St Helens by $0.28 \mathrm{~m}$ (Figure 4.4). Flow restrictions tend to raise upstream water levels, and if the degree of flow restriction is underestimated modeled water levels in St Helens may be underestimated.

These results are useful in considering the effect of future channel modifications, i.e., will dredging help to alleviate flood risk while not increasing the instances of low 
water? (See Jay et al., 2010 for discussion of trends in water level in Portland/Vancouver over the past century). A final factor to consider is the role of floodplains. Although a large amount of the historical floodplain has been isolated or filled (Marcoe \& Pilson, 2017), floodplains still play a significant aspect in flood behavior by reducing upstream flood heights and diffusing flood waves. Finding ways to open up more of the floodplain may serve the dual role of increasing wildlife habitat and reducing flood risk.

\section{Chapter 6: Concluding Remarks and Future Direction}

I have examined flood risk in the Lower Columbia River through a detailed analysis of water level and discharge records from the late 19th century to the present and through simulation of extreme flood events. Due to anthropogenic (reservoir management, flow diversion, dredging) and natural stressors, there have been significant changes in tidal datums throughout the LCRE. Historical records such as tide logs of the Columbia River in Astoria and the daily water level records of the Willamette River in Portland serve two purposes. First, the long data records dating back to the mid-1800s are used to estimate trends in water levels. This analysis showed that Mean Low Water dropped in Portland and Vancouver by $1.5 \mathrm{~m}$ under low flow conditions. The analysis also shows that the $M_{2}$ tide in Astoria increased by $0.08 \mathrm{~m}(8.4 \%)$ since the late-19th century. Second, the presence of these hydrological records along with detailed bathymetry data has allowed me to create a calibrated model of the Lower Columbia River, with late 19th-century bathymetry. I used simulation-based approach to evaluate how bathymetric modification to the river channel alters the propagation of tides and flood waves. The deeper channel and reduction in the tidal prism since the late-19th century has allowed for ocean tides to progress further 
upstream, resulting in a larger tidal range for any given discharge condition. In large floods, these changes in bathymetry help to confine modern flow in river channels, increase flow velocity, bed stress, and water levels.

In the first research study, Chapter 3, I simulated a large spring freshet (6 months, $25 \times 10^{3} \mathrm{~m}^{3} \mathrm{~s}^{-1}$ peak) on the modern and historical models. Spring freshets of this magnitude are not a common occurrence today due to reservoir management in the Upper Columbia River, and a general reduction in the amount of rainfall and snowfall in the Pacific Northwest. Nevertheless, it is useful to model this type of event in the modern LCRE to understand how bathymetric alterations have altered flood risk in the Portland area. The results show that there has been a decrease in baseline water levels under low-moderate discharge conditions, but peak flood magnitude in Portland are similar. The study highlights two competing hydrodynamic effects, the deeper channel causes a reduction in damping, leading to a reduction in baseline water levels. By contrast, isolation of the floodplain, and installation of higher modern levees have the effect of raising water levels during an extreme flood event. The study also shows that although the historical river was rougher (lower Chézy coefficient), peak water levels were limited by extensive inundation of the floodplain.

In the second research study, Chapter 4, my focus shifted from a comparison of past and present flood risks to the present and future flood risks. I simulated the February 1996 Willamette River flood, a 7-day winter rain-on-snow event with a similar peak magnitude as the spring freshet simulated in Chapter 3. Due to projected long-term climate-induced changes in precipitation, studies project that the magnitude of the 
discharge in extreme winter flood events may increase by up to $20 \%$ in the next century. In addition to potential increases in runoff in the next century, sea level rise will raise coastal water levels by $0.5-1.4 \mathrm{~m}$. In simulations incorporating sea level rise, I found that the full effects of coastal sea level rise do not propagate to Portland, $184 \mathrm{rkm}$ from the coast. Water levels in Portland increased by 0.39m in simulations of the February 1996 flood with $1.5 \mathrm{~m}$ sea level rise at the coast. The reason is that the increased depth caused a reduction in damping. The reduced damping lowers the friction slope from the coast to Portland, mitigating some of the effects of sea level rise.

The projected climate-induced increase in discharge in extreme events is a far larger threat than the sea level rise in Portland. In the simulation of the February 1996 flood, I found that peak water levels in Portland increased by $0.26 \mathrm{~m}$ per meter of sea level rise. I also found that peak water levels in Portland are largely insensitive to coastal storm surges and the tidal phase. By contrast, a $10 \%$ increase in runoff resulted in a $0.78 \mathrm{~m}$ increase in the peak water level in Portland. The increase in flood risk is most prominent upstreamof St Helens.

The last significant aspect of this study is the importance of coastal processes in the estuary, and the tidal river. I found that coastal perturbations such as tides, and storm surge propagate upriver and affect the magnitude and timing of the peak water levels as far upriver as Longview, WA, $107 \mathrm{rkm}$ upstream of the coast. Similar to how there is an increase in tidal range in the Lower Columbia River in the last century due to dredging, the increased sea level also allows storm surges and tides to propagate far into the tidal river. 
In the final research study, Chapter 5, I continued my examination of the February 1996 flood, and I analyzed junction dynamics in Portland. The purpose of the study is to attempt to understand how flood waves and river discharge interact within the river junction around Sauvie Island. The results show that the Multnomah Channel reduced peak water levels in Portland by $0.35 \mathrm{~m}$ during the February 1996 flood. The water levels in Portland are driven during the flood by discharge and the interaction of three junctions. At Junction B (see Figure 5.1-5.3), discharge from the Columbia River water level reduces the surface slope along the Willamette River between the confluence with Multnomah Channel and Kelley Point (Figure 5.3). At Junction A (confluence of Willamette R./Multnomah Ch.), the wetlands on the northern segment of Sauvie Island acted as a sink in the rising limb of the flood. The same wetlands act as a source on the falling limb of the flood. Along the Columbia River, overbank discharge into the north Sauvie Island wetlands caused a reduction in the surface slope. This further increased the backwater effect along the mainstem Columbia River. Finally, at Junction C (St Helens), constriction of the downstream channel raises water level gradients. I saw a similar increase in water level gradient near St Helens in a simulation of the modern freshet (see Figure 3.11h).

At Longview and downstream locations, factors such as storm surge, and tidal phase may also need to be considered in determining the backwater effect (See Chapter 4). Aside from the variations in the water level, the observed hysteresis also causes bed stress to lead elevation. This has important implications for sediment transport, as it can lead to a large amount of sediment moved initially and then deposited downstream. In a sea level rise scenario, the amount of hysteresis is slightly reduced in part because there are higher 
initial water levels before the flood begins as compared to the baseline scenario. The results, in general, show that even in a modern system, floodplain inundation is still an important factor in normal flow conditions and extreme events. It is possible that finding effective means to open the floodplain may help to reduce flood risk (see Marcoe \& Pilson, 2017).

In summary, I analyzed extreme flood events in the Portland area over the last century. Through analysis of tidal records and simulations of extreme events, I was able to parse out some of the consequences of bathymetric alterations over the past century. I was able to model a spring freshet on the modern and historical models. The results of Chapter 3 bring up an important question that is beyond the scope of this dissertation. How have winter rain-on-snow events changed over the past century? Although 19th-century records from Columbia River tributaries such as the Sandy River and the Lewis Washougal River are scarce, it would be interesting to know if the historical bathymetry offered advantages in dealing with shorter timescale floods such as the February 1996 event. The second study continued with extreme events, and I analyzed present and future flood risks due to winter rain-on-snow events. The results highlight how coastal effects such as storm surge and storm propagate into the tidal river and affect the timing and magnitude of the flood. An area of future research could be a more comprehensive study of the interaction between fluvial discharge and coastal perturbations during a rain-on-snow event. This should involve a more comprehensive study of the interaction between tides and storm surge during as two factors were found to be the largest contributors to flood risk on the coast and in the estuary. In the final study, I analyzed junction dynamics in the Portland 
area during a rain-on-snow event. I was able to gain insight into how the interactions at the junction affect water levels in the Portland area. A question yet to be answered is: Can increasing floodplain access reduce future flood risk? 


\section{References}

Arcement Jr, G.J., V.R. Schneider (1989). Guide for Selecting Manning's Roughness Coefficients for Natural Channel and Floodplains United States Geological Survey Water-supply Paper 2339, pubs.usgs.gov/wsp/2339/report.pdf

Avi, B. (2017). Statewide Levee Database for Oregon, Release 1.0: Major Agricultural and Urban Areas in Western Oregon and along the Columbia River, report, Oregon Department of Geology and Mineral Industries, Portland, OR

Board, O. S., \& National Research Council. (2012). Sea level rise for the coasts of California, Oregon, and Washington: past, present, and future. National Academies Press.

Bottom, D. L., Simenstad, C. A., Burke, J., Baptista, A. M., Jay, D. A., Jones, K. K., ... \& Schiewe, M. H. (2005). Salmon at River's End: The Role of the Estuary in the Decline and Recovery of Columbia River salmon, Technical Memorandum NMDS-NWFSC-68, NOAA, Seattle, WA

Bowen, A. J., \& Gray, D. A. (1972). The tidal regime of the River Thames; long-term trends and their possible causes. Philosophical Transactions of the Royal Society of London. Series A, Mathematical and Physical Sciences, 272(1221), 187-199.

Burgette, R. J., Weldon, R. J., \& Schmidt, D. A. (2009). Interseismic uplift rates for western Oregon and along-strike variation in locking on the Cascadia subduction zone. Journal of Geophysical Research: Solid Earth, 114(B1). 
Burke, J.L. (2010). Georeferenced historical topographic survey maps of the Columbia River Estuary, School of Aquatic and Fishery Sciences, University of Washington, Seattle, WA. Funded by the U.S. Corps of Engineers, Portland District and NOAA Northwest Fisheries.

Buschman, F. A., Hoitink, A. J. F., Van Der Vegt, M., \& Hoekstra, P. (2010). Subtidal flow division at a shallow tidal junction. Water Resources Research, 46(12)

Cai, H., Savenije, H. H., Yang, Q., Ou, S., \& Lei, Y. (2012). Influence of river discharge and dredging on tidal wave propagation: Modaomen Estuary case. Journal of Hydraulic Engineering, 138(10), 885-896.

Chang, H., \& Jung, I. W. (2010). Spatial and temporal changes in runoff caused by climate change in a complex large river basin in Oregon. J. Hydrol, 388(3-4), 186-207.

Chernetsky, A. S., Schuttelaars, H. M., \& Talke, S. A. (2010). The effect of tidal asymmetry and temporal settling lag on sediment trapping in tidal estuaries. Ocean Dynamics, 60(5), 1219-1241.

Cox, R., Wadsworth, R. A., \& Thomson, A. G. (2003). Long-term changes in salt marsh extent affected by channel deepening in a modified estuary. Continental Shelf Research, 23(17-19), 1833-1846.

Cunge, J. A., Holly, F. M., \& Verwey, A. (1980). Practical aspects of computational river hydraulics.

Deka, P., \& Chandramouli, V. (2003). A fuzzy neural network model for deriving the river stage—discharge relationship. Hydrological sciences journal, 48(2), 197-209. 
Dodge, R. O. (1976). Construction of the 40-foot Channel in Columbia River.

Dronkers, J. J. (1964). Tidal computations in rivers and coastal waters.

Egbert, G. D., \& Erofeeva, S. Y. (2002). Efficient inverse modeling of barotropic ocean tides. Journal of Atmospheric and Oceanic Technology,19(2), 183-204.

Elias, E. P., Gelfenbaum, G., \& Van der Westhuysen, A. J. (2012). Validation of a coupled wave-flow model in a high-energy setting: The mouth of the Columbia River. Journal of Geophysical Research: Oceans, 117(C9).

Familkhalili, R., \& Talke, S. A. (2016). The effect of channel deepening on tides and storm surge: A case study of Wilmington, NC. Geophysical research letters, 43(17), 9138-9147.

Fong, D. A., Monismith, S. G., Stacey, M. T., \& Burau, J. R. (2009). Turbulent stresses and secondary currents in a tidal-forced channel with significant curvature and asymmetric bed forms. Journal of Hydraulic Engineering, 135(3), 198-208.

Friedrichs, C. T., \& Aubrey, D. G. (1994). Tidal propagation in strongly convergent channels. Journal of Geophysical Research: Oceans, 99(C2), 3321-3336.

Giese, B.S., \& D.A. Jay (1989). Modeling tidal energetics of the Columbia River estuary, 29(6), Estuarine, Coastal and Shelf Science, 549-571

Godin, G. (1999). The propagation of tides up rivers with special considerations on the upper Saint Lawrence River. Estuarine, Coastal and Shelf Science, 48(3), 307-324.

Halmstad, A., Najafi, M. R., \& Moradkhani, H. (2013). Analysis of precipitation extremes with the assessment of regional climate models over the Willamette River Basin, USA. Hydrological Processes, 27(18), 2579-2590. 
Hamilton, P. (1990). Modeling salinity and circulation for Columbia River Estuary, Progress in Oceanography, 25(1-4), 113-156

Helaire, L.T. (2016). Modeling of Historic Columbia River Flood Impacts Based on Delft3D Simulations

Helaire, L., Talke, S. A., Jay, D. A., \& Mahedy, D. (2019). Historical Changes in Lower Columbia River and Estuary Floods: A Numerical Study. Journal of Geophysical Research: Oceans. doi: 10.1029/2019JC015055

Henshaw, F. F., \& Dean, H. J. (1915). Surface Water Supply of Oregon. US Government Printing Office.

Hickson, R. E. (1912). A report on the establishment of river gages on lower Columbia \& Willamette rivers. Report to the US Army Corps of Engineers.

Hickson, R. E., \& Rodolf, F. W. (1950). History of Columbia River jetties. Coastal Engineering Proceedings, 1(1), 32.

Hickson, R. E. (1961). Columbia River ship channel improvement and maintenance. Journal of the Waterways and Harbors Division, 87(3), 71-94.

Hoitink, A. J. F., \& Jay, D. A. (2016). Tidal river dynamics: Implications for deltas. Reviews of Geophysics, 54(1), 240-272.

Huang, A., Peng, W., Liu, X., Du, Y., Zhang, S., Wang, S., .. \& Dong, F. (2017). Characteristics and factors influencing the hysteresis of water area-stage curves for poyang lake. Water, 9(12), 938. 
Hudson, A. S., Talke, S. A., Branch, R., Chickadel, C., Farquharson, G., \& Jessup, A. (2017). Remote measurements of tides and river slope using an airborne lidar instrument. Journal of Atmospheric and Oceanic Technology, 34(4), 897-904.

Hydraulics, D. (2006). Delft3D-FLOW user manual. Delft, the Netherlands.

Jain, S. K., \& Chalisgaonkar, D. (2000). Setting up stage-discharge relations using ANN. Journal of Hydrologic Engineering, 5(4), 428-433

Jay, D. A. (2009). Evolution of tidal amplitudes in the eastern Pacific Ocean. Geophysical Research Letters, 36(4).

Jay, D. A., Borde, A. B., \& Diefenderfer, H. L. (2016). Tidal-fluvial and estuarine processes in the Lower Columbia River: II. Water level models, floodplain wetland inundation, and system zones. Estuaries and coasts, 39(5), 1299-1324.

Jay, D. A., \& Flinchem, E. P. (1997). Interaction of fluctuating river flow with a barotropic tide: A demonstration of wavelet tidal analysis methods. Journal of Geophysical Research: Oceans, 102(C3), 5705-572

Jay, D. A., Leffler, K., \& Degens, S. (2010). Long-term evolution of Columbia River tides. Journal of waterway, port, coastal, and ocean engineering, 137(4), 182-191.

Jay, D. A., \& Naik, P. K. (2011). Distinguishing human and climate influences on hydrological disturbance processes in the Columbia River, USA. Hydrological Sciences Journal, 56(7), 1186-1209.

Kärnä, T., Baptista, A. M., Lopez, J. E., Turner, P. J., McNeil, C., \& Sanford, T. B. (2015). Numerical modeling of circulation in high-energy estuaries: A Columbia River estuary benchmark. Ocean Modelling, 88, 54-71. 
Kärnä, T., \& Baptista, A. M. (2016). Evaluation of a long-term hindcast simulation for the Columbia River estuary. Ocean Modelling, 99, 1-14.

Kassenbaum, C. (2011). Structure and Hydraulic Analysis of Columbia River Pile Dikes, 192 pp., AECOM, Seattle, WA

Keshtpoor, M., Puleo, J. A., Shi, F., \& Ma, G. (2015). 3D numerical simulation of turbulence and sediment transport within a tidal inlet. Coastal Engineering, 96, 1326.

Kidby, H. A., \& Oliver, J. G. (1965). Erosion and accretion along Clatsop Spit. In Proceedings Santa Barbara specialty conference. ASCE.

Kopp, R. E., Horton, R. M., Little, C. M., Mitrovica, J. X., Oppenheimer, M., Rasmussen, D. J., ... \& Tebaldi, C. (2014). Probabilistic 21st and 22nd century sea-level projections at a global network of tide-gauge sites. Earth's future, 2(8), 383-406.

Kopp, R. E., DeConto, R. M., Bader, D. A., Hay, C. C., Horton, R. M., Kulp, S., ... \& Strauss, B. H. (2017). Evolving understanding of Antarctic ice-sheet physics and ambiguity in probabilistic sea-level projections. Earth's Future, 5(12), 1217-1233.

Kukulka, T., \& Jay, D. A. (2003a). Impacts of Columbia River discharge on salmonid habitat: 1. A nonstationary fluvial tide model, Journal of Geophysical Research: Oceans, 108(C9).

Kukulka, T., \& Jay, D. A. (2003b). Impacts of Columbia River discharge on salmonid habitat: 2. Changes in shallow-water habitat, Journal of Geophysical Research: Oceans, 108(C9). 
Leffler, K. E., \& Jay, D. A. (2009). Enhancing tidal harmonic analysis: Robust (hybrid L1/L2) solutions. Continental Shelf Research, 29(1), 78-88.

Limerinos, J. T. (1970). Determination of the Manning coefficient from measured bed roughness in natural channels.

Lockett, J. B. (1959). Interim consideration of the Columbia River entrance. Journal of the Hydraulics Division, 85(1), 17-40.

MacCready, P., Banas, N. S., Hickey, B. M., Dever, E. P., \& Liu, Y. (2009). A model study of tide-and wind-induced mixing in the Columbia River Estuary and plume. Continental Shelf Research, 29(1), 278-291.

Manning, A. J., Van Kessel, T., Melotte, J., Sas, M., Winterwerp, H., \& Pidduck, E. L. (2011). On the consequence of a new tidal dock on the sedimentation regime in the Antwerpen area of the Lower Sea Scheldt. Continental Shelf Research, 31(10), S150-S164.

Marcoe, K., \& Pilson, S. (2017). Habitat change in the lower Columbia River estuary, 1870-2009. Journal of Coastal Conservation, 21(4), 505-525.

McIndoe, J.F., \& Thomson, E.B. (1911), Willamette River, Oregon, from Portland to Oregon City (in three sheets), map, U.S. Army Corp of Engineers, Washington DC

Merrifield, M. A., \& Thompson, P. R. (2018). Interdecadal Sea Level Variations in the Pacific: Distinctions Between the Tropics and Extratropics. Geophysical Research Letters, 45(13), 6604-6610. 
Mote, P. W., \& Salathé, E. P. (2010). Future climate in the Pacific Northwest. Climatic change, 102(1-2), 29-50.

Munoz, S. E., Giosan, L., Therrell, M. D., Remo, J. W., Shen, Z., Sullivan, R. M., ... \& Donnelly, J. P. (2018). Climatic control of Mississippi River flood hazard amplified by river engineering. Nature, 556(7699), 95.

Naik, P. K., \& Jay, D. A. (2005). Estimation of Columbia River virgin flow: 1879 to 1928. Hydrological Processes: An International Journal, 19(9), 1807-1824.

Naik, P. K., \& Jay, D. A. (2011). Distinguishing human and climate influences on the Columbia River: changes in mean flow and sediment transport. Journal of hydrology, 404(3-4), 259-277.

Najafi, M. R., \& Moradkhani, H. (2015). Multi-model ensemble analysis of runoff extremes for climate change impact assessments. Journal of Hydrology, 525, 352361.

National Geophysical Data Center (NGDC) (2003) U.S. Coastal Relief Model - Northwest Pacific. National Geophysical Data Center, NOAA. doi:10.7289/V5H12ZXJ

Nicolle, A., \& Karpytchev, M. (2007). Evidence for spatially variable friction from tidal amplification and asymmetry in the Pertuis Breton (France). Continental Shelf Research, 27(18), 2346-2356.

Orem, H. M. (1968). Discharge in the lower Columbia River basin, 1928-65 (Vol. 550). US Geological Survey.

Parker, B. B. (2007). Tidal analysis and prediction. 
Passeri, D. L., Hagen, S. C., Medeiros, S. C., \& Bilskie, M. V. (2015). Impacts of historic morphology and sea level rise on tidal hydrodynamics in a microtidal estuary (Grand Bay, Mississippi). Continental Shelf Research, 111, 150-158.

Pawlowicz, R., Beardsley, B., \& Lentz, S. (2002). Classical tidal harmonic analysis including error estimates in MATLAB using T_TIDE. Computers \& Geosciences, 28(8), 929-937.

Petersen- Øverleir, A. (2006). Modelling stage-discharge relationships affected by hysteresis using the Jones formula and nonlinear regression. Hydrological Sciences Journal, 51(3), 365-388.

Pinter, N., Jemberie, A. A., Remo, J. W., Heine, R. A., \& Ickes, B. S. (2008). Flood trends and river engineering on the Mississippi River system. Geophysical Research Letters, 35(23).

Public Acts of the $47^{\text {th }}$ Congress, 1882, Session I, Ch. 375 (1882)

Ralston, D. K., Talke, S., Geyer, W. R., Al-Zubaidi, H. A., \& Sommerfield, C. K. (2019). Bigger Tides, Less Flooding: Effects of Dredging on Barotropic Dynamics in a Highly Modified Estuary. Journal of Geophysical Research: Oceans, 124(1), 196211.

River and Harbor Act of 1905, Pub. L. No. 58-215, 33 Stat. 1117 (1905)

River and Harbor Act of 1912, 37 Stat. 201 (1912)

River and Harbor Act of 1930, Pub. L. No. 71-520, 46 Stat. 918 (1930)

River and Harbor Act of 1954, Pub. L. No 83-780, 68 Stat. 1248 (1954) 
Rivers and Harbors Act of 1962, Pub. L. No 87-874, 76 Stat. 1173 (1962)

Rivers and Harbors Appropriation Act of 1899, 30 Stat. 1121 (1899)

Roelvink, J. A., \& Van Banning, G. K. F. M. (1995). Design and development of DELFT3D and application to coastal morphodynamics. Oceanographic Literature Review, 11(42), 925.

Rudorff, C. M., Melack, J. M., \& Bates, P. D. (2014). Flooding dynamics on the lower Amazon floodplain: 1. Hydraulic controls on water elevation, inundation extent, and river-floodplain discharge. Water Resources Research, 50(1), 619-634.

Salaheldin, T. M., Imran, J., \& Chaudhry, M. H. (2004). Numerical modeling of threedimensional flow field around circular piers. Journal of Hydraulic Engineering, 130(2), 91-100.

Salathé Jr, E. P., Hamlet, A. F., Mass, C. F., Lee, S. Y., Stumbaugh, M., \& Steed, R. (2014). Estimates of twenty-first-century flood risk in the Pacific Northwest based on regional climate model simulations. Journal of Hydrometeorology, 15(5), 18811899.

Sassi, M. G., Hoitink, A. J. F., de Brye, B., Vermeulen, B., \& Deleersnijder, E. (2011). Tidal impact on the division of river discharge over distributary channels in the Mahakam Delta. Ocean Dynamics, 61(12), 2211-2228

Sauer, V. B., \& Turnipseed, D. P. (2010). Stage measurement at gaging stations (p. 45). US Department of the Interior, US Geological Survey. 
Sherwood, C. R., Jay, D. A., Harvey, R. B., Hamilton, P., \& Simenstad, C. A. (1990). Historical changes in the Columbia River estuary. Progress in Oceanography, 25(1-4), 299-352.

Shields, C. A., \& Kiehl, J. T. (2016). Atmospheric river landfall-latitude changes in future climate simulations. Geophysical Research Letters,43(16), 8775-8782.

Spatial Hazard Events and Losses Database for the United States (SHELDUS), 2017. URL: http://hvri.geog.sc.edu/SHELDUS/ (assessed 15, July, 2017)

Stocker, T. F., Qin, D., Plattner, G. K., Tignor, M., Allen, S. K., Boschung, J., ... \& Midgley, P. M. (2013). Climate change 2013: The physical science basis.

Sweet, W. V., \& Park, J. (2014). From the extreme to the mean: Acceleration and tipping points of coastal inundation from sea level rise. Earth's Future, 2(12), 579-600.

Talke, S. A., \& Jay, D. A. (2013). Nineteenth century North American and Pacific tidal data: Lost or just forgotten? Journal of Coastal Research, 29(6a), 118-127.

Talke, S. A., \& Jay, D. A. (2017). Archival water-level measurements: Recovering historical data to help design for the future.

Tawfik, M., Ibrahim, A., \& Fahmy, H. (1997). Hysteresis sensitive neural network for modeling rating curves. Journal of Computing in Civil Engineering, 11(3), 206-211

Tebaldi, C., Strauss, B. H., \& Zervas, C. E. (2012). Modelling sea level rise impacts on storm surges along US coasts. Environmental Research Letters, 7(1), 014032. 
Templeton, W. J., \& Jay, D. A. (2012). Lower Columbia River sand supply and removal: estimates of two sand budget components. Journal of Waterway, Port, Coastal, and Ocean Engineering, 139(5), 383-392.

Thorn, F.M. (1888). Columbia River Sheet No. 6 Fales Landing to Portland, United States Coast and Geodetic Survey, Washington, D.C.

United States Weather Bureau (1878-1888). Discharge estimates of the Willamette River in Salem, OR, National Weather Service Archives, Portland, OR

United States Weather Bureau (1879-1898). Water level records from the Willamette River in Portland, OR, City of Portland Archives, Portland, OR

United States Weather Bureau (1893-1946). Daily river stages at river gage stations on the principals rivers of the United States, 1893-1946

USACE (n.d.). Building Strong® at the Mouth of the Columbia River. Retrieved from https://www.nwp.usace.army.mil/Locations/Oregon-Coast/Mouth-of-the$\underline{\text { Columbia/ }}$

USACE (1915). Report of the Secretary of War, Annual Report of the Chief of Engineers for historical summary giving the scope of previous projects for the improvement of certain rivers and harbors, U.S. Govt. Print. Off., Washington, D.C.

USACE (1963). Water Surface Profiles, Floods - 1876, 1894, 1933, 1946, 1948, 1950 and 1956, U.S. Army Corp of Engineers, Portland District

USACE (1997). February 1996 post flood report: hydrometeorological evaluation, USACE, Portland, OR 
USACE (2010). Lower Columbia River Digital Terrain Model, USACE, Portland, OR

USC\&GS (1877). United States National Coast \& Geodetic Survey Columbia River tide logs, National Archives, College Park, MD

USEPA (2016). United States Environmental Protection Agency, Portland Harbor RI/FS feasibility study, Seattle (WA). 276 p., Prepared by USEPA Region 10.

Waananen, A. O., Harris, D. D., \& Williams, R. C. (1970). Floods of December 1964 and January 1965 in the Far Western States: Part 2. Streamflow and Sediment Data. US Government Printing Office.

Wang, J., Yi, S., Li, M., Wang, L., \& Song, C. (2018). Effects of sea level rise, land subsidence, bathymetric change and typhoon tracks on storm flooding in the coastal areas of Shanghai. Science of the total environment, 621, 228-234.

Warner, J. C., Schoellhamer, D., \& Schladow, G. (2003). Tidal truncation and barotropic convergence in a channel network tidally driven from opposing entrances. Estuarine, Coastal and Shelf Science, 56(3-4), 629-639.

Water Resources Development Act of 1999, Pub. L. 106-53, 113 Stat. 269 (1999)

Zaron, E. D., \& Jay, D. A. (2014). An analysis of secular change in tides at open-ocean sites in the Pacific. Journal of Physical Oceanography, 44(7), 1704-1726.

Zhang, Y., Baptista, A. M., \& Myers, E. P. (2004). A cross-scale model for 3D baroclinic circulation in estuary-plume-shelf systems: I. Formulation and skill assessment. Continental Shelf Research, 24(18), 2187-2214.

Zhang, Y., \& Baptista, A. M. (2008). SELFE: a semi-implicit Eulerian-Lagrangian finiteelement model for cross-scale ocean circulation. Ocean modelling, 21(3-4), 71-96. 
Zhang, Q., \& Werner, A. D. (2015). Hysteretic relationships in inundation dynamics for a large lake-floodplain system. Journal of hydrology, 527, 160-171.

Zhang, X. L., Zhang, Q., Werner, A. D., \& Tan, Z. Q. (2017). Characteristics and causal factors of hysteresis in the hydrodynamics of a large floodplain system: Poyang Lake (China). Journal of hydrology, 553, 574-583.

Zhu, J., Weisberg, R. H., Zheng, L., \& Han, S. (2015). Influences of channel deepening and widening on the tidal and nontidal circulations of Tampa Bay. Estuaries and Coasts, 38(1), 132-150. 


\section{Appendix A: Supporting Information for Chapter 3}

\section{A.1 - Model Grids}

In the Delft3D simulations we use a depth dependent Chézy roughness formulation $\left[\mathrm{m}^{1 / 2} \mathrm{~s}-\right.$

${ }^{1}$ ]. The model grid is split into five domains in the Modern model (Figure A.1) and six domains in the Historical model (Figure A.2).

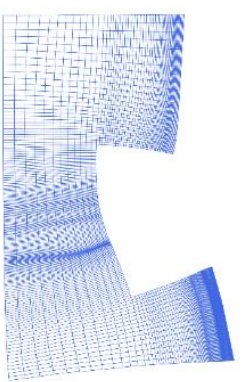

A

depth $<-3 \mathrm{~m}$

Chézy $=25$

$0 \mathrm{~m}>$ depth $\geq-3 \mathrm{~m}$

Chézy $=93$

$\operatorname{depth} \geq 3 \mathrm{~m}$

Chézy $=96$

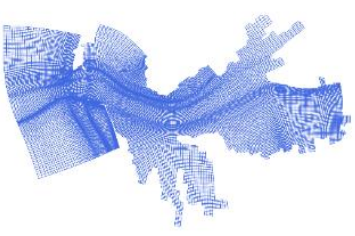

B

depth $<-3 \mathrm{~m}$

Chézy $=25$

$0 \mathrm{~m}>\operatorname{depth} \geq-3 \mathrm{~m}$

Chézy $=90$

$3 \mathrm{~m}>$ depth $>0 \mathrm{~m}$

Chézy $=93$

depth $\geq 3 \mathrm{~m}$

Chézy $=96$
C

depth $<-4 \mathrm{~m}$

Chézy $=5$

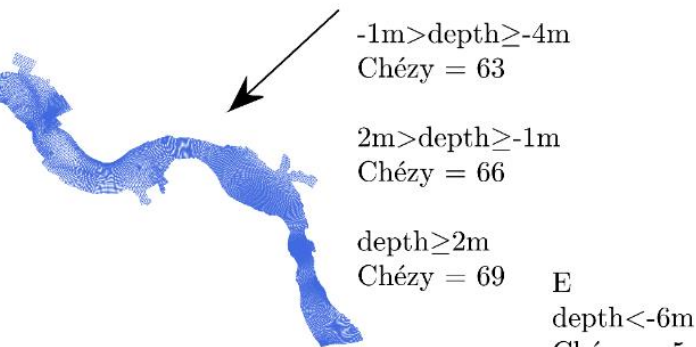

$\mathrm{D}$

depth $<-5 \mathrm{~m}$

Chézy $=5$

$-2 m>$ depth $\geq-5 m$

Chézy $=61$

depth $\geq-1 \mathrm{~m}$

Chézy $=59$
Chézy $=5$

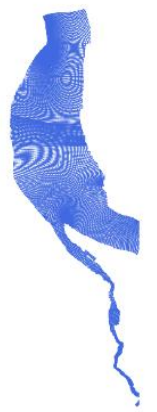

$-3 m>$ depth $\geq-6 m$

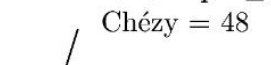

depth $\geq-3 m$ Chézy $=55$

Figure A1: Chévy roughness parameterization of the Modern Model. Depth is in meters, positive relative to NAVD88 (North American Vertical Datum of 1988). 


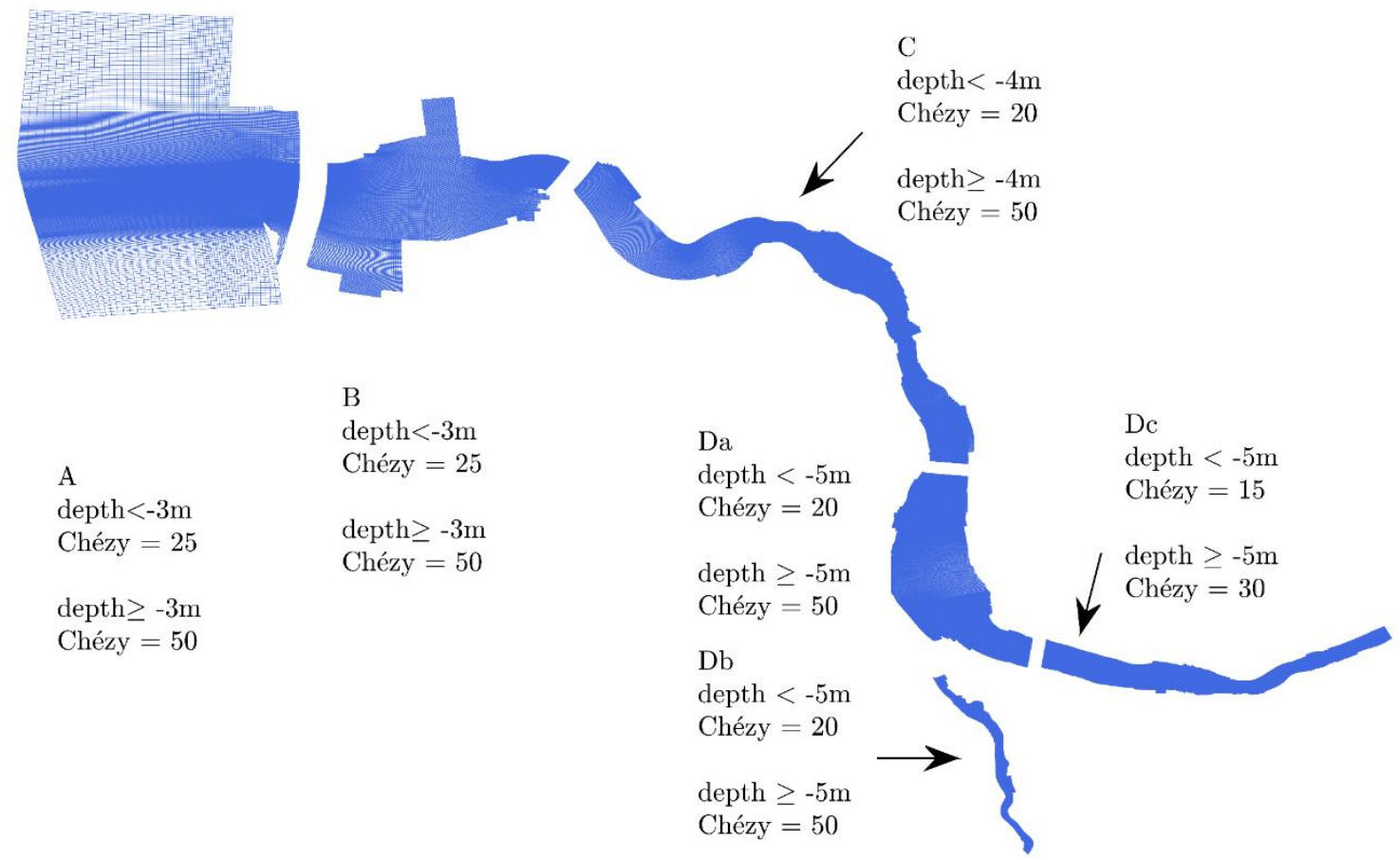

Figure A.2: Chévy roughness parameterization of the Historical Model. Depth is in meters, positive downwards relative to NAVD88.

\section{A.2 - Nonlinear Regression}

In this study we are seeking to develop a regression to hindcast late $19^{\text {th }}$ century daily water levels in Portland, based on river discharge, coastal tidal range, and the level of overbank discharge. The nonlinear model used to correlate water level with river discharge is based on the work of Jay et al. (2016) where a nonlinear regression was used to hindcast water levels from measured discharge in Vancouver and Portland. We begin by developing a rating curve from measured water level, as wells as measured and estimated river discharge. We then estimate coastal water levels in Astoria, OR from 18791898. Finally, we apply a nonlinear regression model to describe the rating curve. 
Daily water levels readings were taken at Morrison Bridge on the Willamette River in Portland from 1879-1898. Along with the water level readings, we used measured and estimated discharge to develop a rating curve (Figure A.3). The rating curve uses the combined downstream discharge of the Willamette River and the backwater discharge from the Columbia River. The Columbia River discharge is based on United States Geological Survey [USGS] readings at The Dalles (CR rkm 307) and is lagged by a day (USGS site \# 14105700 https://waterdata.usgs.gov/nwis/inventory/).

The discharge at The Dalles accounts for an average of $97 \%$ of the total Interior sub-basin of the Columbia River (Jay \& Naik, 2011), but the reach of the Columbia River between The Dalles and Portland may account for a somewhat higher percentage of the flow during major, western sub-basin rain and rain-on-snow events. To investigate this problem, we examine the discharge of the Sandy River, the largest of the tributaries between Bonneville Dam and Portland, and compare it to Willamette River discharge. For Willamette River discharge, we used discharge estimates of the Willamette River at Morrison Bridge (see Helaire, 2016 for details on the methodology). Restricting the rating curve to days with Willamette River discharge below $500 \mathrm{~m}^{3} \mathrm{~s}^{-1}$ or total discharge above $20,000 \mathrm{~m}^{3} \mathrm{~s}^{-1}$. The restriction is based on analysis of Willamette River discharge in the $20^{\text {th }}$ century. There is some evidence of a correlation between high Willamette River discharge and high discharge from other Columbia River tributaries downstream of the The Dalles. Table 1 shows some correlation between the Willamette River at Morrison Bridge and the Sandy River below the Bull Run River. The implication is that other nearby Columbia River tributaries (i.e. the Washougal, Hood, and Lewis Rivers) have a similar response, 
and that the Columbia River discharge at The Dalles may underestimate the Columbia River backwater affect in Portland. Restricting the rating curve to days where the majority of the discharge is backwater discharge from the Columbia River significantly reduces the scatter in the rating curve (Figure A.3).

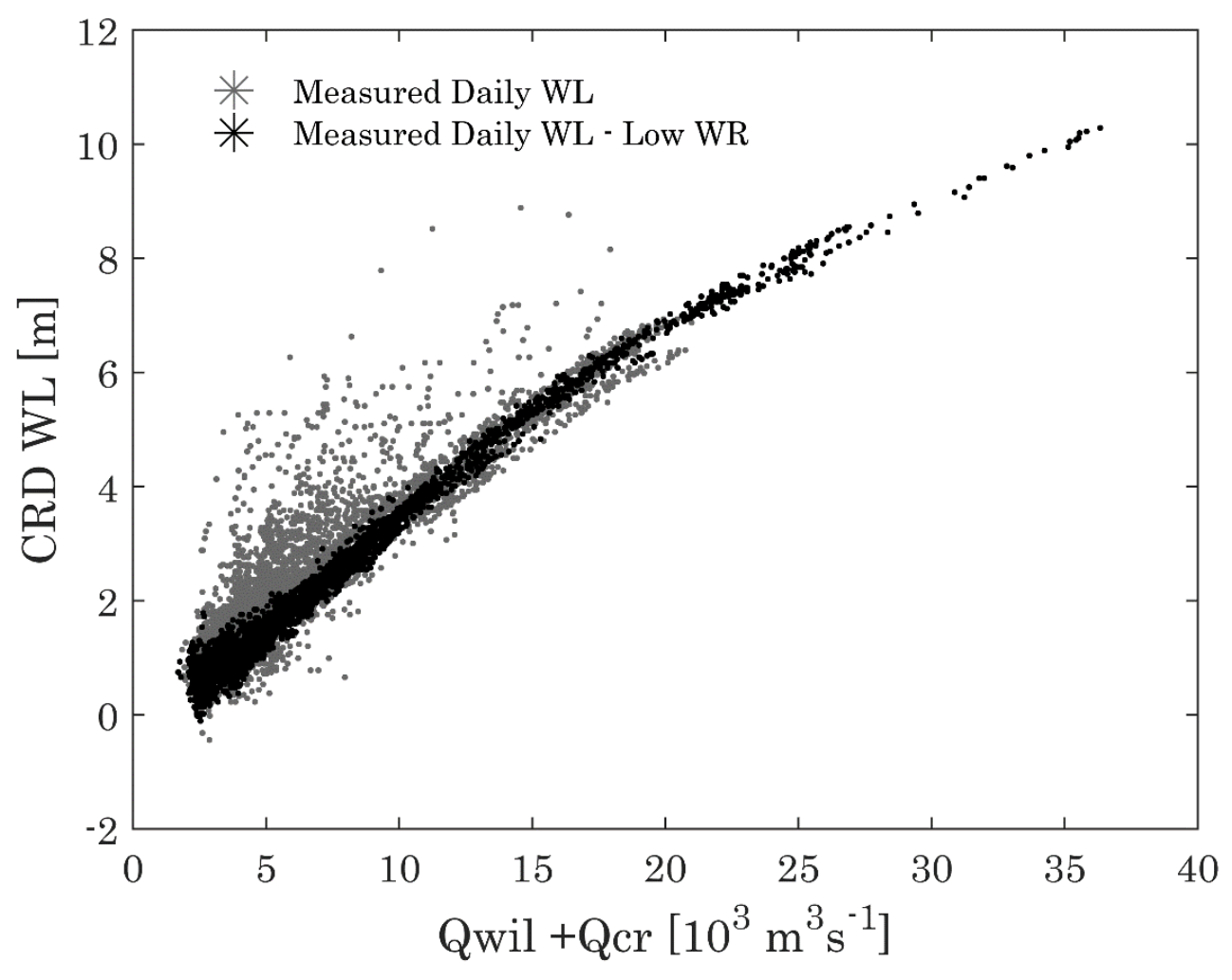

Figure A.3: Rating curve of daily water level at Morrison Bridge (1879-1898).

Black dots represent days with Willamette River discharge below $500 \mathrm{~m}^{3} \mathrm{~s}^{-1}$, or days with total discharge above $20 \times 10^{3} \mathrm{~m}^{3} \mathrm{~s}^{-1}$ total discharge.

Water levels in Portland are tidally influenced, so there is a need to estimate coastal tidal range. The tidal record at Astoria has no readings from 1879-1898, but I hindcast water levels using hourly readings from 1870-1876 (Figures A.4). The tidal constituents are obtained by running harmonic analysis using r_t_tide (Leffler and Jay, 2009) without 
nodal corrections on Astoria hourly water level readings from 1870-1876 (Figure A.5). The resultant tidal amplitudes and phases are then used to hindcast water levels in Astoria from 1879-1898 (Figure A.6). We then determine the water level range for every tidal day ( $25 \mathrm{hr})$ at Astoria, OR from 1879-1898.

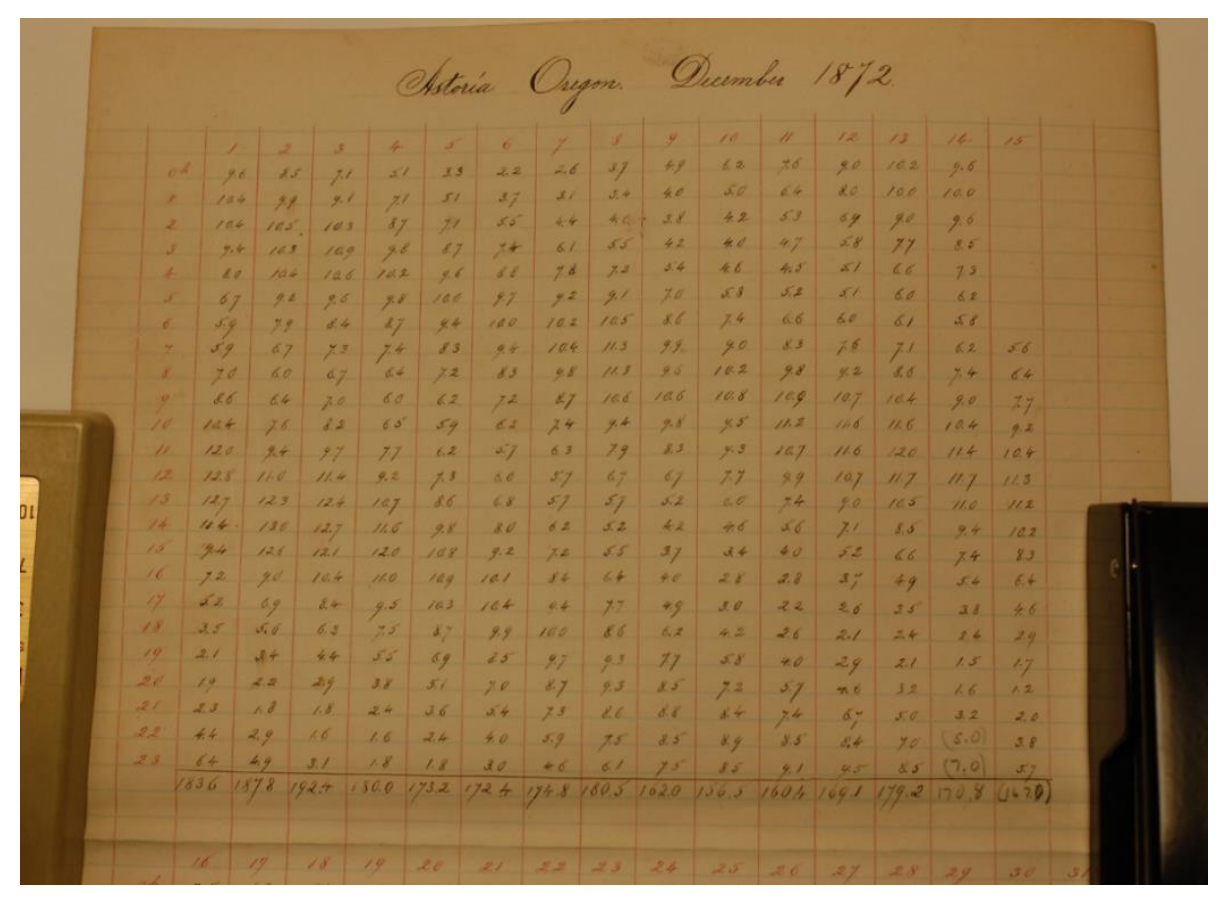

Figure A.4: Hourly water level on the Columbia River in Astoria, OR for December 1872 


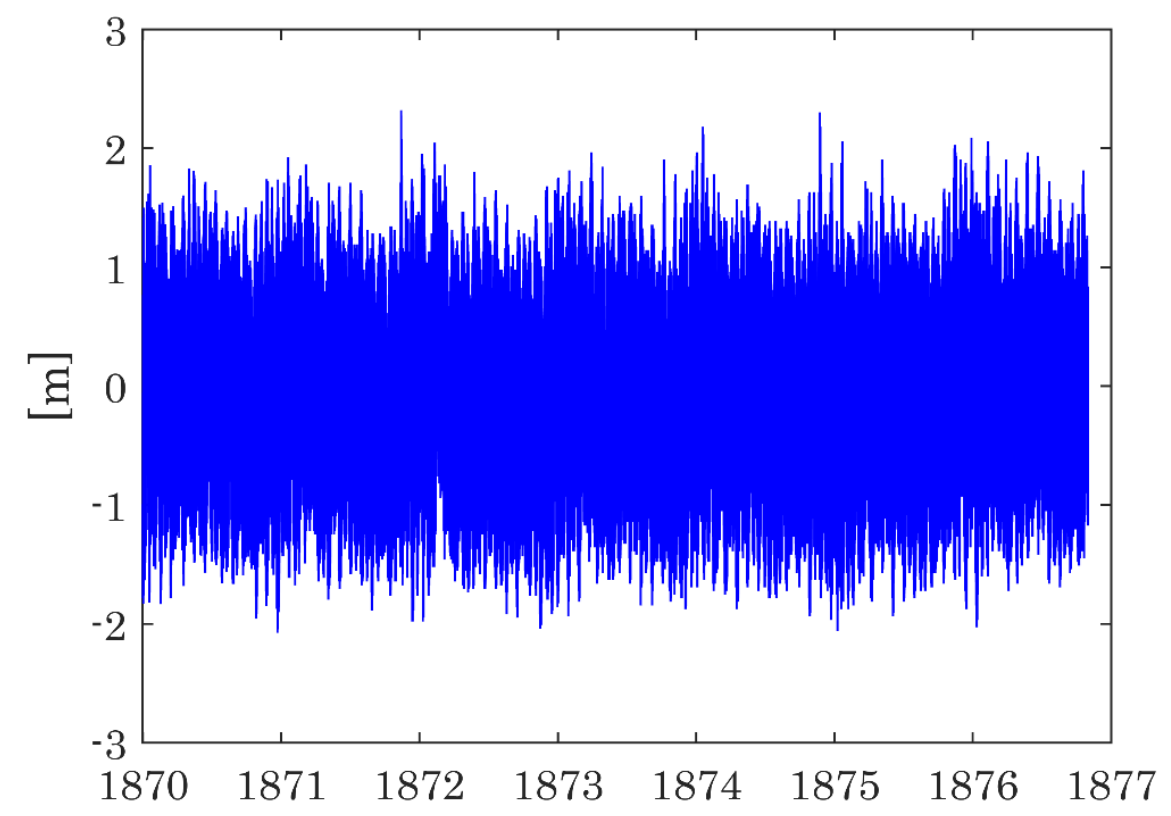

Figure A.5: Demeaned water levels on the Columbia River in Astoria, OR 1870 - 1876.

We apply a nonlinear regression similar to the one applied in the work of Jay et al. (2016). The equation is modified to account for overbank flow. The majority of the readings occur at low discharge, so to ensure that the regression does not favorably bias low discharge readings, we use a weighing scheme that gives higher weights to the less frequent, high discharge readings. The combined discharge is bin averaged into $10^{3} \mathrm{~m}^{3} \mathrm{~s}^{-1}$ bins. The assigned weights are roughly equal to the inverse of the square root of the occurrences in that bin. This scheme assigns samples in densely populated bins a lower weight, and samples in sparse bins a higher weight (Figure A.7).

$$
W L=a_{0}+\underbrace{a_{1}\left(Q_{W R}\right)^{m 1}}_{\begin{array}{c}
\text { Willamette } \\
\text { River }
\end{array}}+\underbrace{a_{2}\left(Q_{T D}\right)^{m 2}}_{\begin{array}{c}
\text { Columbia } \\
\text { River }
\end{array}}+\underbrace{a_{3}\left(\frac{T_{R A}^{2}}{\left(Q_{T D}+Q_{W R}\right)^{m 3}}\right)}_{\text {Neap-Spring }}+\underbrace{a_{4} \max \left(\frac{Q_{W R}+Q_{T D}}{Q_{C R T}} \mid 1\right)^{m 2}}_{\begin{array}{c}
\text { Overbank } \\
\text { Inundation }
\end{array}}
$$

In Equation A.1, water level in Portland depends on Willamette River discharge, Columbia River discharge, downstream tidal range and overbank inundation. By observation, there 
is a change in surface slope at $\sim 20 \times 10^{3} \mathrm{~m}^{3} \mathrm{~s}^{-1}$ combined discharge, i.e. the critical discharge (Figure A.3). This value is based on Historical flood levels (see USACE; 1963 and Figure A.8), and is approximately the discharge required for overbank flow in the Portland area. At a combined discharge below critical discharge, the last term in Equation A.1 (overbank inundation) becomes a constant and combines with $a_{0}$ to describe the constant offset. Above the critical discharge, the term modifies the rating curve and helps to account for the change in surface slope of the rating curve at high discharge.

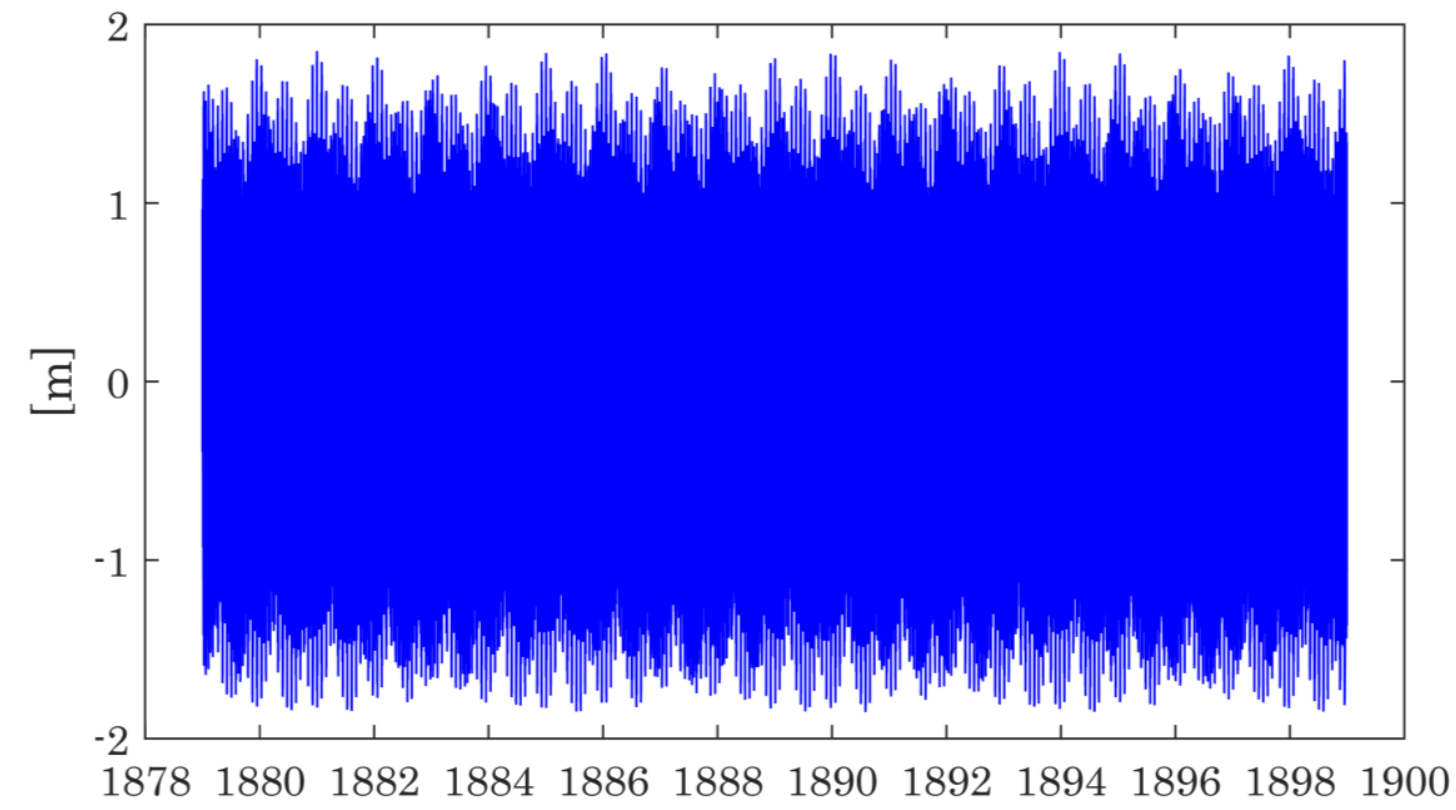

Figure A.6: Demeaned predicted water level for the Columbia River in Astoria, OR from 1879-1898. 

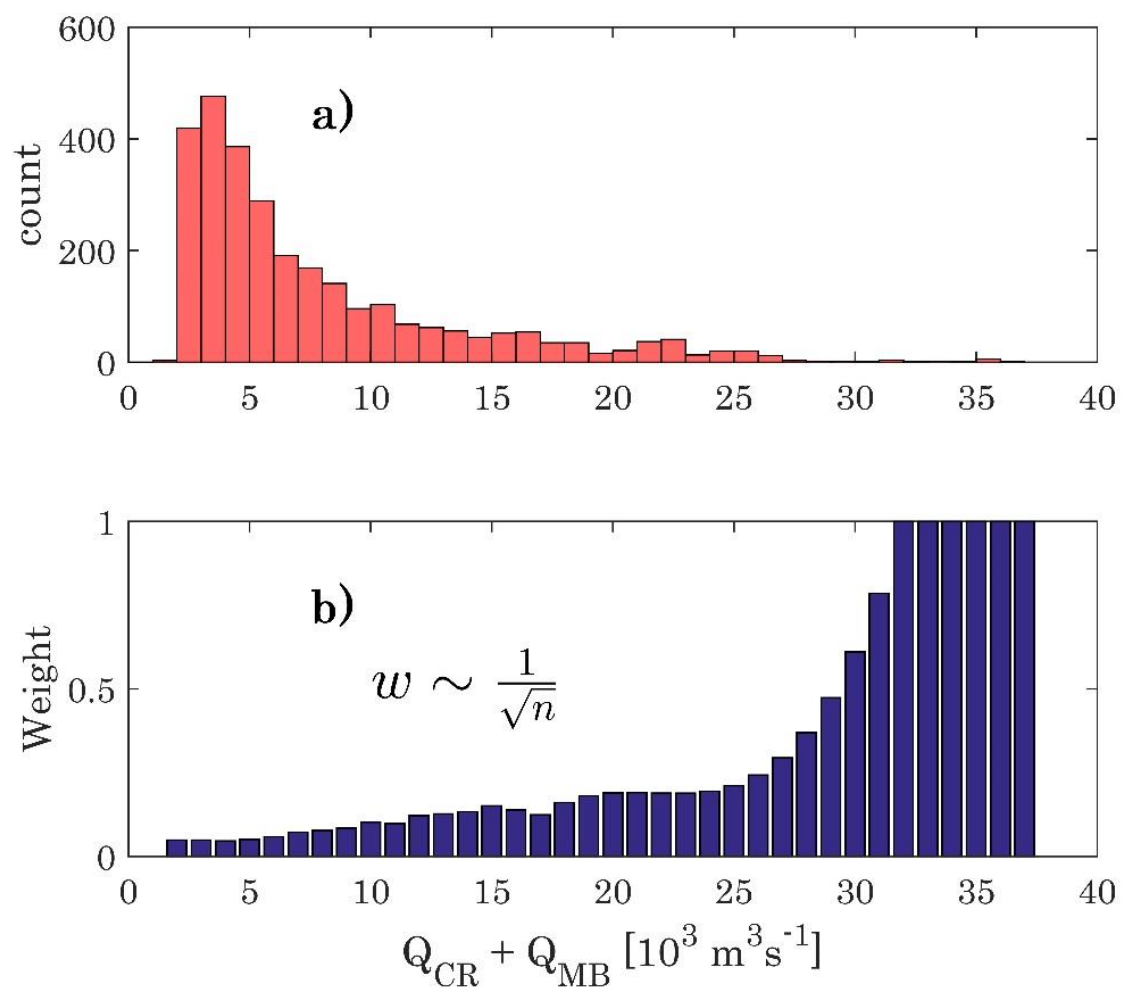

Figure A.7: (a) Histogram of total daily average discharge at Morrison Bridge 1879-1898. (b) nonlinear regression model bin weights. 


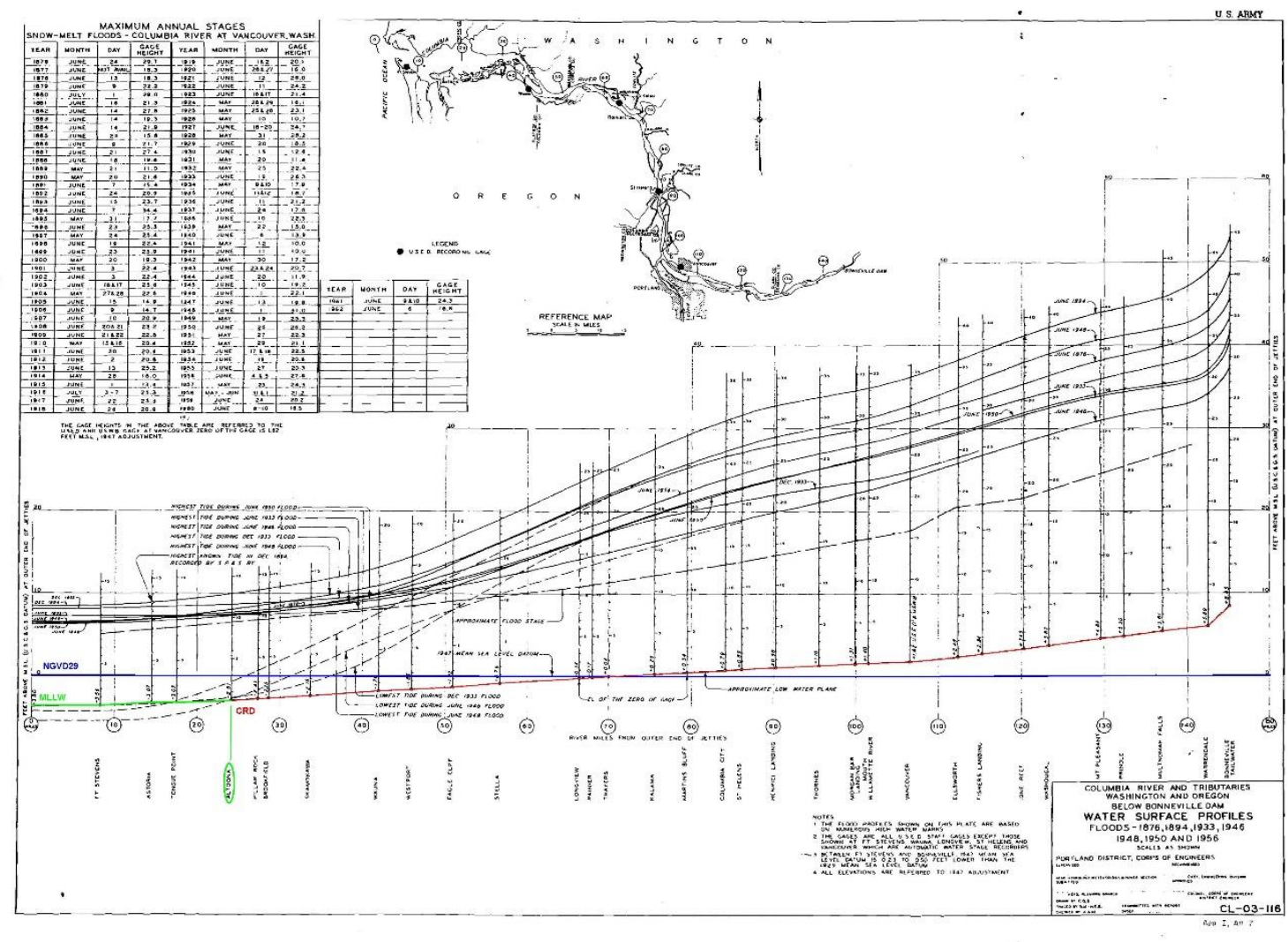

Figure A.8: 1963 Columbia River water surface profiles for major floods in 1876, 1894, 1933, 1946, 1948, 1950 and 1956 (USACE, 1963).

\section{A.3 - Modern Levees}

A significant amount of the historical floodplains has been isolated by levees (Marcoe \& Pilson, 2017). Levees are present throughout the LCRE, and used to protect farmland, residences, and businesses from flood waters. Figure A.9 shows a Google Earth image of the LCRE between Skamokawa, WA and Longview, WA. Islands such as Tenasillahe Island and Puget Island are almost totally isolated from the river. Levees also surround large floodplains between Westport, OR, and Mayger, OR. Figure A.10 is a 
Google Earth image of the LCRE between Burke Island, and Vancouver, WA. The city of Woodland, WA (Figure A.10, top left) and Sauvie Island are mostly surrounded by levees.

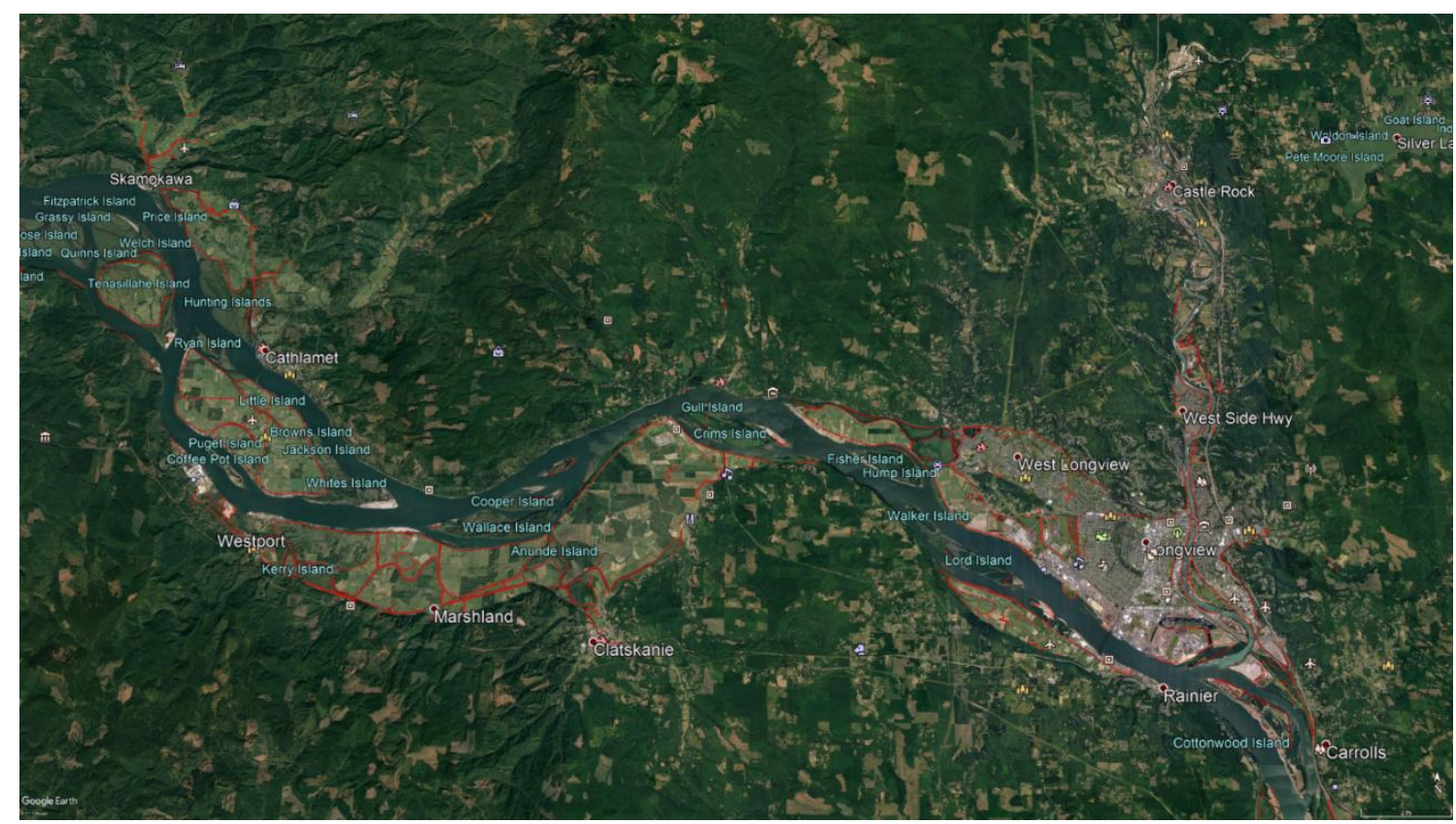

Figure A.9: Google Earth image of Columbia River between Skamokawa, WA and Longview, WA.

Red lines are the centerline of flood control levees (Avi, 2107). Accessed May 19, 2019 


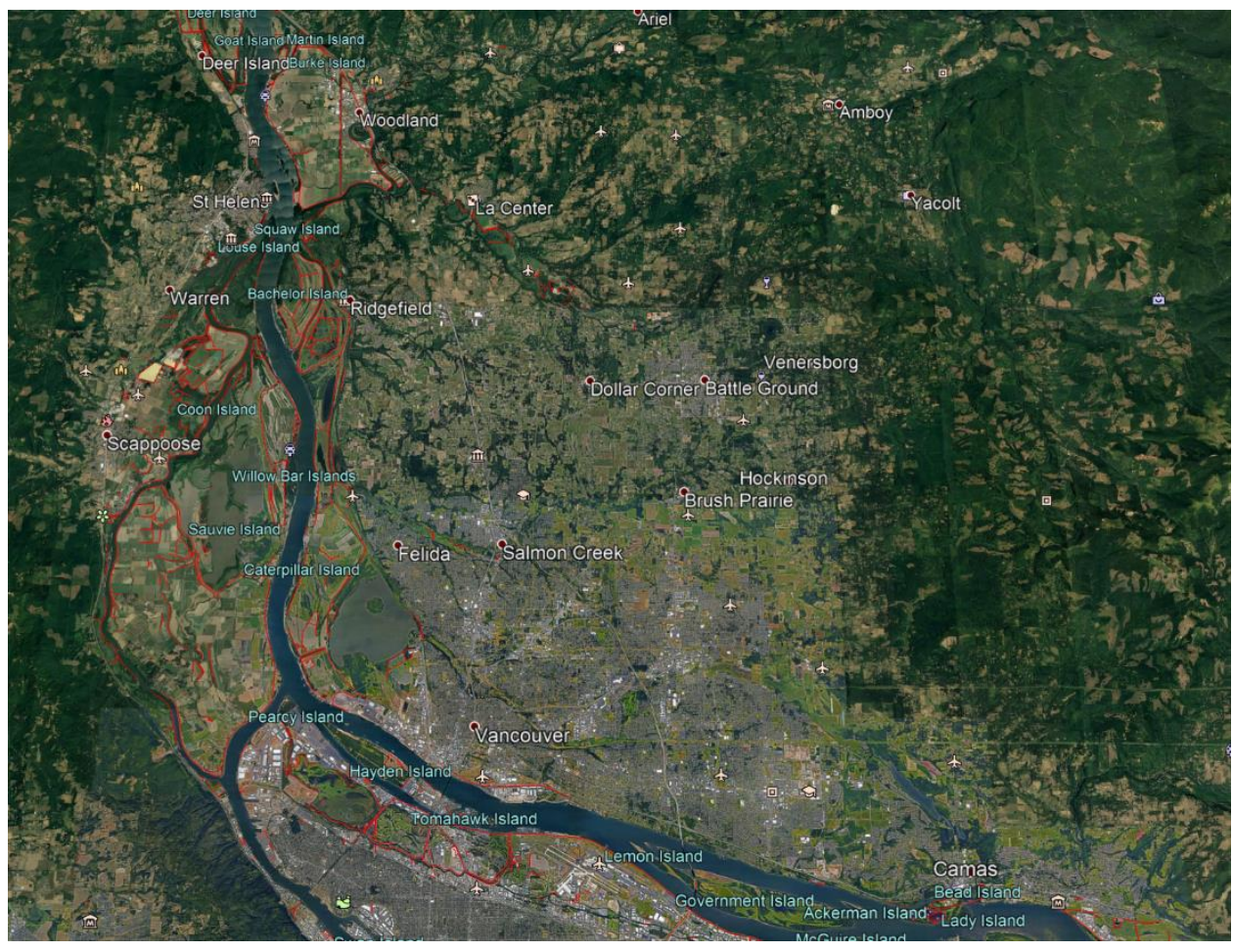

Figure A.10: Google Earth image of the Columbia River between Burke Island and Vancouver, WA.

Red lines are the centerline of flood control levees (Avi, 2107). Accessed May 19, 2019 


\section{A.4 - Acceleration Terms - Spring Freshet}
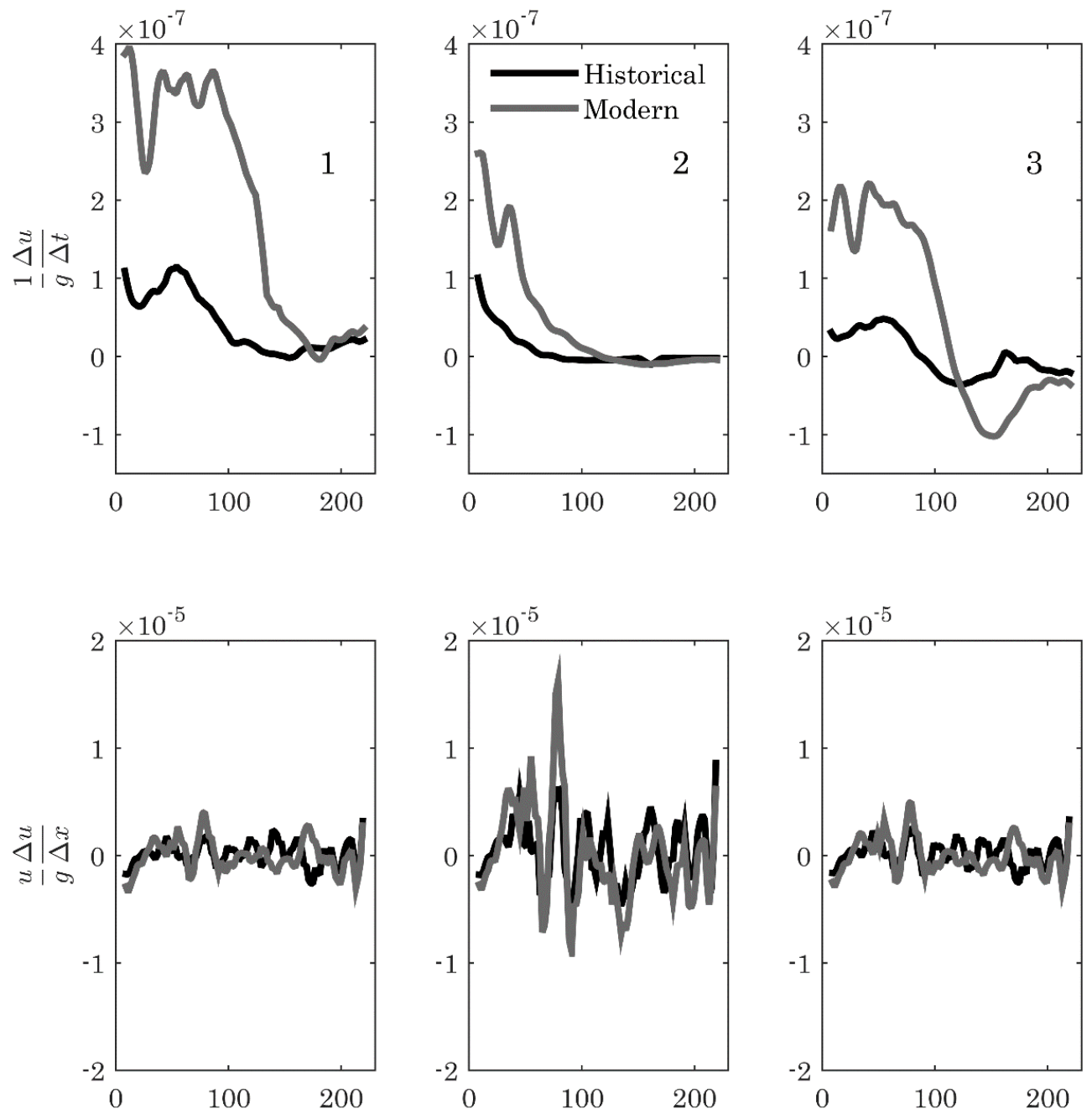

Figure A.11: Tidally averaged values of (top row) temporal acceleration and (bottom row) spatial acceleration during three phases of the $25 \times 10^{3} \mathrm{~m}^{3} \mathrm{~s}^{-1}$ freshet 


\section{A.5 - Sandy River/Willamette River Correlation}

Table A.1: Correlation between Willamette R. at Portland flood events and Sandy R. below Bull Run R. since 1927.

\begin{tabular}{ccccc}
\hline Date & Peak WR $\left(10^{3} \mathrm{~m}^{3} \mathrm{~s}^{-1}\right)$ & Date & Peak SR $\left(10^{3} \mathrm{~m}^{3} \mathrm{~s}^{-1}\right)$ & SR/WR $(\%)$ \\
\hline $1964-12-25$ & 12.032 & $1964-12-22$ & 1.637 & 13.6 \\
\hline $1943-01-03$ & 11.920 & $1942-12-31$ & 0.493 & 4.13 \\
\hline $1996-02-09$ & 11.893 & $1996-02-07$ & 1.628 & 13.69 \\
\hline $1965-01-30$ & 10.163 & $1965-01-28$ & 1.068 & 10.50 \\
\hline $1961-02-13$ & 10.187 & $1961-02-10$ & 0.648 & 6.37 \\
\hline $1953-01-21$ & 9.745 & $1953-01-18$ & 0.875 & 8.98 \\
\hline $1945-12-31$ & 9.243 & $1945-12-28$ & 1.036 & 11.21 \\
\hline $1946-12-17$ & 9.182 & $1946-12-17$ & 0.980 & 10.67 \\
\hline
\end{tabular}

WR - USGS 14211720, SR - USGS 14142500 


\section{Appendix B: Supporting Information for Chapters 4 and 5}

\section{B.1 - Tidal Boundary Conditions}

Operationally, tidal amplitudes and phases are obtained from the Oregon Tidal Prediction Software for the northwest and southwest corners of the ocean boundary (Figure B.1) and interpolated along the western ocean boundary (dashed line). A Neumann-type boundary is applied on the north and south boundary of the ocean domain (solid red line) and ensures that a constant slope is modeled along the north and south boundary of the ocean in the model.

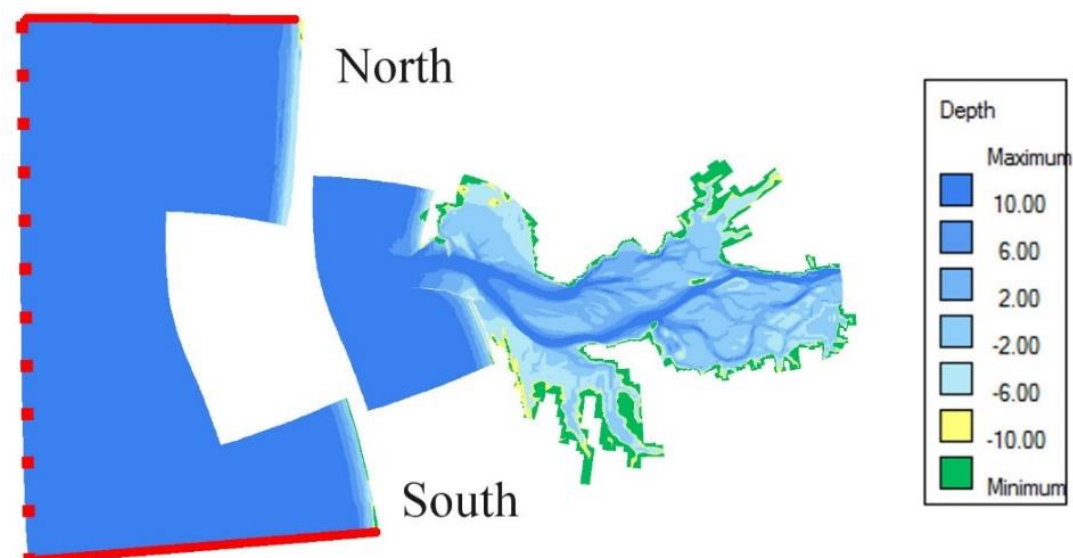

Figure B.1: (left) A domain, Pacific Ocean (right) B - domain - Lower Columbia River estuary

\section{B.2 - Thin Dams}

Bridge piers, pile dikes and other flow obstructions in the Portland Metro Area (both Columbia and Willamette Rivers) act to restrict water flow during flood conditions and are modeled with the use of "thin dams" (Figures B.2 \& B.3). These thin dams simulate flow obstructions by blocking discharge through the affected cells in the model grid. The 
efficacy of all these setup choices is tested by comparing simulations of the 1996 flood against maps of the 1996 flood boundary and available satellite imagery.

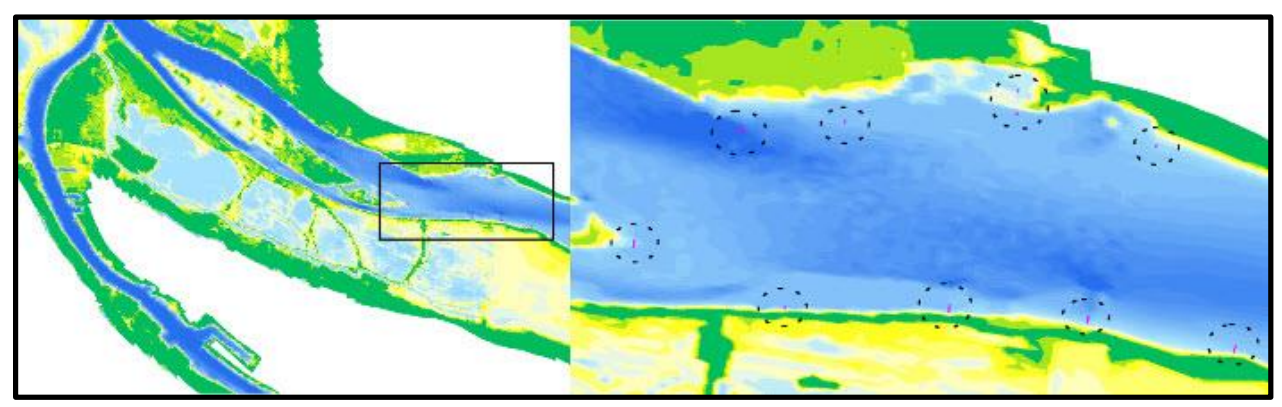

Figure B.2: Delft3D thin dams in the Columbia River upstream of Vancouver

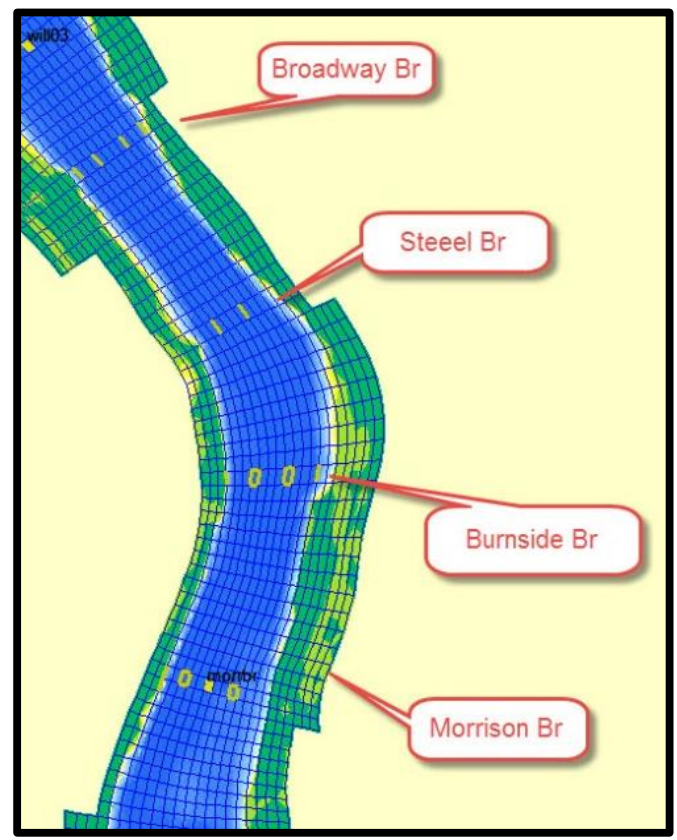

Figure B.3: Thin dams used to simulate pilings on bridges in the Willamette River.

\section{B.3 - Discharge Boundary Conditions}

The discharge boundary conditions used in the model are shown in Figures B.4, B.5, and B.6. The discharge of the Willamette River, the Clackamas River, and small creeks upstream of Portland (e.g., Johnson Creek) are modeled with a boundary condition 
at the Willamette Falls in Oregon City, based on discharge measurements at the Morrison Bridge in downtown Portland (USGS gauge 14211720). Downstream of Portland, the Kalama River (USGS 14223500), Lewis River, and Cowlitz River (USGS 14243000) discharges are based on a combination of measured and inferred discharge (Tables B.1 \& B.2; see below for details.). The discharge boundary of the Lewis River includes the effects of both the Lewis River (USGS station 14220500) and the East Fork of the Lewis River (USGS station 14222500).

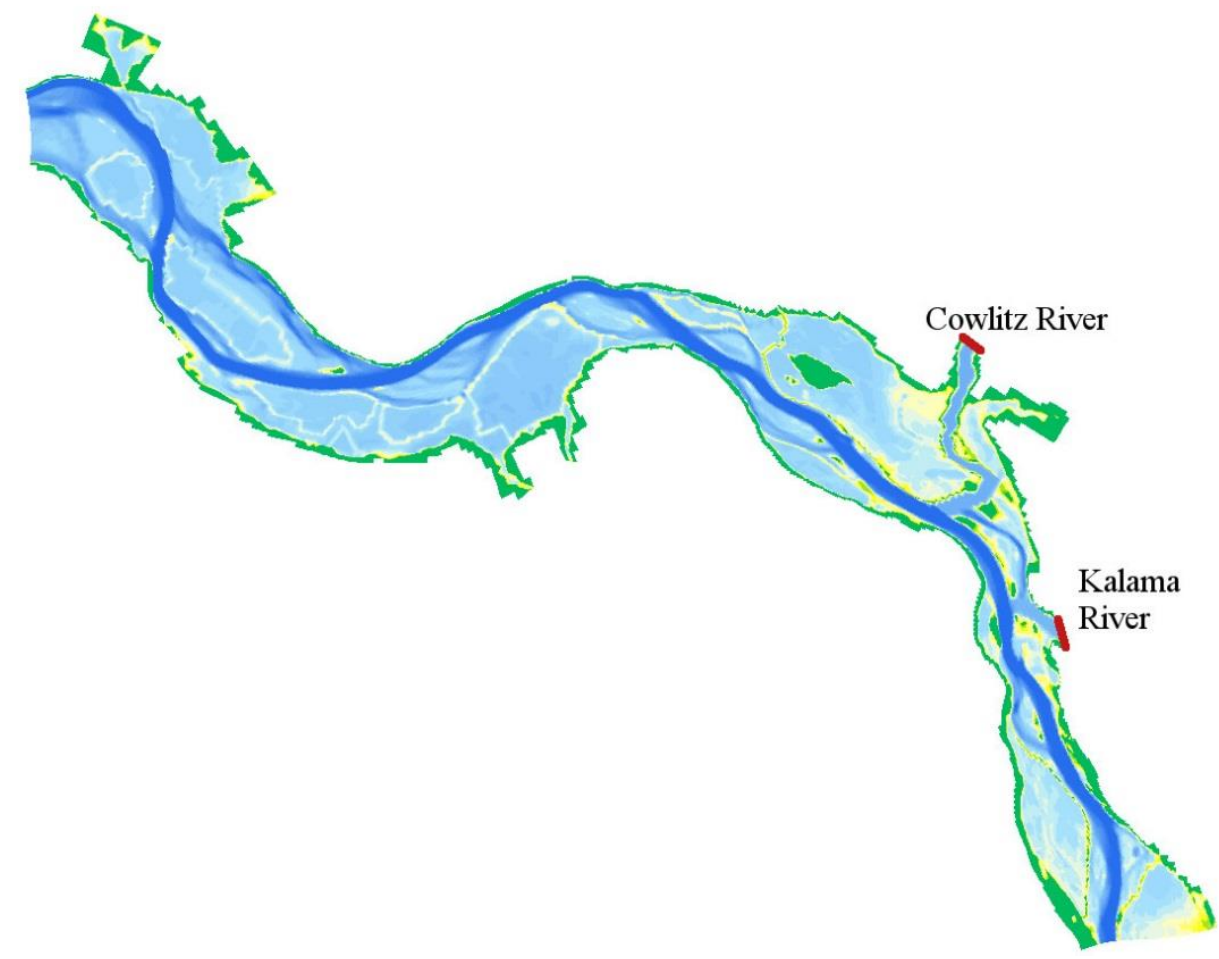

Figure B.4: Model domain within the Lower Columbia River model showing discharge boundaries for the Cowlitz River and Kalama River 

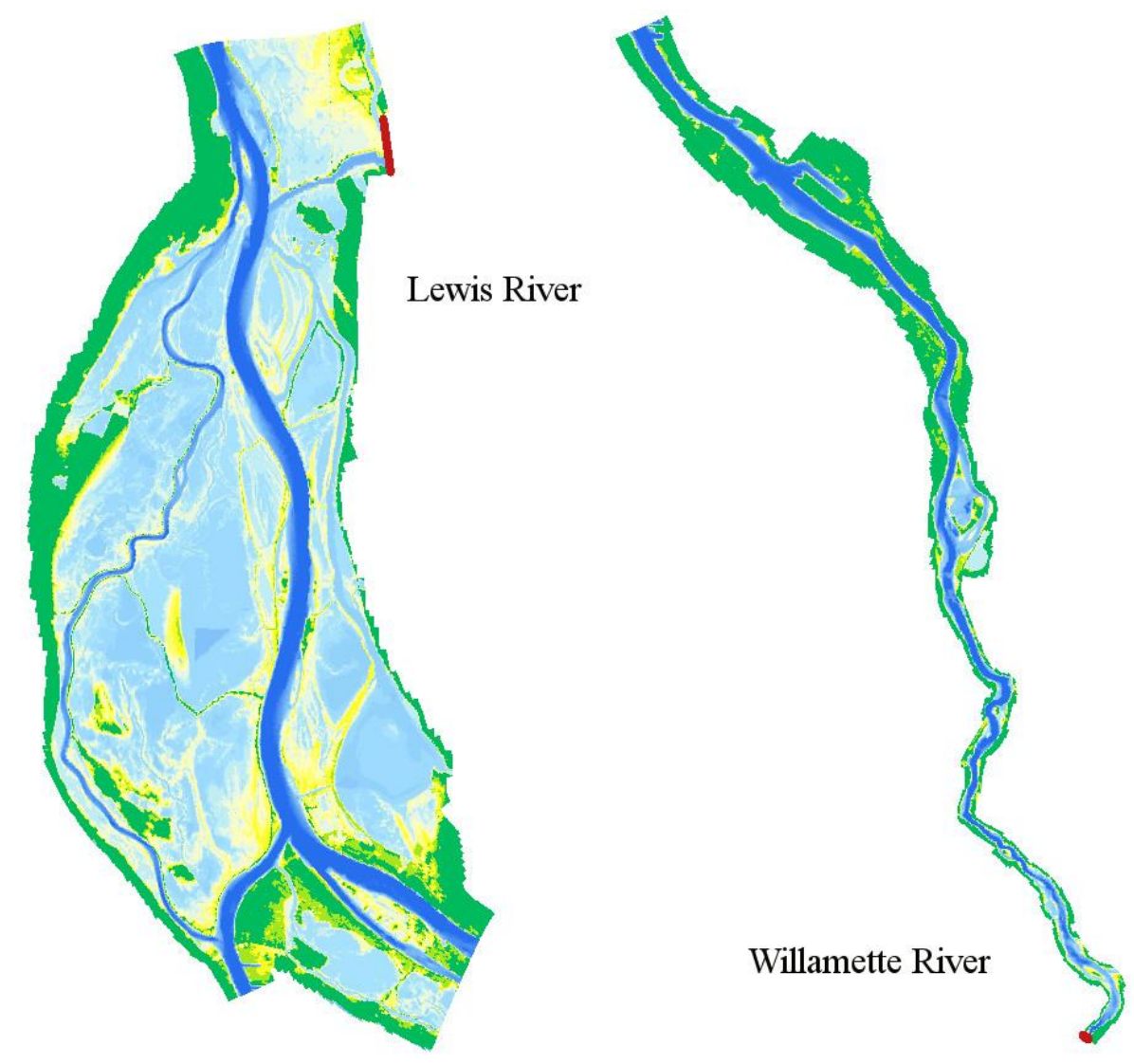

Figure B.5: (left) Columbia River model domain with Lewis River discharge boundary (right) Willamette River model domain with Willamette River discharge boundary.

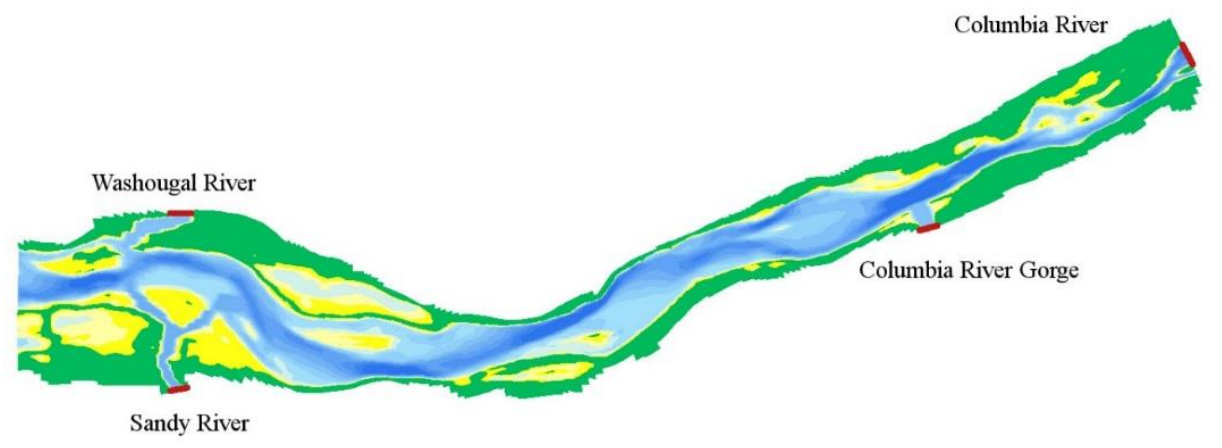

Figure B.6: - Columbia River model domain representing with discharge boundaries for Sandy River, Washougal River, Columbia River Gorge and Columbia River. 
Records from several major tributaries are available from the 1996 flood report. (see USACE, 1997 and Table B.1 below). However, at several gauges, there is no detail data (hourly or less), which complicates the calibration and validation of this event. Table B.2 is a list of the supplementary discharge sources used to gain a better understanding of the timing and magnitude of the flood along the Lower Columbia River.

Table B.1: Measured river discharge used to construct discharge boundaries in flow model.

\begin{tabular}{|c|c|c|c|}
\hline River & Site & Source & Discharge \\
\hline Willamette River & Morrison $\mathrm{Br}$ & USGS 14211720 & $\begin{array}{l}\text { daily average } \\
\text { peak flood }\end{array}$ \\
\hline Columbia River & Bonneville Dam & $\mathrm{FPC}$ & hourly \\
\hline Sandy River & Below Bull Run & USGS 14142500 & $30 \mathrm{~min}$ \\
\hline Washougal River & Washougal, WA & USGS 14143500 & peak flood \\
\hline Lewis River & Ariel, WA & USGS 14220500 & $\begin{array}{l}\text { daily average } \\
\text { peak flood }\end{array}$ \\
\hline E Fork Lewis River & Heisson, WA & USGS 14222500 & $\begin{array}{l}\text { daily average } \\
\text { peak flood }\end{array}$ \\
\hline Kalama River & Kalama, WA & USGS 14223500 & peak flood \\
\hline Cowlitz River & Castle Rock, WA & USGS 14243000 & $15 \mathrm{~min}$ \\
\hline
\end{tabular}

Measured river discharge used to construct discharge boundaries in flow model. USGS data at https://waterdata.usgs.gov/nwis . FPC (Fish Passage Center) data available at http://www.fpc.org/river/flowspill/FlowSpill_Query.html

\section{B.3.1 Columbia River}

Along the Columbia River, the model has seven discharge boundaries, four upstream of the confluence with the Willamette River at Kelley Point (rkm163), and three downstream of Kelley Point. Upstream of Kelley Point are the Washougal River (rkm 194), the Sandy River (rkm 197), the Columbia River Gorge (rkm 223), and the Columbia River at Bonneville (rkm 233). Downstream of Kelley Point is the Lewis River (rkm 140), the Kalama River (rkm 117), and the Cowlitz (rkm 110). These six tributary rivers are the largest systems between the Bonneville Dam (rkm 234) and Beaver Army Terminal (rkm 86) and all had a peak discharge of at least $500 \mathrm{~m}^{3} \mathrm{~s}^{-1}$ during the flood. 
The discharge from the ungauged Columbia River Gorge estimated through comparisons with the hydrograph of nearby watersheds and scaled to take into account different watershed areas. While necessarily a rough estimate, I argue that not including such ungauged areas would lead to larger errors. A good comparison to measured water level data validates this approach (see Chapter 4). Specifically, I analyze three rivers with limited flow regulation, the Sandy River below Bull Run, the Bull River at Bull Run, OR (USGS 14140000) and the Hood River near Hood River, OR (USGS 14120000). During the flood, all three rivers have three discharge peaks occurring at roughly the same time (Figure B.7). I, therefore, infer that the combined creeks in the Gorge area would produce a similar hydrograph.
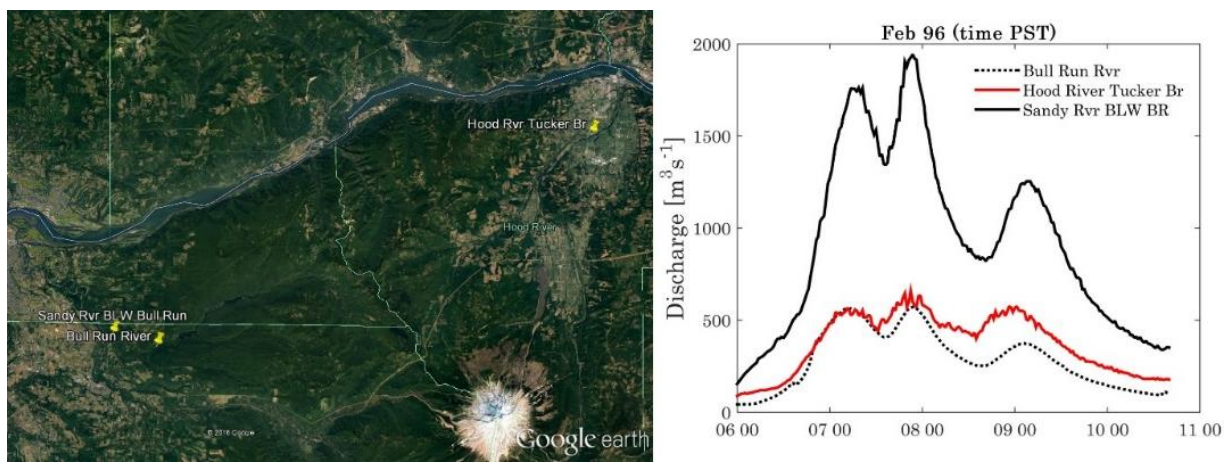

Figure B.7: (left) Google Earth of gauge locations (right) Sandy River, Bull Run River and Hood River discharge during peak of Feb. 1996 Flood.

The hydrograph of the Washougal River is constructed with the assumption that it has a discharge hydrograph similar to the Sandy River. Given the lack of timing data, I assume similar timing as the Sandy River and I set the discharge ratio between the Sandy River and the Washougal River to the ratio of their watershed areas. For the Columbia River Gorge (USGS HUC10 1708000108) watershed, though there is no measured flood 
discharge, I make estimates based on the size of the basin and the response of nearby watersheds. The discharge from this watershed is scaled with the same timing as the Sandy River and discharge proportional to the Washougal River. The Washougal River with a 279.7 sq. km drainage basin produced a peak discharge of $767 \mathrm{~m}^{3} \mathrm{~s}^{-1}$. The Columbia River Gorge watershed has a $426 \mathrm{sq}$. km drainage basin so I assume the peak discharge during the February 1996 Flood was $1171 \mathrm{~m}^{3} \mathrm{~s}^{-1}$. Based on these assumptions I produced the hydrographs for the Sandy River, Washougal River and the Columbia River Gorge in Figure B.8. Including ungauged flows approximately doubles the contribution of the local tributaries to Columbia River flow at Vancouver, and is a significant portion (14\%) of the total Columbia River boundary during the peak of the flood. The discharge time series used in the model are applied directly in the Lower Columbia River model that extends upstream to Bonneville (Helaire, 2016). 

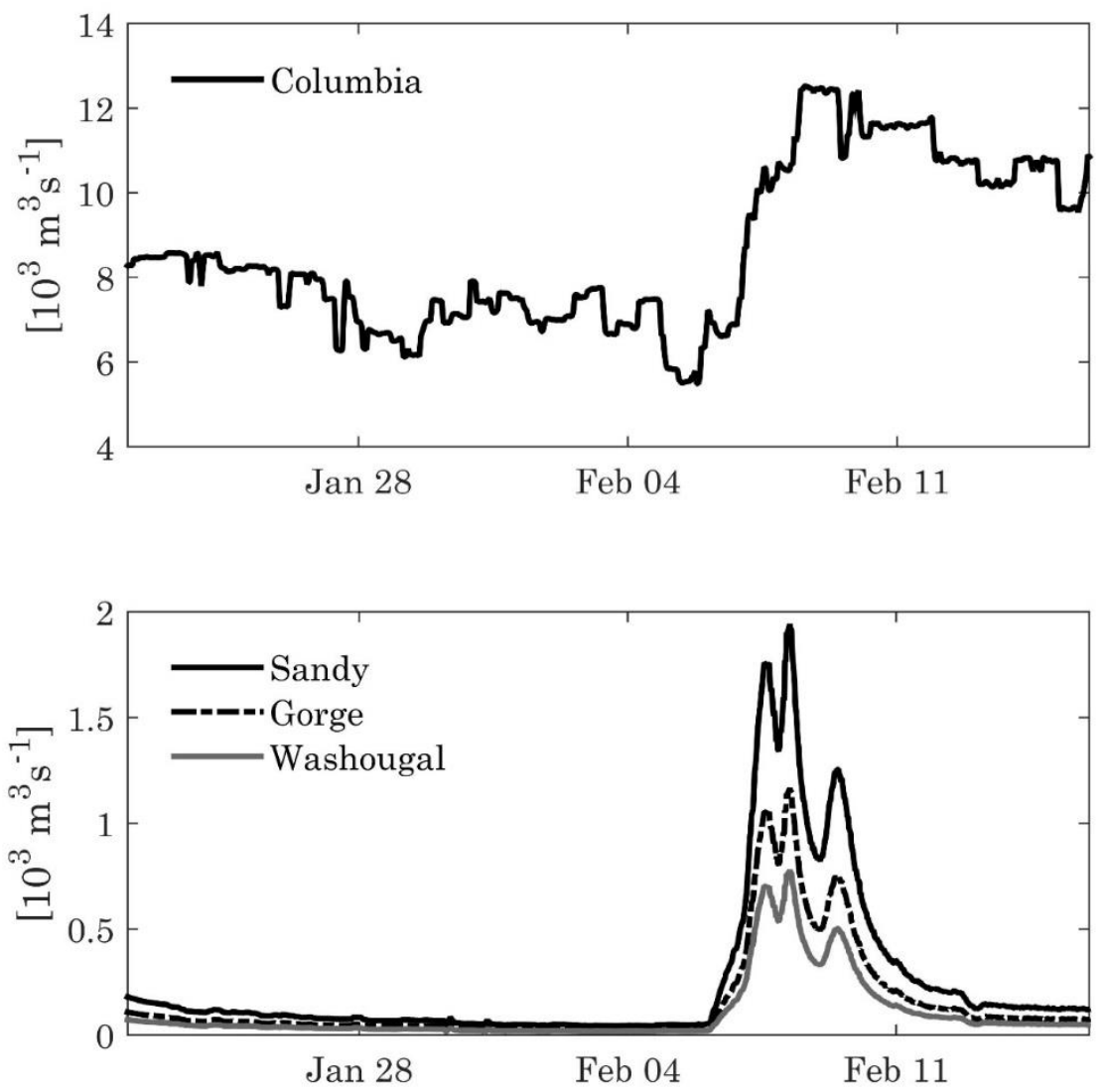

Figure B.8: (top) Hydrograph for the Columbia River (bottom) Hydrographs for the Sandy River, Columbia River Gorge and Washougal River.

\section{B.3.2 Downstream Tributaries}

The following sections detail the methods used to obtain the discharge time for the Columbia tributaries downstream of Kelley Point except for the Willamette River. This section will describe the discharge boundary for the Lewis River, Kalama River, and the Cowlitz River.

\section{B.3.2.1 Lewis River}

During the flood, the Lewis River discharge into the Columbia River peaked at over $3,000 \mathrm{~m}^{3} \mathrm{~s}^{-1}$, based on peak discharge estimates. No detailed data is available from the 
Lewis River or the East Fork of the Lewis River, so a discharge time series was constructed that matched the peak measured discharge, and conserved mass concerning the measured daily average discharge. The response of the Lewis River during a flood event is inferred from the hydrographs of four floods occurring after 1999 (Figure B.9). Based on the response of these floods I assume that the Lewis River has a step response during a flood. From January 20, 1996, to February 6, 1996, I interpolate the discharge time series from measured daily average discharge. During this period, the measured discharge remained below $100 \mathrm{~m}^{3} \mathrm{~s}^{-1}$. On February 8, 1996, I assume the discharge to remain the same all day and remain constant for part of the day on February 9, 1996. The discharge was assumed to rise to peak measured discharge over six hours and remain at the peak discharge for the remainder of the day. The timing was such that the modeled daily average discharge was close to the measured daily average discharge. In the following four days, the discharge for each day was constant at the measured daily average discharge with six-hour transitions in discharge between successive days (Figure B.10). 

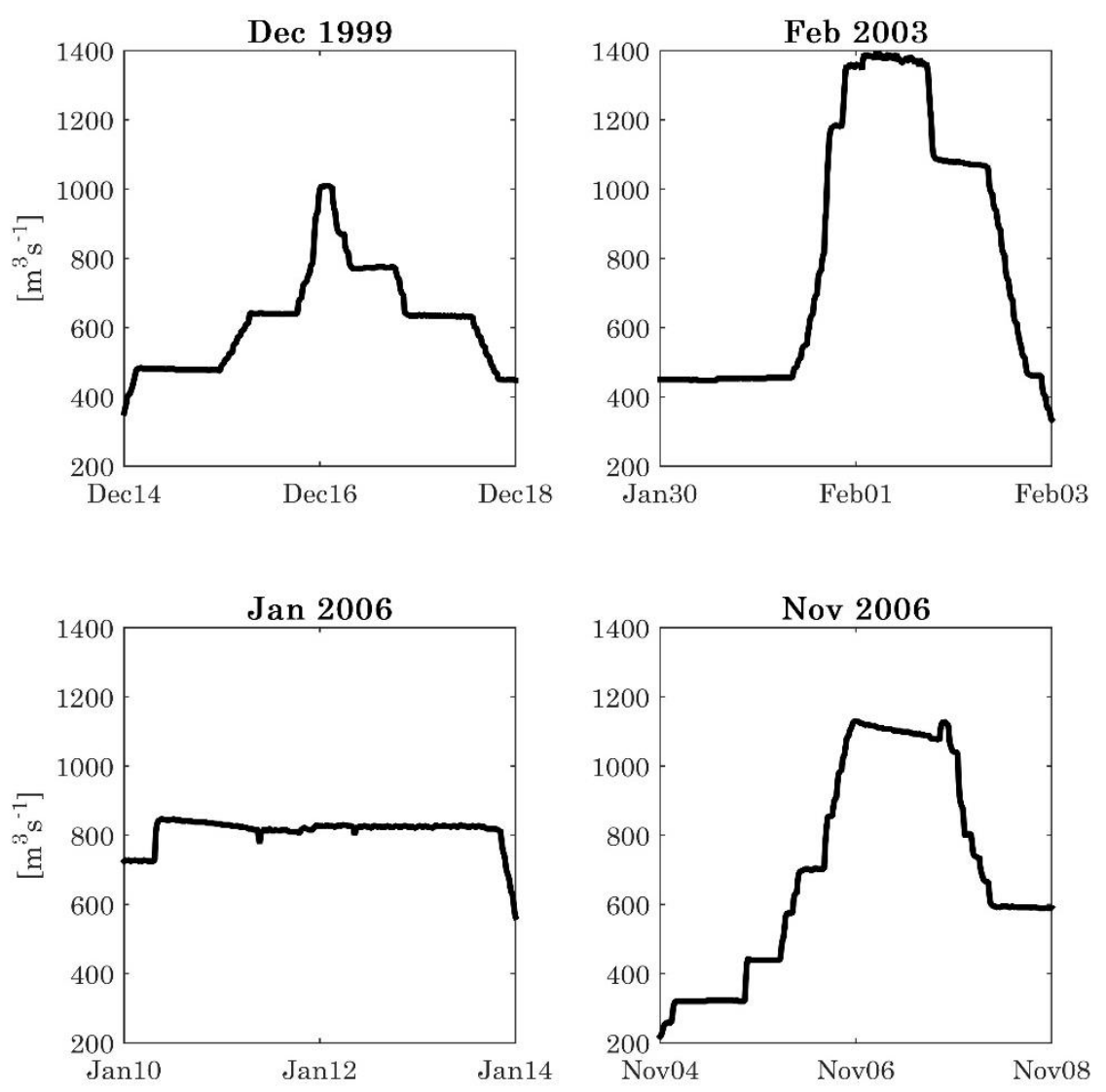

Figure B.9: Discharge time series for the four largest discharge events on the Lewis River at Ariel, WA (USGS 14220500).
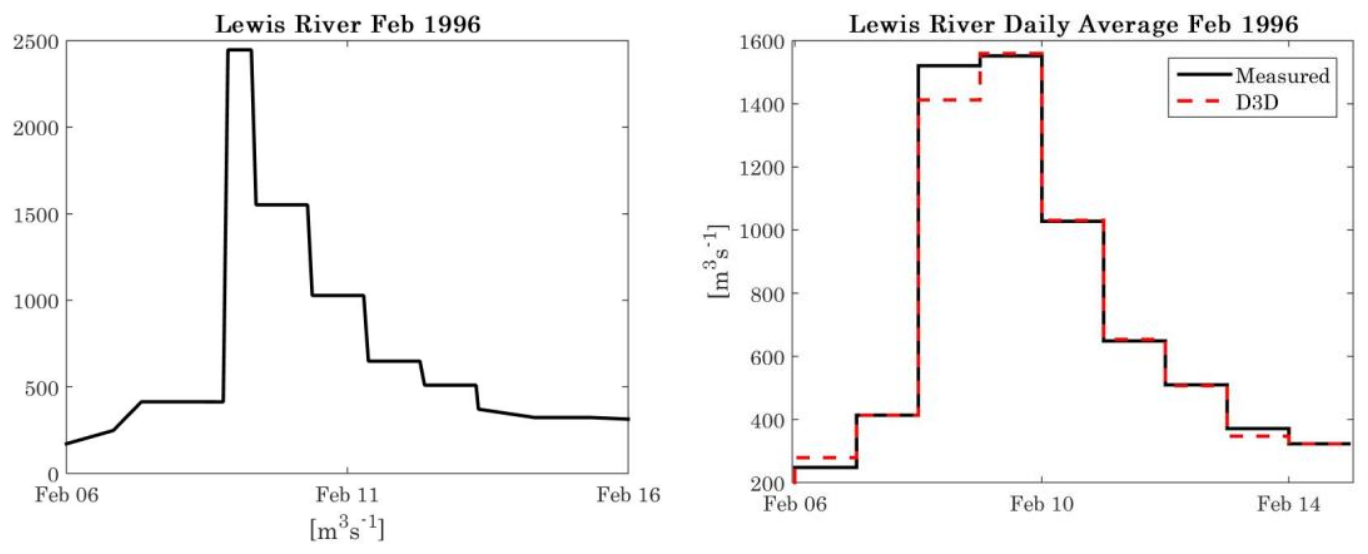

Figure B.10: (left) Delft3D discharge time series. (right) Comparison of measured daily average discharge and Delft3D daily average discharge of the Lewis River. 
The flood event from January 30 - February 5, 2003, is used as an analog to construct the discharge time series for the East Fork of the Lewis River. The East Fork of the Lewis River is unregulated so the discharge time appears to more like a skewed normal distribution function. The discharge time series is filtered using a moving average filtered with a local regression using a weighted linear least square and a 2nd-degree polynomial. (See https://www.mathworks.com for information on smooth function in Matlab). The scaled discharge reaches a peak of $809 \mathrm{~m}^{3} \mathrm{~s}^{-1}$ cubic meters, matching the peak value measured by USGS on February 8, 1996. According to the USGS, the gauge at Heisson, WA captures discharge from $59 \%$ of the drainage basin. The assumption is made that the ungauged area in the watershed provides the same amount of same discharge/area ratio as the gauged area. The discharge is increased by $41 \%$ to account for approximately 1100 $\mathrm{m}^{3} \mathrm{~s}^{-1}$ to account for the ungauged drainage area. The discharge time series is shifted so that the peak of the flood occurs on February 8, 1996. Figure B.11 shows the transformation from the 2003 event to a discharge time series for the February 1996 event.

The discharge boundaries for the Lewis River and the East Fork of the Lewis River are added together and combined into a single discharge boundary (Figure B.12), applied at the Lewis Boundary on the Delft3D grid. 

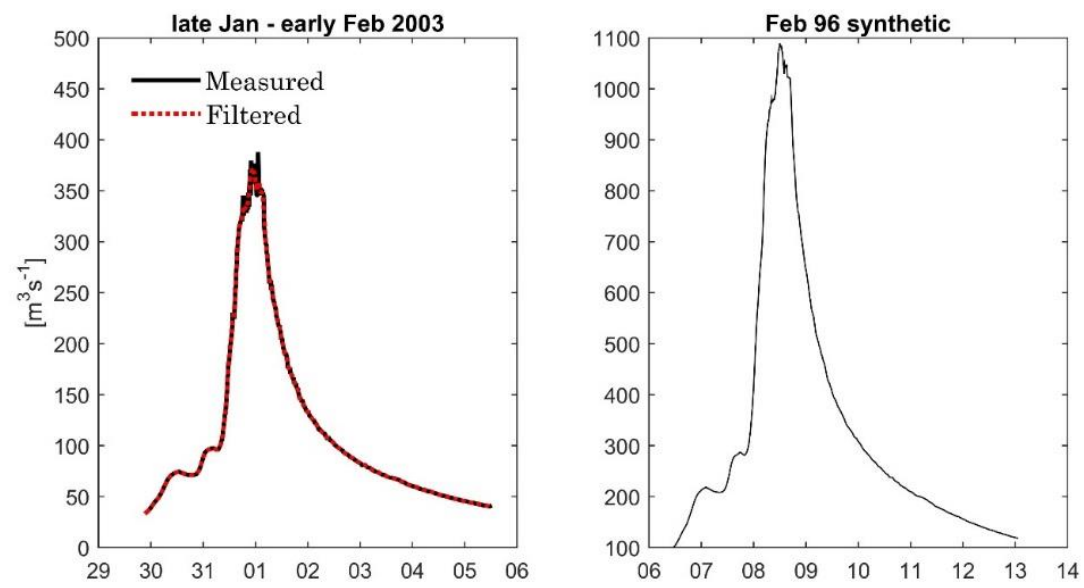

Figure B.11: (left) Flood event late Jan - early Feb 2003 on East Fork of the Lewis River (USGS 14222500) (right) Delft3D discharge hydrograph for Feb. 1996 event.

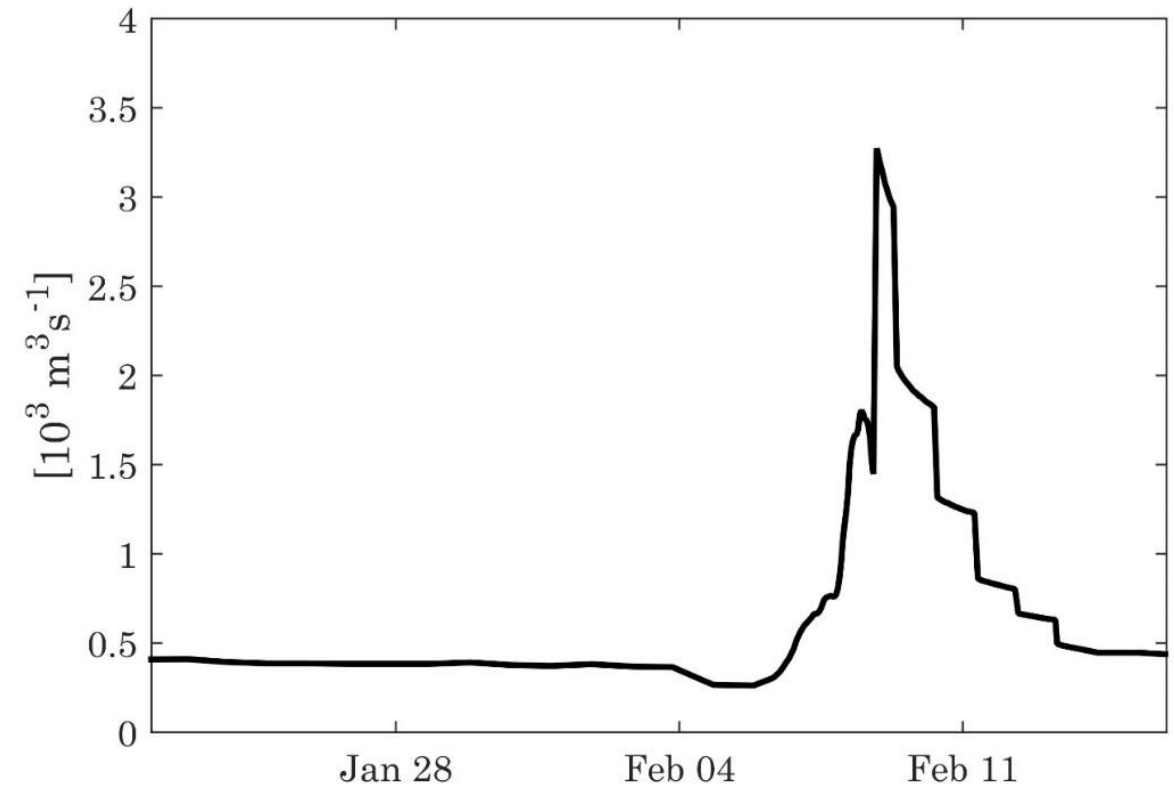

Figure B.12: Discharge boundary for the combined Lewis River and East Fork of the Lewis River used in the model for the February 1996 flood event. 


\section{B.3.2.2 Kalama River}

Only a peak flood discharge is available during the February 1996 flood; therefore, I used the flood event from January 30 - February 5, 2003, on the East Fork of the Lewis River as an analog for the Kalama River during the February 1996 flood (Figure B.11). The 2003 flood event $\left(380 \mathrm{~m}^{3} \mathrm{~s}^{-1}\right.$ peak discharge), scaled to have a peak of $644 \mathrm{~m}^{3} \mathrm{~s}^{-1}$, is within 5\% of the measured peak of the Kalama River during the 1996 flood (Figure B.13).

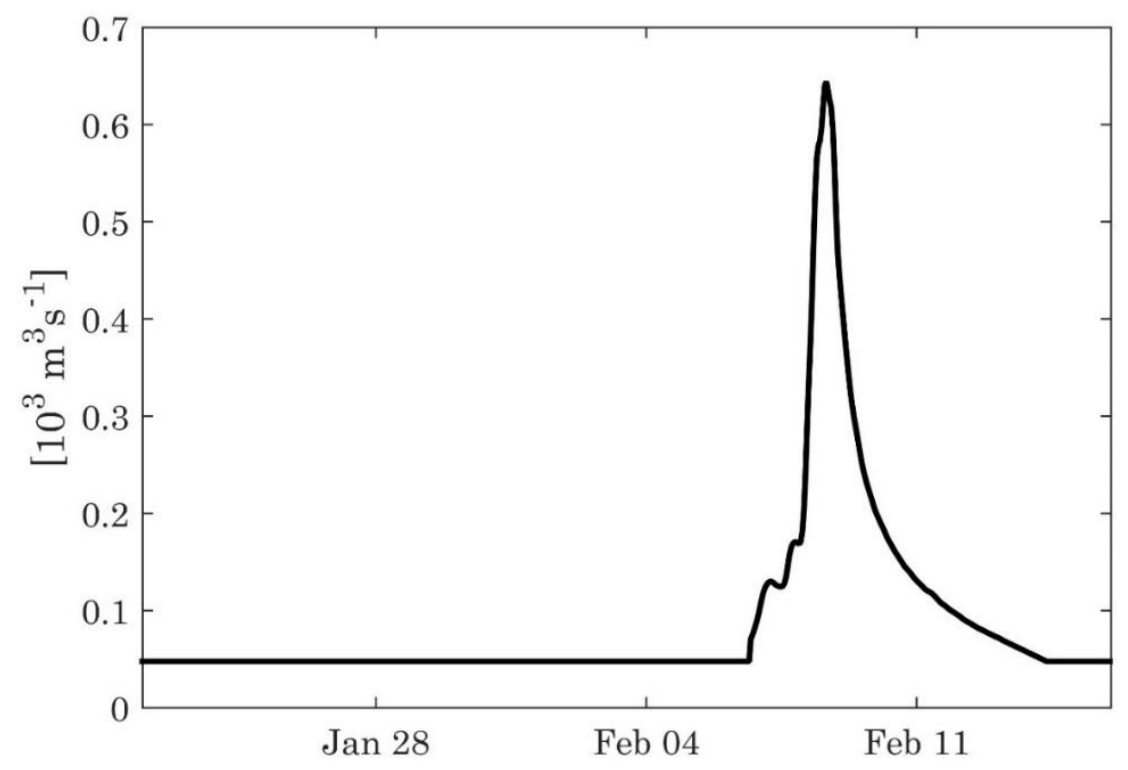

Figure B.13: Delft3D discharge boundary for Kalama River during the peak of the Feb. 1996 flood event.

\section{B.3.3 Willamette River}

The Willamette River boundary is applied at the head of tides at Oregon City (i.e., Willamette Falls, see Figure B.5). The combined flow from the Willamette River, Clackamas River, and Johnson Creek are applied at this boundary for simplicity. This 
discharge at this boundary is derived from daily average discharge at Morrison Bridge and the measured peak discharge on February 9, 1996. Data are linearly interpolated to obtain an hourly discharge hydrograph. The discharge peak is shifted back 15 hours to take into account the travel time of the flood between Oregon City and downtown Portland (Figure B.14).

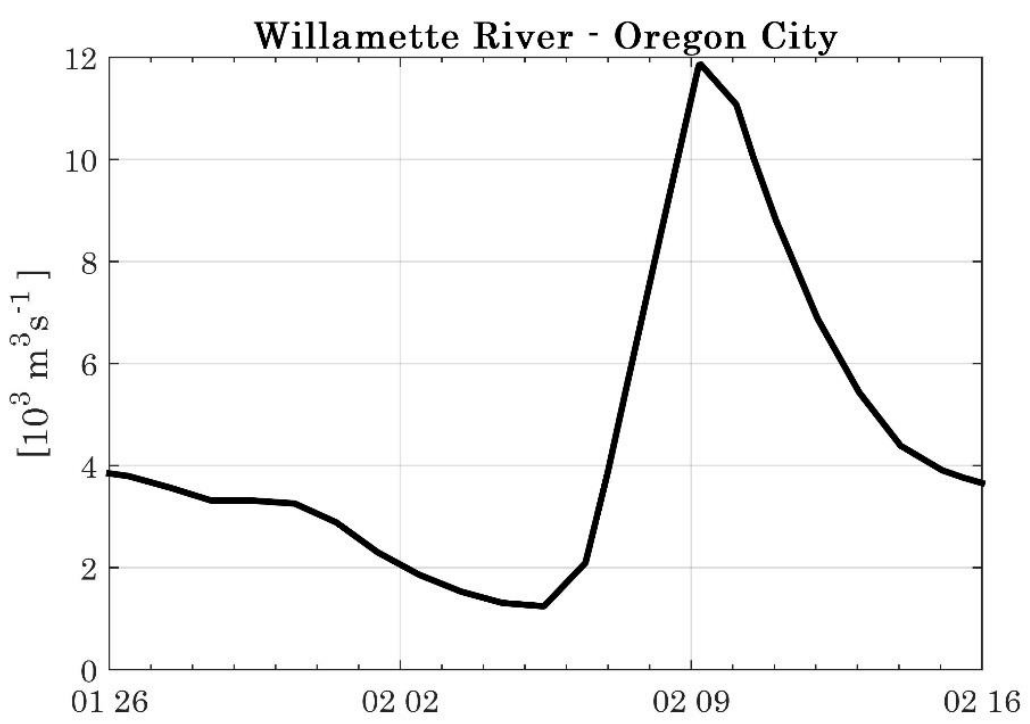

Figure B.14: Willamette River discharge boundary at Oregon City, OR in the Delft3D model.

In part, because the measured discharge conditions are only at a daily resolution, the exact shape of the measured water level in Portland is not exactly reproduced, as shown by a close-up of modeled and measured results in downtown Portland (Figure B.15). Though the unexplained fluctuations of up to $0.1 \mathrm{~m}$ occur in the Morrison Bridge water level data suggest there is some uncertainty in the water level measurement, I note that the general shape of the flood is also reproduced by the St Johns Bridge measurement. 


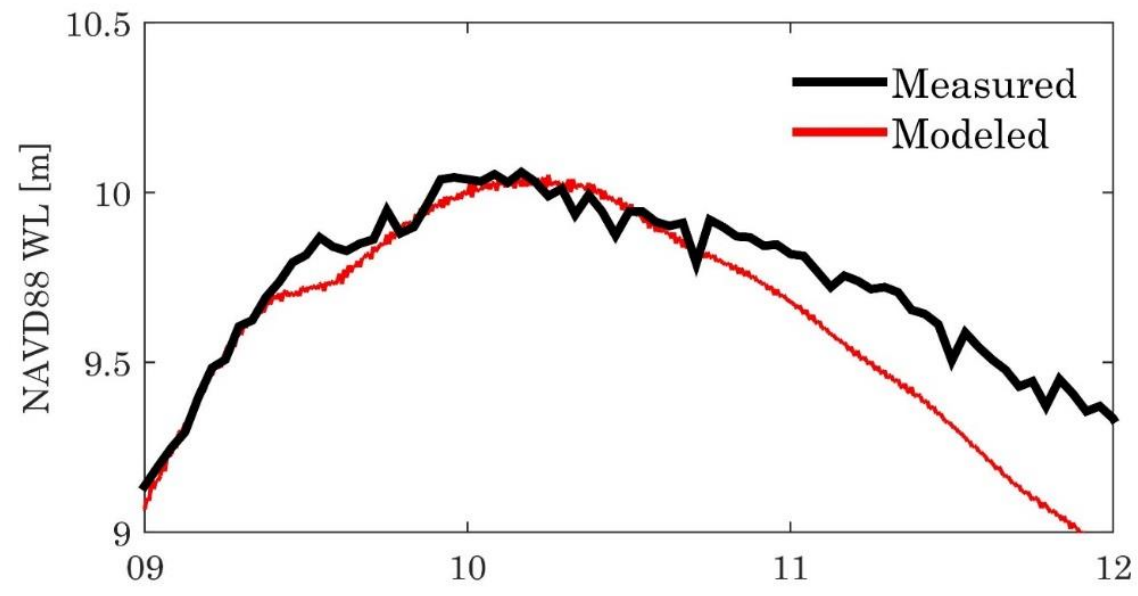

Figure B.15: Closeup of the hydrograph of water levels at Morrison Bridge during the peak of the flood. Time is on GMT.

\section{B.4 - Discharge Calibration}

Another aspect of the calibration involves ensuring that downstream discharge matches the measured values. I use the USGS gauge at Beaver Army Terminal as a check of the downstream discharge. The model has a monitoring cross-section that approximates the Columbia River discharge at Beaver Army Terminal (rkm 87). My goal was to ensure that the modeled discharge was within the estimated error bounds of the measurement, which I infer to be $+/-10 \%$. The results of the simulation show that the model discharge is at least $10 \%$ higher than the modeled discharge from Feb 7-9, 1996 (Figure B.16). Beyond Feb 9, the modeled discharge falls within $10 \%$ of the modeled discharge. 

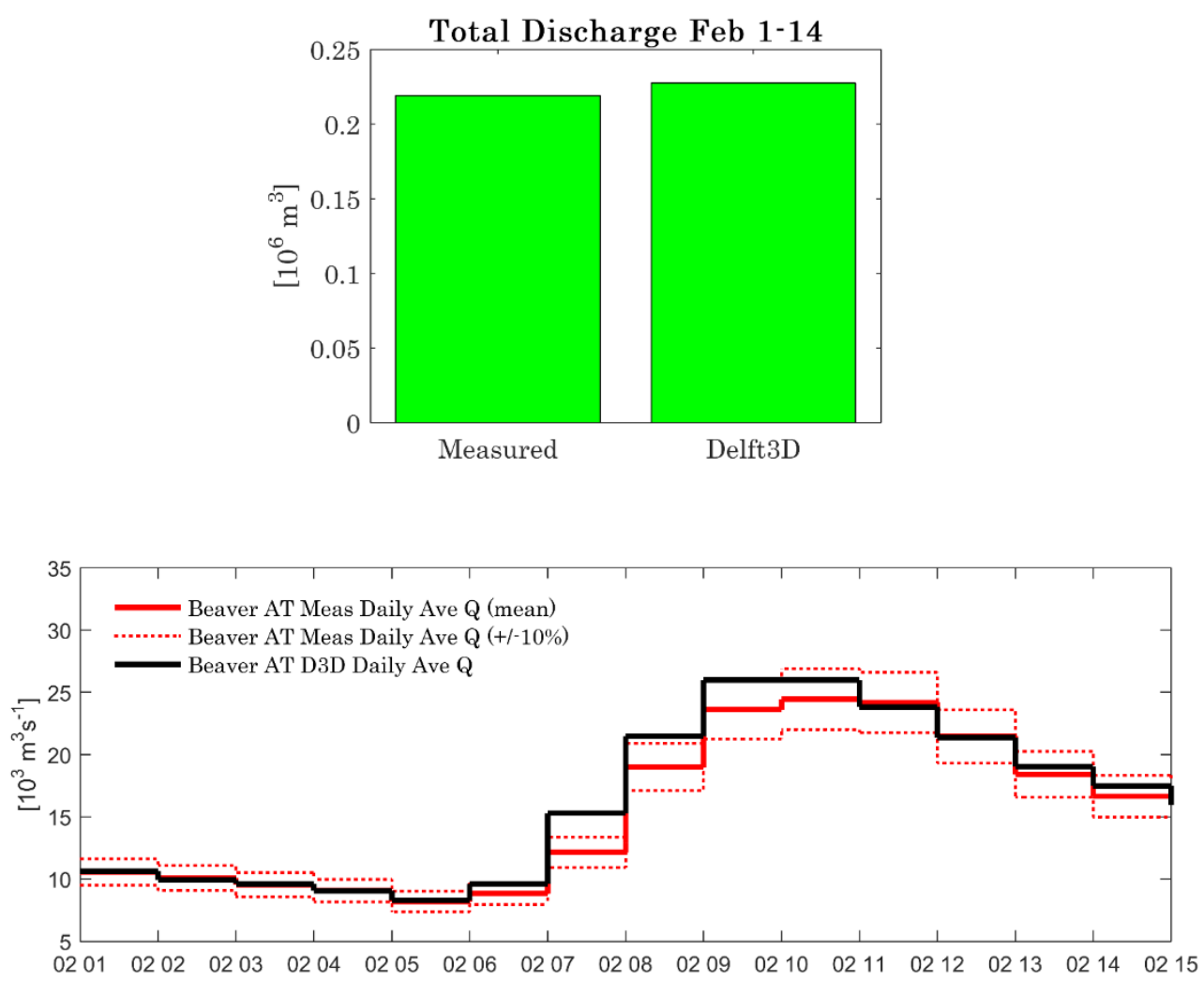

Figure B.16: (top) Modeled and measured cumulative discharge at Beaver Army Terminal (CR rkm 86). (bottom) Modeled and measured daily average discharge

\section{B.5 - Area Extent of Flooding}

In modeling the February 1996 flood, it is important to accurately replicate the inundation as well as the water level. Satellite images provide an excellent qualitative measure of the flooding extent. Landsat images from February 2, 1996 (before the flood), and February 11, 1996 (just after the flood peaked in Portland) are using evaluating the effectiveness of the model (Figures B.17). The satellite image from February 11 was used to validate the model inundation (see section 4.3.2 and Figure 4.7). 


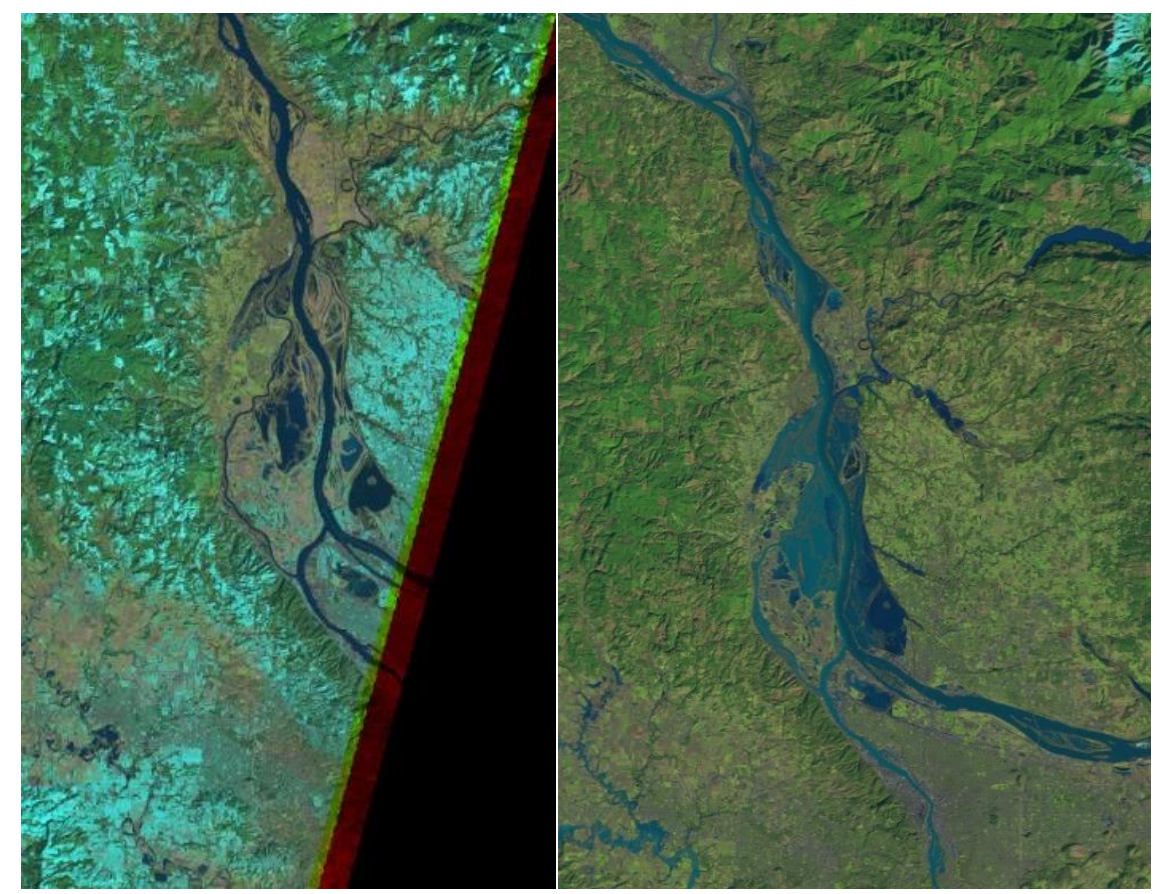

Figure B.17: Landsat 5 images of Portland Metro Area (left) February 2, 1996 and (right) February 11, 1996. Landsat-5 image courtesy of the U.S. Geological Survey.

\section{B.6 - St Johns Bridge Water Level}

A data set at St John's Bridge is utilized to calibrate the model simulations. This data was provided by the City of Portland, Bureau of Environmental Services. Figure B.18 shows the uncorrected data at St Johns Bridge and the data set at Morrison Bridge. 


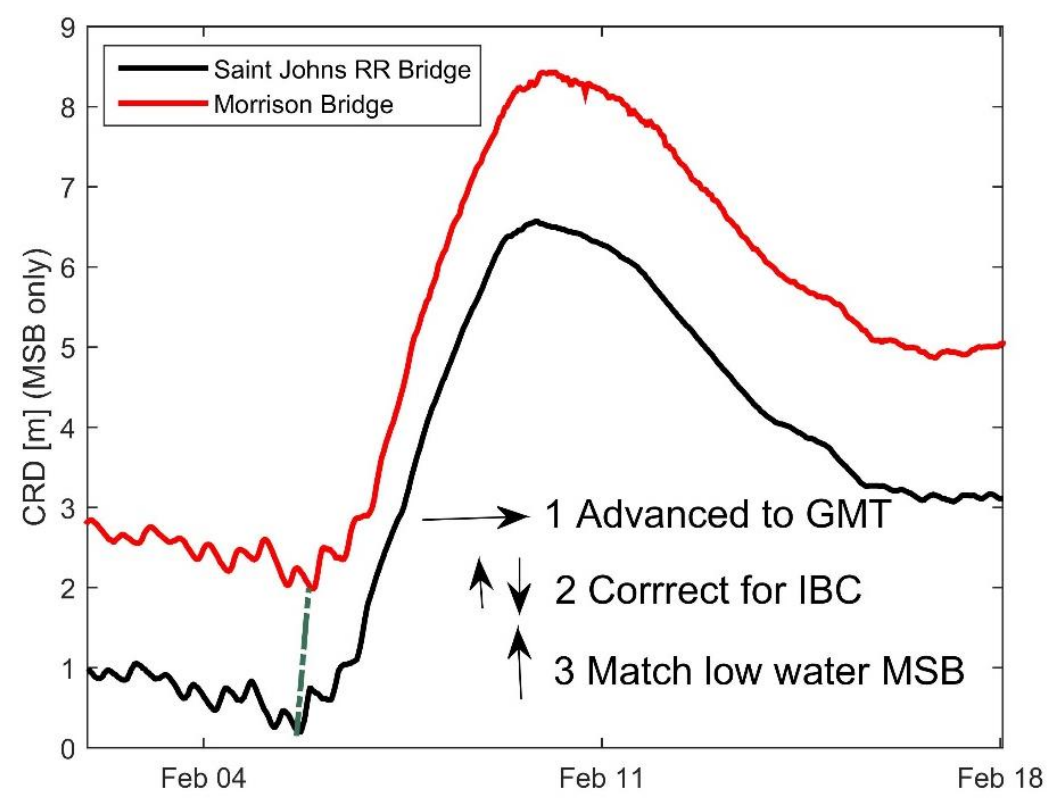

Figure B.18: Uncorrected water level at St John Bridge and measured water level at St Johns Bridge.

Figure B.19 shows the measured Sea Level Pressure at Portland International Airport as reported by the National Climate Data Center (USW00024229 https://www.ncdc.noaa.gov/) and the applied pressure correction (Equation B.1).

$$
\rho g h=\left(p-p_{a t m}\right)
$$



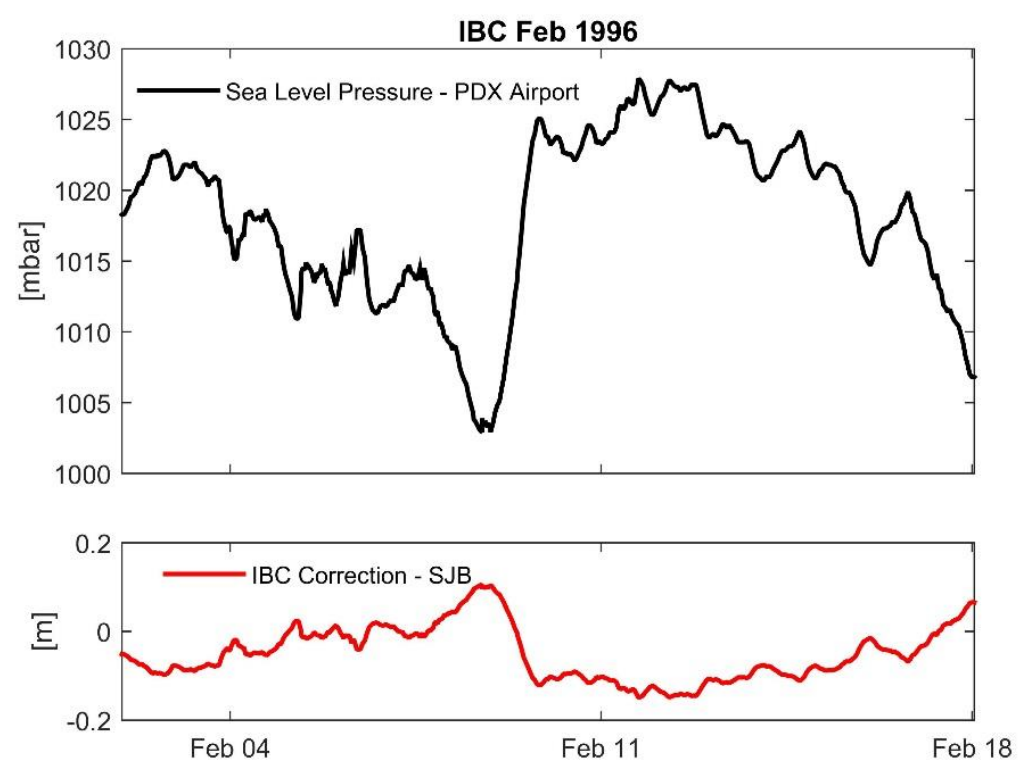

Figure B.19: (top) Measured Sea Level Pressure at Portland International Airport (bottom) pressure correction applied to Saint John Bridge water level

In the final step, I match the low water at Morrison Bridge with the low water at Saint Johns Bridge to produce the final data set (Figure B.20)

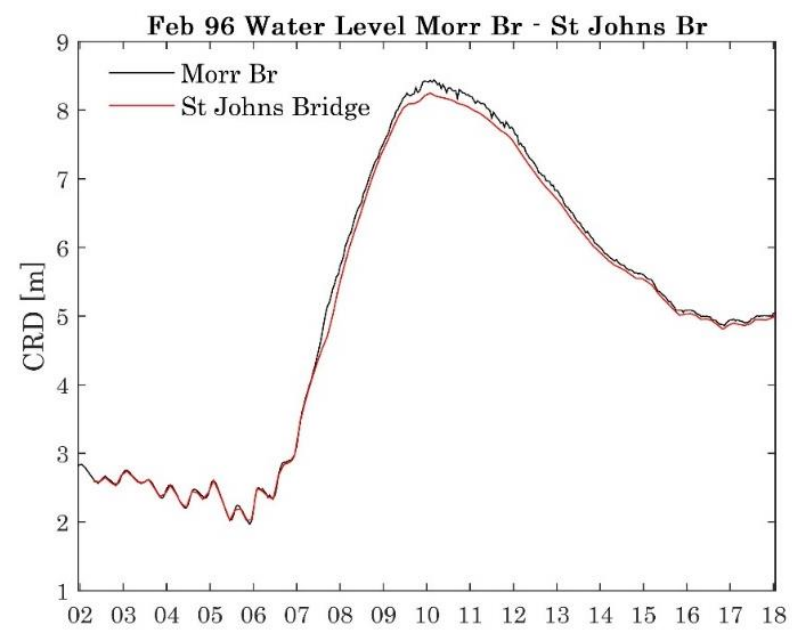

Figure B.20: Adjusted water level at the St Johns Bridge and the Morrison Bridge. 
Table B.2: Supplementary discharge data used in analysis of the February 1996 Willamette River flood in the Portland Metro Area.

\begin{tabular}{llll}
\hline River & Site & Source & Discharge \\
\hline Willamette River & Salem, OR & USGS & $30 \mathrm{~min}$ \\
South Yamhill & McMinnville, & USGS & peak flood \\
Pudding River & Woodburn, OR & USGS & $30 \mathrm{~min}$ \\
Tualatin River & West Linn, WA & USGS & $30 \mathrm{~min}$ \\
Clackamas River & Estacada, OR & USGS & $15 \mathrm{~min}$ \\
Hood River & Hood River, & USGS & $30 \mathrm{~min}$ \\
Bull Run River & Bull Run, OR & USGS & $30 \mathrm{~min}$ \\
\hline
\end{tabular}

